\title{
SEMISCALE BLOWDOWN AND EMERGENCY CORE COOLING (ECC) PROJECT \\ TEST REPORT-.
}

TESTS 848, 849, AND 850 (ECC INJECTION)

D. I. OLSON
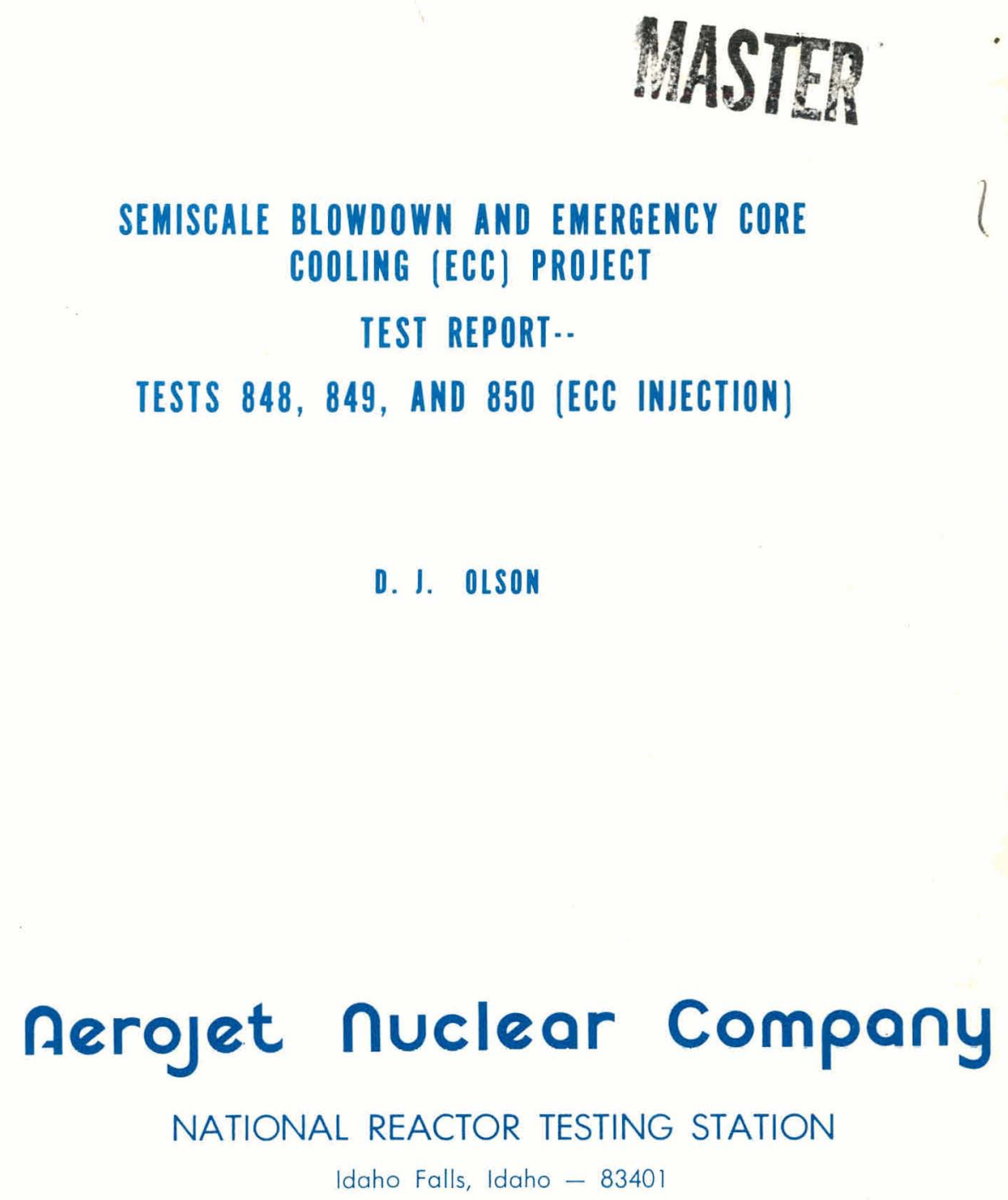

Date Published-June 1972

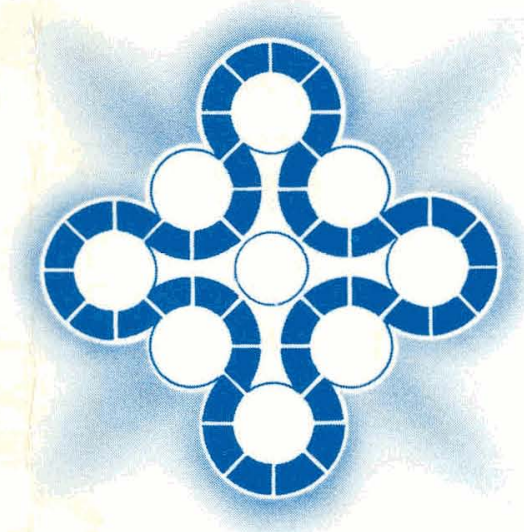

Idaho Falls, Idaho - 83401 


\section{DISCLAIMER}

This report was prepared as an account of work sponsored by an agency of the United States Government. Neither the United States Government nor any agency Thereof, nor any of their employees, makes any warranty, express or implied, or assumes any legal liability or responsibility for the accuracy, completeness, or usefulness of any information, apparatus, product, or process disclosed, or represents that its use would not infringe privately owned rights. Reference herein to any specific commercial product, process, or service by trade name, trademark, manufacturer, or otherwise does not necessarily constitute or imply its endorsement, recommendation, or favoring by the United States Government or any agency thereof. The views and opinions of authors expressed herein do not necessarily state or reflect those of the United States Government or any agency thereof. 


\section{DISCLAIMER}

Portions of this document may be illegible in electronic image products. Images are produced from the best available original document. 


$$
\begin{gathered}
\text { Printed in the United States of America } \\
\text { Available from } \\
\text { National Technical Information Service } \\
\text { U. S. Department of Commerce } \\
528 j \text { Put Royal Road } \\
\text { Springfield, Virginia } 22151 \\
\text { Price: Printed Copy } \$ 3.00 ; \text { Microfiche } \$ 0.95
\end{gathered}
$$

\section{LEGAL NOTICE}

This report was prepared as an account of work sponsored by the United States Government. Neither the United States nor the United States Atomic Energy Commission, nor any of their employees, nor any of their contractors, subcontractors, or their employees, makes any warranty, express or implied, or assumes any legal liability or responsibility for the accuracy, complete ness or usefulness of any information, apparatus, product or process disclosed, or represents that its use would not infringe privately owned rights. 


\section{SEMISCALE BLOWDOWN AND EMERGENCY CORE COOLING}

\section{(ECC) PROJECT TEST REPORT --}

TESTS 848,849 , AND 850 (ECC INJECTION)

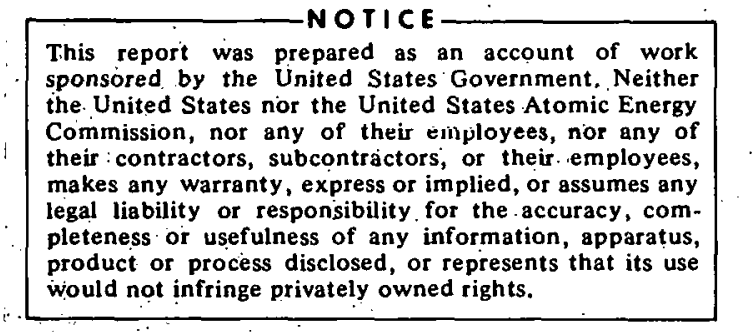

BY

D. J. Olson

AEROJET NUCLEAR COMPANY

Date Published - June 1972

PREPARED FOR THE U. S, ATOMIC ENERGY COMMISSION

IDAHO OPERATIONS OFFICE

UNDER CONTRACT NO. $(10-1)-1375$ 


\begin{abstract}
This document presents the results of three decompression experiments (Tests 848, 849, and 850) performed in the Semiscale Blowdown and Emergency Core Cooling (ECC) Project as part of the Water Reactor Safety Program of the U. S. Atomic Energy Commission. The data are intended to provide a basis for measuring the maturity of analytical codes used to predict the response of pressurized water reactors to decompression and ECC injection for a hypothetical major loss-of-coolant accident (LOCA).

Semiscale Tests 848,849 , and 850 were inlet-break tests of a system that Includes an operating loop and a vessel with an electrically heated core. Tests 848 and 849 involved injection of ECC from a pressurized accumulator during decompression. Test 850 was performed from the same initial conditions, but without ECC, to provide a basis for comparison. The objectives of these tests were to obtain more detalled experimental information relative to the effects of ECC on primary system decompression and to determine the mechanism responsible for the expulsion of ECC liquid from the vessel inlet plenum which had occurred in previous semiscale ECC-Injection tests. Data from these three tests provide a general explanation of the expulsion mechanism.

The purpose of this report is to present the data from semiscale Tests 848,849 , and 850 in sufficlent detail to be directly usable by those groups engaged in LOCA analysis for pressurized water reactors. The substantial and significant differences between a large nuclear reactor and the semiscale apparatus, and the differences in the related phenomenologies during postulated LOCA's, make invalid any direct extrapolation of the results of these tests to a reactor. The tests are intended only for purposes of analysis methods develópment and evaluation. The test results presented include pressure, fluid and material temperatures, density, flow rates, and fluid quality as functions of time.
\end{abstract}




\section{SUMMARY}

The objective of the Semiscale Blowdown and Emergency Core Cooling (ECC) Project, which is part of the Water Reactor Safety Program of the U. S. Atomic Energy Commission, is to provide experimental data for assessing the capability and adequacy of analytical models which are used to quantify thermal-hydraulic phenomena in large pressurized water reactors during a loss-of-coolant accident (LOCA). The semiscale tests also provide data to assist in meeting the overall Loss-of-Fluid Test (LOFT) program objectives. The semiscale experimental apparatus is not capable of providing demonstration tests of ECC systems in power reactors [a].

Semiscale Tests 848,849 , and 850 were initiated by cold leg breaks of a system that includes a vessel with internals and one complete operating loop. During Tests 848 and 849 , ECC was injected from a pressurized accumulator. The specific objective of these tests was to provide more detailed experimental data relative to the effects of ECC on primary system decompression, and, additionally, to define the mechanism responsible for the expulsion of all accumulator ECC fluld from the vessel which had been observed in previous ECCinjection tests. Test 850 was performed from initial conditions similar to those for Tests 848 and 849 , but without ECC, to provide a basis for comparison. An evaluation of the experfmental data for the three tests indicates that measurements of fluid properties as functions of time and system location are adequate to describe the thermal-hydraulic response of the semiscale system to the test conditions imposed. The substantial and significant differences between a large nuclear reactor and the semiscale apparatus, and the differences in the related phenomenologies during postulated LOCA's, make invalid any direct extrapolation of the results of this test to a reactor. The tests are intended only for purposes of analysis methods development and evaluation.

The purpose of this report is to present the data from these three tests in sufficient detail to be directly usable by those groups engaged in model development for the analysis of the LOCA in a pressurized water reactor (PWR). The individual variables measured at various system locations are presented together with a brief interpretation and discussion of the results. Variables not measured directly have been calculated and the data plotted in the appropriate engineering units for convenience of interpretation. Necessary corrections have been applied to the data. The techniques for these corrections are provided in appendices.

A summary of observations concerning the data from Tests 848,849 , and 850 is presented in Section IV. Some of the observations are summarized here. These observations are presented in the same order as they appear in the report. The order is not intended to reflect the priority or importance of the observations.

[a] Terms such as "ECC system", "core", "steam generator", and "pressure vessel", historically have been used to designate components of the semiscale system. The semiscale components are designed to produce physical processes which can be investigated in small systems, and are not intended to be scale models or to represent all physical aspects of their counterparts in reactor systems. The existence of related components in a nuclear reactor has suggested the terminology used in the semiscale program. 
The subcooled decompression processes in the piping and the vessel plenum follow the behavior expected for the test system configuration and for the relative break size represented in these tests. The maximum pressure difference across the core during subcooled decompression was about 50 psi. The effect of controlling the break size with a nozzle instead of an orifice in the blowdown assembly was to damp out more quickly, and reduce in magnitude, the subcooled pressure oscillations in the system.

Little effect was noted in the behavior of the loop and vessel fluid due to ECC injection except for locations in the direct path of ECC flow from the inlet plenum to the break. Initiation of ECC injection caused no discernible effect on inlet plenum pressures. Mixing of the ECC with the initial fluid present in the inlet plenum was incomplete; fluid layers of different subcooling were evident in the lower plenum with the bottom layer as much as $70^{\circ} \mathrm{F}$ subcooled. Except for locations in the path to the break, fluid density was unaffected by the presence of ECC in the system. No significant overall difference in cladding temperature behavior was evident from comparison of data for tests with and without ECC.

The total fluid flow rate out the break was insensitive to ECC injection. Mass balances indicated that about half of the initial system fluid mass was discharged from the vessel side of the break and about half was discharged from the cold leg side of the break. The maximum fluid inventory in the vessel inlet plenum during ECC injection was about 75 pounds, which was insufficient to reach the bottom of the core.

For the first 8 to 10 .sec of ECC injection, some ECC liquid fell to the bottom of the vessel inlet plenum and mixed with a small amount of the primary fluid inventory while the larger percentage of ECC liquid was entrained in the steam back-flow through the core and was carried out the break. As the steam velocity and, concurrently, liquid entrainment decreased, the level of accumulated liquid in the inlet plenum increased until an open flow path to the break was interrupted: When this interruption occurred, a chugging behavior was initiated because of the buildup and release of pressure in the vessel. As discussed in the report, apparently the same mechanism which caused the chugging eventually resulted in the expulsion of essentially all fluid from the vessel. 


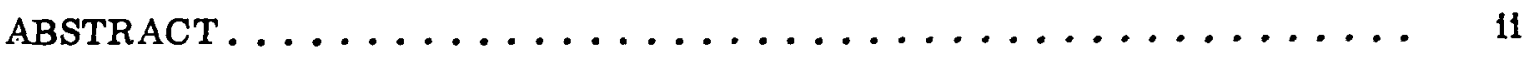

SUMMARY $\ldots \ldots \ldots \ldots \ldots \ldots \ldots \ldots \ldots \ldots \ldots \ldots \ldots \ldots \ldots \ldots \ldots$

I. INTRODUCTION ......................... 1

II. HARDWARE CONFIGURATION AND TEST CONDITIONS . . . . . . . 3

III. SEQUENCE OF EVENTS FOR SEMISCALE TESTS 848, 849, and 850 . 10

IV. PRESENTATION OF TEST DATA .................... 12

1. PRESSURE .............................. 12

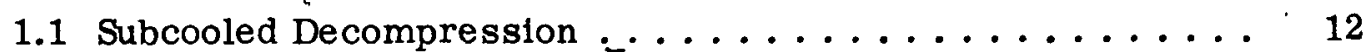

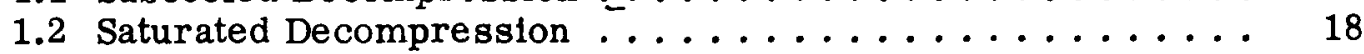

1.3 Dffferential Pressure . . . . . . . . . . . . . . 21

2. TEMPERATURE ...................... 23

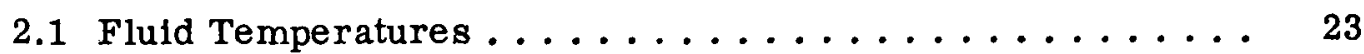

2.2 Material Temperatures................... 29

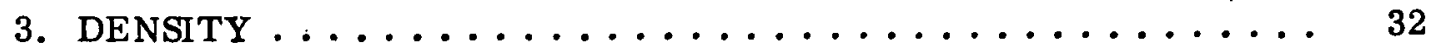

4. WATER REMAINING IN SYSTEM . . . . . . . . . . . 35

V. DISCUSSION OF TEST RESULTS. . . . . . . . . . . . . . 36

1. FLUID FLOW RATES . . . . . . . . . . . . . . . . 36

2. FLUID QUALITY ......................... 43

3. EMERGENCY CORE COOLING ................. 46

3.1 ECC Behavior ...................... 47

3.2 ECC Expulsion Mechantsm ............... 50

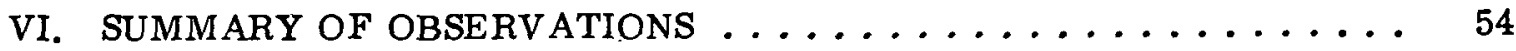

VII. REFERENCES .......................... 57

APPENDIX A -- DATA RECORDED -- SEMISCALE TESTS 848, 849,

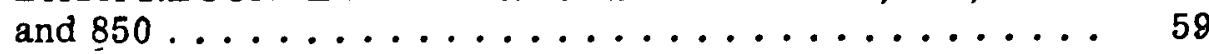

APPENDIX B - METHODS USED TO NORMALIZE TEST DATA TO ACCOUNT FOR INSTRUMENT DRIFT AND THERMAL EFFECTS .................... 67

B-I。 PRESSURE ........................... 69

B-II. DIFFERENTIAL PRESSURE ................. 70 
B-III. TEMPERATURE $\ldots \ldots \ldots \ldots \ldots \ldots \ldots \ldots \ldots \ldots \ldots$

B-IV. DENSTTY ....................... 70

B-V. MOMENTUM FLUX ................. 70

APPENDIX C -- SELECTED EXAMPLES OF DIGITIZED DATA --

SEMISCALE TESTS 848,849 , and $850 \ldots \ldots \ldots \ldots 73$

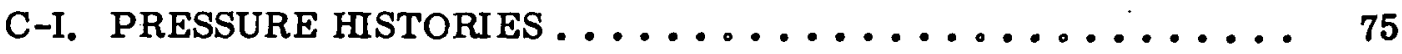

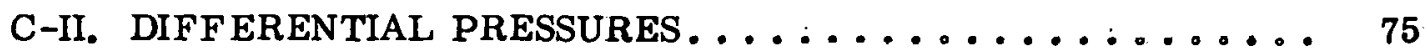

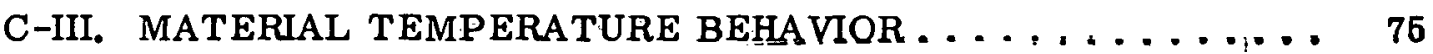

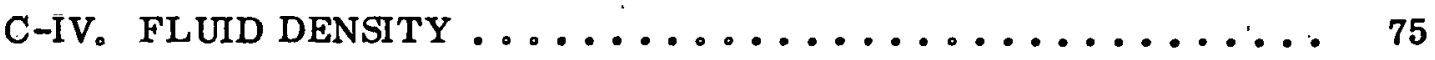

C-V. MOMENTUM FLUX $\ldots \ldots \ldots \ldots \ldots \ldots \ldots \ldots \ldots$

FIGURES

1. Single-loop semiscale - high inlet break configuration $\ldots \ldots \ldots 4$

2. Blowdown nozzle for Test $849 \ldots \ldots \ldots \ldots \ldots \ldots \ldots \ldots$

3. Semiscale vessel cutaway showing ECC injection nozzle $\ldots \ldots \ldots 6$

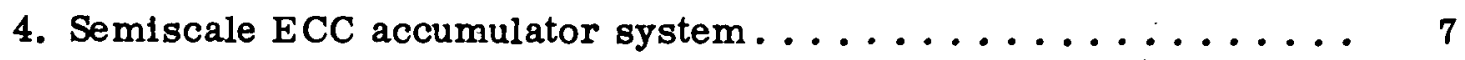

5. Semiscale vessel internals -- heater pin and thermocouple locations . . . . . . . . . . . . . . . 8

6. Sequence of events for Tests 848,849 , and $850 \ldots \ldots \ldots \ldots \ldots 11$

7. Test 848 subcooled decompression -- blowdown nozzle, vessel nozzles, and inlet plenum ................. 13

8. Test 849 subcooled decompression -- blowdown nozzle, vessel nozzles, and inlet plenum . . . . . . . . . . . . . 13

9. Test 850 subcooled decompression -- blowdown nozzle, vessel

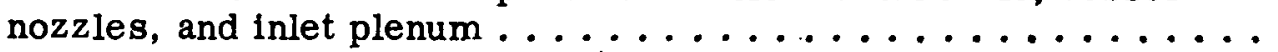

10. Test 848 subcooled decompression -- vessel pressures and pressure difference $\ldots \ldots \ldots \ldots \ldots \ldots \ldots \ldots \ldots \ldots \ldots \ldots$

11. Test 849 subcooled decompression -- vessel pressures and pressure difference $\ldots \ldots \ldots \ldots \ldots \ldots \ldots \ldots \ldots \ldots \ldots \ldots$

12. Test 850 subcooled decompression -.- vessel pressures and pressure difference 
13. Test 848 subcooled decompression -- steam generator pressures

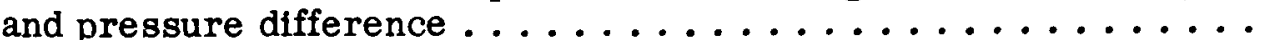

14. Test 849 subcooled decompression -- steam generator pressures and pressure difference ....................

15. Test 850 subcooled decompression -- steam generator pressures

16. Test 848 vessel plenum pressures and differential pressure . . . . 19

17. Test 849 vessel plenum pressures and differential pressure . . . . 19

18. Test 850 vessel plenum pressures and differential pressure..... 20

19. Vessel pressures - Test $848 \ldots \ldots \ldots \ldots \ldots$

20. Inlet plenum pressure $\ldots$ Tests 848,849 , and $850 \ldots \ldots \ldots \ldots$

21. Comparison of differential pressure across pump during Tests

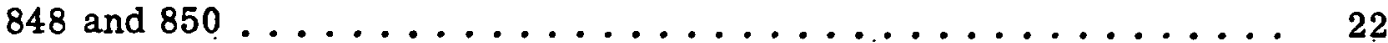

22. Comparison of differential pressure across core during Tests

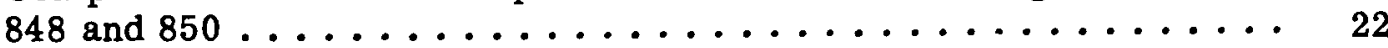

23. Vessel plenum temperatures $\ldots$ Tests 848,849 , and $850 \ldots \ldots 24$

24. Vessel fluid temperatures -- Test $848 \ldots \ldots \ldots \ldots \ldots \ldots$

25. Comparison of inlet and outlet plenum temperatures for

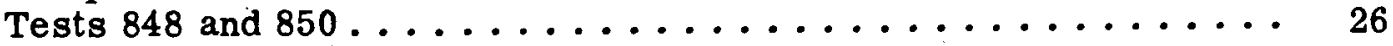

26. Fluid temperatures in lower plenum -- Test $848 \ldots \ldots \ldots$

27. Fluid temperatures in lower plenum -- Test $849 \ldots \ldots \ldots \ldots$

28. Fluid temperatures in lower plenum $\ldots$ Test $850 \ldots \ldots \ldots$

29. Loop fluid temperatures - Test $848 \ldots \ldots \ldots \ldots \ldots \ldots \ldots$

30. Loop fluid temperatures -- Test $850 \ldots \ldots \ldots \ldots \ldots$

31. Cladding temperatures at the midplane of an outside pin $\ldots \ldots \ldots$

32. Cladding temperatures at the top of a center pln $\ldots \ldots \ldots \ldots$

33. Cladding temperatures at the top of an outside pin ......... 31

34. Density at the steam generator outlet for Tests 848 and $850 \ldots \ldots 32$

35. Density at the pump outlet for Tests 848 and $850 \ldots \ldots \ldots \ldots$

36. Density at the vessel outlet plenum for Tests 848,849 , and $850 \ldots 34$ 
37. Density at the vessel inlet plenum for Tests 848 and $850 \ldots \ldots$. . . . . 34

38. System discharge rate - Tests 848 and $850 \ldots \ldots \ldots \ldots_{\ldots} \ldots \ldots \ldots$

39. Hot leg flow rate $\ldots$ Tests 848 and $850 \ldots \ldots \ldots \ldots$

40. Vessel fluld mass balance - Test $848 \ldots \ldots \ldots \ldots \ldots$

41. Integrated fluid mass $\ldots$ Tests 848 and $850 \ldots \ldots \ldots$

42. Fluid quallty at the hot leg . . Tests 849 and $850 \ldots \ldots$. . . . . . . 44

43. Fluid quality at the cold leg -- Tests 848 and $850 \ldots \ldots$. . . . . . 44

44. Fluid quality in the blowdown nozzle $\ldots$ Tests 848 and $850 \ldots 45$

45. Fluid quality in the vessel outlet plenum -. Tests 849 and $850 \ldots \ldots 46$

46. Density at the vessel inlet plenum and inlet nozzle $\ldots$ Test $848 \ldots \ldots 7$

47. Drag disc output at the inlet nozzle - Tests 848 and $850 \ldots \ldots 9$

48. Density at the blowdown nozzle $\ldots$ Tests 848 and $850 \ldots \ldots \ldots \ldots$. . . 50

49. Differential pressure across the steam generator bypass --

Test 849

50. Differential pressure between outlet plenum and blowdown nozzle --

Tests 849 and $850 \ldots \ldots \ldots \ldots \ldots \ldots \ldots$. . . . . . . . . . . . . 52

A-1. Single-loop semiscale isometric ................. 63

A-2. In-vessel instrumentation . . . . . . . . . . . . . . . . 64

A-3. Heater pin and thermocouple locations $\ldots \ldots \ldots$.......... 65

C-1. Outlet nozzle pressure -- Test $848 \ldots \ldots \ldots \ldots \ldots \ldots$

C-2. Outlet nozzle pressure - Test $849 \ldots \ldots \ldots \ldots \ldots \ldots$

C-3. Outlet nozzle pressure - Test $850 \ldots \ldots \ldots \ldots \ldots$

C-4. Steam generator outlet pressure $\ldots$ Test $848 \ldots \ldots \ldots \ldots$

C-5. Steam generator outlet pressure -- Test $849 \ldots \ldots \ldots \ldots \ldots$

C-6. Steam generator outlet pressure -- Test $850 \ldots \ldots \ldots \ldots$

C-7. Inlet nozzle pressure - Test $848 . \ldots \ldots \ldots \ldots \ldots$

C-8. Inlet nozzle pressure $\ldots$ Test $849 \ldots \ldots \ldots \ldots \ldots$

C-9. Inlet nozzle pressure $\ldots$ Test $850 \ldots \ldots \ldots \ldots \ldots \ldots$

C-10. Outlet plenum pressure $\ldots$ Test $848 \ldots \ldots \ldots \ldots$. . . . . . . 81 
C-11. Outlet plenum pressure $\ldots$ Test $849 \ldots \ldots \ldots \ldots$

C-12. Outlet plenum pressure - Test $850 \ldots \ldots \ldots \ldots$

C-13. Differential pressure -- Inlet to outlet plenum -- Test $848 \ldots \ldots$. . . 83

C-14. Differential pressure -- Inlet to outlet plenum -- Test $849 \ldots \ldots$. . . 83

C-15. Differential pressure .- Inlet to outlet plenum -- Test $850 \ldots \ldots 4$

C-16. Differential pressure across the vessel $\ldots$ Test $848 \ldots \ldots \ldots$. . . 84

C-17. Differential pressure across the vessel -- Test $849 \ldots \ldots$. . . . . 85

C-18. Differential pressure across the vessel - Test $850 \ldots \ldots$. . . . . 85

C-19. Differential pressure across the steam generator -- Test $848 \ldots \ldots 86$

C-20. Differential pressure across the steam generator -- Test $849 \ldots \ldots 6$

C-21. Differential pressure across the steam generator $\ldots$ Test $850 \ldots \ldots 7$

C-22. Pump differential pressure $\ldots$ Test $848 \ldots \ldots \ldots \ldots$. . . . . . . 87

C-23. Pump differential pressure - Test $849 \ldots \ldots \ldots \ldots \ldots$

C-24. Pump differential pressure - Test $850 \ldots \ldots \ldots \ldots$

C-25. Cladding temperature of the center pin - bottom - Test $848 \ldots \ldots 9$

C-26. Cladding temperature of the center pin - bottom - Test $849 \ldots \ldots 9$

C-27. Cladding temperature of the center pin - bottom - Test $850 \ldots . .90$

C-28. Cladding temperature of an outside pin - bottom -- Test $848 \ldots \ldots 9$

C-29. Cladding temperature of an outside pin - bottom -- Test $849 \ldots \ldots 91$

C-30. Cladding temperature of an outside pin - bottom -- Test $850 \ldots \ldots 9$

C-31. Cladding temperature of an inside pin - midplane -- Test $848 \ldots \ldots$. . 92

C-32. Cladding temperature of an inside pin - midplane -- Test $849 \ldots \ldots 2$

C-33. Cladding temperature of an inside pin - midplane -- Test $850 \ldots \ldots 3$

C-34. Cladding temperature of an outside pin - top - - Test $848 \ldots \ldots$. . 93

C-35. Cladding temperature of an outside pin - top -- Test $849 \ldots \ldots 4$

C-36. Cladding temperature of an outside pin - top - Test $850 \ldots \ldots 4$

C-37. Cladding temperature of an outside pin - bottom -- Test $848 \ldots \ldots 95$

C-38. Cladding temperature of an outside pin - bottom -- Test 849. . . . 95 
C-39. Cladding temperature of an outside pin - bottom -- Test 850 . . . . 96

C-40. Hot leg density - Test $849 \ldots \ldots \ldots \ldots$

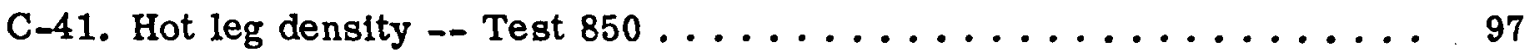

C-42. Inlet nozzle density - Test $848 \ldots \ldots \ldots \ldots \ldots \ldots_{\ldots} \ldots \ldots \ldots \ldots$

C-43. Inlet nozzle density -- Test $849 \ldots \ldots \ldots \ldots \ldots$

C-44. Blowdown nozzle density $\ldots$ Test $848 \ldots \ldots \ldots$. . . . . . . . . 98

C-45. Blowdown nozzle density -- Test $849 \ldots \ldots \ldots$. . . . . . . . yy

C-46. Blowdown nozzle density -- Test $850 \ldots \ldots$. . . . . . . . . . 99

C-47. Inlet plenum density $\ldots$ Test $848 \ldots \ldots \ldots$. . . . . . . . . . 100

C-48. Inlet plenum density $\ldots$ Test $849 \ldots \ldots \ldots \ldots$

C-49. Inlet plenum density - Test $850 \ldots \ldots \ldots \ldots$. . . . . . . . . 101

C-50. Core density -- Test $848 \ldots \ldots \ldots \ldots \ldots \ldots \ldots$

C-51. Core density $\ldots$ Test 849. . . . . . . . . . . . . . . . 102

C-52. Drag disc output - cold leg -- Test $850 \ldots \ldots \ldots \ldots$

C-53. Drag disc output - inlet nozzle $\ldots$ Test 849. . . . . . . . . . 103

C-54. Drag disc output - blowdown nozzle - Test $848 \ldots \ldots \ldots \ldots$. . . . 103

\section{TABLES}

I. Initial and Test Conditions for Semiscale Tests 848,849 , and $850 \ldots 9$

II. Water Remaining Following Decompression $\ldots \ldots \ldots \ldots$

A-I. Summary of Recorded Data for Semiscale Tests 848, 849, and $850 \ldots \quad 62$ 


\title{
SEMISCALE BLOWDOWN AND EMERGENCY CORE COOLING
}

\author{
(ECC) PROJECT TEST REPORT -- \\ TESTS 848,849 , AND 850 (ECC INJECTION)
}

\section{INTRODUCTION}

The Semiscale Blowdown and Emergency Core Cooling (ECC) Project[1] is part of the Water Reactor Safety Program [2] of the U. S. Atomic Energy Commission. Experiments are conducted by establishing, in model systems, conditions that simulate probable operating conditions in the range of those expected in an operating reactor and then initiating a simulated primary piping break of controlled size and location. The phenomena occurring in the system after the break are observed and recorded for subsequent analysis.

A primary objective of the semiscale project is to provide an experimental data base to help assess the capability and adequacy of analytical models which are used to quantify thermal-hydraulic phenomena in large PWR's during a hypothetical LOCA. Information is needed which will allow analytical representation of the following:

(1) The system decompression characteristics and fluid mass flow from the system

(2) The avallability of primary coolant to the core during blow- down

(3) The heat transfer mechanisms controlling core thermal response during system decompression

(4) The demand requirements for ECC dellvery to the core and the importance of various system and break parameters affecting those requirements

(5) The effect of ECC injection on primary system decompression

(6) The forces generated during blowdown and the mechanical response of system components to those forces.

The semiscale tests also provide data to assist in meeting the overall objectives of the Loss-of-Fluid Test (LOFT) program.

The semiscale tests discussed in this report employed a vessel with electrically heated core, one complete operating loop, and a pressurized accumulator ECC system [a]. Tests 848,849 , and 850 were conducted from similar initial conditions and under similar operational procedures to clarify certain ECC-related phenomena observed in earlier semiscale ECC-injection

[a] Terms such as "ECC system", "core", "steam generator", and "pressure vessel" historically have been used to designate components of the semiscale system. The semiscale components are designed to produce physical processes which can be investigated in small systems, and are not intended to be scale models or to represent all physical aspects of their counterparts in reactor systems. The existence of related components in a nuclear reactor has suggested the terminology used in the semiscale program. 
tests[a]. Tests 848 and 849 were inlet break ECC injection experiments in which provisions were made to valve off the gas flow from the accumulator following depletion of ECC liquid and to bypass the lowest elevation region of the loop following ECC injection. Test 850 was performed from initial conditions similar to those of Tests 848 and 849 , but without ECC injection, in order to provide a basis for comparison. The se tests provide data on steamliquid entrainment and on two-phase mixing of fluids resulting from the injection of a subcooled liquid into a steam or two-phase fluid environment. The data from these tests are intended to be used as a measure of the maturity of analytical tools used to predict the response of pressurized water reactors to a hypothetical LOCA and subsequent ECC infection. The substantial and significant differences between a large nuclear reactor and the semiscale apparatus, and the differences in the related phenomenologies during postulated LOCA's, make invalid any direct extrapolation of the results of this test to a reactor. The tests are intended only for purposes of analysis methods development and evaluation.

Semiscale test results have been reported for tests involving vessels with and without unheated internals[3], tests with the present single-loop system configuration with and without unheated vessel internals [4-6], tests with the present system with core heat [7], and an initial test with ECC inJection [8].

A primary purpose of this report is to present the results of Semiscale Tests 848,849 , and 850 in sufficlent detall to be of use to those groups engaged in model development and assessment. Included in this report are a description of the hardware configuration and test conditions, an account of procedures and sequence of events, a presentation of measured test data, a discussion of the test results, and a summary of observations. Also included, as appendices, are a summary of the data recorded, the methods used to normalize the data, and examples of the digitized test data for Tests 848,849 , and 850 .

[a] During previous semiscale ECC injection tests, Tests 846 and 847 , the data indfcated that ECC accumulated in the inlet plenum of the vessel during the ECC injection period. The accumulated water was, however, expelled from the vessel and out the break immediately following the end of ECC injection. For these two tests the ECC accumulator gas was not valved off following the injection of all ECC liquid and the gas was, therefore, suspected to be the expulsion .mechanism for ECC that had accumulated in the inlet plenum. 


\section{HARDWARE CONFIGURATION AND TEST CONDITIONS}

Specific information on the single-loop semiscale system hardware configuration, operating procedures, data recording equipment, and data processing techniques has been presented previously[9]. Figure 1 shows the general arrangement of components for the single-loop tests. Test 848 and 850 were conducted with the rupture disc assembly in the high inlet location (Station 35) and with the blowdown assembly orificed to $10 \%\left(0.009 \mathrm{ft}^{2}\right)$ of the pipe crosssectional area, giving a break area to system volume ratio of $0.0007 \mathrm{ft}^{-1}$. For Test 849 the blowdown assembly was equipped with a nozzle (length-todiameter ratio about 15 ) rather than an orifice for simulating a $10 \%$ break. The general construction of the nozzle is depicted in Figure 2.

For Tests 848 and 849 , ECC from an accumulator system was injected directly into the inlet plenum of the vessel at the center-line elevation of the inlet nozzle and at an angular displacement of 37 degrees from the inlet nozzle, as shown in Figure 3. The semiscale accumulator ECC injection system, shown in Figure 4, consists of an accumulator having a gas-to-liquid volume ratio typical of accumulators in commercial PWR plants and appropriate piping and valves. The accumulator contained $2.6 \mathrm{ft}^{3}$ of liquid (sufficient to cover the semiscale core) and $1.4 \mathrm{ft}^{3}$ of nitrogen gas. Initiation of ECC injection was controlled by a swing check valve which opened when the pressure in the vessel inlet plenum fell below the accumulator charge pressure. The ECC delivery rate was controlled by the pressure difference between the accumulator and the inlet plenum, and by the use of orifices and a throttle valve in the ECC line. For Test 848, provision was made to valve off the ECC accumulator nitrogen flow by means of a quick closing valve as soon as gas flow was evident from a flow detector located in the ECC line. This procedure still allowed a small amount of gas to vent to the inlet plenum. For Test 849 the valve was closed a few seconds earlier than in Test 848 , thereby prohibiting gas discharge to the vessel. A bypass line across the steam generator low point from Stations 4 to 6 (Figure 1) was also installed for Test 849 in order to remove the possibility of a water seal at the loop low point which could cause pressure buildup in the vessel outlet plenum. A quick opening valve was included in the lineand was operated simultaneously with the quick closing valve in the ECC line.

The electrically heated core used in these tests to establish a pressure difference between the hot and cold leg fluids consisted of 120 heater pins located in the vessel on a 31/32-in.-triangular pitch. The vessel internals, heater rod positions, and thermocouple locations are shown in Figure 5. The cartridge type heaters are composed of a 9-in.-Nichrome heating element within a 65-mil, 0.44-in.-OD, Nickel-200 sheath. The heated length is insulated with boron nitride; the remainder is insulated with magnesium oxide. The heaters

are capable of operating at a heat flux of $1000 \mathrm{~W} /$ in. $^{2}$, giving a total power capability of about $1.5 \mathrm{MW}$. 


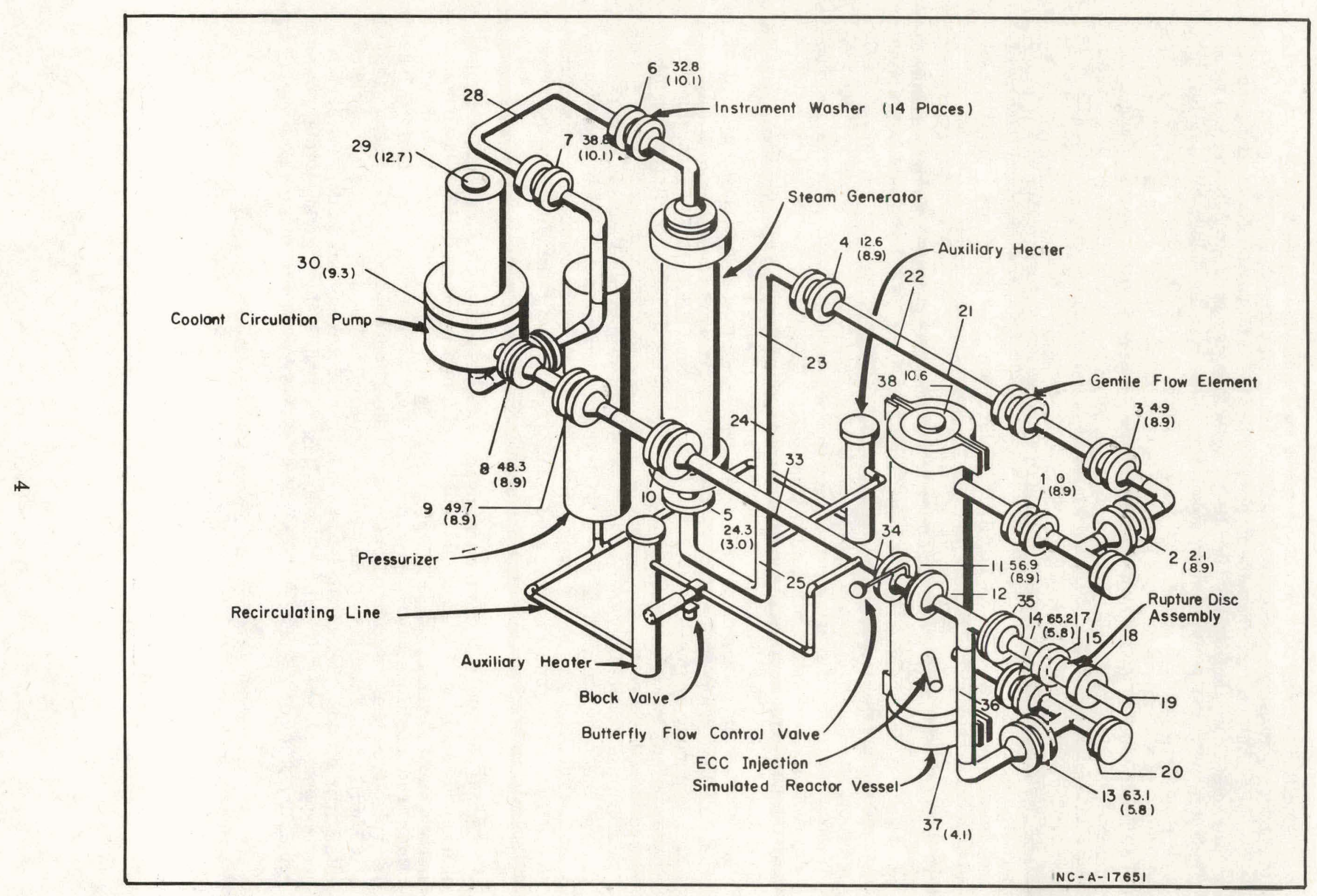

Fig. 1 Single-loop semiscale -- high inlet break configuration. 


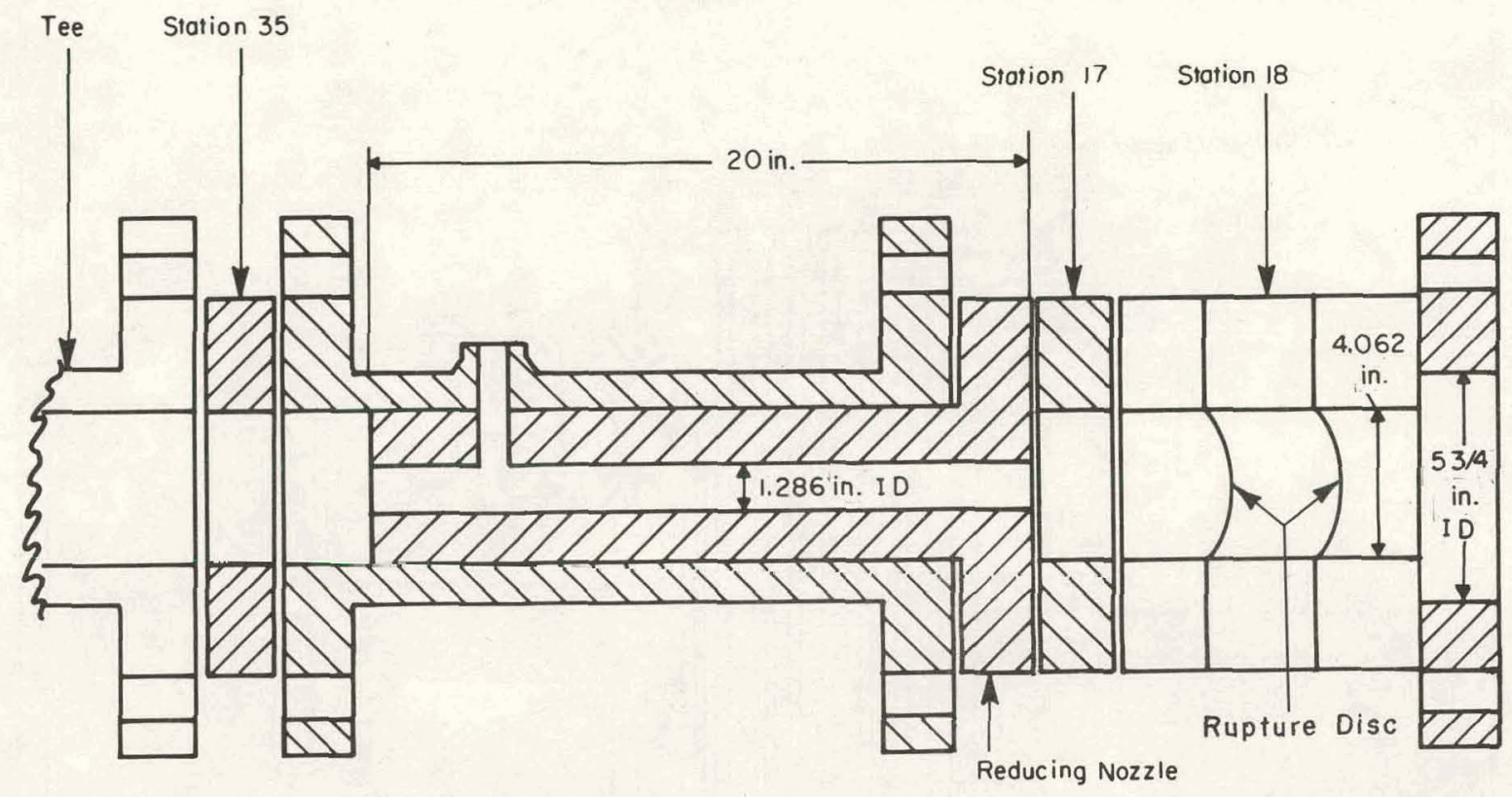

INC-B-17913

Fig. 2 Blowdown nozzle for Test 849 .

Orifices that were installed in the loop during a previous test to study the effect of pressure drops remained in Tests 848 through 850 . The orifice plates were located as follows:

\begin{tabular}{lccc}
\multicolumn{1}{c}{ Location } & Plate Thickness (in.) & Diameter (in.) \\
\cline { 1 - 1 } Station 2 (upstream) & 1.0 & 1.54 \\
Station 3 (downstream) & 0.5 & 3.37 \\
Station 7 (upstream) & 1.0 & 1.63 \\
Station 13 (center) & 1.94 & 2.10
\end{tabular}

Table I summarizes the test and initial conditions for Tests 848,849 , and 850. A summary of the test procedure and sequence of events is included in the next section. 


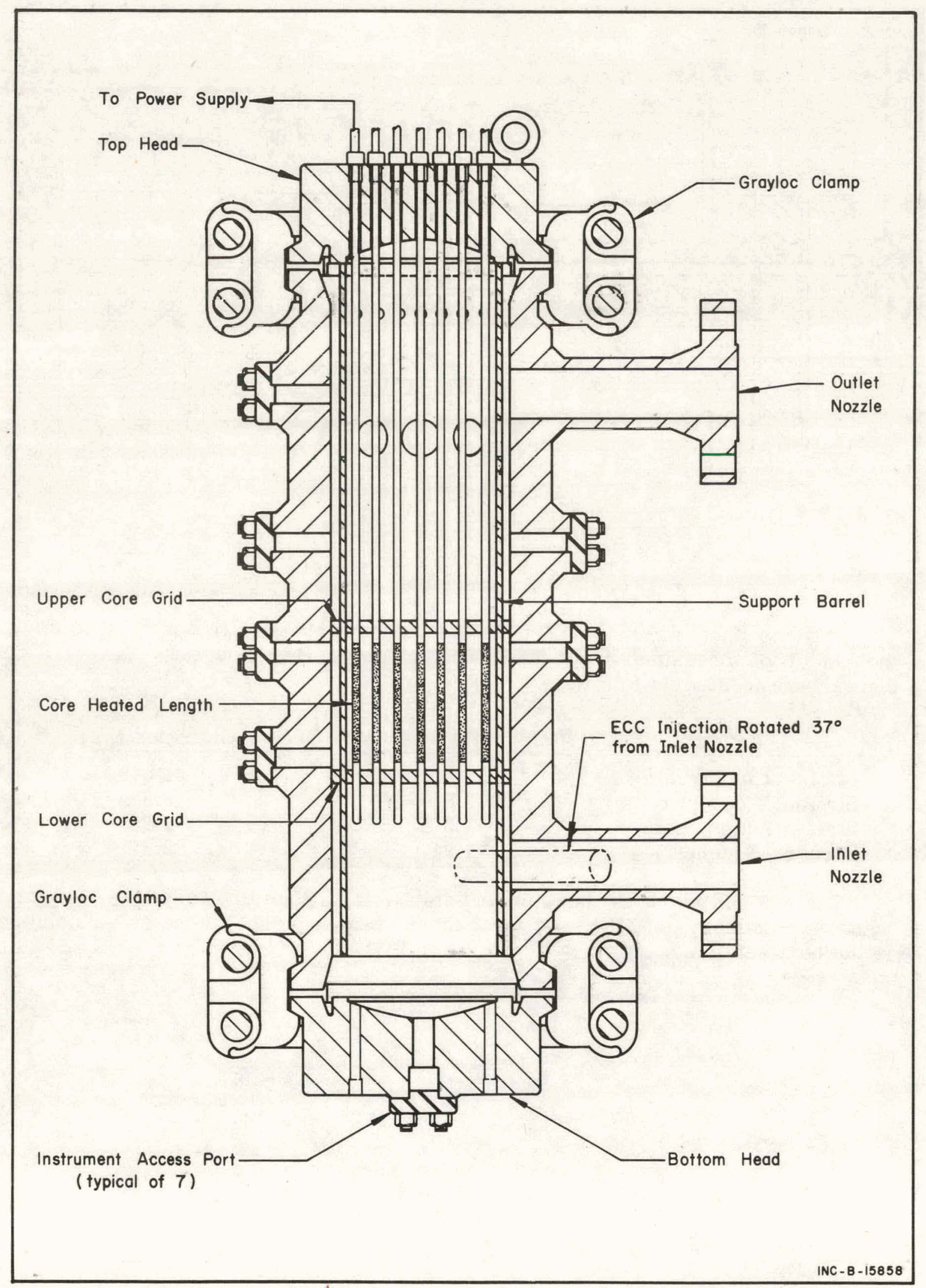

Fig. 3 Semiscale vessel cutaway showing ECC injection nozzle. 
1

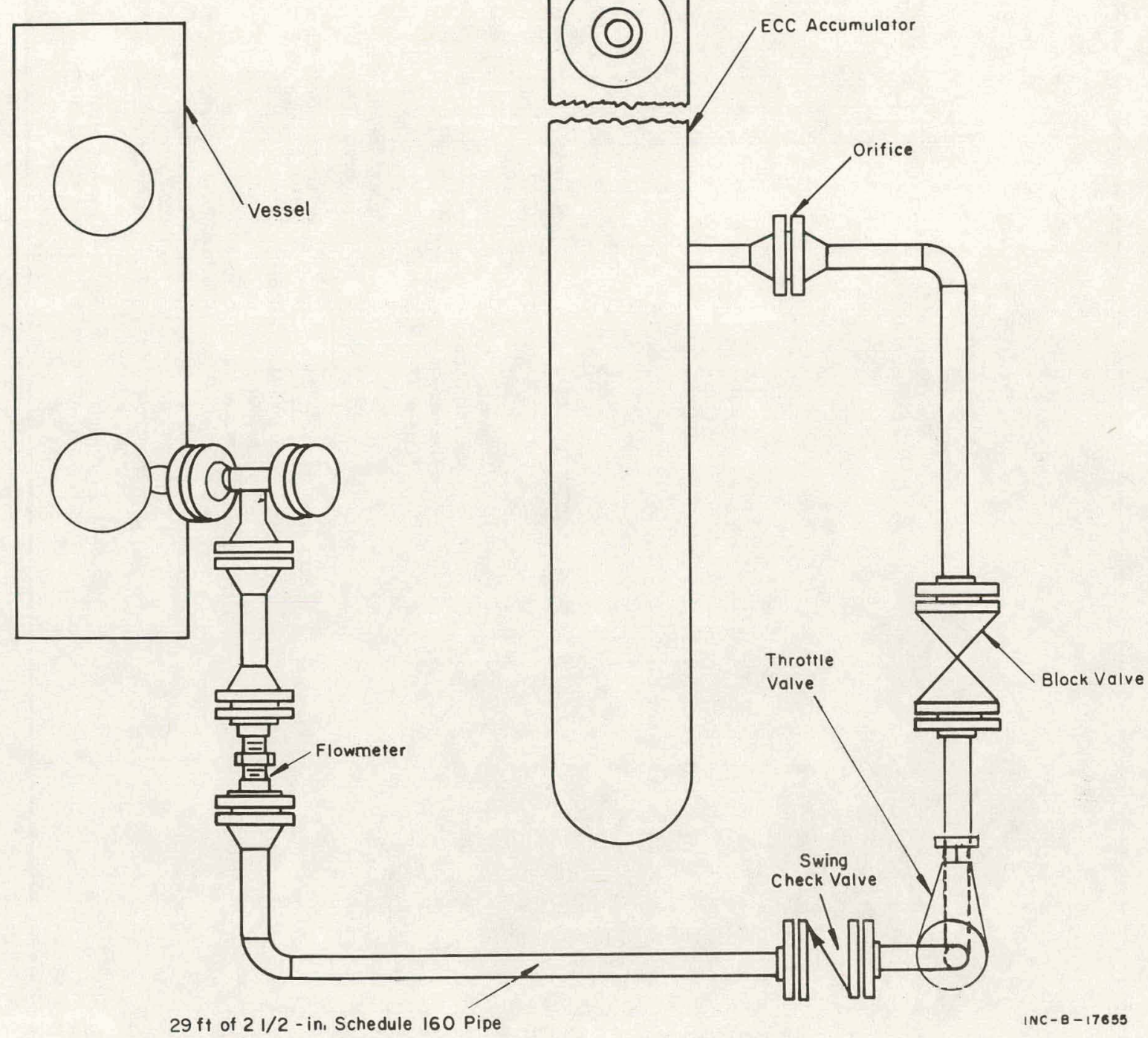

Fig. 4 Semiscale ECC accumulator system. 


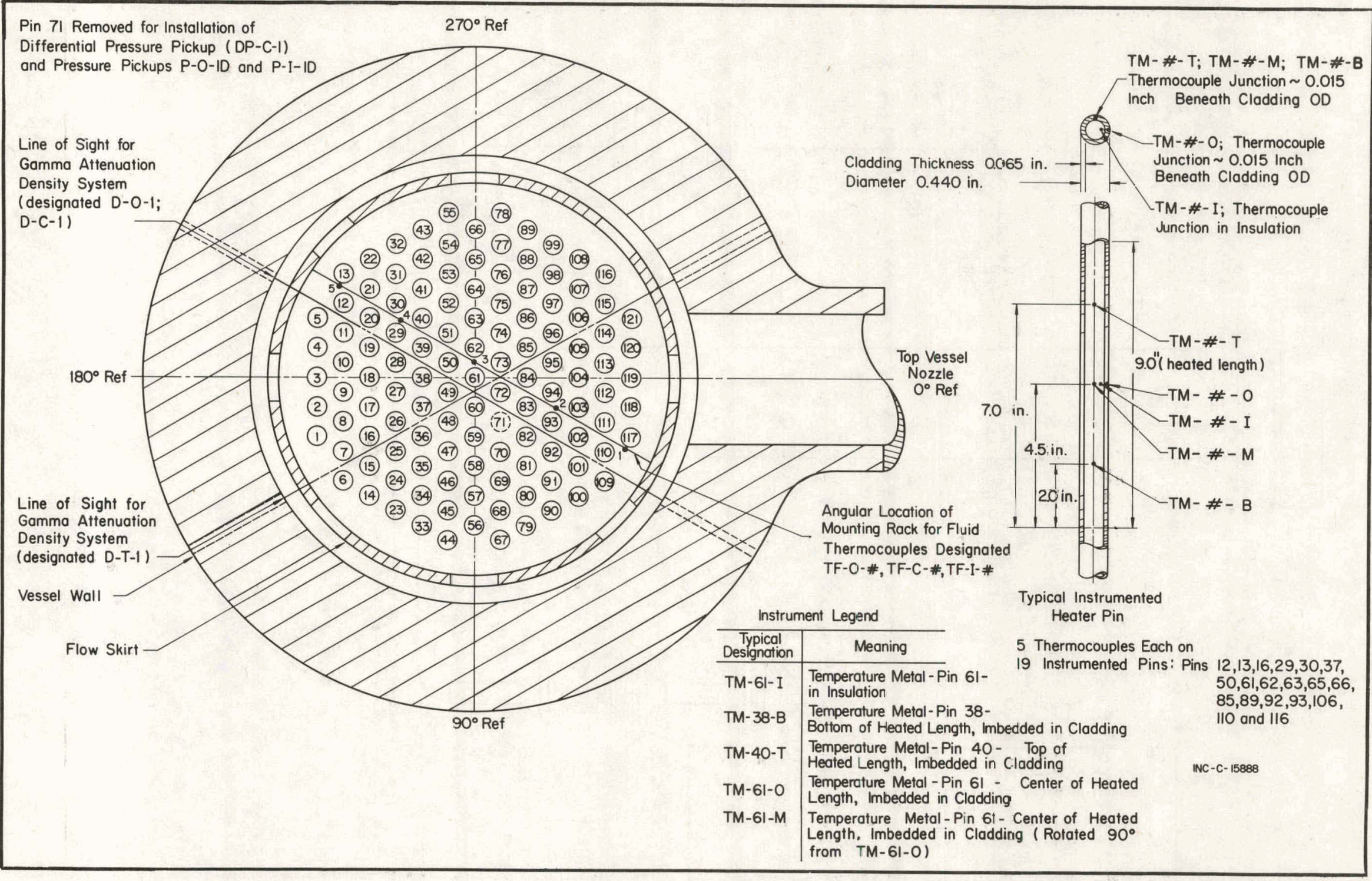

Fig. 5 Semiscale vessel internals -- heater pin and thermocouple locations. 
TABLE I

INITIAL AND TEST CONDITIONS FOR SEMISCALE TESTS 848, 849: AND 850

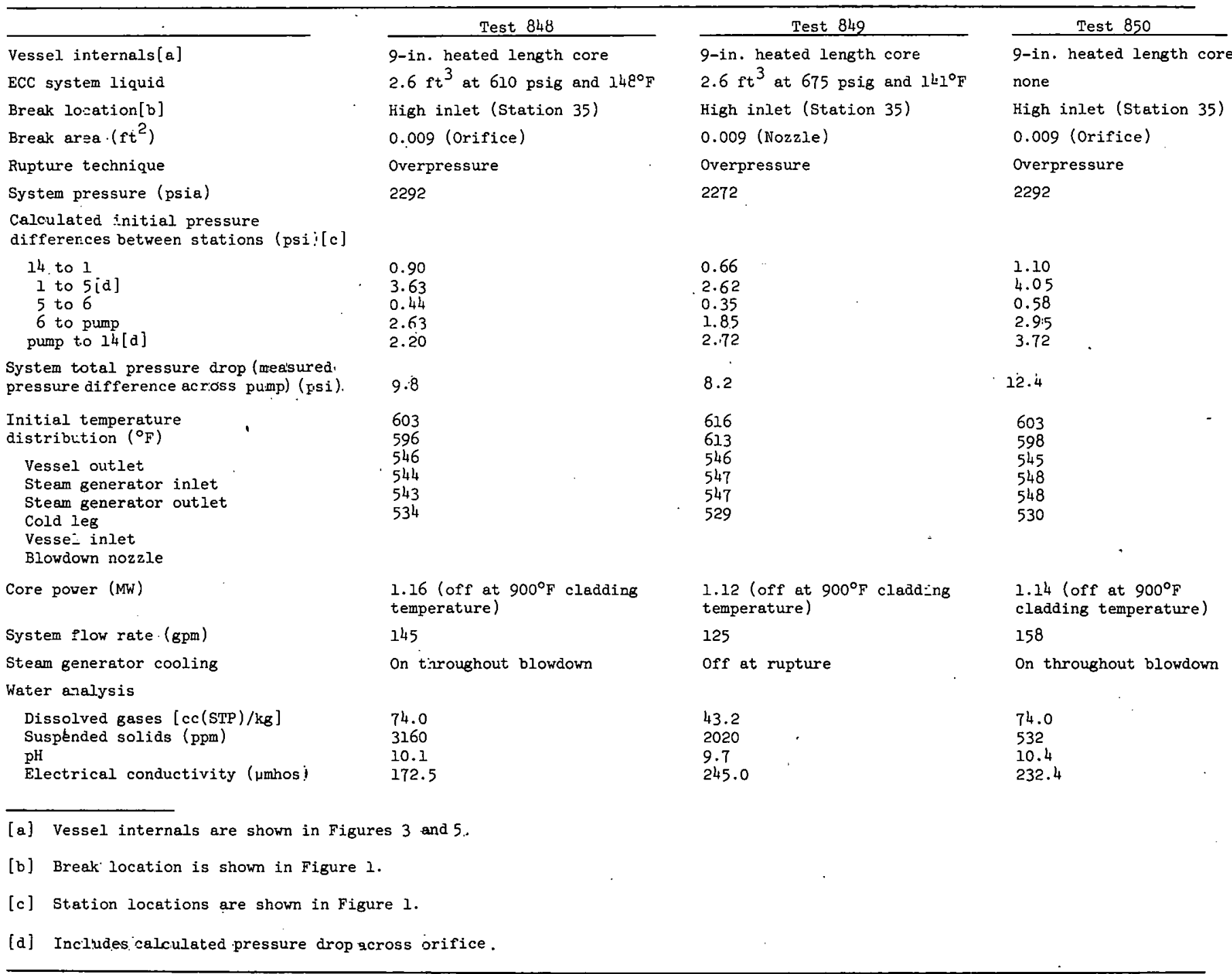




\section{SEQUENCE OF EVENTS FOR SEMISCALE TESTS 848, 849, AND 850}

The major events and the time sequence for Tests 848,849 , and 850 are displayed in Figure 6. The same general sequence of events occurs for all tests. Warmup of the system to the desired initial system pressure and 18othermal temperature was achleved by operation of the two auxiliary heaters (Figure 1) in the auxiliary circulation loop. This process required 8 to $10 \mathrm{hr}$. During warmup, excess fluid due to thermal expansion was drained from the system through a throttle valve near the pump inlet.

Several minutes prior to test initiation the auxiliary heaters were turned off and the block valve in the auxillary loop was closed. Steam generator operation was inftiated and about $80 \%$ full power was applied to the core to continue heatup. The power was gradually increased to the pretest level. The initial temperature difference across the core and the temperature distribution throughout the loop were established by controlling the primary system flutd flow with the variable speed semiscale pump and concurrently controlling the cooling water flow to the steam generator secondary spray. Just prior to system rupture, the pressurizer makeup pump and heaters were turned off.

System rupture was initiated by overpressurizing the outer rupture disc of the rupture disc assembly in the blowdown nozzle (system pressure ruptures the Inner disc within 1 to $2 \mathrm{msec}$ ). The blowdown nozzle was attached to a tee in the cold leg at the elevation of the outlet nozzle (Figure 1) and was orificed to a flow area of $0.009 \mathrm{ft}^{2}$, or $10 \%$, of the pipe cross-sectional area.

Injection of ECC into the vessel inlet plenum was initiated by operation of a swing check valve when the inlet plenum pressure dropped below the accumulator charge pressure $(610 \mathrm{psig}$ for Test $848,675 \mathrm{psig}$ for Test 849$)$. For Test 848, ECC 1njection commenced 9 sec after rupture; for Test 849 , $10 \mathrm{sec}$ after rupture. The average rate of ECC injection was $40 \mathrm{gpm}$ for Test 848 and $35 \mathrm{gpm}$ for Test 849. ECC liquid injection was complete at $38 \mathrm{sec}$ and 36.5 sec after rupture for Tests 848 and 849 , respectively.

For these tests, a quick closing valve was installed in the ECC discharge line in order to valve off the accumulator gas flow after the ECC had been depleted. The valve was closed when a velocity sensing device in the ECC discharge line indicated high velocity gas flow. This procedure resulted in valving off the major portion of accumulator gas flow; a small amount of gas, however, did reach the inlet plenum in Test 848 .

For Test 849 , the ECC block valve was closed when a thermocouple located at the level of the discharge line penetration in the ECC accumulator indicated rapid cooling due to gas expansion. This procedure resulted in isolating the ECC system from the primary system when about $95 \%$ of the ECC fluid had been injected, thereby preventing the injection of any accumulator gas to the inlet plenum.

The primary pump was shut off 3.5 to $6.5 \mathrm{sec}$ after system rupture for all tests; pump coastdown was complete about 30 to $40 \mathrm{sec}$ later. Core power was shut off between 6.4 and $8.0 \mathrm{sec}$ after rupture $\left(900^{\circ} \mathrm{F}\right.$ cladding temperature). Cooling water was supplied to the secondary side of the steam generator throughout blowdown for Tests 848 and 850 ; for Test 849 , steam generator operation was terminated at system rupture. Decompression was essentially complete within 50 to 55 sec. 


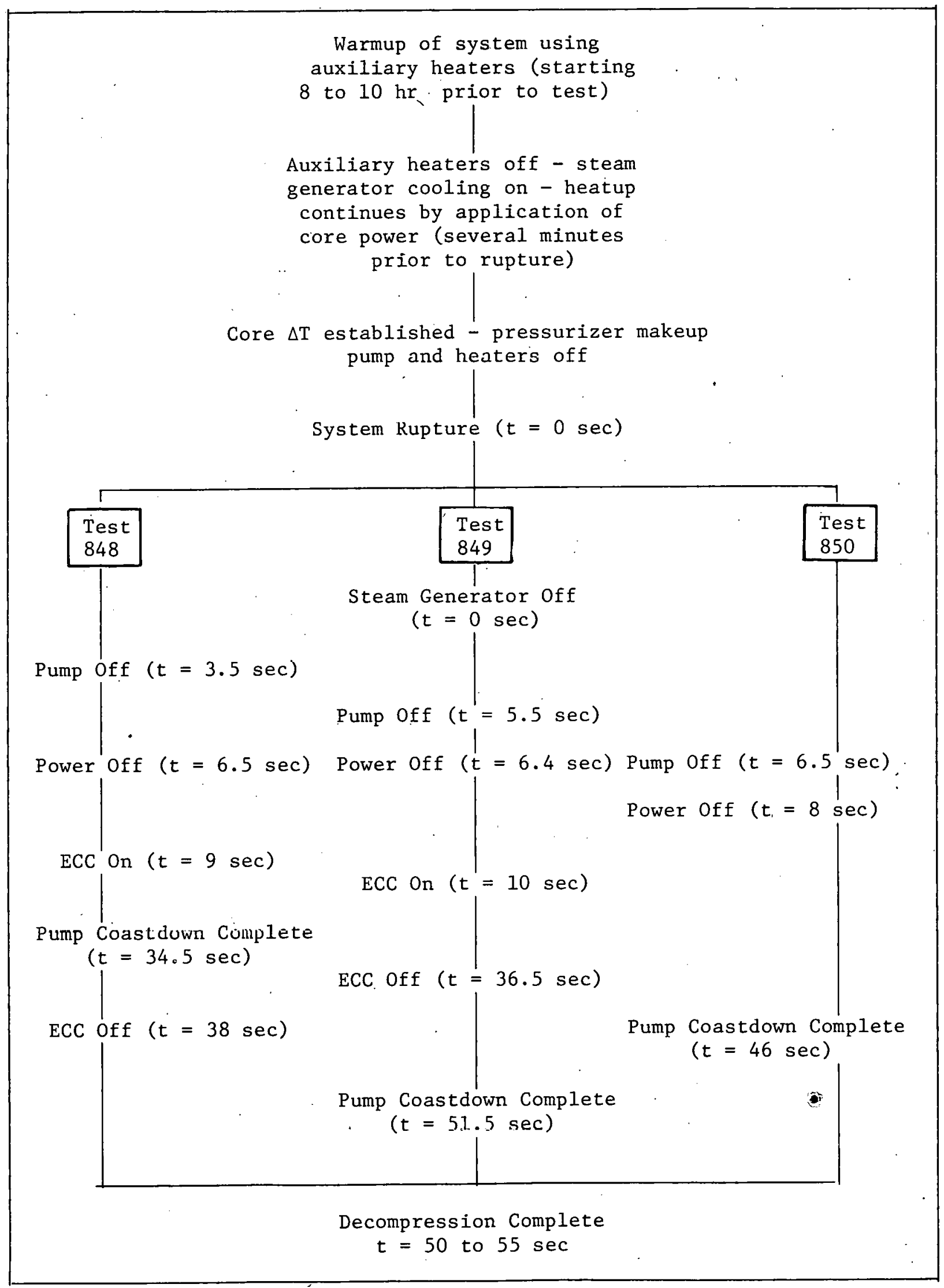

Fig. 6 Sequence of events for Tests 848,849 , and 850 . 


\section{PRESENTATION OF TEST DATA}

This section of the report presents, with comment, the measured test data for Semiscale Tests 848, 849, and 850. A summary of the measurements made for these tests is included in the appendices. This section Includes discussion of fluid pressures, fluld and material temperatures, fluid density, and water remaining in the system following decompression. Section $V$ of the report further discusses the test results from the standpoint of certain variables (for example, flow rates and fluld qualtty) calculated from measured test data.

An additional measured quantity, momentum flux, is included in the discussion of fluid flow rates in Section V. Momentum flux data are used in conjunction with density data to determine the flow rates.

\section{PRESSURE}

The discussion of the pressure measurements is divided into three parts. The first part discusses subcooled flutd expansion (subcooled decompression) and presents data from the first $80 \mathrm{msec}$ of blowdown. Subsequent (long term) pressure data are reviewed in the second part, saturated decompression. The third part presents data obtalned from differential pressure measurements. The initial pressure differences between various system locations were presented in Table I.

\subsection{Subcooled Decompression}

Pressure behavior during subcooled decompression at the vessel inlet and outlet nozzles, the blowdown nozzle, and the inlet plenum is shown for Tests 848, 849, and 850 in Figures 7, 8, and 9, respectively. The curves for Tests 848 and 850 (Figures 7 and 9) are very nearly identical, both in the magnitude and the time sequence of subcooled pressure oscillations. The identical subcooled pressure behavior is a result of conducting Tests 848 and 850 from the same initial conditions, and is a measure of the reproductibility of the test data. In Figure 7 (Test 848), the first decompression wave recorded in the blowdown nozzle occurred $1.5 \mathrm{msec}$ prior to system rupture and resulted from prerupture yielding of the upstream rupture disc. The second, and largest, decompression wave resulted from the rupture itself. The beginning of decompression at other locations in the system is displaced in time from that indicated in the blowdown nozzle by the sonic transport time. For example, the wave set up by prerupture yielding and the decompression wave from rupture arrived at the inlet nozzle about $1.5 \mathrm{msec}$ after they were recorded at the blowdown nozzle (the distance from the blowdown nozzle to the inlet nozzle is about $5 \mathrm{ft}$ and the sonic velocity is $2970 \mathrm{ft} / \mathrm{sec}$ ). The general fluctuations observed in the subcooled decompression histories are those to be expected as a result of the sonic relaxation processes characteristic of this piping configuration for the relative break size (10\% of pipe area) in these tests. 


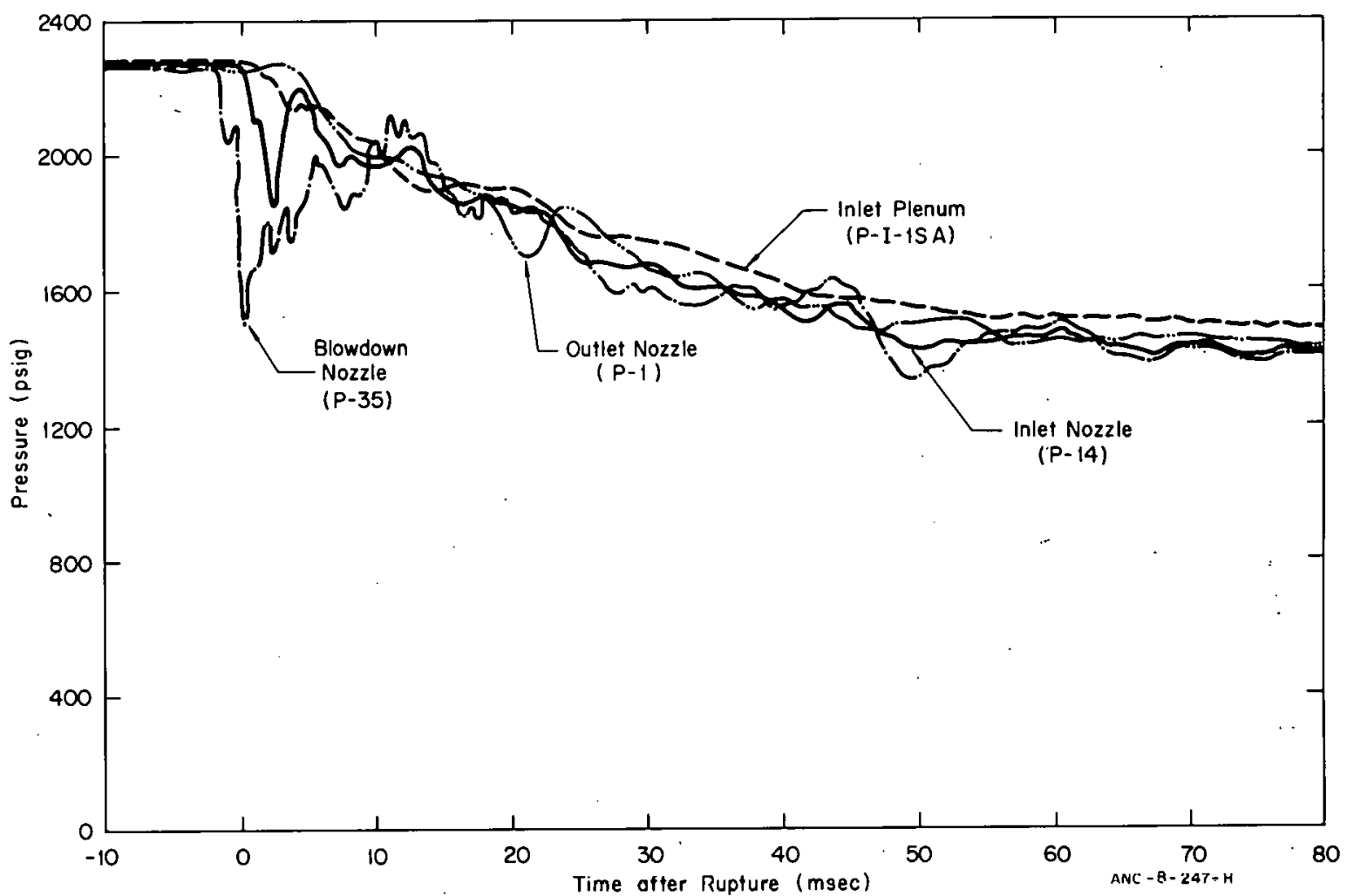

Fig. 7 Test 848 subcooled decompression -- blowdown nozzle, vessel nozzles, and inlet plenum.

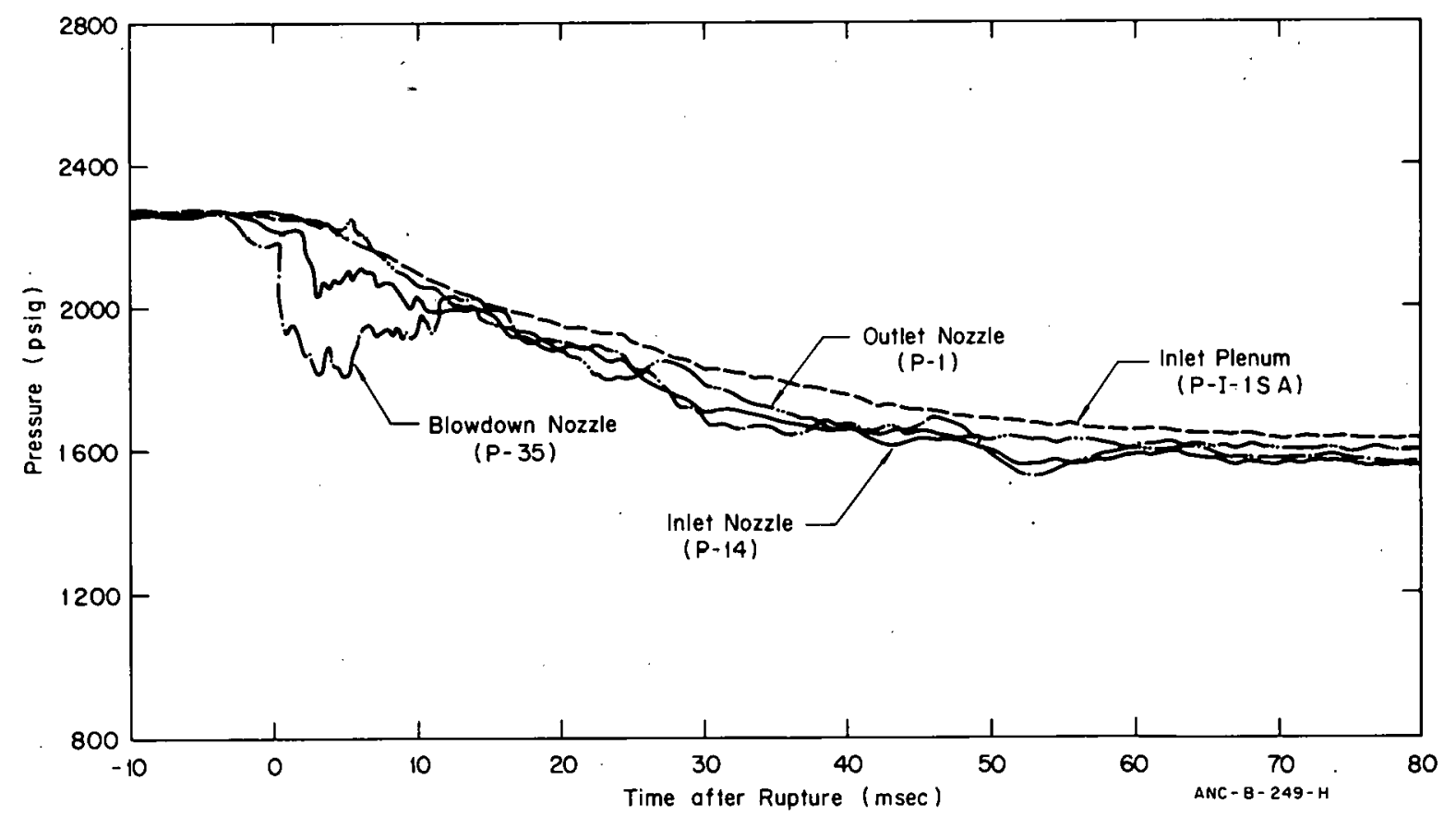

Fig. 8 Test 849 subcooled decompression -- blowdown nozzle, vessel nozzles, and inlet plenum. 


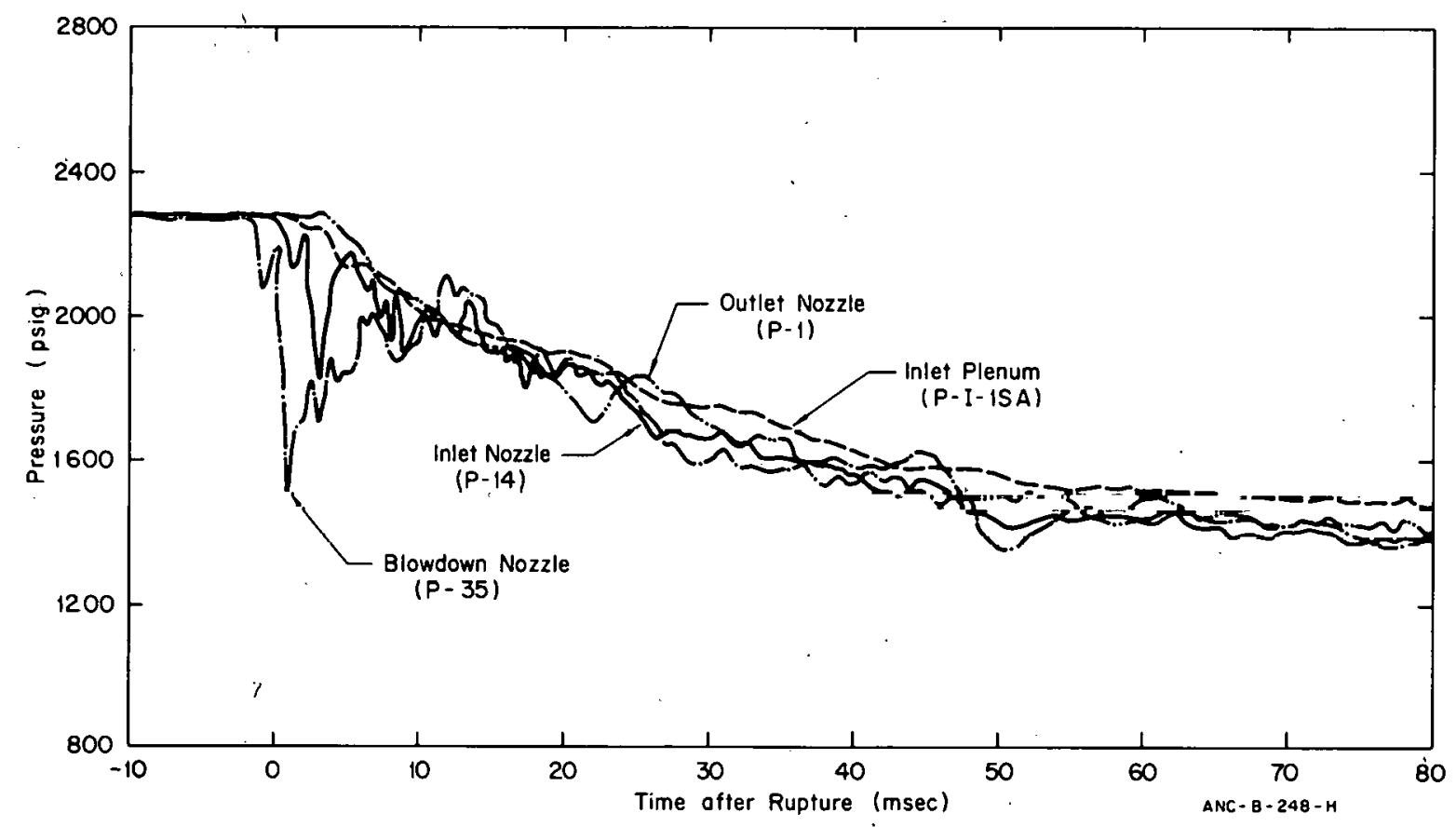

Fig. 9 Test 850 subcooled decompression -- blowdown nozzle, vessel nozzles, and inlet plenum.

The information in Figure 8 reflects the geometric difference in the blowdown assembly for Test 849 , in which the $10 \%$ break was simulated by a nozzle (length-to-diameter ratio of about 15) rather than by an orifice. The general effect of the nozzle was to damp out more quickly, and to reduce in magnitude, the subcooled pressure oscillations in the blowdown and inlet nozzles.

The subcooled pressure histories for the vessel inlet and outlet plenums for Tests 848, 849, and 850 are given in Figures 10, 11, and 12. Included on these figures are the differences in pressure between the inlet and outlet plenums (that is, the pressure difference across the core). These three figures show that subcooled decompression results in random differential pressure oscillations over a period of about 50 to $55 \mathrm{msec}$.

The subcooled pressures of the steam generator inlet and outlet are shown in Figures 13, 14, and 15 for Tests 848, 849, and 850, respectively. The included curves of pressure difference across the steam generator were obtained for each test by subtracting the pressure magnitude at the outlet from that at the inlet. The curves for Test 848 and 850 (Figures 13 and 15) are almost identical in magnitude and shape. The first pressure oscillation is from 400 to -300 psi with the pressure difference diminishing rapidly to less than $\pm 100 \mathrm{psi}$. Inspection of Figure 14 indicates that the shape of the curves for Test 849 is very similar to those of the other two tests, but that 


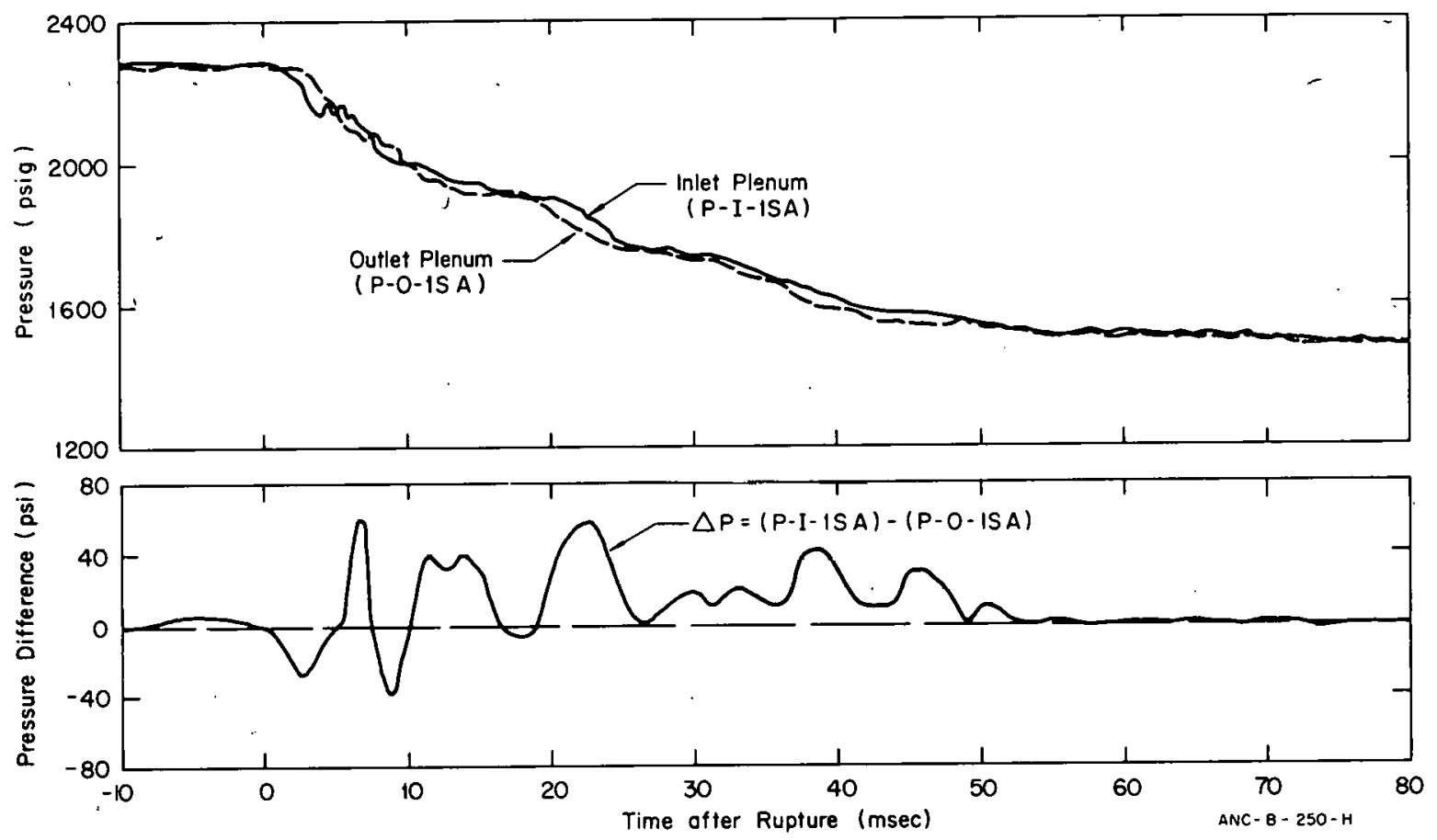

Fig. 10 Test 848 subcooled decompression -- vessel pressures and pressure difference.
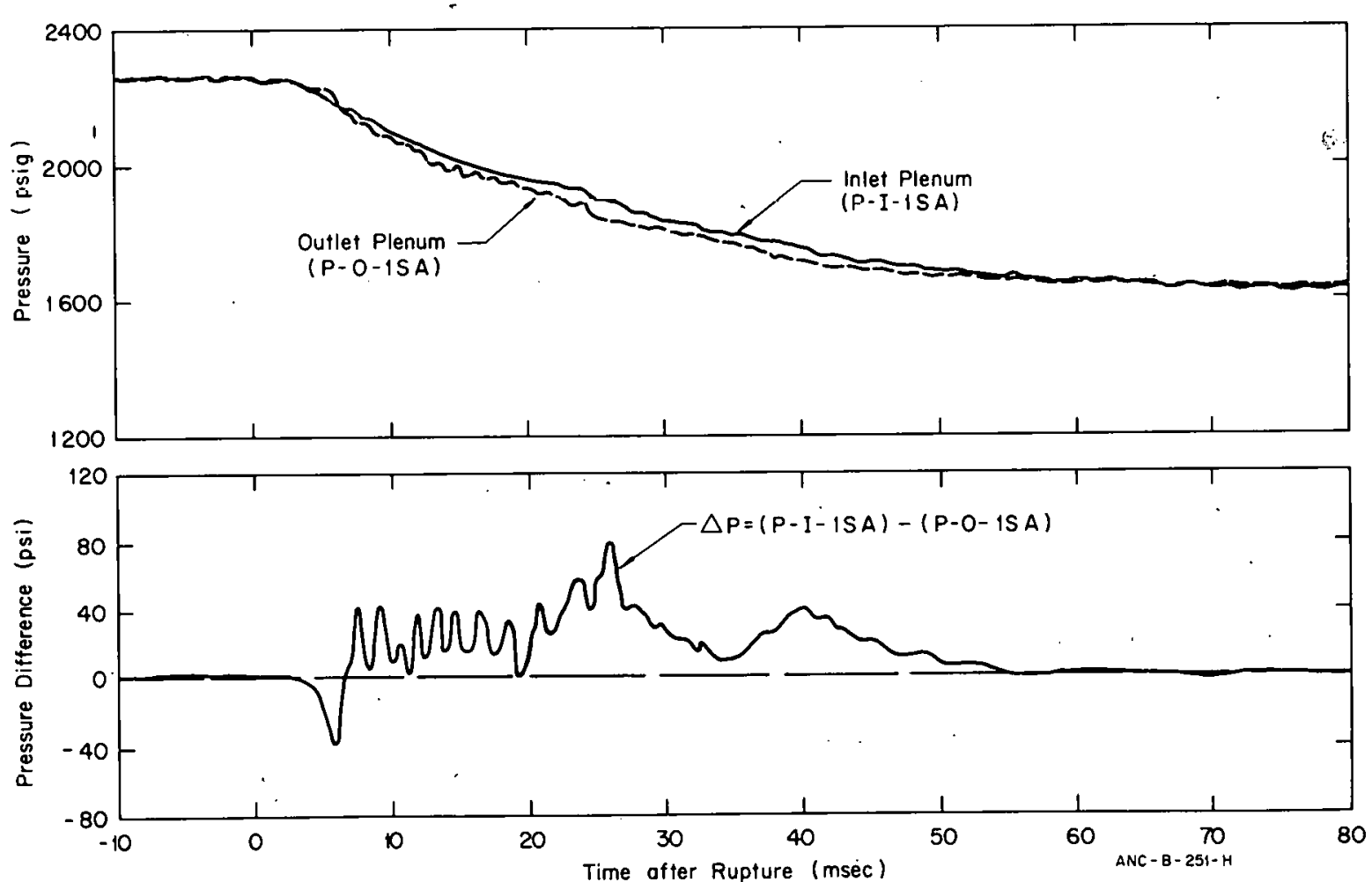

Fig. 11 Test 849 subcooled decompression -- vessel pressures and pressure difference. 


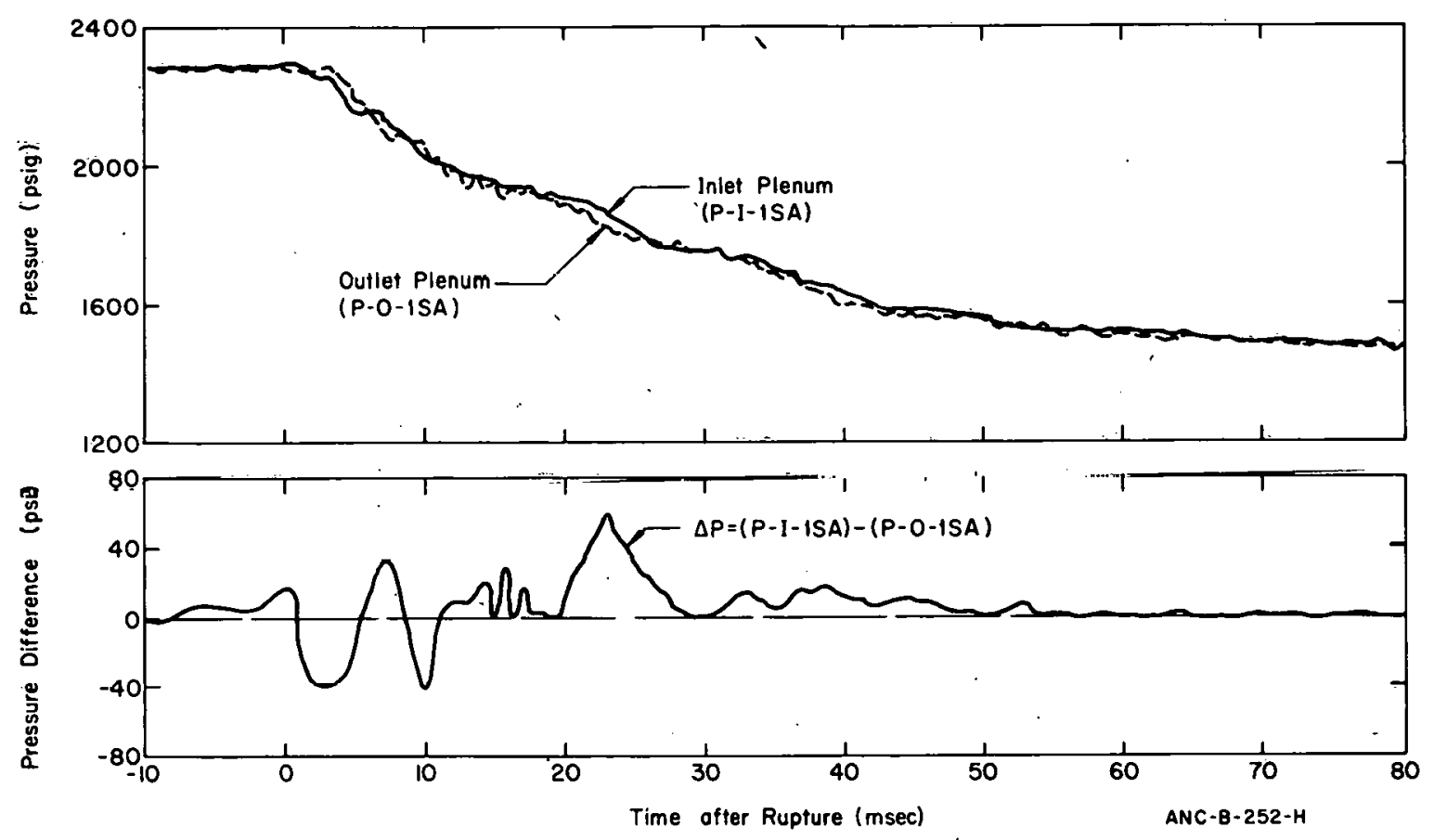

Fig. 12 Test 850 subcooled decompression -- vessel pressures and pressure difference.
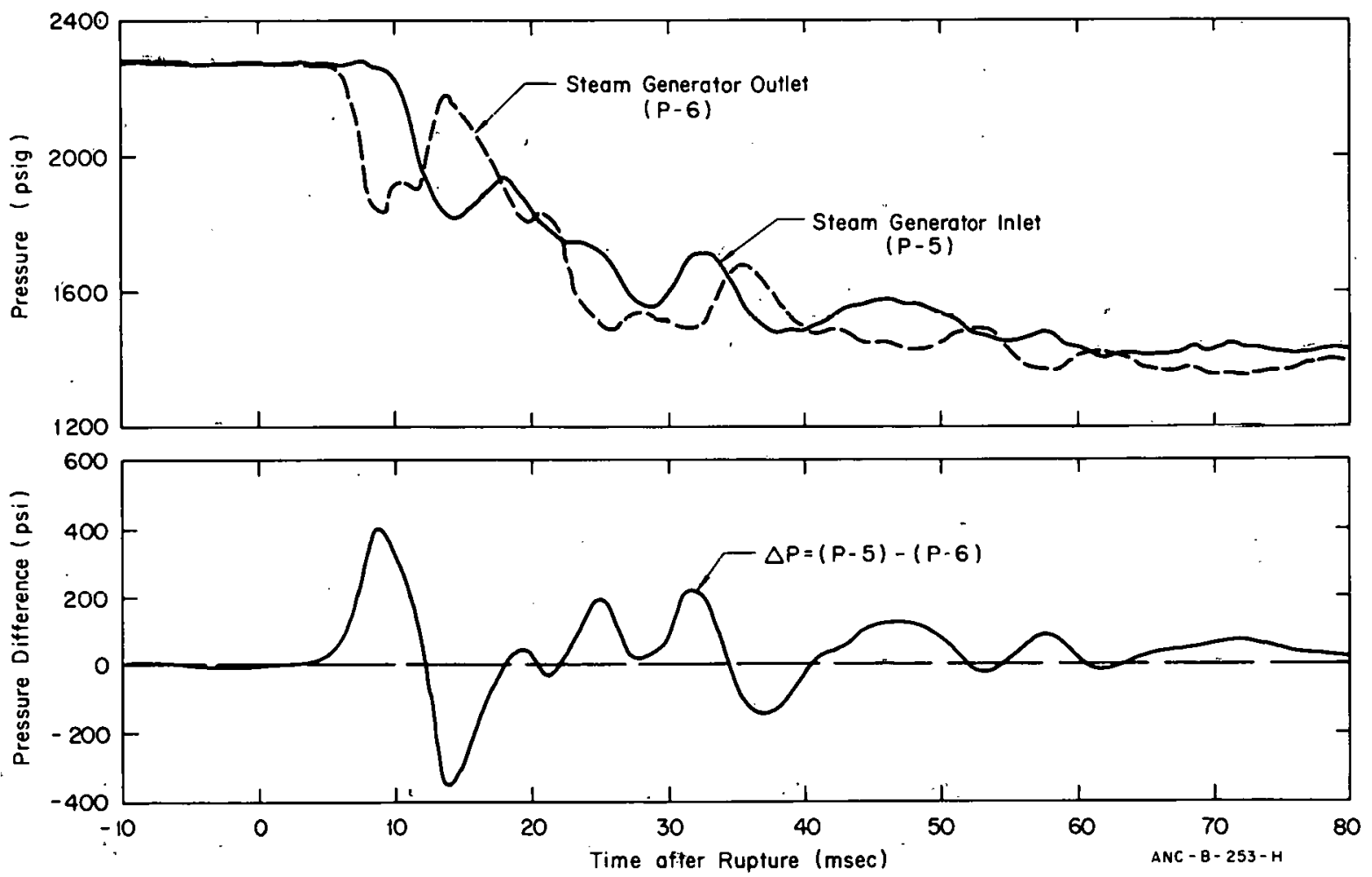

Fig. 13 Test 848 subcooled decompression -- steam generator pressures and pressure difference. 

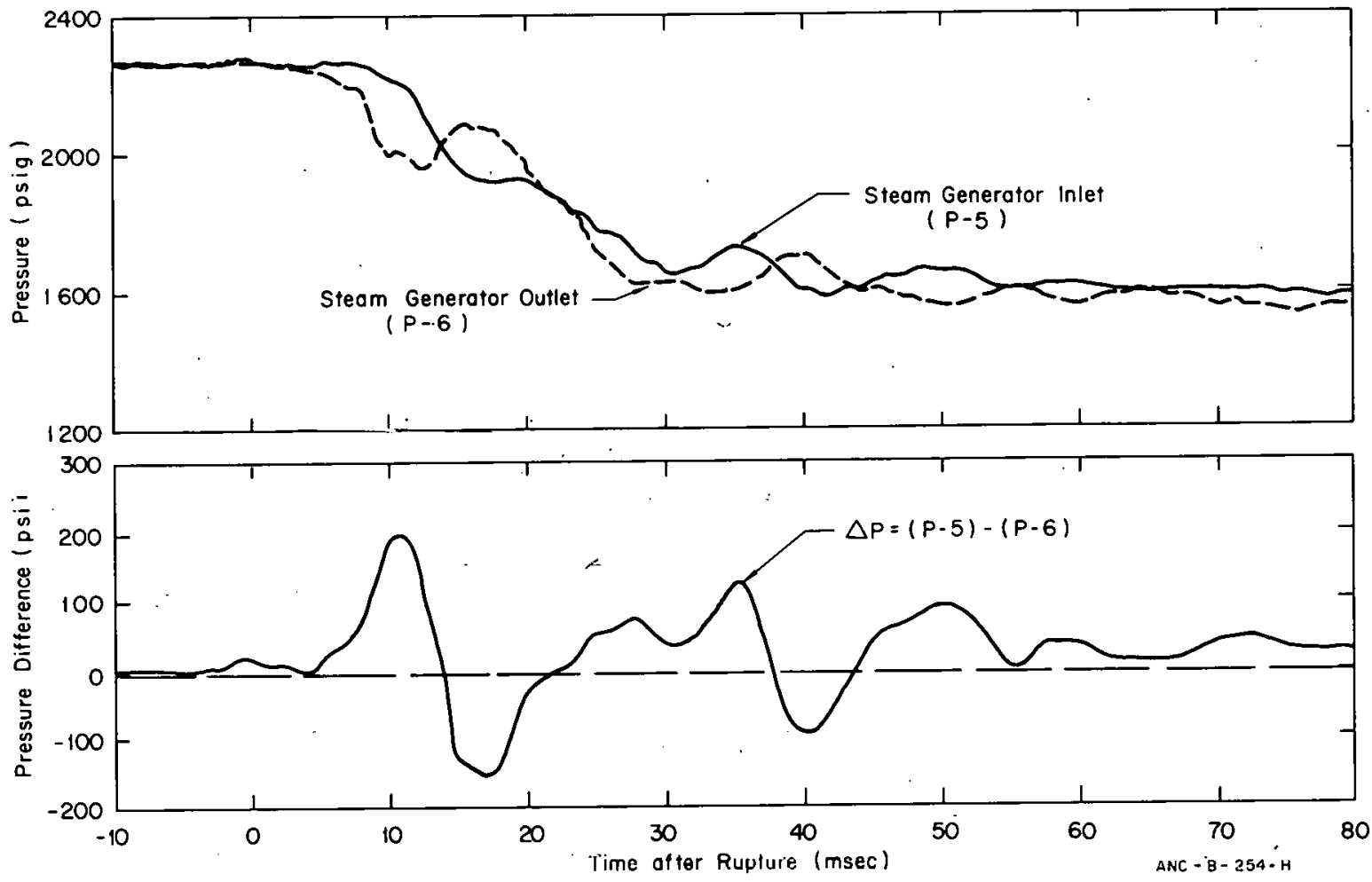

Fig. 14 Test 849 subcooled decompression -- steam generator pressures and pressure difference.

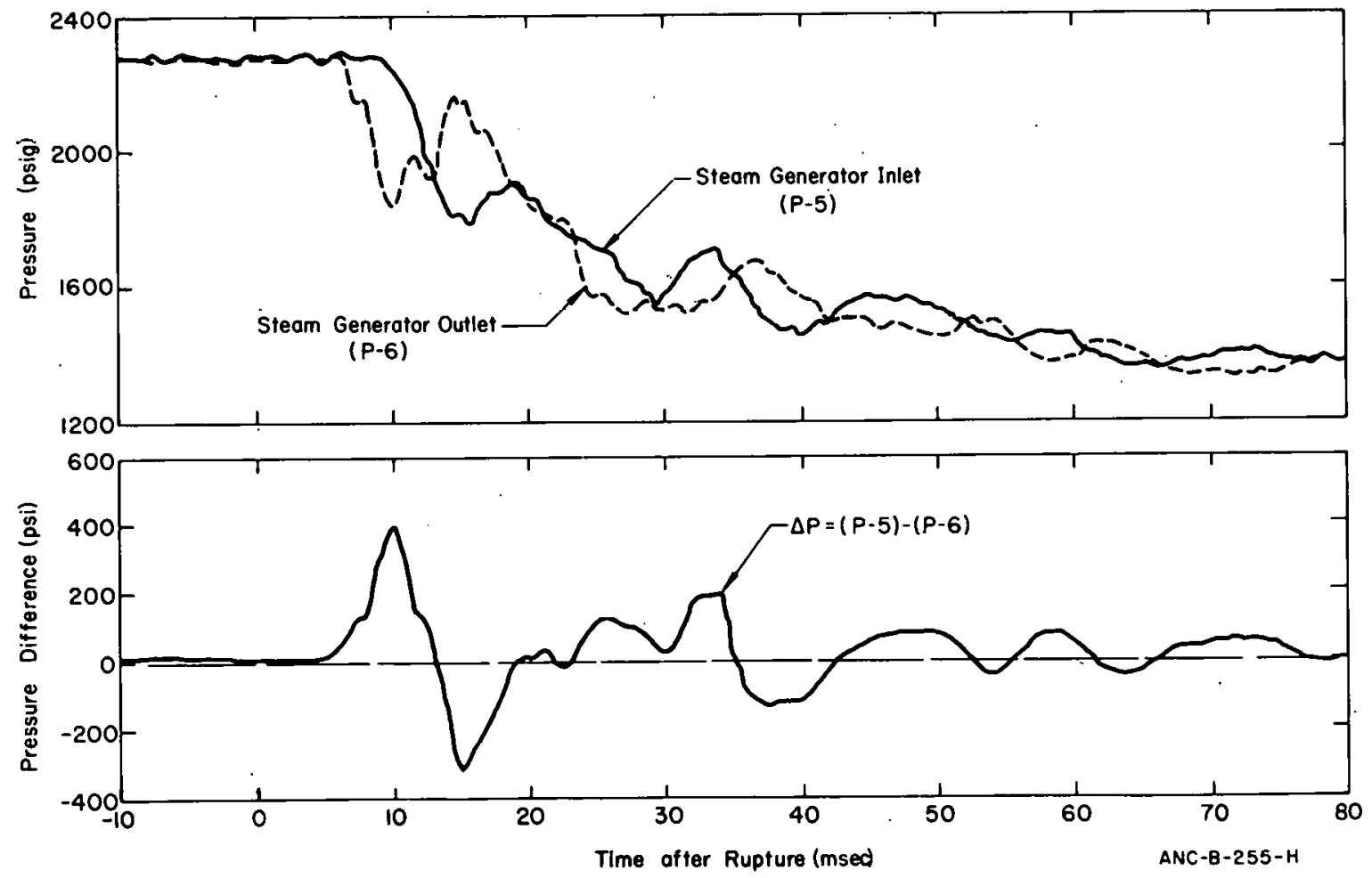

Fig. 15 Test 850 subcooled decompression -- steam generator pressures and pressure difference. 
the magnitude of the pressure difference oscillations is less by half. The first cycle is from 200 to -150 psi with subsequent oscillations diminishing rapidly to about $\pm 50 \mathrm{psi}$. This behavior reflects the damping effect of the nozzle during Test 849. For all three tests, the pressure difference across the steam generator was primarily positive (normal flow direction) by the end of subcooled decompression.

\subsection{Saturated Decompression}

Saturated decompression begins 50 to $55 \mathrm{msec}$ after rupture when the system has decompressed to the saturation pressure for the initial outlet temperature (the highest initial temperature in the system). At this time the outlet plenum fluid becomes saturated and begins to enter the two-phase regime while fluids at other locations of the system, initially at a colder temperature, are still undergoing subcooled decompression. A period of transition continues until the system has decompressed to the saturation pressure of the fluid at the coldest initial temperature (vessel inlet plenum). Saturated decompression of the fluid in the inlet plenum began 0.7 to 0.8 sec after rupture for Tests 848,849 , and 850 .

The fact that saturated decompression begins at different times at various locations in the system, depending on the initial temperature distribution, is important from the standpoint of core integrity. The initial temperature difference between the inlet and outlet plenums was 55 to $69^{\circ} \mathrm{F}$. The pressure difference between plenums corresponding to the simultaneous existence of saturation conditions in both plenums is 500 to 700 psi. Figures 16, 17, and 18 present the measured vessel plenum pressures and pressure differentials for the first $3.2 \mathrm{sec}$ of decompression for Tests 848,849 , and 850 , respectively; maximum pressure differentials between plenums were 40 to $60 \mathrm{psi}$, decreasing to less than $10 \mathrm{psi}$ by $0.8 \mathrm{sec}$ after rupture. The conclusion can therefore be reached that saturation conditions did not exist concurrently in both the inlet and outlet plenums during the initial portion of saturated blowdown. This conclusion is supported by fluid temperature measurements, which are presented in the next section. Briefly, the temperature data show that the fluid in the inlet plenum is subcooled for the first $0.7 \mathrm{sec}$ of decompression.

The pressure histories for the vessel plenums are presented in Figure 19 for Test 848 , and are typical of Tests 849 and 850 . In general, once the system decompressed to the saturation pressure of a locallzed temperature, the fluid at that location changed from subcooled to two-phase fluid. As soon as saturation conditions were established throughout the system, fluid pressure corresponded closely to saturation pressure for the remainder of the blowdown.

Figure 20 shows, for comparison, the inlet plenum pressure for all three tests. The curves are in very close agreement, with any difference being attributable to the slight difference in initial temperatures. The initiation of ECC injection is noted in Figure 20; no measurable effect on lower plenum pressure was evident. The pause in the decompression process, as indicated in the pressure traces at 11 to $12 \mathrm{sec}$ for Test 848 , which is also evident for Test 850 , is attributed to the passage of higher density fluid from the pressurizer . and not to the ECC fluid. 

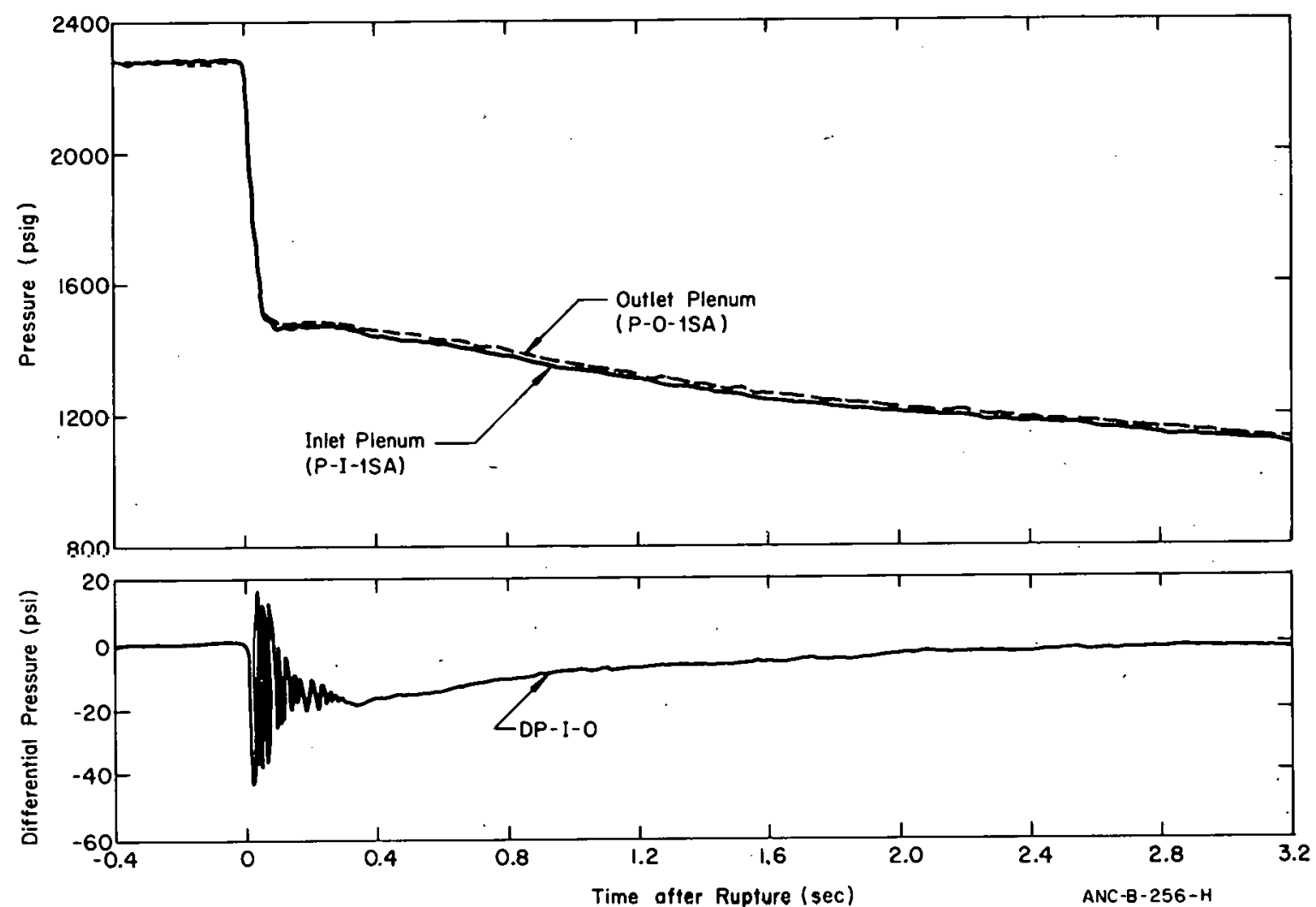

Fig. 16 Test 848 vessel plenum pressures and differential pressure.
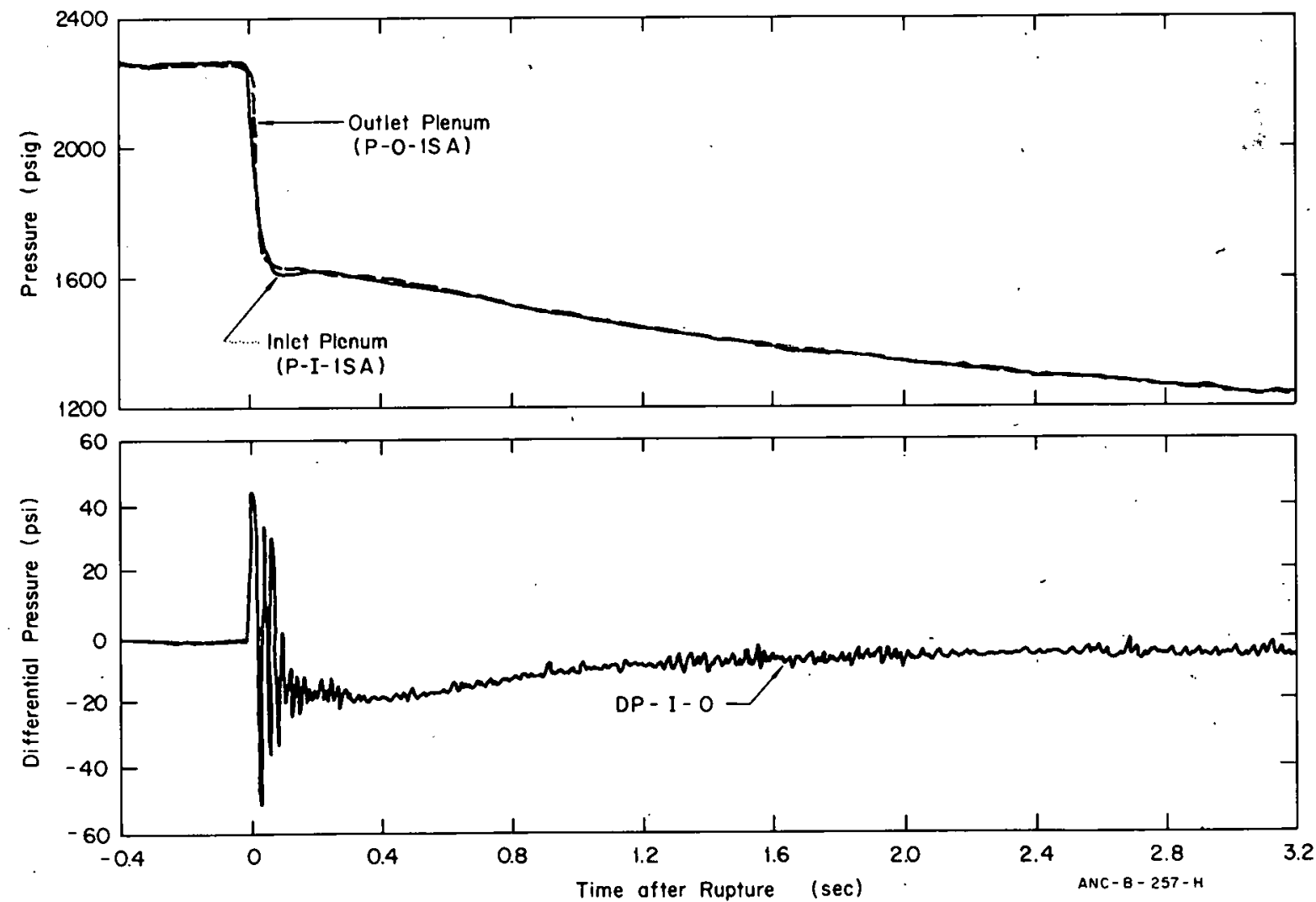

Fig. 17 Test 849 vessel plenum pressures and dfferential pressure. 

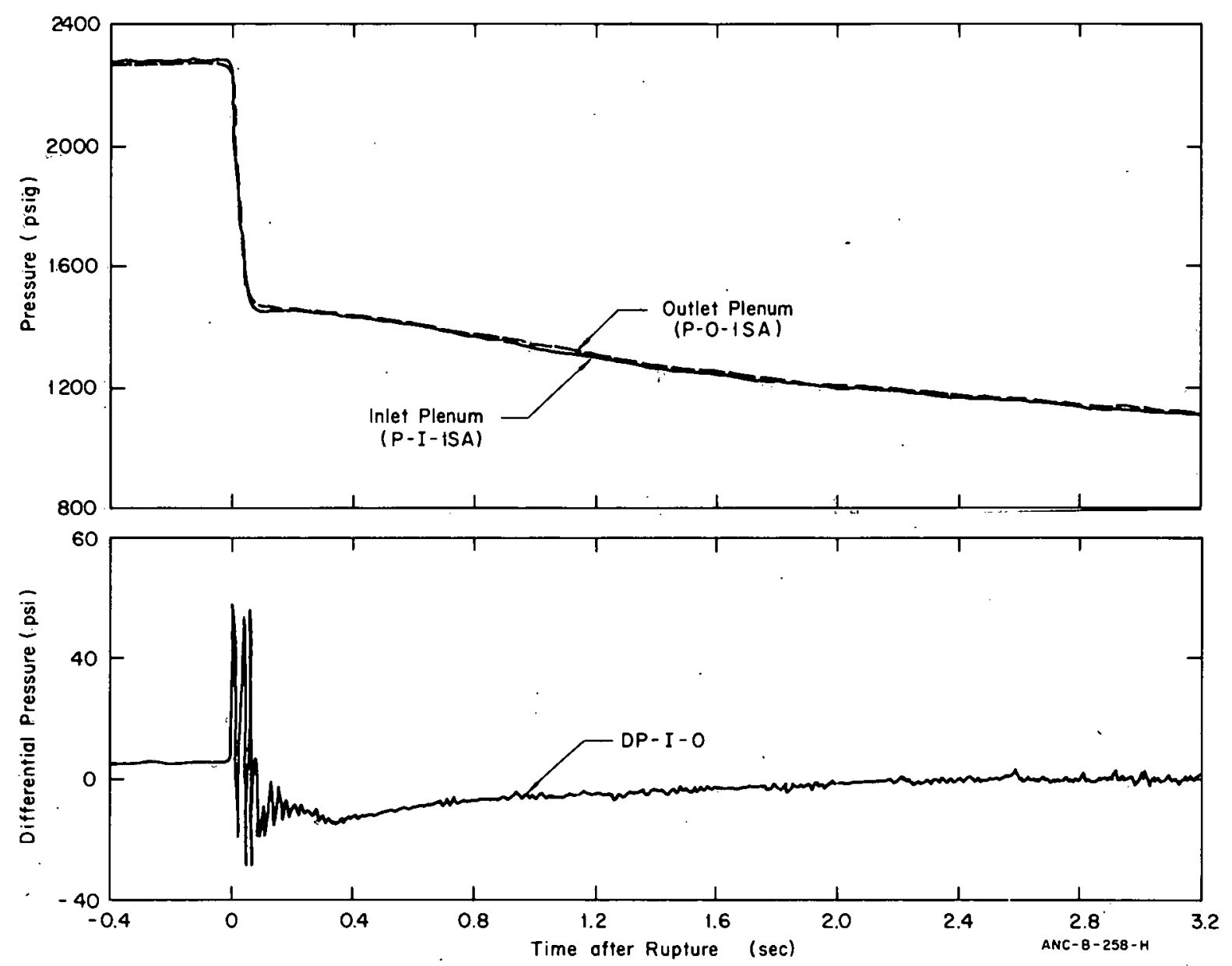

Fig. 18 Test 850 vessel plenum pressures and differentlal pressure.

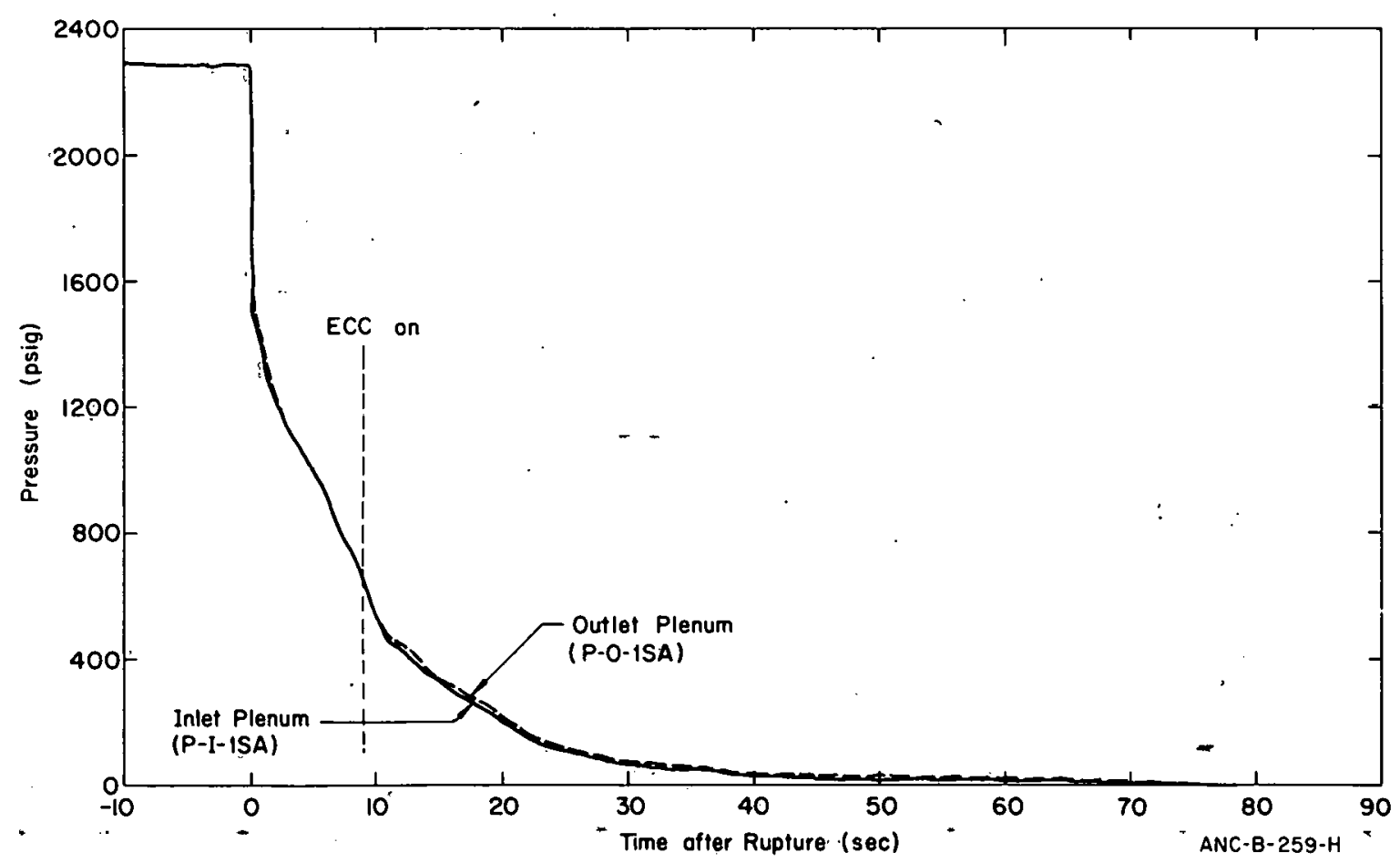

Fig. 19 Vessel pressures -- Test 848. 


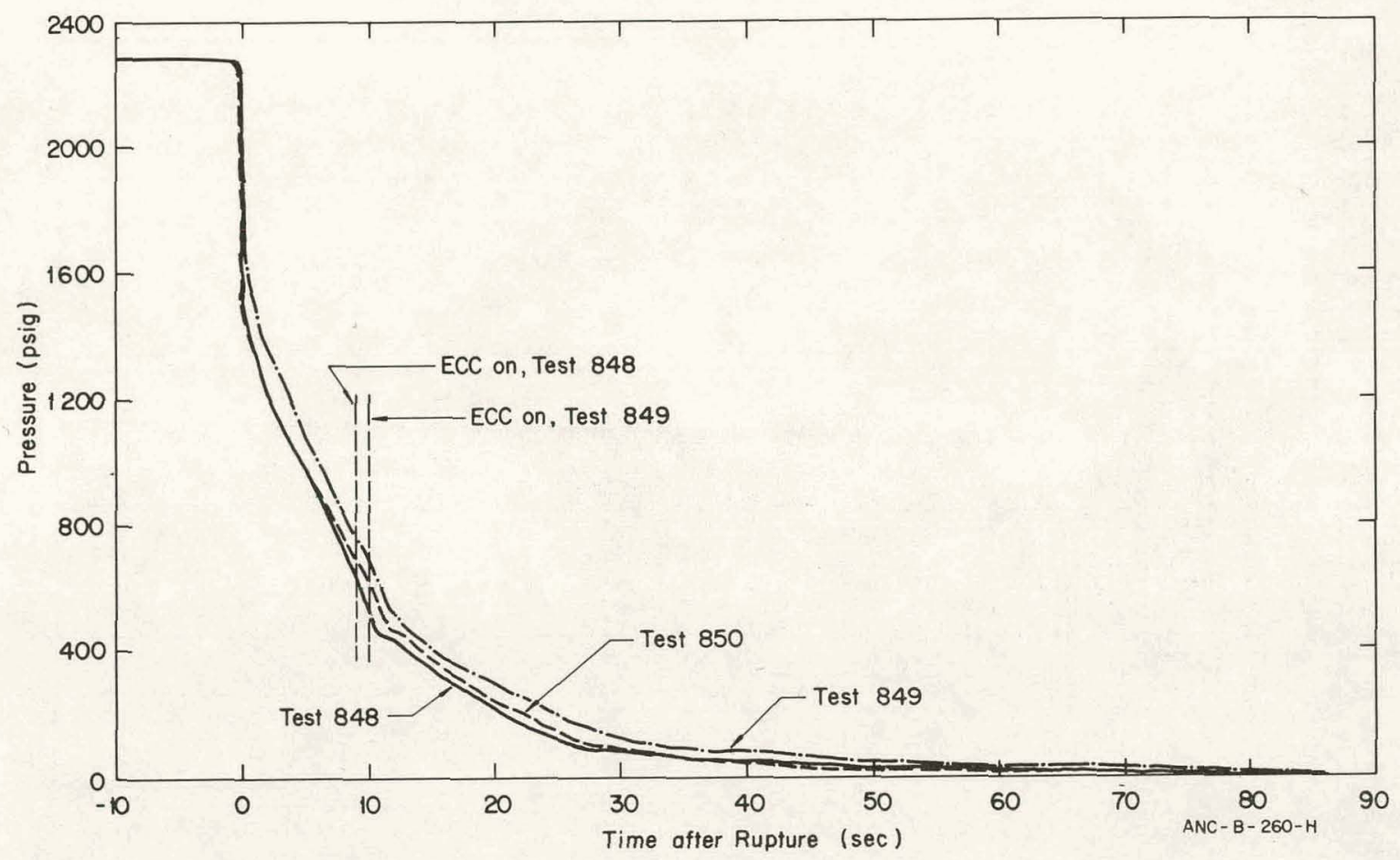

Fig. 20 Inlet plenum pressure -- Tests 848,849 , and 850 .

Additional pressure histories for various locations in the system are given in Appendix C, Figures $\mathrm{C}-1$ through $\mathrm{C}-12$.

\subsection{Differential Pressure}

Measurements of differential pressure were made across the core, the vessel, the steam generator, the pump, the flow control valve, and between the outlet plenum and blowdown nozzle. The differential pressure histories around the loop for Tests 848, 849, and 850 are included in Appendix C.

Figure 21 shows the pressure differential across the pump for Tests 848 and 850 ; the data are typical of other loop differential pressure measurements. Pressure spikes are evident in the data for Test 848 shortly after ECC injection begins. However, similar pressure spikes are apparent in the data for Test 850 which was performed without ECC injection, indicating that this differential pressure behavior was not a result of ECC injection. Figure 22 presents a comparison of differential pressure histories across the core (between vessel plenums) for Tests 848 and 850 (shorter term data were included in Figures 16 and 18). The data in Figure 22 do not indicate any appreciable effects due to the arrival and presence of ECC fluid in the vessel inlet plenum.

Additional differential pressure data are presented in the discussions of flow rates and emergency core cooling in Section $\mathrm{V}$ of this report. 


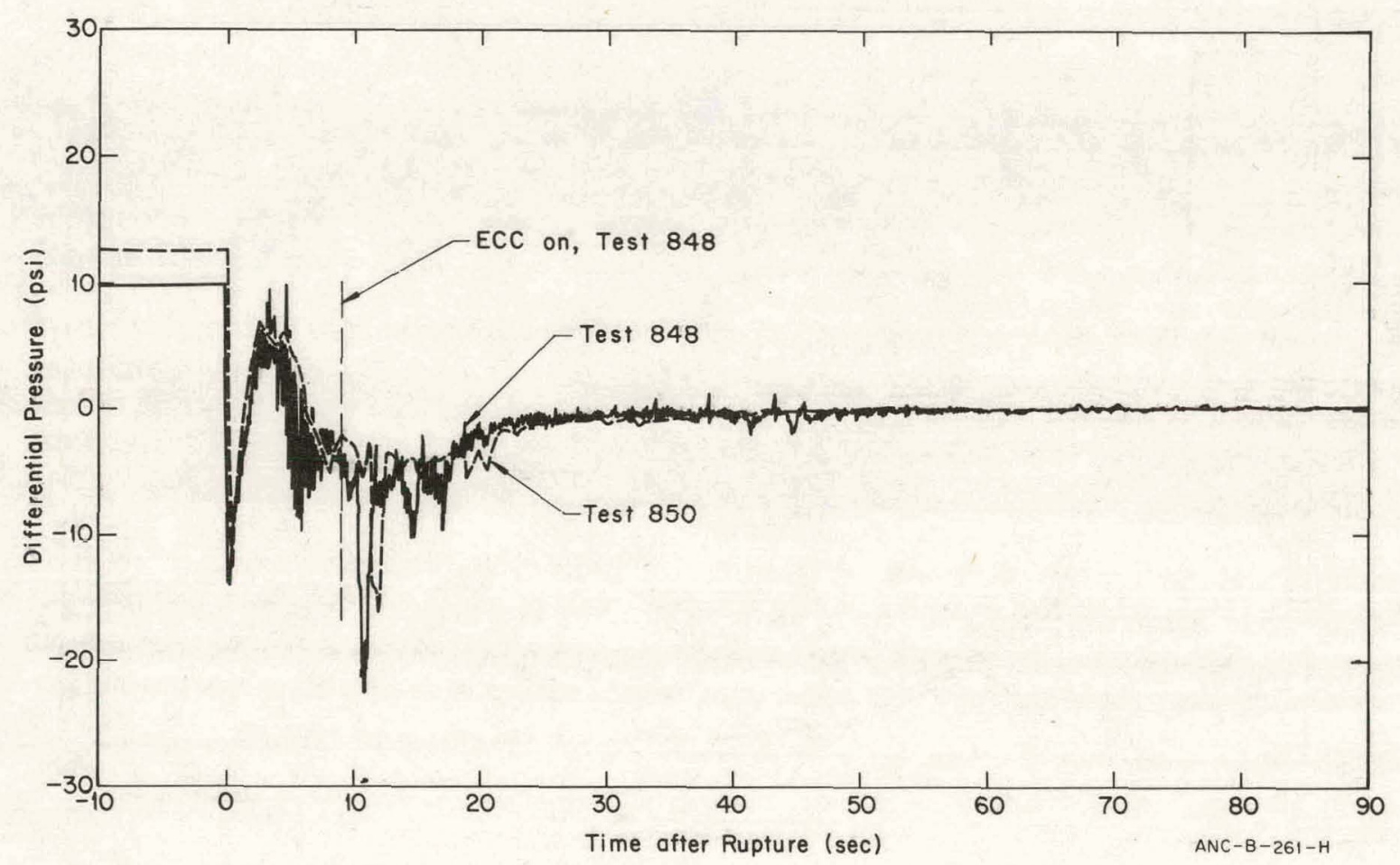

Fig. 21 Comparison of differential pressure across pump during Tests 848 and 850 .

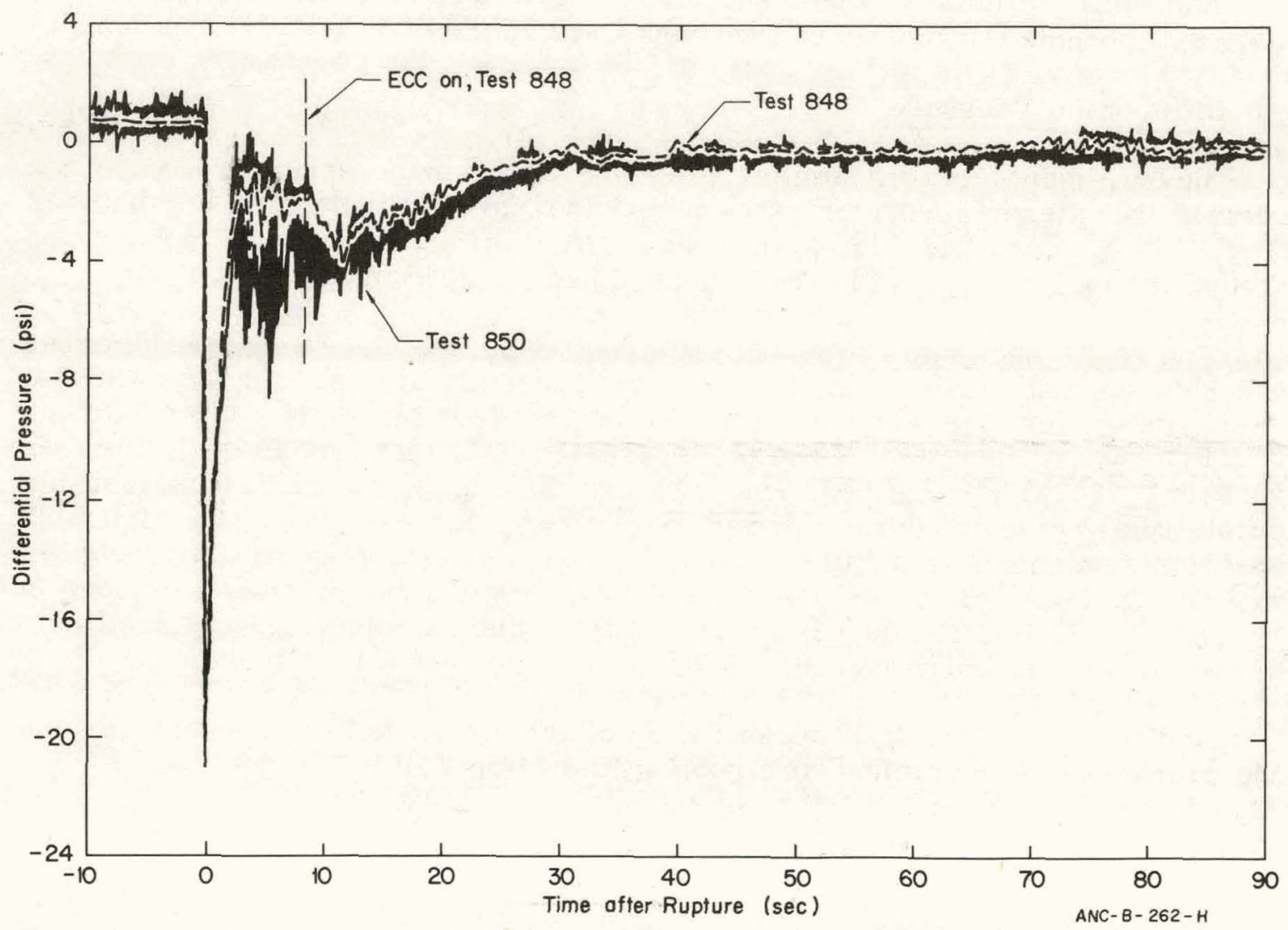

Fig. 22 Comparison of differential pressure across core during Tests 848 and 850 . 


\section{TEMPERATURE}

The presentation of measured temperature data is separated into a section on fluid temperatures and a section on material (pin cladding and insulator, vessel internals, and piping) temperatures. All temperatures recorded during the decompression tests were measured with Chromel-Alumel thermocouples. The overall accuracy of these measurements is considered to be within $\pm 5 \%$ of full scale (within $\pm 30^{\circ} \mathrm{F}$ ).

To improve the accuracy of the initial fluid temperature measurements, resistance temperature bulbs (RTB's), with an accuracy of within $\pm 1^{\circ} \mathrm{F}$, were installed at strategic locations in the system. All loop fluid temperature data have been normalized at the initial test conditions to agree with the initial temperature indicated by the closest RTB. The accuracy of the normalized transient temperatures is estimated to be within $\pm 1 \%$ of full scale, or within $\pm 6^{\circ} \mathrm{F}$.

\subsection{Fluid Temperatures}

The initial fluid temperature distribution was given in Table I. In general, system fluid temperatures dropped slightly during the subcooled expansion of the fluid following rupture. For fluid measurement stations in the direct flow path from the inlet plenum to the break, this slight decrease in fluid temperature was followed by a comparatively large increase to temperatures higher than the pretest cold leg temperature. This behavior is apparent in Figure 23 which shows vessel inlet and outlet plenum temperatures for all three tests for the early portion of decompression. The fluid in the outlet plenum, initially at a higher temperature, saturated earlier and at a higher pressure than the fluid in the lower plenum, thereby resulting in fluid stagnation in the outlet plenum and reverse flow through the core. The reverse flow carried a two-phase fluid at a relatively higher enthalpy than the inlet plenum fluid. The hotter fluid, upon mixing with the inlet plenum fluid, caused the temperature of the inlet plenum fluid to rise. At the same time, the outlet plenum was decompressing at a somewhat faster rate than the inlet plenum. At approximately 0.7 to $0.8 \mathrm{sec}$, temperature equilibrium between the plenums was reached.

Figure 24 shows the entire transient fluid temperature history for invessel locations during Test 848 and is typical of the results for all inlet break ECC injection tests performed to date. The temperatures, once having reached saturation at about $0.8 \mathrm{sec}$ after rupture, remained within about $5^{\circ} \mathrm{F}$ of one another, indicating nearly uniform saturation conditions throughout the vessel. This uniformity corresponds to the pressure histories presented earlier (Figure 16) which indicated very little pressure difference between the vessel plenums after $0.8 \mathrm{sec}$. About 33 sec after rupture, the thermocouples located in the inlet plenum ( 5 in. below the lower grid plate) indicated the presence of ECC fluid. The inlet plenum fluid temperature, shown in Figure 24, deviates from the saturation temperature and indicates a rather large degree of cooling at this time. The initial 20 to $30^{\circ} \mathrm{F}$ fluctuations in inlet plenum fluid temperature are due to the presence of ECC liquid and the subsequent larger $\left(75^{\circ} \mathrm{F}\right)$ temperature drop is attributable to the passage of the small amount of cold gas which escaped from the ECC accumulator just prior to valve shutoff in Test 848. 


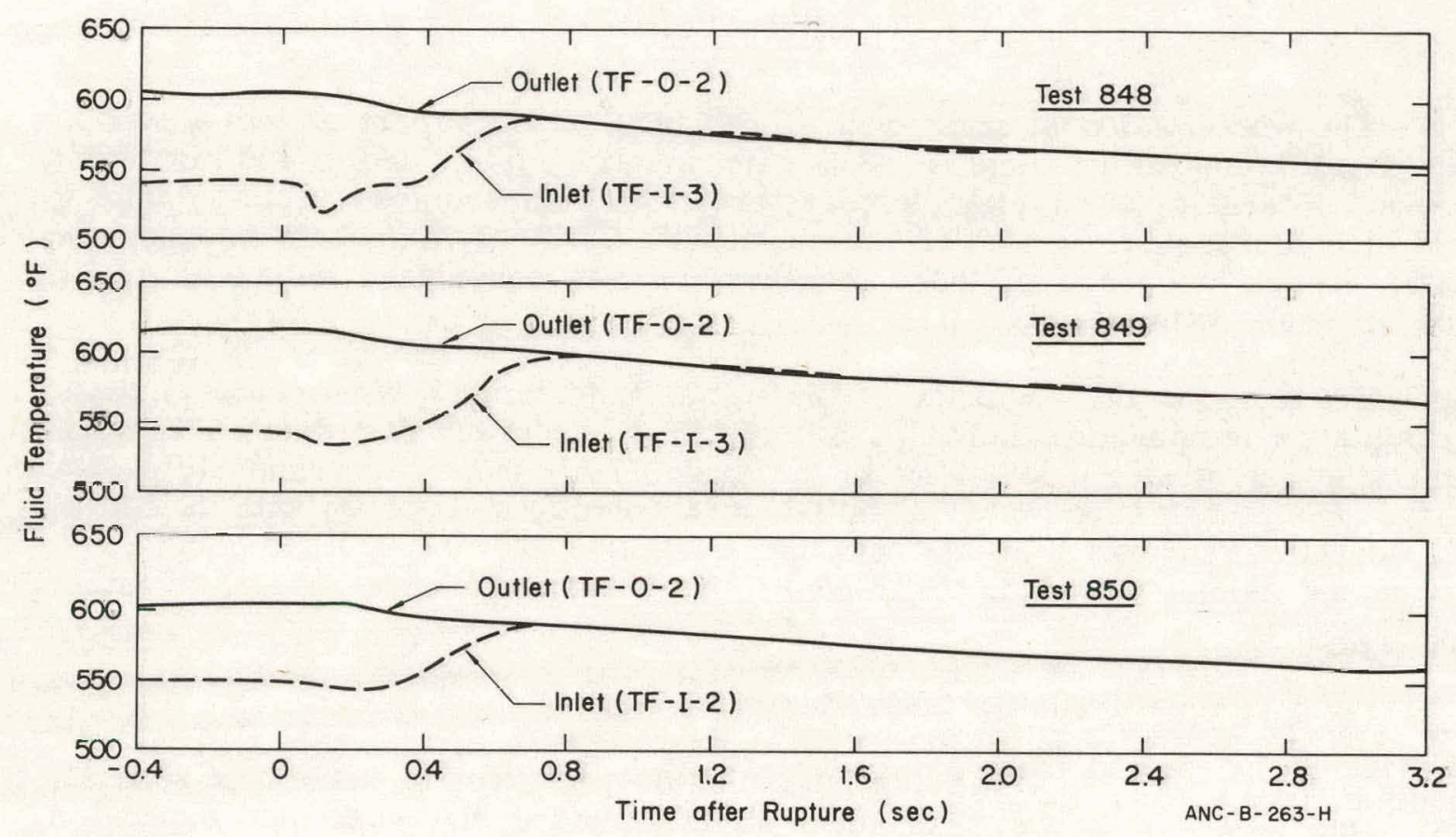

Fig. 23 Vessel plenum temperatures -- Tests 848,849 , and 850 .

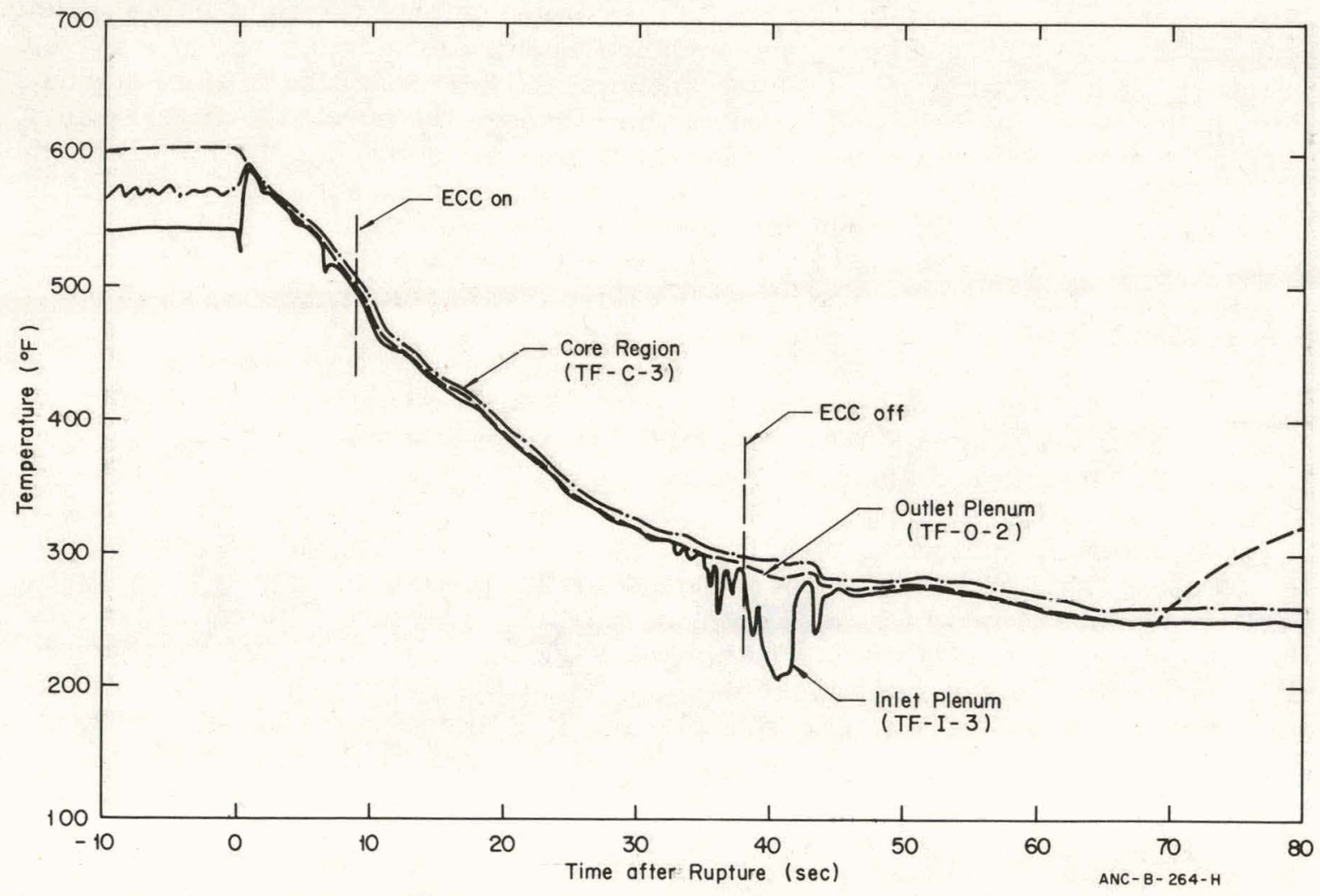

Fig. 24 Vessel fluid temperatures -- Test 848 . 
Figure 25 shows the inlet and outlet plenum fluld temperatures for a test with ECC (Test 848) and for a test without ECC (Test 850). The data indicate that ECC injection has little effect on vessel fluid temperature untll late in the transient. About $30 \mathrm{sec}$ after rupture for the test without ECC, a dryout condition occurred at the upper elevations in the inlet plenum and the heat radiated by nearby metal surfaces caused the thermocouple (TF-I -3) to record a rapid increase in fluid temperature. Because some ECC fluid was present in the inlet plenum, the dryout did not occur at the same location during Test 848 .

Figures 26, 27, and 28 show the flutd temperatures at various elevations in the inlet plenum for Tests 848, 849, and 850. Five thermocouples were located at elevations ranging from 0.5 to 15 in. above the bottom head in order to evaluate the degree of mixing between primary coolant and ECC fluid in the inlet plenum. For Tests 848 and 849 , the fluid temperatures began to diverge shortly after initiation of ECC injection. The presence of ECC was recorded first at the lowest elevation and then progressively upward; however, the fluid temperature at the highest elevation in the inlet plenum continued at very nearly the saturation temperature of the system and did not indicate appreciable cooling due to ECC injection until late in the transient (about 33 to $35 \mathrm{sec}$ ). These data lead to the conclusion that, for the ECC infection Tests 848 and 849 , the fluid in the inlet plenum was not homogeneous. Stratified layers of fluid at different degrees of subcooling were evident. The degree of subcooling varied with height in the lower plenum, with as much as $70^{\circ} \mathrm{F}$ subcooling near the bottom head of the vessel for Test 849 . Figure 28 presents comparable inlet plenum fluid temperature data for Test 850 without ECC. The stratification of fluid which occurred for the tests involving ECC is not apparent from the data for Test 850. As mentioned previously, a dryout condition occurred late in Test 850 causing the temperatures at the higher elevations to increase.

Also apparent from Figures 26, 27, and 28 is the effect on inlet plenum fluid temperatures immediately after rupture when hotter flutd from the outlet plenum flows down through the inlet plenum toward the break. For all three tests, fluid temperature data at the highest elevations are the first to indicate the reversed flow.

As noted previously, a small amount of gas from the ECC accumulator entered the inlet plenum during Test 848; the accumulator was valved off sooner for Test 849 and no gas reached the inlet plenum. The large drop (about $75^{\circ} \mathrm{F}$ ) evident in the fluid temperature data at the highest inlet plenum location for Test 848 is absent in the comparable data for Test 849.

Figures 29 and 30 compare loop fluid temperature behavior for tests with (Test 848, typlcal) and without (Test 850) ECC. The thermocouple located in the vessel inlet nozzle for Test 848 recorded passage of slugs of colder fluld beginning at about $28 \mathrm{sec}$, which was a result of a chugging phenomena caused by pressure oscillations in the vessel, discussed more fully in Section $\mathrm{V}-3$. In both tests the temperature at the steam generator inlet (TF -5) dropped shortly after rupture to a value below the cold leg temperature and recovered to the cold leg saturation values 2 to $3 \mathrm{sec}$ later. This behavior was a result of colder fluld from the auxiliary loop (Figure 1) reaching the steam generator inlet and indicates that loop flow was maintained in the normal direction around the loop, at least for the first few seconds of decompression. 


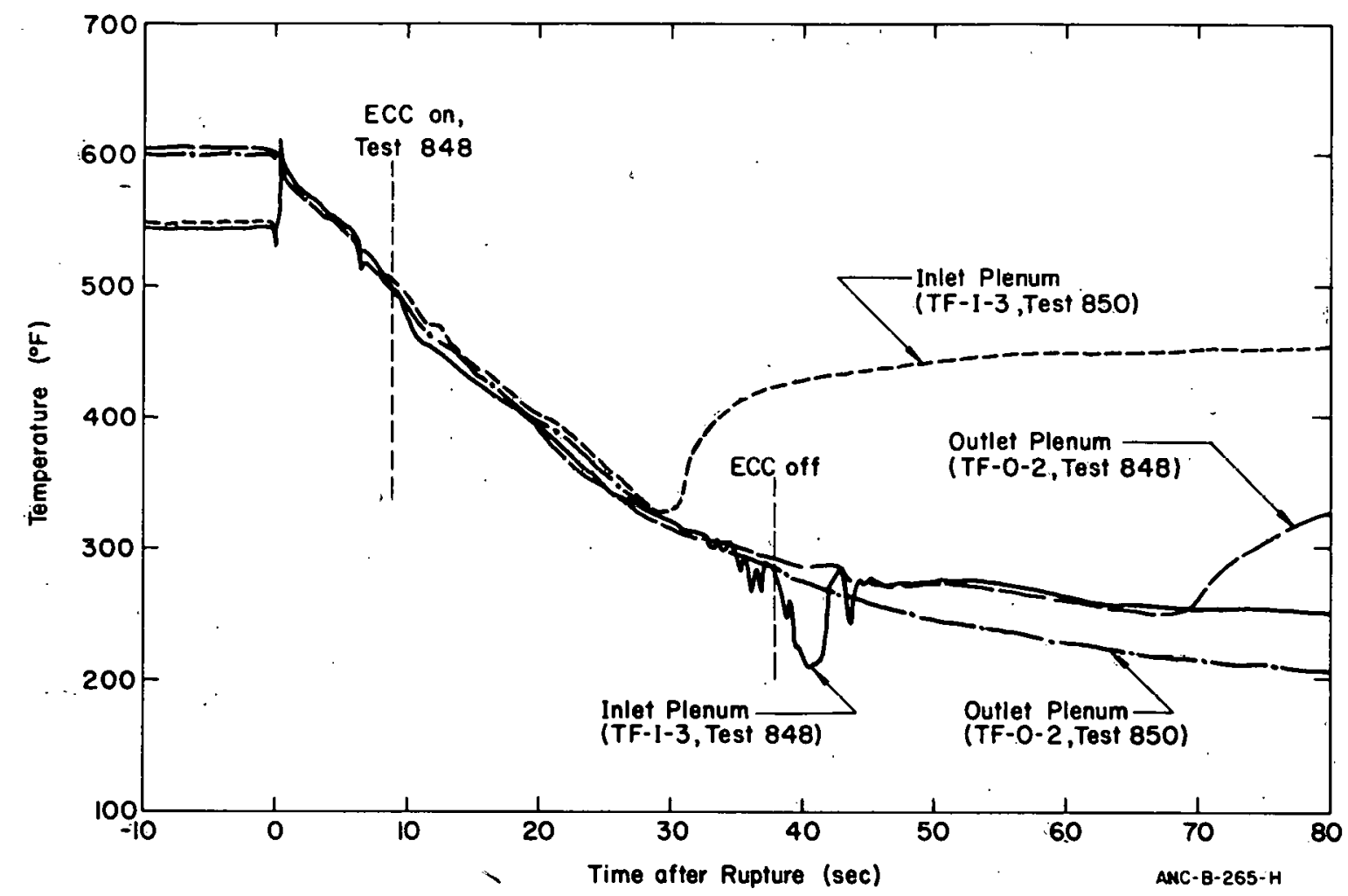

Fig. 25 Comparison of inlet and outlet plenum temperatures for Tests 848 and 850 .

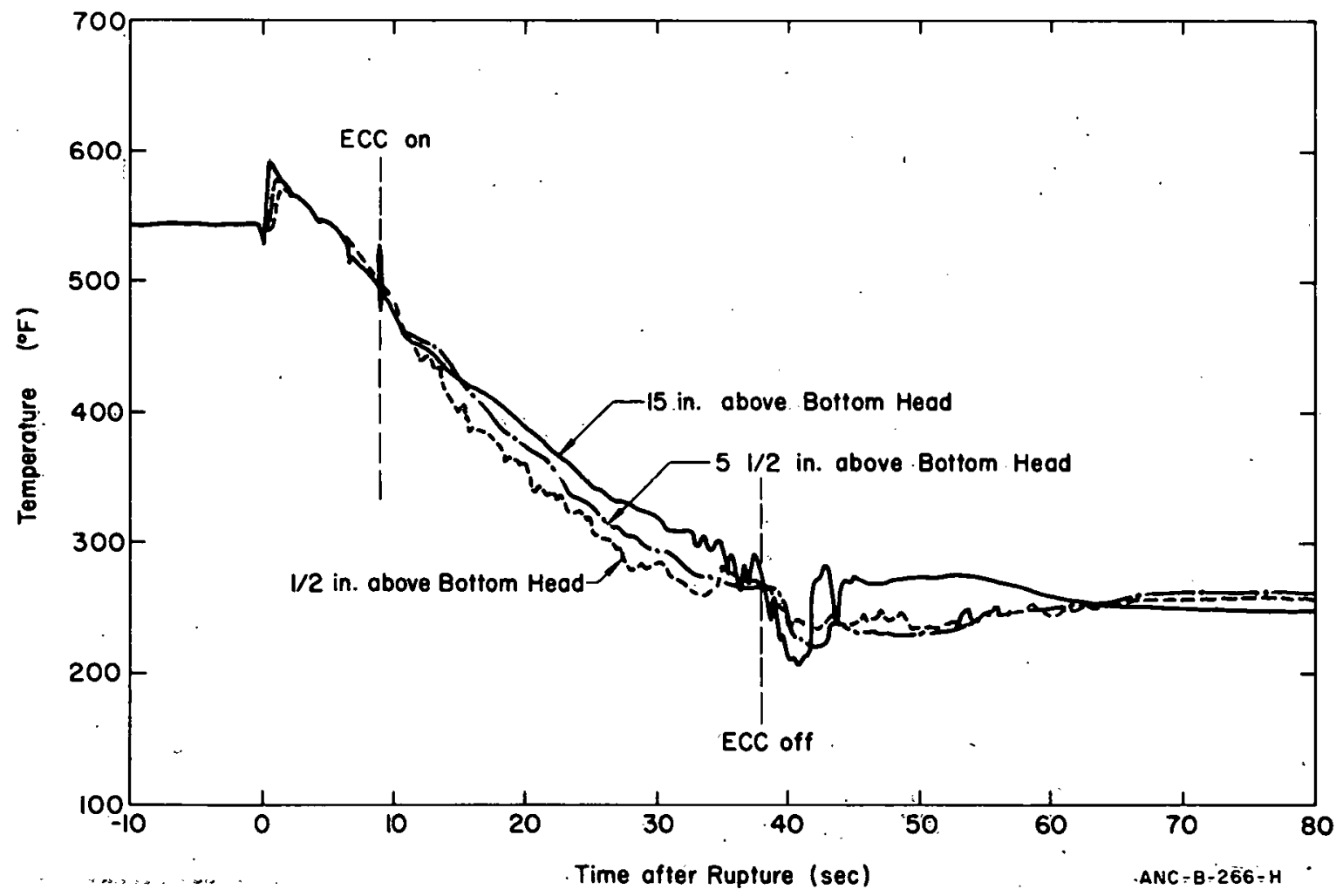

Fig. 26 Fluid temperatures in lower plenum -- Test 848. 


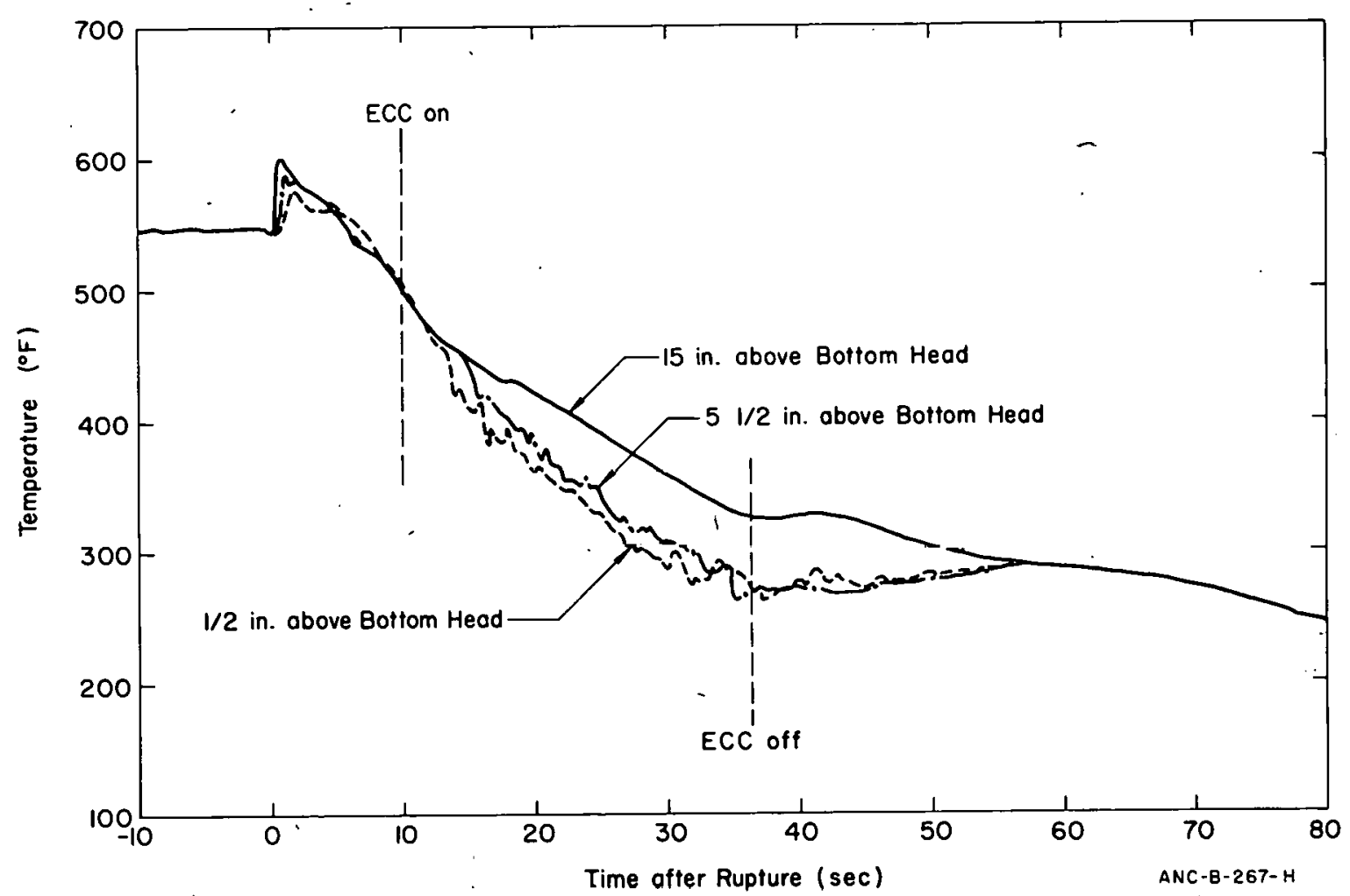

Fig. 27 Fluid temperatures in lower plenum -- Test 849.

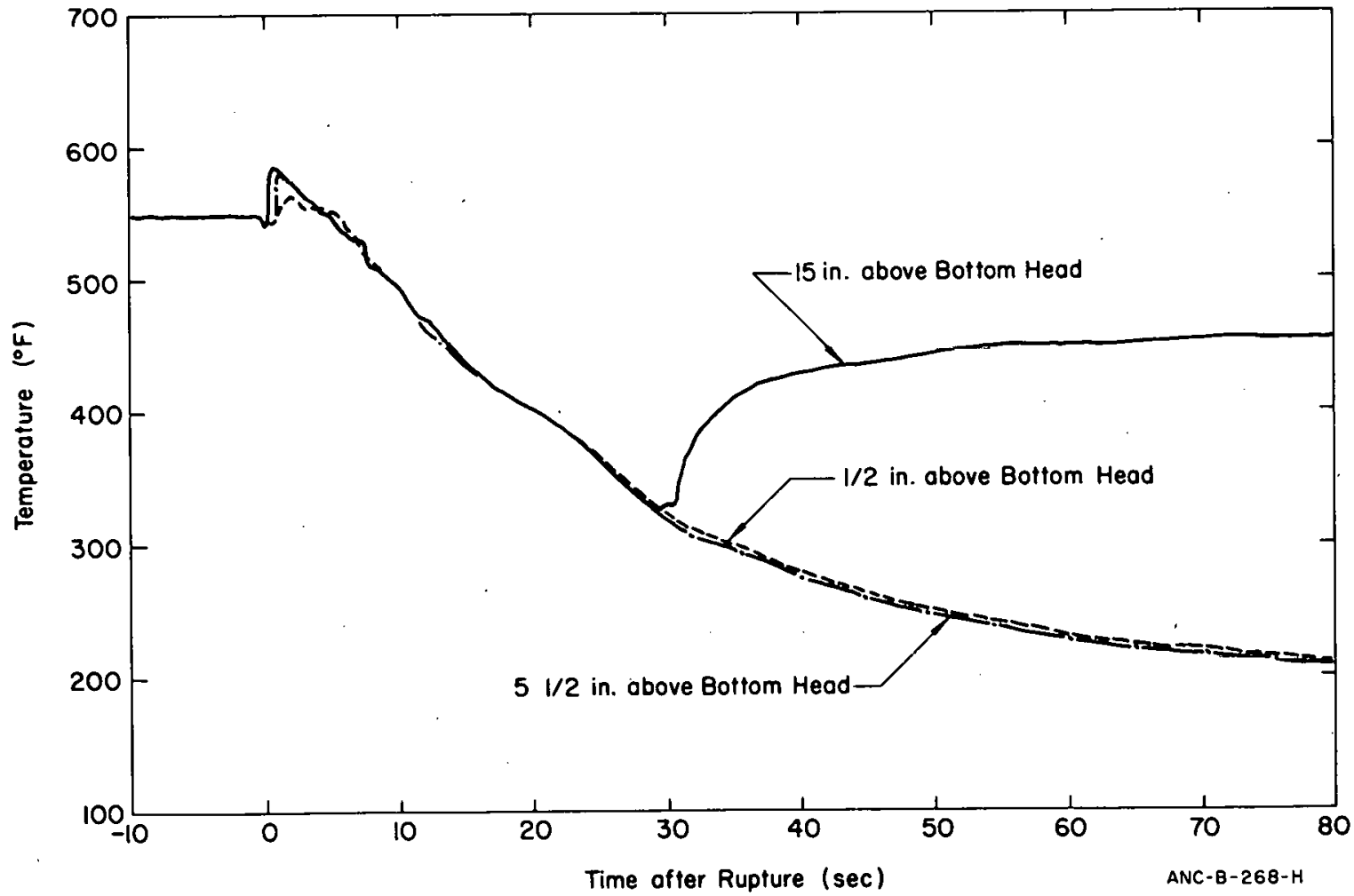

Fig. 28 Fluid temperatures In lower plenum -- Test 850 . 


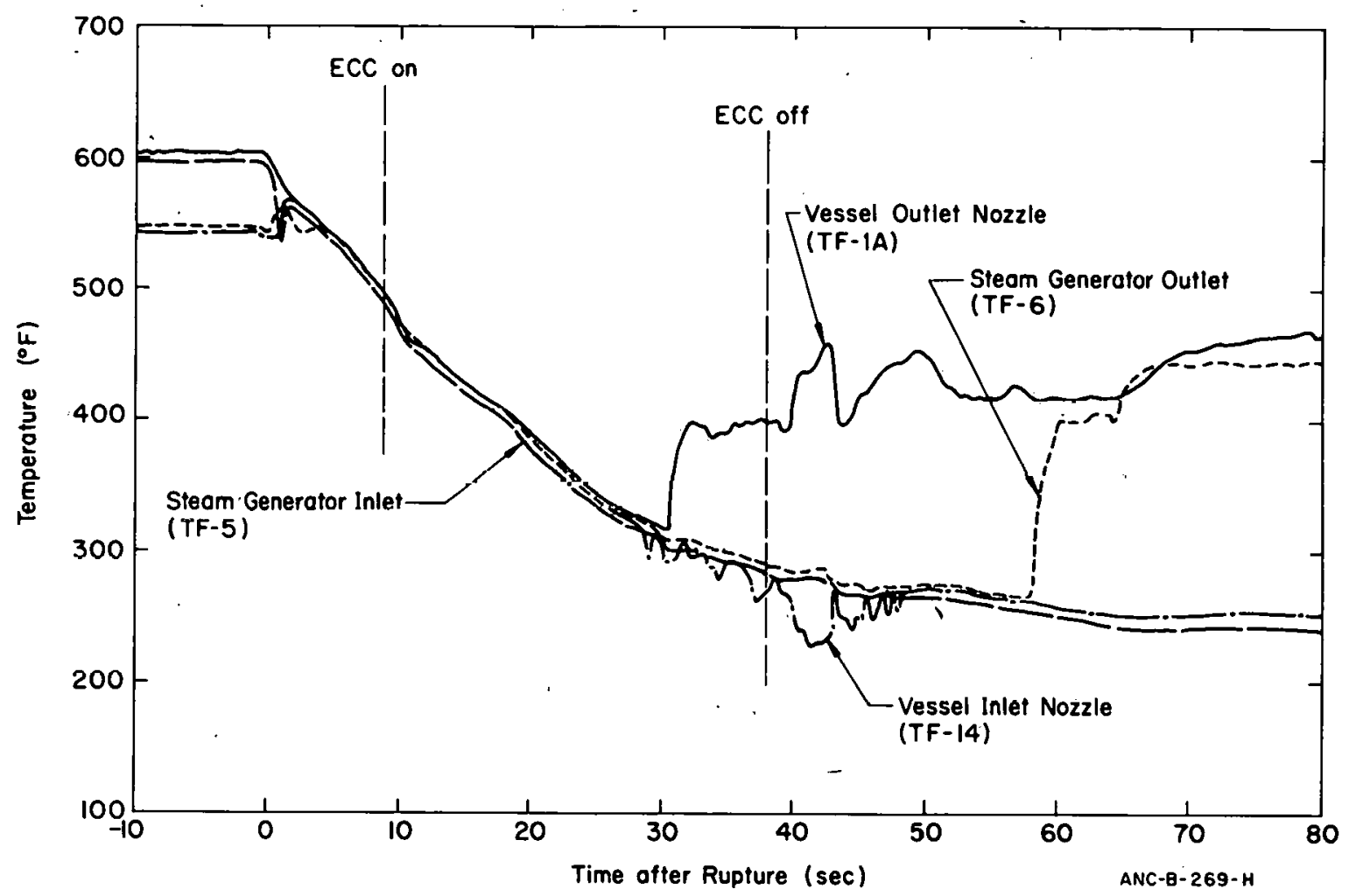

Fig. 29 Loop fluid temperatures -- Test 848.

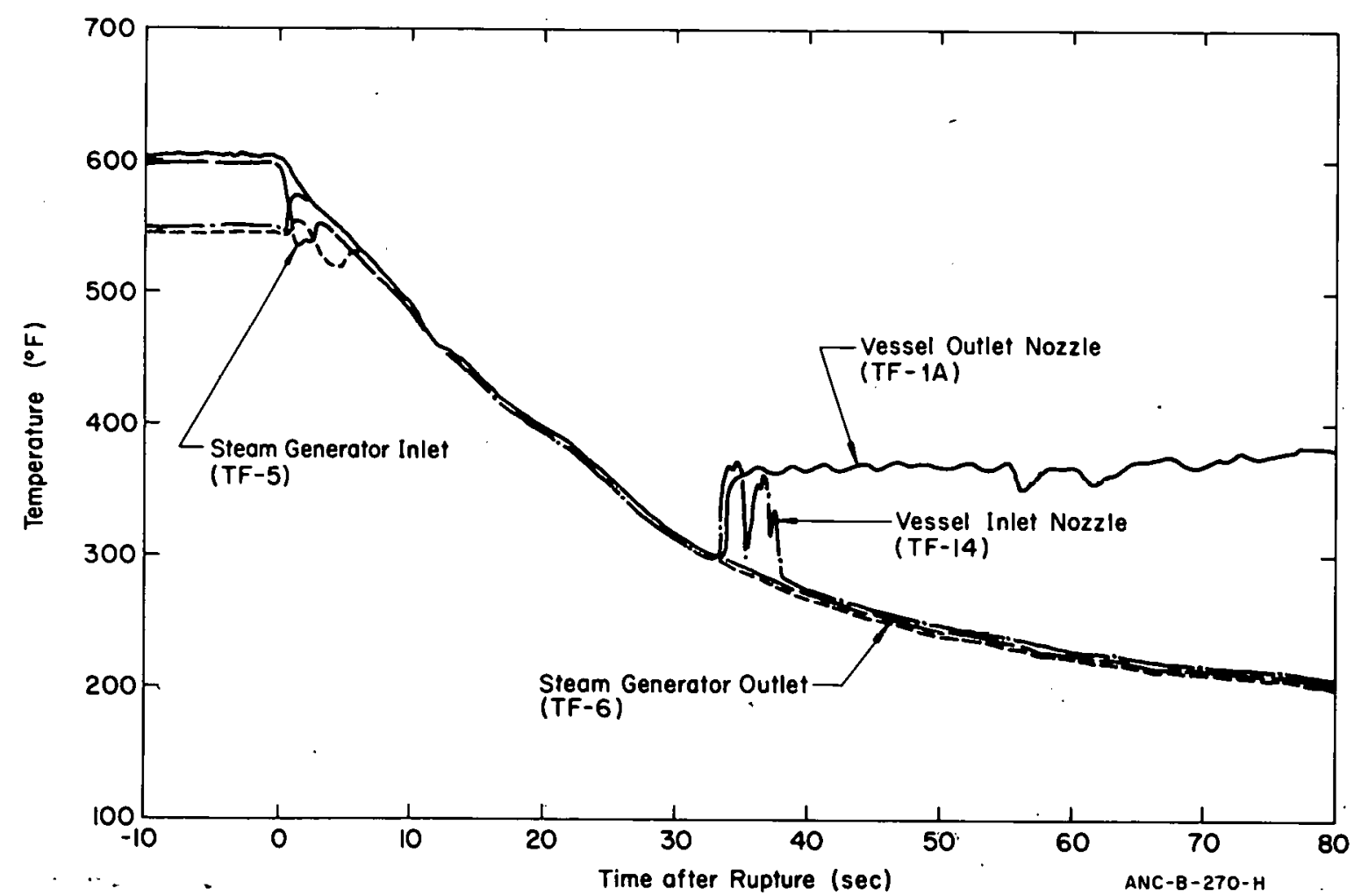

Fig. 30 Loop fluld temperatures -- Test 850 . 
As soon as the vessel outlet and hot leg fluid decompressed to the inlet plenum and cold leg saturation pressure and temperature, all fluid temperatures decreased according to saturation conditions (hot and cold leg saturation temperatures differ by only 10 to $15^{\circ} \mathrm{F}$ ). During later stages of saturated blowdown, when the quality of the fluid in the vicinity of a thermocouple became high, the thermocouple received heat through radiation from nearby metal surfaces and, as a result, the data from the thermocouples affected show erratic temperature behavior. This phenomenon is referred to in this report as temperature "breakaway".

Figures 29 and 30 evidence that, except for locations on the direct path from the inlet plenum to the break, ECC injection had little influence on loop fluid temperature behavior.

\subsection{Material Temperatures}

Examples of core material temperature behavior are shown for Tests 848,849 , and 850 in Figures 31,32 , and 33. Figure 31 shows the cladding temperature for an outside pin at the midplane elevation (TM-13-0). The first indications of departure from nucleate boiling (DNB) occurred at about $2.5 \mathrm{sec}$ after rupture; the major DNB temperature increases at this location began about $5 \mathrm{sec}$ after rupture. Turnaround of the cladding temperatures for Tests 848 and 849 occurred shortly after power shutoff and 2 or 3 sec before the initiation of ECC injection. For the test without ECC (Test 850), cladding cooling subsequent to DNB was very slow; by $80 \mathrm{sec}$, the cladding temperature had only decreased to a value near the initial temperature at that location. However, post-DNB cooling during the ECC injection tests was quite rapid.

Examination of cladding temperature behavior at other locations indicates that the difference in cooling behavior following temperature turnaround is not necessarily due to ECC injection. Figure 32 shows a comparison of temperature behavior for the top elevation of the center pin (TM-61-T). PostDNB cooling is similar for all three tests. Test 850 without ECC exhibits behavior quite similar to that of Test 848 which included ECC injection.

Figure 33 compares cladding temperatures during the three tests for the top location (TM-110-T) of an outside pin located nearly 180 degrees from the outside pin discussed previously (Figure 31). DNB did not occur at this location, indicating a local high degree of cooling for all three tests until temperature breakaway due to dryout conditions occurred at 25 to 28 sec. Included in Figure 33 is a typical plot of material temperature behavior of the core flow skirt. Flow skirt and pin cladding temperatures at the location shown were quite similar for all three tests.

On the basis of the cladding temperature behavior in the entire core, the results indicate no significant differences between tests with and without ECC. Even localized differences between tests cannot be definitely attributed to ECC injection. Rather, the material temperature behavior appears to be more a function of steam fiow paths down through the core. Additional pin cladding temperature data for Tests 848,849 , and 850 are presented in digitized form in Appendix $\mathrm{C}$ for a variety of core locations and elevations. 


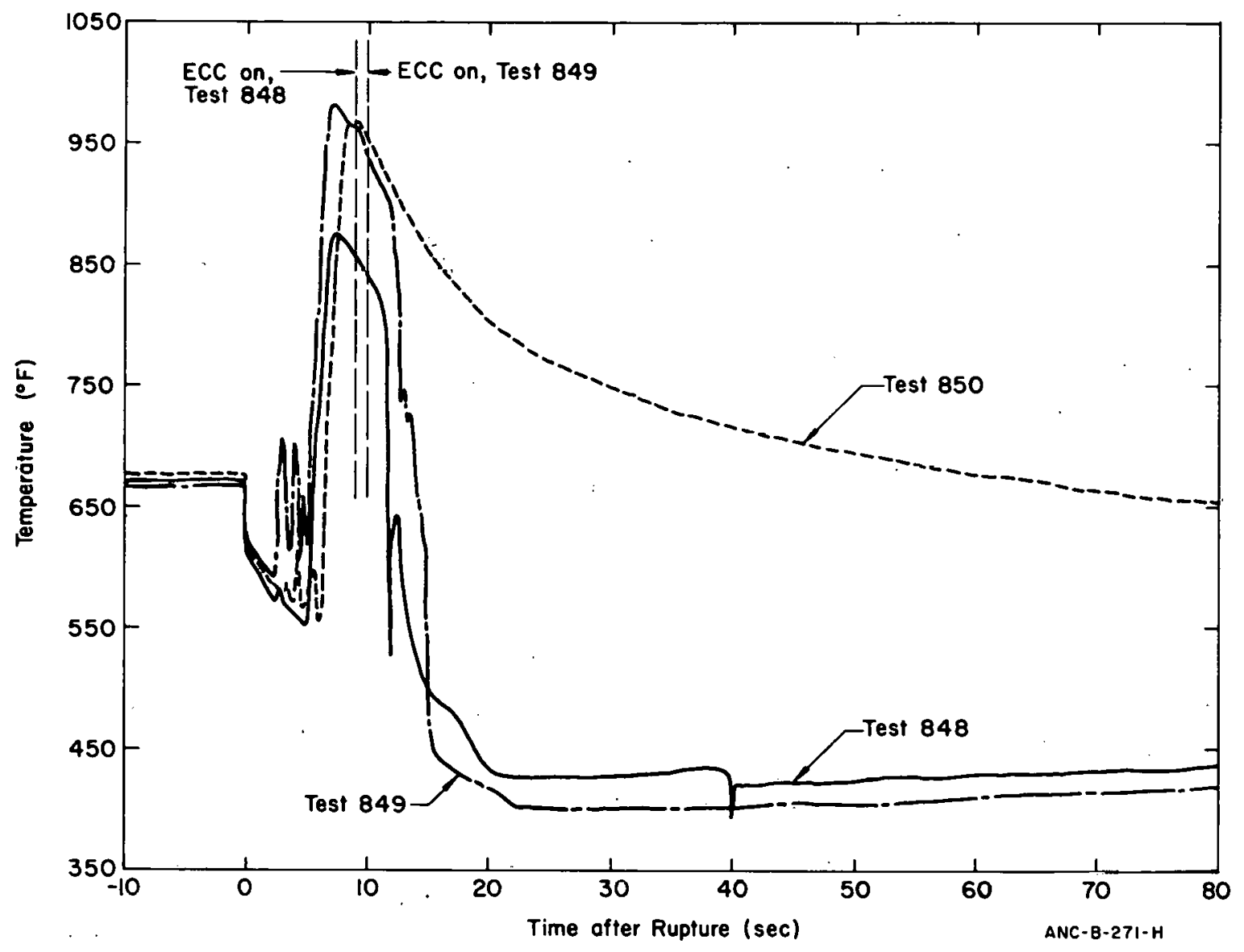

Fig. 31 Cladding temperatures at the midplane of an outside pin (TM-13-0). 


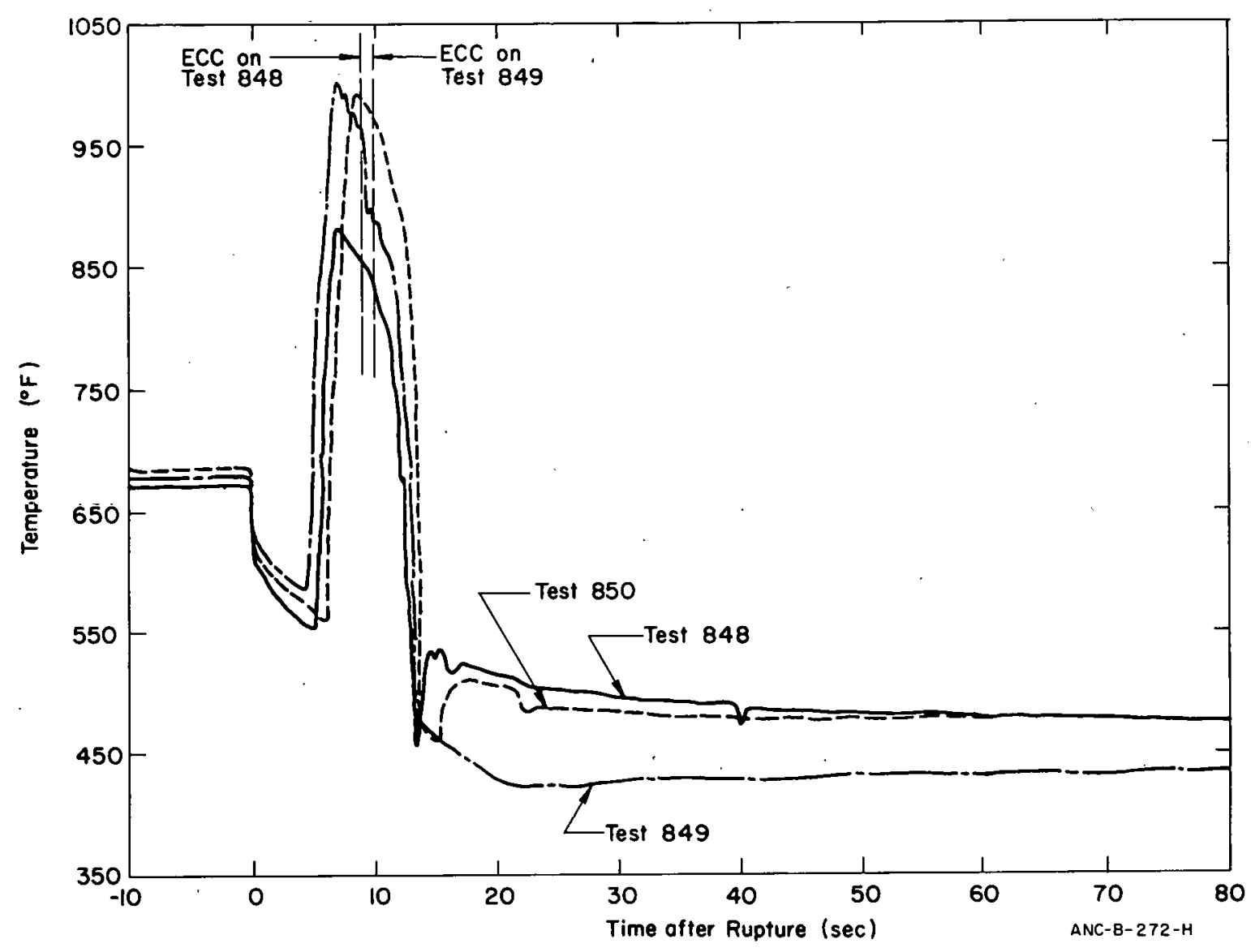

Fig. 32 Cladding temperatures at the top of a center pin (TM-61-T).

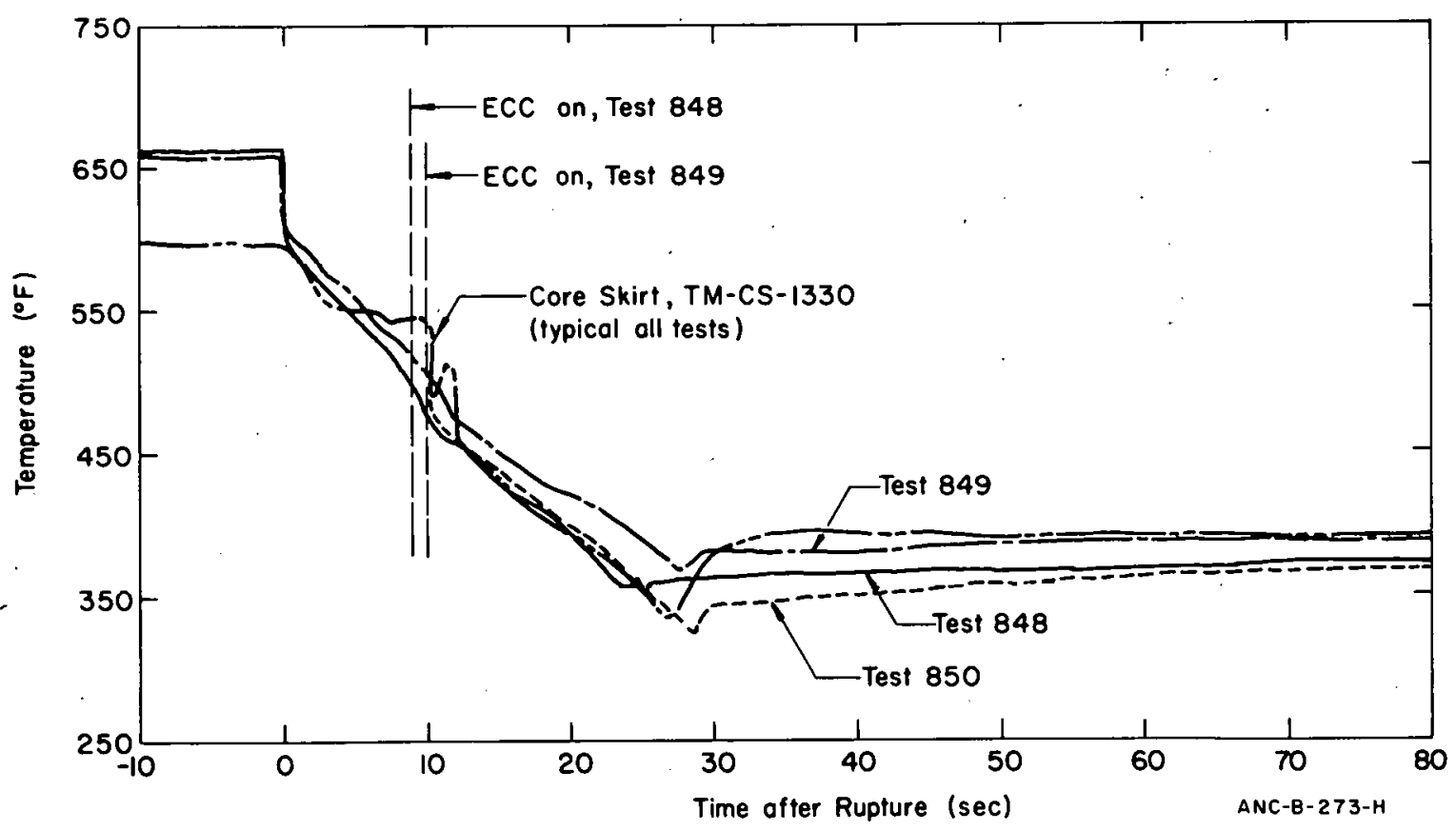

Fig. 33 Cladding temperatures at the top of an outside pin (TM-110-T). 


\section{DENSITY}

Fluid density data for semiscale tests are obtained by a gamma attenuation technique which provides a measurement of the average density across the cross-sectional area being monitored. The normalization and conversion methods used in connection with the measurement technique are discussed in Appendix B. The estimated accuracy of the results is within about $\pm 2 \mathrm{lb} / \mathrm{ft}^{3}$.

A comparison of typical loop density data for tests with and without ECC is given in Figures 34 and 35 for locations at the steam generator outlet and the pump discharge, respectively. In both cases the density data closely agree, indicating that ECC injection had little effect on loop fluid behavior. The cold leg density, in both cases, was unaffected by the rupture for 4 to 5 sec, but subsequently fell rapidly to value less than $10 \mathrm{lb} / \mathrm{ft}^{3}$. Following the first rapid decline in density, several sporadic density increases occurred for both locations with those at the steam generator outlet being much larger. The increases at the steam generator outlet occur about 1 to 2 sec prior to those at the pump discharge. These density increases occurred elsewhere in the loop and are attributed to high density fluid discharge from the pressurizer and recirculation loop into the hot leg.

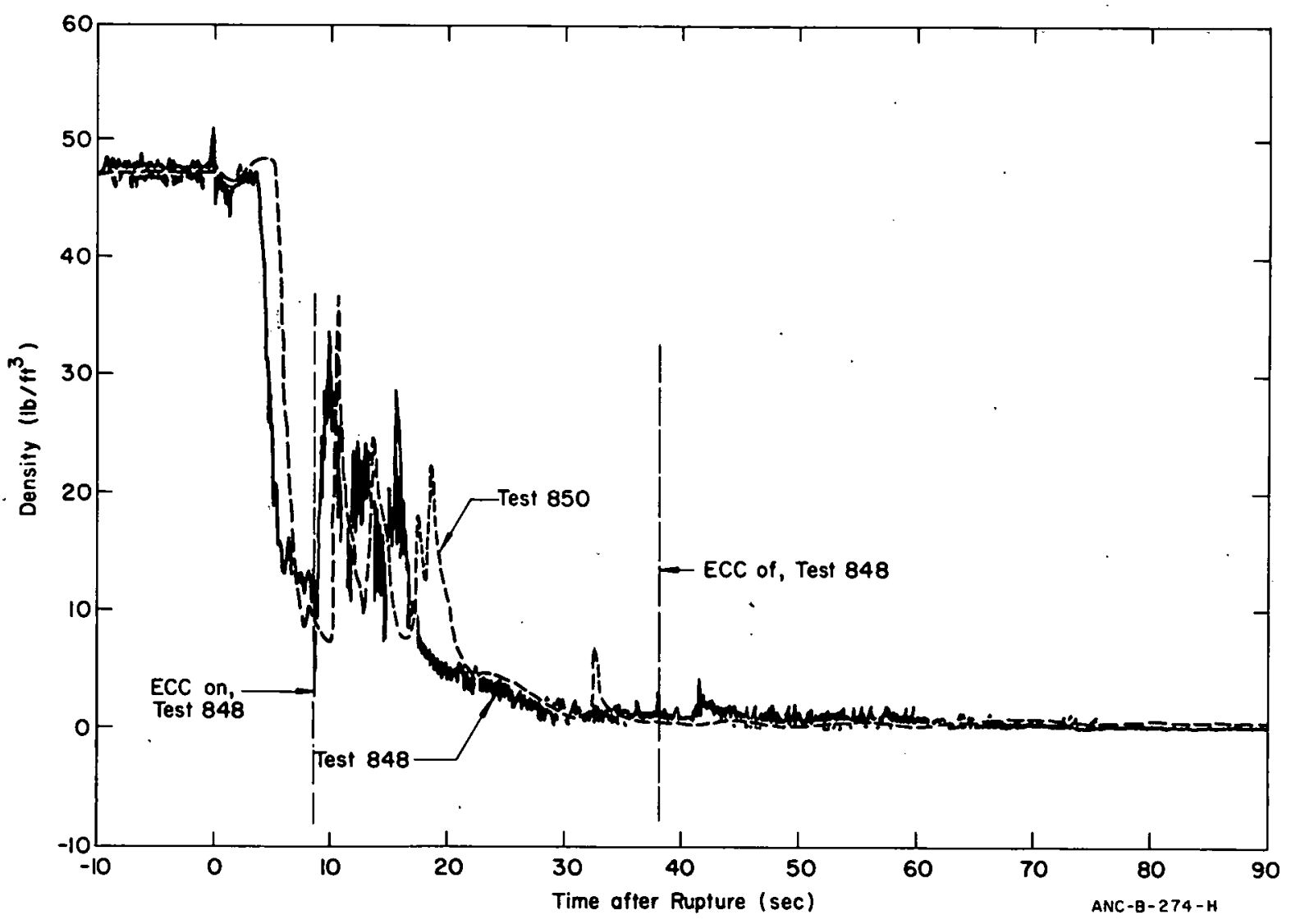

Fig. 34 Density at the steam generator outlet for Tests 848 and 850 . 


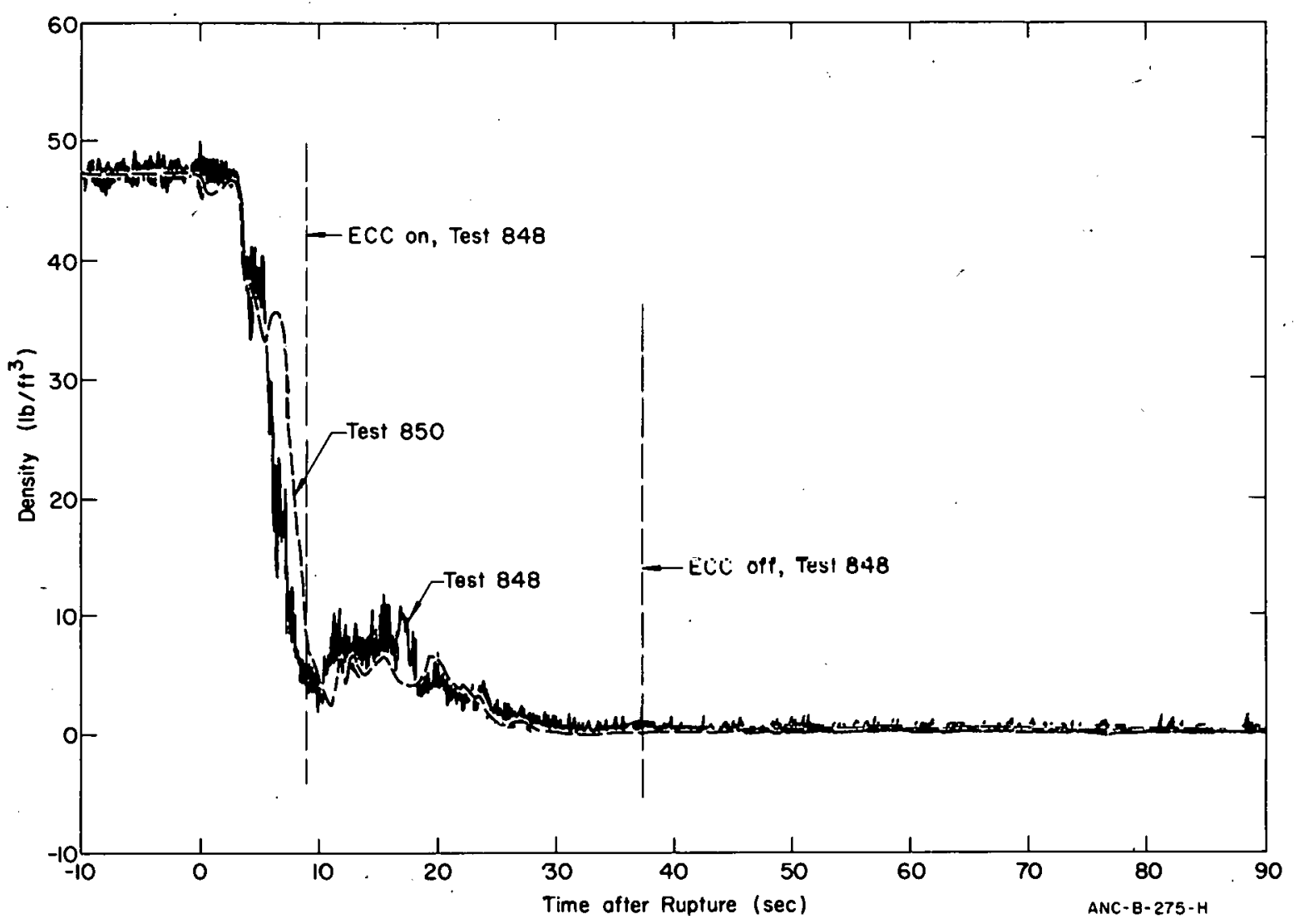

Fig. 35 Density at the pump outlet for Tests 848 and 850 .

Figure 36 is a comparison of outlet plenum densities during Tests 848, 849 , and 850 ; little difference in behavior is indicated among the tests. No effect due to ECC injection is apparent from this comparison.

Figure 37 compares the density behavior in the inlet plenum for the test without ECC (Test 850) and a test with ECC (Test 848). These density data were recorded at the elevation of the inlet nozzle center line (slightly above the midelevation of the plenum). The disadvantage of this location is that during ECC tests, any ECC accumulated in the vessel lower plenum below the elevation of the inlet nozzle cannot be monitored. Fluid conditions, according to monitored density in the inlet plenum, are identical for the first 20 to $21 \mathrm{sec}$ of the transient at which time the density for Test 848 began to increase. The increase was slight for the first 1 to 2 sec and then a step increase to approximately $55 \mathrm{lb} / \mathrm{ft}^{3}$ occurred. This behavior indicates that liquid accumulated in the inlet plenum for Test 848 (typical) at some time after initiation of ECC injection and continued until the level reached the inlet nozzle center line. Once the height of the nozzle center line was reached, erratic oscillations were recorded indicating the level was varying rapidly. At about $47 \mathrm{sec}$, the density suddenly decreased to essentially zero, indicating the fluid level had dropped below the center line of the nozzle. A detalled discussion of this phenomenon is presented in Section V-3. Selected density data for Tests 848,849 , and 850 are included in Appendix C. 

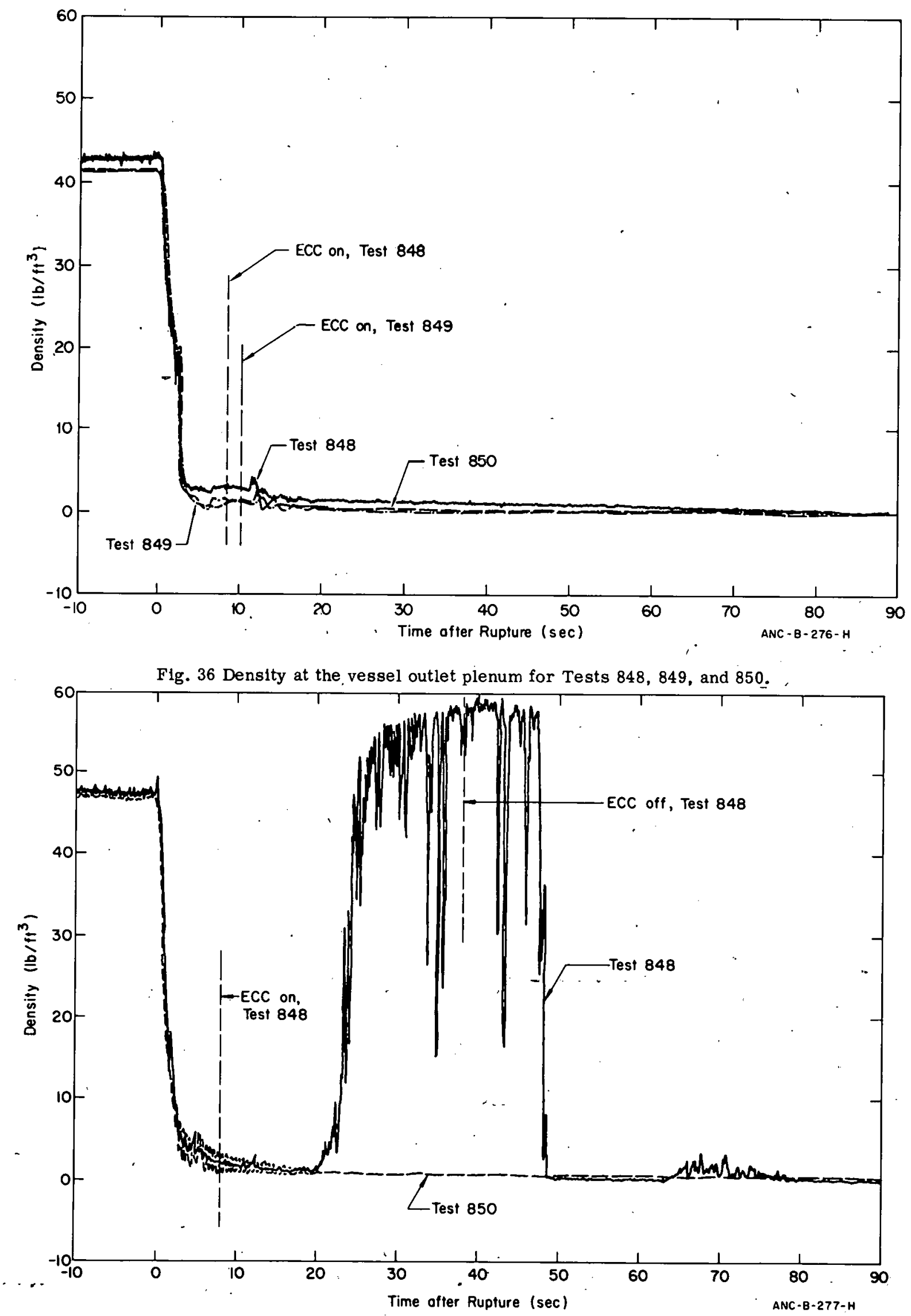

Fig. 37 Density at the vessel inlet plenum for Tests 848 and 850 . 


\section{WATER REMAINING IN SYSTEM}

The amount of water remaining in the system was determined after each test. About six minutes after system rupture (decompression is essentially complete in one minute), drains were opened at low points in the loop (steam generator inlet, pump Inlet, and piping) and vessel (bottom head) to collect residual water. Table II presents the results of this measurement.

TABLE II

WATER REMAINING FOLLOWING DECOMPRESSION

\begin{tabular}{|c|c|c|c|}
\hline Location & Test 848 & Test 849 & Test 850 \\
\hline Loop Low point & $\dot{U}$ & 0 & $0.751 \mathrm{u}$ \\
\hline Pump inlet & 0 & 0 & 0 \\
\hline Steam generator inlet & 0 & $3 \quad 1 b$ & $24.0 \quad 1 b$ \\
\hline Vessel & 0 & $10.5 \mathrm{Ib}$ & $3.0 \quad 1 \mathrm{~b}$ \\
\hline TOTAL & 0 & $13.5 \mathrm{lb}$ & $27.75 \mathrm{lb}$ \\
\hline
\end{tabular}

In terms of $\mathrm{ECC}$ behavior, the water remaining in the lower plenum of the vessel is of most interest. Less than two percent of the initial fluid inventory was collected from the vessel following these tests. As is discussed in Section V, vessel fluid mass balances indicate only about $15 \mathrm{lb}$ of water (about $3 \%$ of the initial fluid) remained in the vessel $60 \mathrm{sec}$ after rupture. Some or all of this remaining fluid boiled off during the subsequent 5 minutes. 


\section{DISCUSSION OF TEST RESULTS}

The previous section of this report has been concerned primarily with the presentation of data which were measured directly and which required a minimum of mathematical processing for presentation. These data have, in turn, been used to calculate additional variables such as fluid flow rates and fluid quality which aid in understanding fluidbehavior during decompression. These additional variables are discussed in succeeding paragraphs. A separate subsection is devoted to the subject of ECC behavior in the semiscale system. The discussions that follow emphasize the comparison between Tests 848 and 850 , a comparison of system behavior with and without ECC injection.

\section{FLUID FLOW RATES}

Calculation of the fluid flow rates during the blowdown transient is accomplished by combining two measured quantities: momentum flux $\left(\rho v^{2}\right)$ and fluld density $(\rho)$. The density measurements were presented and discussed previously (Section IV -3). The momentum flux measurements were made with devices employing a drag disc placed in the flowing fluid. The force exerted on the disc is proportional to the momentum flux, and essentially supplies the velocity component required for calculation of fluid flow rate from the equation:

$$
\dot{\mathrm{m}}=\left[\rho\left(\rho v^{2}\right) A^{2}\right]^{1 / 2}=\rho v A \text {. }
$$

where:

$$
\begin{aligned}
\dot{\mathrm{m}} & =\text { fluid flow rate }(\mathrm{lb} / \mathrm{sec}) \\
\rho & =\text { measured density }\left(\mathrm{lb} / \mathrm{ft}^{3}\right) \\
\rho \mathrm{v}^{2} & =\text { measured momentum flux }\left(\mathrm{lb} / \mathrm{ft}-\mathrm{sec}^{2}\right) \\
\mathrm{A} & =\text { cross-sectional flow area }\left(\mathrm{ft}^{2}\right) .
\end{aligned}
$$

An example of the output signal (volts) from one of the drag disc flowmeters is presented in Appendix $C$. The meter output is converted to momentum flux through a callbration curve for the instrument.

The accuracy of the fluid flow rate calculations is dependent on the accuracy of the momentum flux and density measurements. As mentioned in the discussion of density measurements, estimated accuracy is within $\pm 2 \mathrm{lb} / \mathrm{ft}^{3}$. Flow rate calculations based on very low densities thus must be used with caution. In addition, the drag disc flowmeters are temperature sensitive and are subject to considerable thermal drift during the approximately $400^{\circ} \mathrm{F}$ fluid temperature drop encountered during the blowdown transient. The thermal drift is particularly pronounced, but fortunately somewhat predictable, for tests Involving small breaks and long blowdown times. As outlined in Appendix B,

.. compensation for thermal drift consists of applying a linear correction with time to the measured momentum flux data. 
The highest flow rates recorded for the most recent test geometry utilizing the high inlet $10 \%$ break are on the order of 130 to $150 \mathrm{lb} / \mathrm{sec}$ and occur at the break location. The se high flows are relatively short in duration, however, and diminish to less than $50 \%$ of maximum within $2 \mathrm{sec}$ and to about $10 \%$ within 10 sec. Figure 38 is a comparison of the total system discharge flow rates for Tests 848 and 850 . Of particular note is the close similarity of the discharge flow rate for the two tests for the total time that the test without ECC (Test 850) was discharging (approximately $30 \mathrm{sec}$ ). This similarity indicates that the total system discharge flow rate was insensitive to ECC injection in that initiation and continuance of ECC injection did not cause any significant differences in the flow rates measured. The flow rate for Test 848 continued for another 25 or $30 \mathrm{sec}$, at a rate of about $5 \mathrm{lb} / \mathrm{sec}$, which represents the expulsion of accumulated ECC water from the inlet plenum. The mechanism and significance of this expulsion of accumulated ECC late in blowdown is discussed in greater detail in Section V -3 .

As an example of typical loop flows, Figure 39 shows a comparison of the hot leg flow rates (Station 21) during Tests 848 and 850 . Again, the data for tests with and without ECC are similar. Station 21 is fairly close to the vessel (Figure 1) and, during decompression, the major direction of flow is from Station 21 to the vessel, out the vessel inlet nozzle, and to the break. Any influence on loop flow as a result of ECC injection (such as back flow caused by pressure suppression effects) would be expected to be evidenced by the measurements at Station 21. The only noticeable difference between the two curves of Figure 39, however, is an unexplained one-second time shift. The maximum values, the indicated flow direction, and the area under the two curves are all nearly identical. In terms of flow magnitude and direction, Figure 39 illustrates the general flow behavior for hot leg flow during decompression resulting from a $10 \%$ inlet break. At rupture, a short-duration $(0.5 \mathrm{sec})$ flow occurs in the reverse direction (flow towards vessel), followed by normal flow at about half the initial magnitude for about $5 \mathrm{sec}$, after which time the fiow reverses towards the vessel. The reverse flow continues at a very low flow rate until decompression is complete, with the exception of a few high valued flow spikes due to high density fluid from the pressurizer, as discussed in Section IV-3.

For the subject tests of this report, detectors to measure density, momentum flux, pressure, and fluid temperature were located such that mass balances could be performed for the total system or across desired components. Approprlate detectors were located at the pump discharge (cold leg), vessel inlet, vessel outlet (hot leg) and the blowdown nozzle (total system discharge). From these measurements, mass balances for the loop, for the vessel, and for the system as a whole were made. Figure 40 is a graphic presentation of a mass balance calculation. This figure represents the vessel mass balance for Test 848 which included consideration of vessel stored fluid mass (determined from vessel fluid densities), fluid mass input (hot leg and ECC injection) and fluid mass output (vessel inlet nozzle flow). The data presented indicate that just prior to initiation of ECC injection from the accumulator at $9 \mathrm{sec}$, the vessel was $90 \%$ voided ( $25 \mathrm{lb}$ remained). With an ECC injection rate of about $5 \mathrm{lb} / \mathrm{sec}$, the fluid inventory in the vessel was maintained at $25 \mathrm{lb}$ for about $10 \mathrm{sec}$ before a slight increase in mass inventory began. The maximum inventory prior to depletion of the ECC accumulators was about $75 \mathrm{lb}$ (to the level of the inlet nozzle 


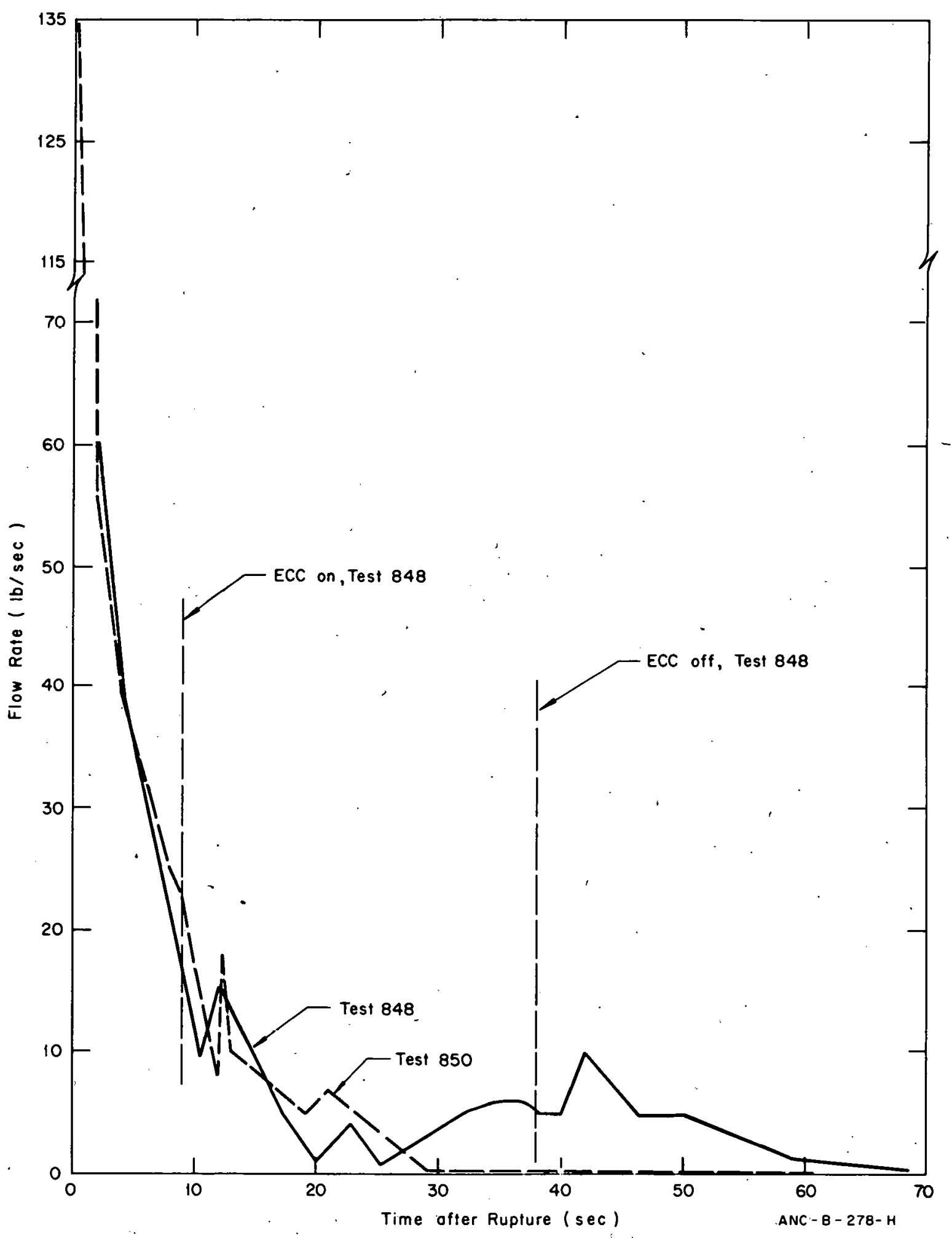

Fig. 38 System discharge rate -- Tests 848 and 850 


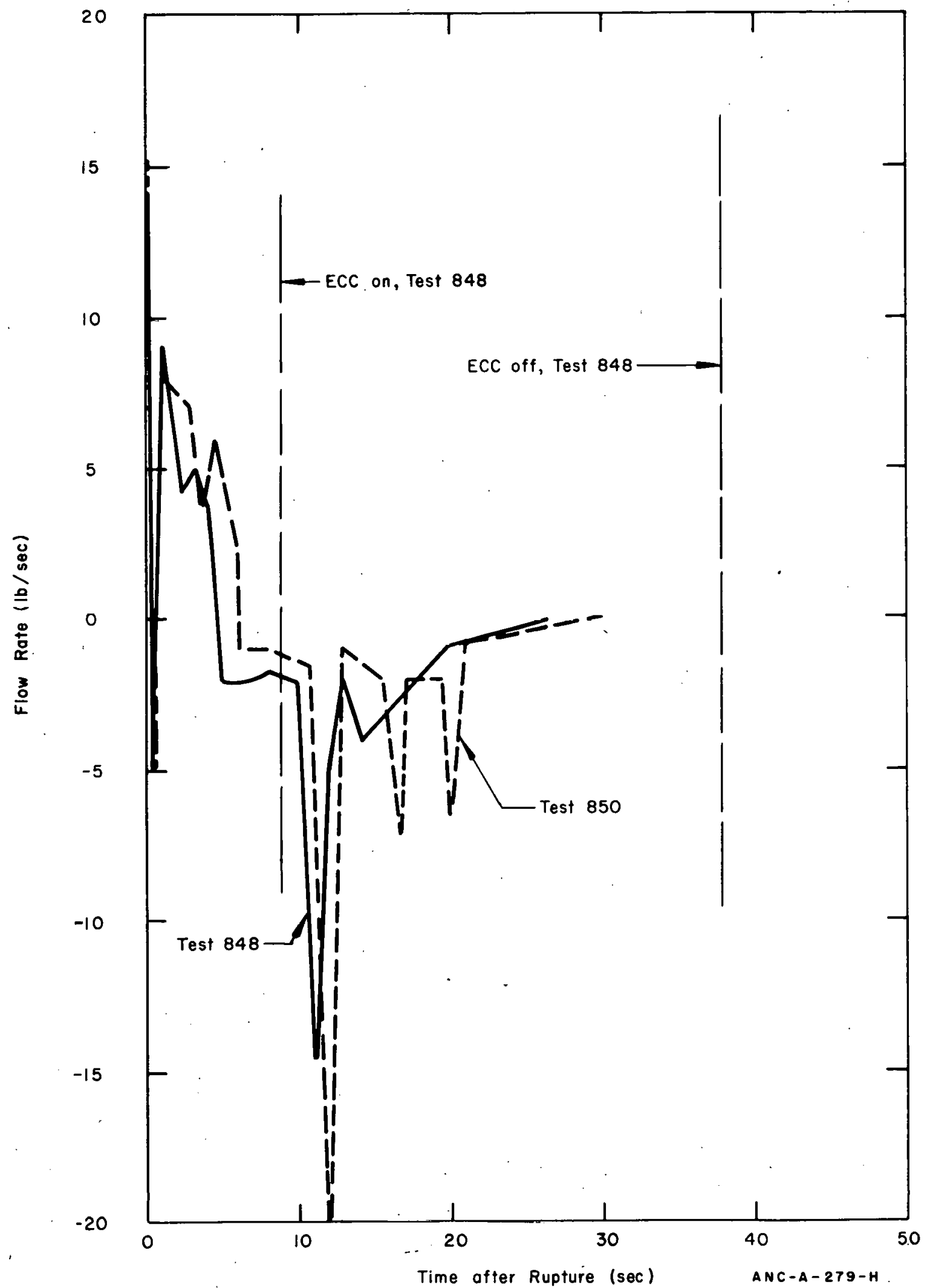

Fig. 39 Hot leg flow rate -- Tests 848 and 850. 


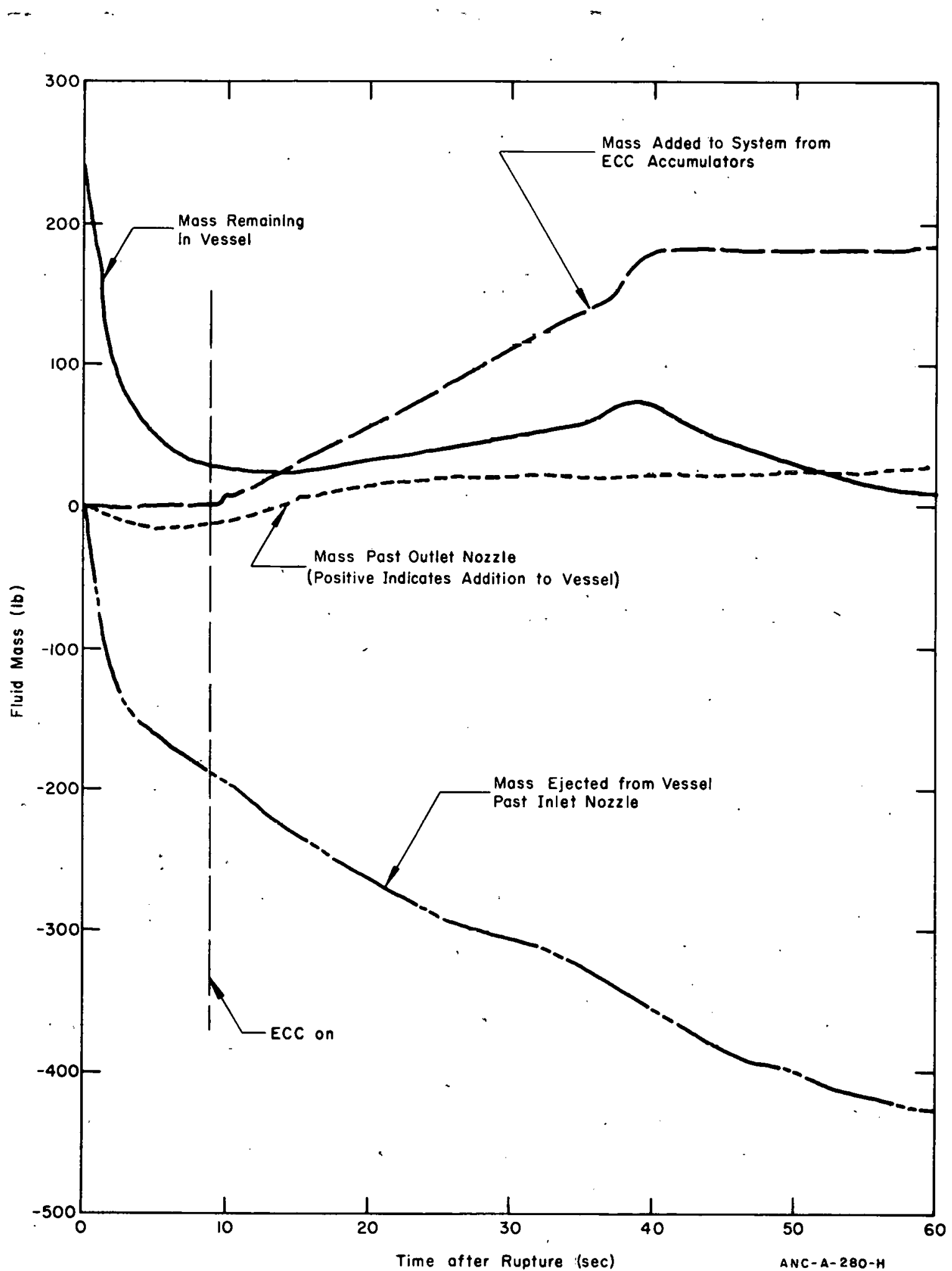

Fig. 40 Vessel fluld mass balance -- Test 848 . . 
center line). Following termination of ECC injection, all accumulated water in the inlet plenum was ejected as a result of pressure pulses occurring in the vessel, as discussed in Section V-3.

System mass balance calculations performed for semiscale Tests 848 and 850 indicate a measurement accuracy of about $95 \%$ in accounting for the fluid mass inventory. Figure 41 shows the results of integration of selected flow rate curves and illustrates the relative contribution of each part of the system to the total system discharge. The net integrated fluid mass into the vessel from the hot leg appears insignificant in relation to other mass inventories. However, as is further discussed in Section V-3, the relatively small hot leg flow seems to play an important role in terms of ECC behavior late in the transient.

The integrated flow rates in Figure 41 for the cold leg and vessel inlet nozzle do not reflect the inital fluid in the piping between the respective,measurement stations and the break. When these fluid masses are included, the results show that for Test 850 , about $50 \%$ of the fluid was discharged from the vessel side of the break and $45 \%$ from the cold leg (nearly 5\% remained in the system after decompression as indicated in Section IV-4).

For Test 848, all ECC infected was discharged from the vessel side of the break; the total ECC fluid mass may be subtracted from the total system discharge and from the inlet nozzle flow to obtain the flow contribution of the initial fluid inventory. The results indicate that about $50 \%$ of the initial fluid mass was discharged from either side of the break.

The relative contributions to discharge of the initial fluid are very similar for Tests 848 and 850 , indicating that ECC injection has no significant effects. Figure 41 also indicates that most of the initial fluid inventory had been discharged prior to ECC injection in Test 848. 


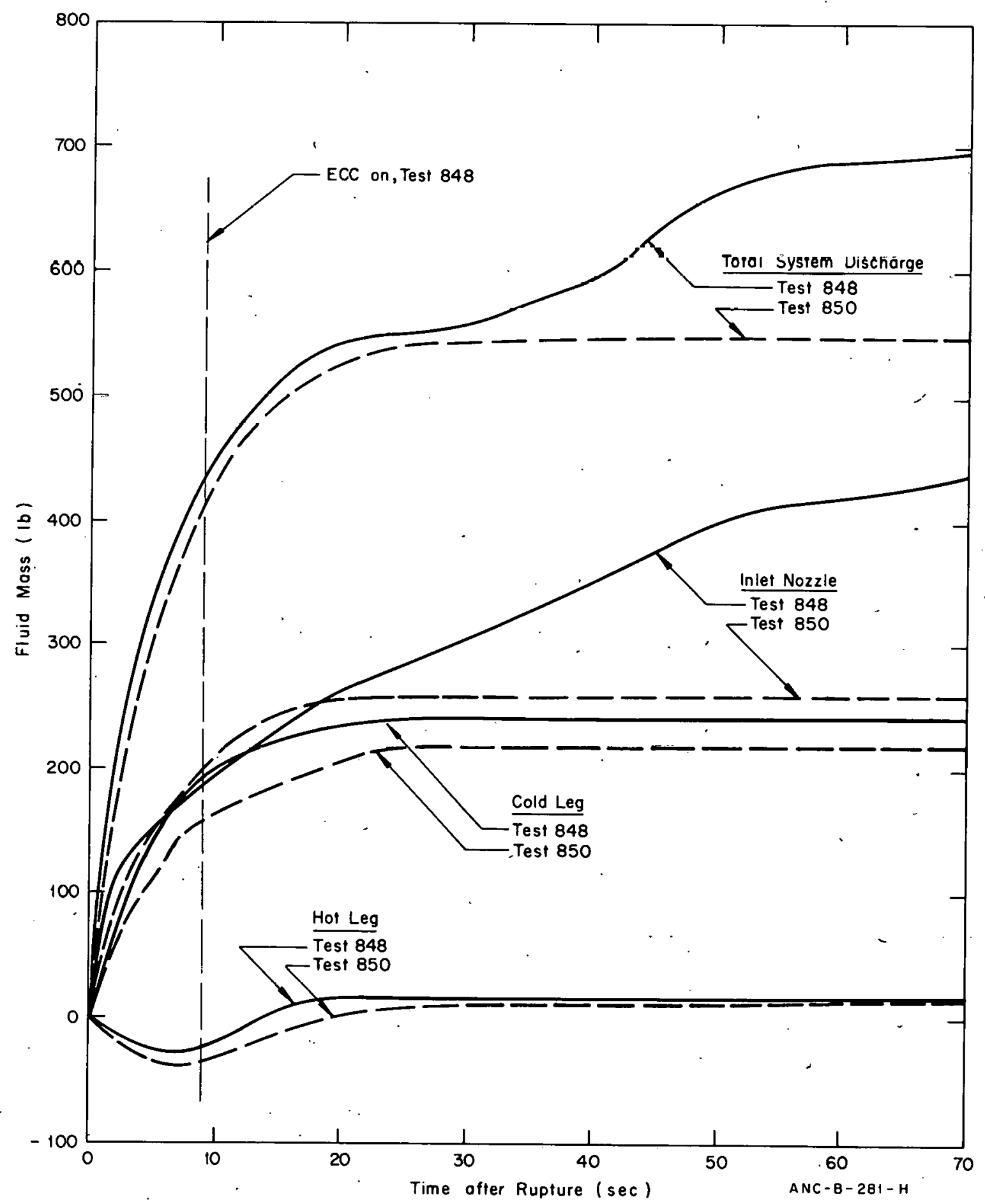

Fig. 41 Integrated fluid mass - Tests 848 and 850 . 


\section{FLUID QUALITY}

The density data have been used in conjunction with the pressure and temperature data to determine the fluid quality in the vessel and at various locations in the loop piping. As mentioned in Section IV-3, the densities were measured with a gamma attenuation technique and are representative of the average fluid density at each specific location. The accuracy of the density measurements at low densities is questionable and, therefore, the quality data derived for low densities must be used with caution. For this report, quality curves have been generated by a computer code that uses as input the fluid density and temperature at each location, together with tabulated values of saturated steam properties, to calculate several thermodynamic water properties, among them quality. The method gives a point by point calculation of quality every 50 msec; however, the calculation becomes erratic both when fluid temperature measurements experience the "breakaway" from saturation due to heat radiation from nearby materials and when very low densities occur.

Figure 42 (hot leg for Tests 849 and 850) and Figure 43 (cold leg for Tests 848 and 850 ) give representative comparisons of loop quality calculations for tests with and without ECC. That loop fluid behavior was insensitive to the presence of ECC injection is supported by the loop fluid quality calculations; the differences in the data presented in Figures 42 and 43 are minor. Hot leg fluid, for the first 10 to $15 \mathrm{sec}$ of the transient, was at a relatively low quality with peak values of about 35\%. Cold leg fluid near the pump discharge experienced a momentary peak at a fairly high quality (about 65 to $90 \%$ ) about $10 \mathrm{sec}$ after rupture. High density slugs of fluid from the pressurizer discharge (Section IV -3) caused this momentary peak in quality to fall to values of 10 to $20 \%$ for a few seconds before high quality fluid was reestablished. Figure 44 gives a comparison of the quality of the discharge flow from the blowdown nozzle for the first $10 \mathrm{sec}$ of the transient for tests with and without ECC. The calculation for the tests with ECC after about $10 \mathrm{sec}$ is an example of the results of a calculation using low densities.

Representative fluid qualities for the vessel locations (inlet and outlet plenum, and core region) are given in Figure 45 for cases with and without ECC. The data indicate a very rapid rise in quality to values close to $100 \%$ within $3 \mathrm{sec}$ after rupture. The results for all three locations within the vessel are almost identical for the first five seconds of decompression. This behavior indicates good coupling between the inlet and outlet plenums of the vessel during the early portion of decompression. 

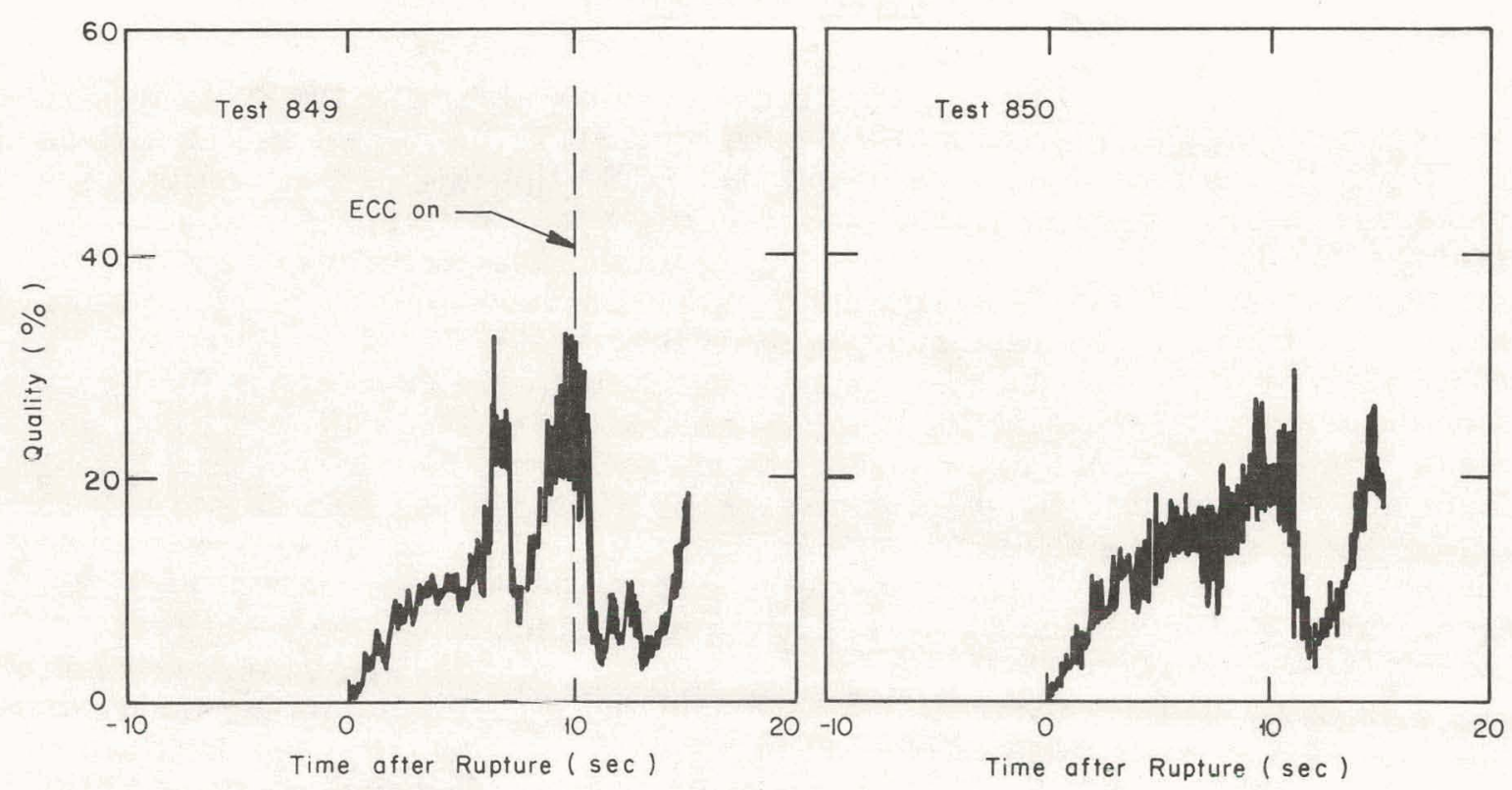

Fig. 42 Fluid quality at the hot leg -- Tests 849 and 850.

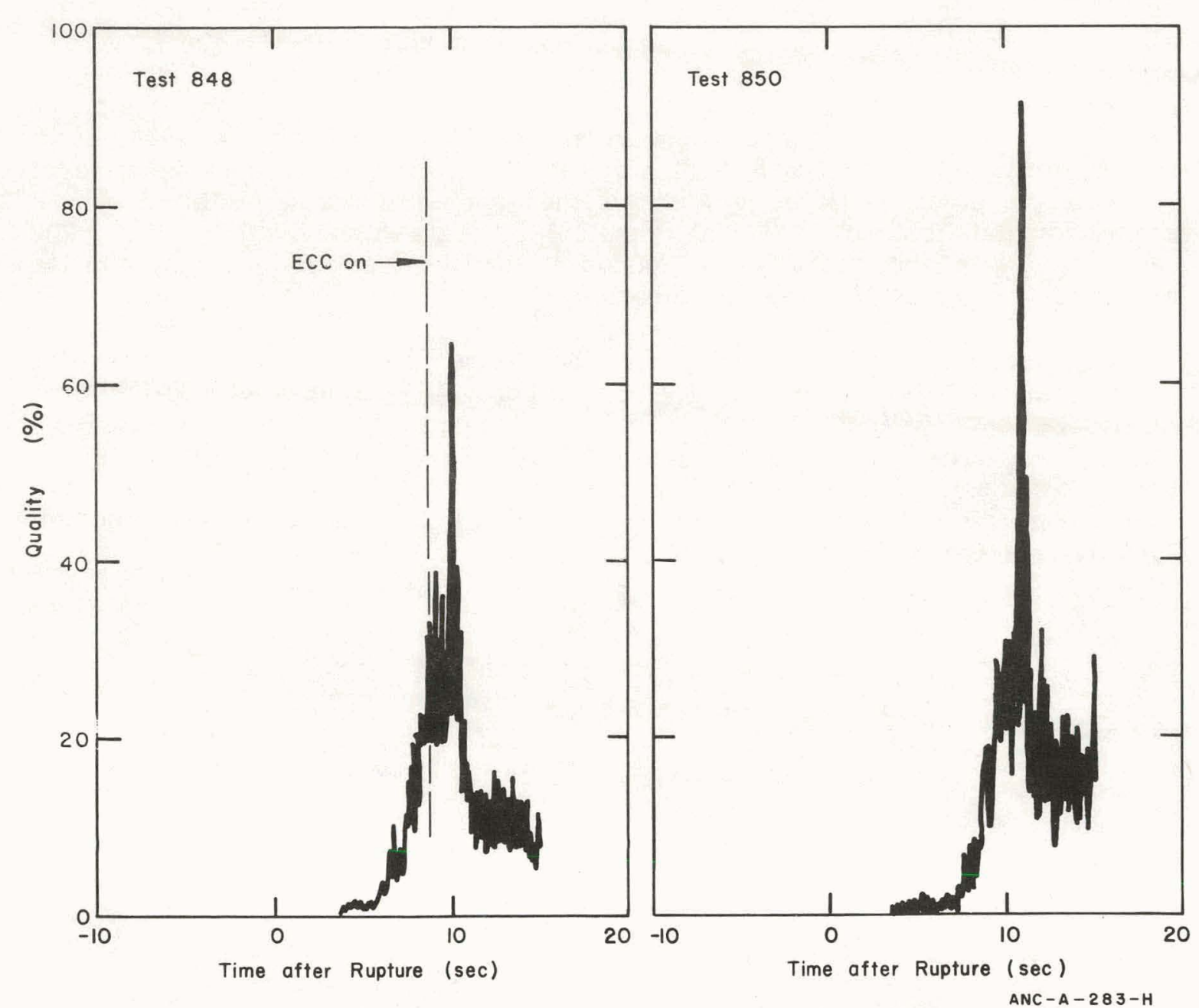

Fig. 43 Fluid quality at the cold leg -- Tests 848 and 850 . 


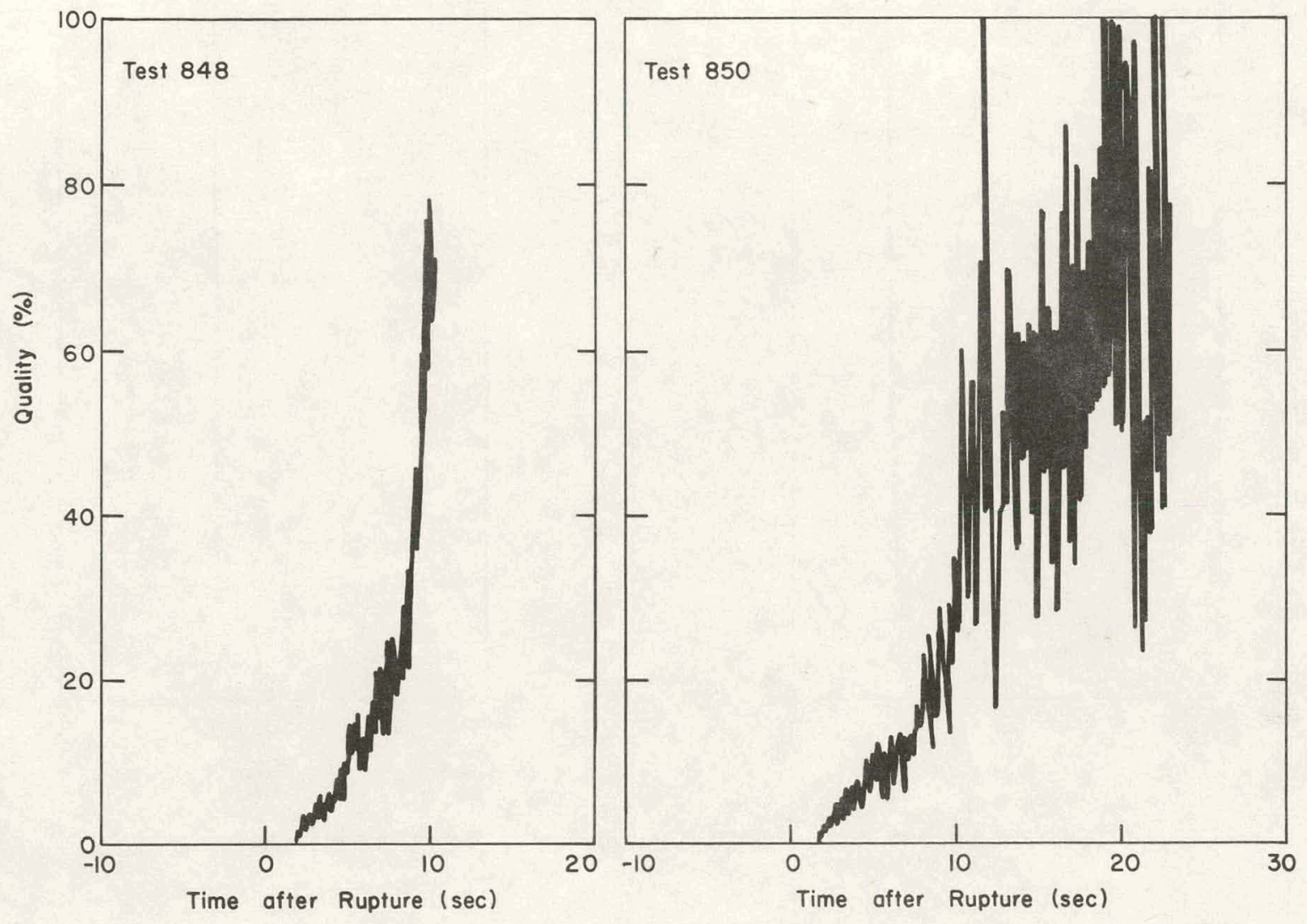

Fig. 44 Fluid quality in the blowdown nozzle -- Tests 848 and 850 . 

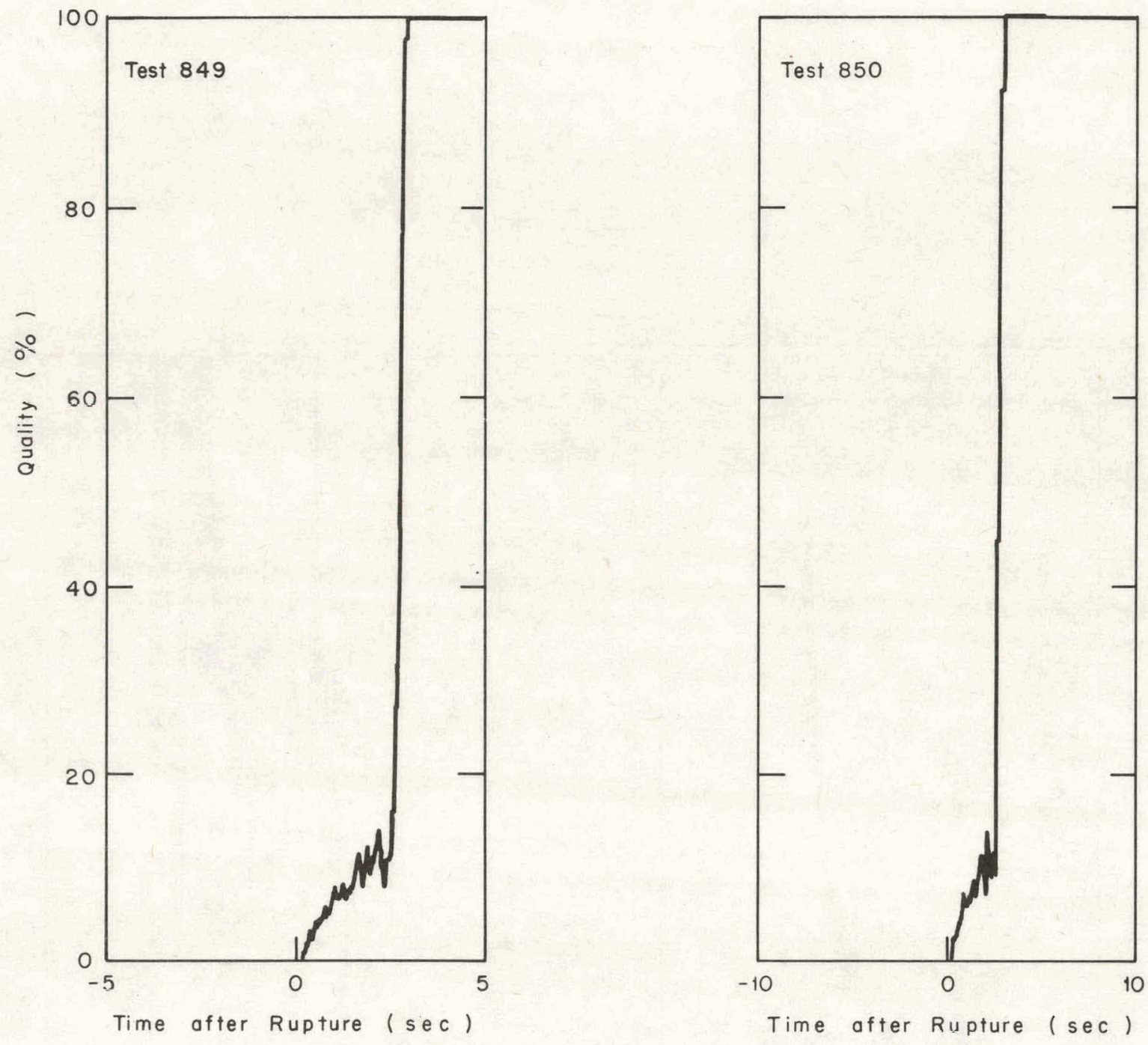

Fig. 45 Fluid quality in the vessel outlet plenum -- Tests 849 and 850 .

\section{EMERGENCY CORE COOLING}

Throughout this report, the influence, or the lack of influence, on semiscale system decompression behavior of ECC injection from an accumulator has been noted. As stated previously, a primary purpose of these three tests was to try to more clearly define the phenomena occurring in the semiscale system which resulted in rapid expulsion of all accumulated water from the inlet plenum of the vessel once ECC injection was terminated. This section of the report, by drawing on all previously presented data, discusses the events occuring in the inlet plenum and elsewhere following initiation of ECC, and puts forth a possible mechanism for the expulsion of accumulated ECC late in the transient. The discussion is based on a comparison of Test 848 with ECC (with supporting information from Test 849) and Test 850 without ECC. 


\subsection{ECC Behavior}

For Test 848, ECC was initiated 9 sec after system rupture. About 159 $1 \mathrm{~b}$ of ECC was injected directly into the inlet plenum at a fairly constant rate of $5.5 \mathrm{lb} / \mathrm{sec}$ from an accumulator pressurized at 610 psig with nitrogen gas. Mass balance calculations indicated a vessel fluid mass inventory just prior to ECC injection of about $25 \mathrm{lb}$. Density measurements in the vessel indicated about $10 \mathrm{lb}$ of steam at this time; the remaining $15 \mathrm{lb}$ is assumed to be a low quality fluid mixture in the inlet plenum.

The path followed by the ECC fluid during the initial portion of the 29-sec injection period is illustrated by the inlet plenum and nozzle densities shown in Figure 46. Vessel densities had decreased to about $2 \mathrm{lb} / \mathrm{ft}^{3}$ by the time ECC injection was initiated. Immediately following the start of ECC injection, the density at the inlet nozzle (Station 14) began a gradual increase, whereas the density at the inlet plenum leveled off at about $1 \mathrm{lb} / \mathrm{ft}^{3}$ and remained at this value for about 10 sec before increasing rather sharply. Since the density measurement in the inlet plenum was made at the level of the center line of the inlet nozzle, a water volume of $1 \mathrm{ft}^{3}$ could have existed in the lower inlet plenum without being monitored. Thus, mass balance calculations and measurements other than density must be relied upon for analysis of ECC fluid behavior in the lower inlet plenum.

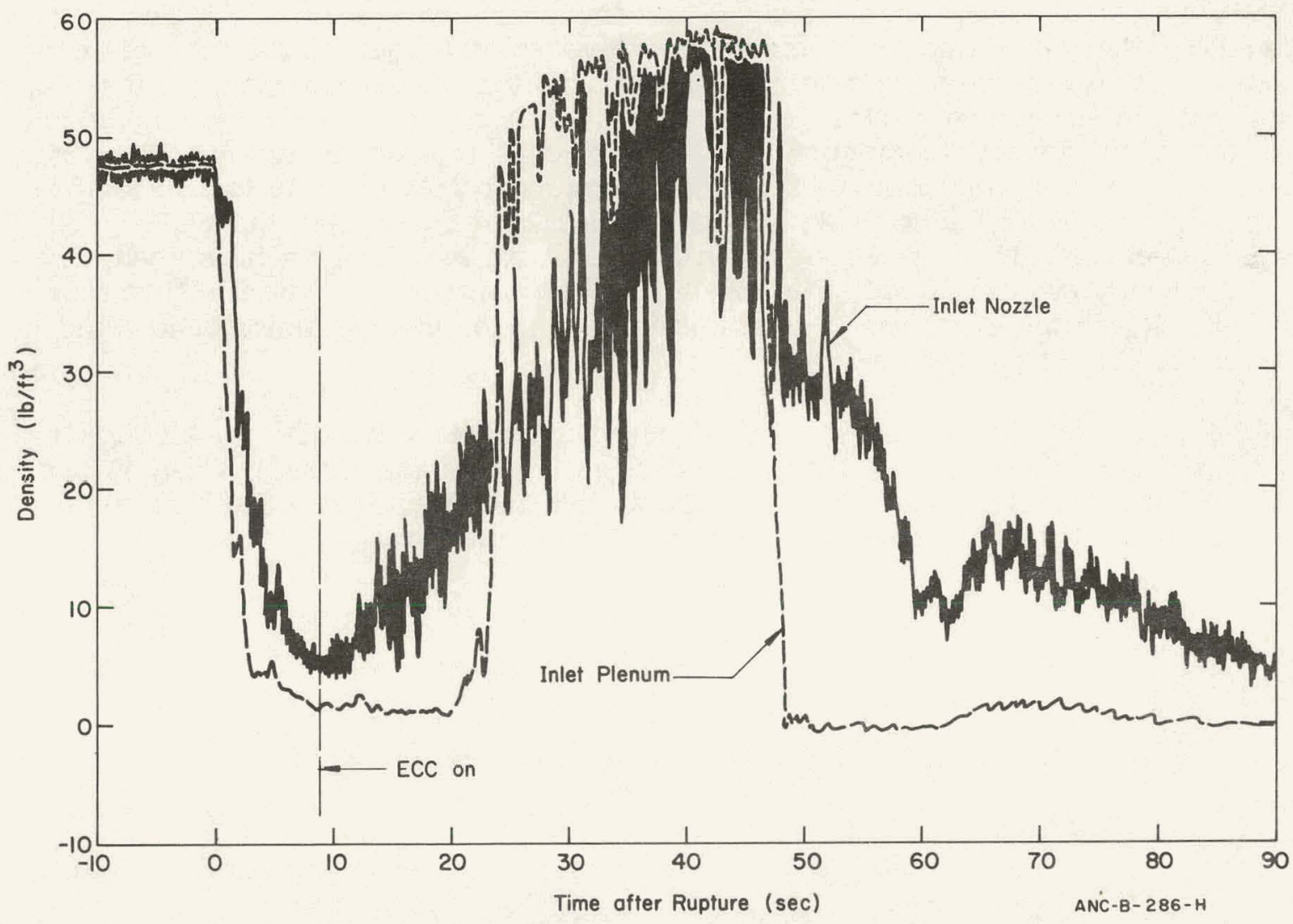

Fig. 46 Density at the vessel inlet plenum and inlet nozzle -- Test 848 . 
As mentioned previously, mass balance calculations indicated a vessel mass inventory of about $25 \mathrm{lb}$ (15 lb in the lower plenum) just prior to ECC initiation. This inventory was maintained for about $10 \mathrm{sec}$, during which time about $55 \mathrm{lb}$ (nearly a third of the total ECC fluid mass, Figure 40) of ECC was injected. During this same period of time, fluid temperatures measured at locations on the vertical rack in the inlet plenum were beginning to decrease (in succession from bottom to top) below saturation conditions (Figure 26). The conclusion is that, during the early stages $(8$ to $10 \mathrm{sec}$ ) of ECC injection, some ECC fell to the bottom of the inlet plenum and mixed with the fluid already there, whereas the remainder of the ECC was entrained in the steam back flow down through the core and was carried out the break. As steam velocities down through the core decreased, more injected ECC fell to the bottom of the inlet plenum rather than being entrained with steam and carried away.

Water gradually accumulated in the lower plenum until the fluid level reached in the inlet flow skirt, interrupting a direct flow path to the break, which in turn allowed more rapid liquid accumulation in the lower plenum (noted by the steep increase in density on Figure 46). Even though the core steam flow was sufficiently low to allow accumulation of liquid in the inlet plenum, the system pressure at this time (22 to $24 \mathrm{sec}$ ) was still about $100 \mathrm{psig}$. When the fluid level cut off the direct flow path to the break, the vessel pressure increased due to steam back flow from the hot leg and steam generation within the vessel itself. As the pressure increased sufficiently to push the liquid below the flow skirt, the steam escaped and the pressure was relieved. The water head in the inlet line then forced the level to rise again in the inlet plenum, setting up an oscillatory, or "chugging", motion. This chugging occurred at the rate of about two cycles per second and is clearly visible in a comparison of the inlet nozzle momentum flux (drag disc) measurements for Tests 848 and 850, shown on Figure 47. The chugging began about 10 to $12 \mathrm{sec}$ after initiation of ECC injection and continued for 6 to $8 \mathrm{sec}$ after the ECC system was valved off $(38 \mathrm{sec})$. From about 32 to $34 \mathrm{sec}$, the chugging increased, both in frequency and amplitude. The mass balances indicate that the fluidinventory in the lower plenum was a maximum just prior to ECC shutoff and rapidly decreased shortly thereafter.

Figure 48 is a plot of the density measurement at Station 35 showing the passage of slugs of fairly high density fluid beginning at about 41 sec. A comparison with the data for Test 850 indicates that these high density slugs are ECC fluid being expelled from the inlet plenum. 

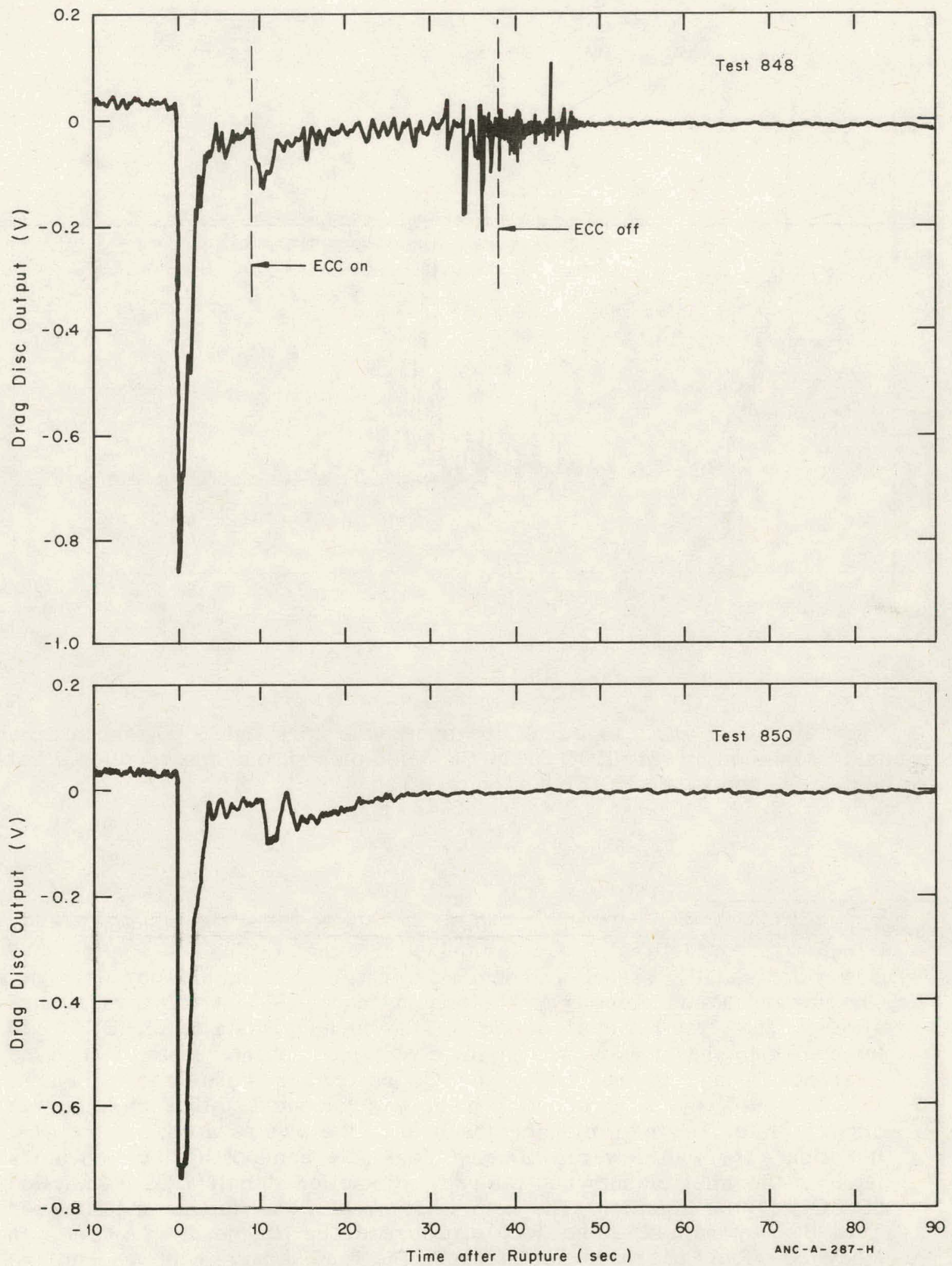

Fig. 47 Drag disc output at the inlet nozzle -- Tests 848 and 850. 


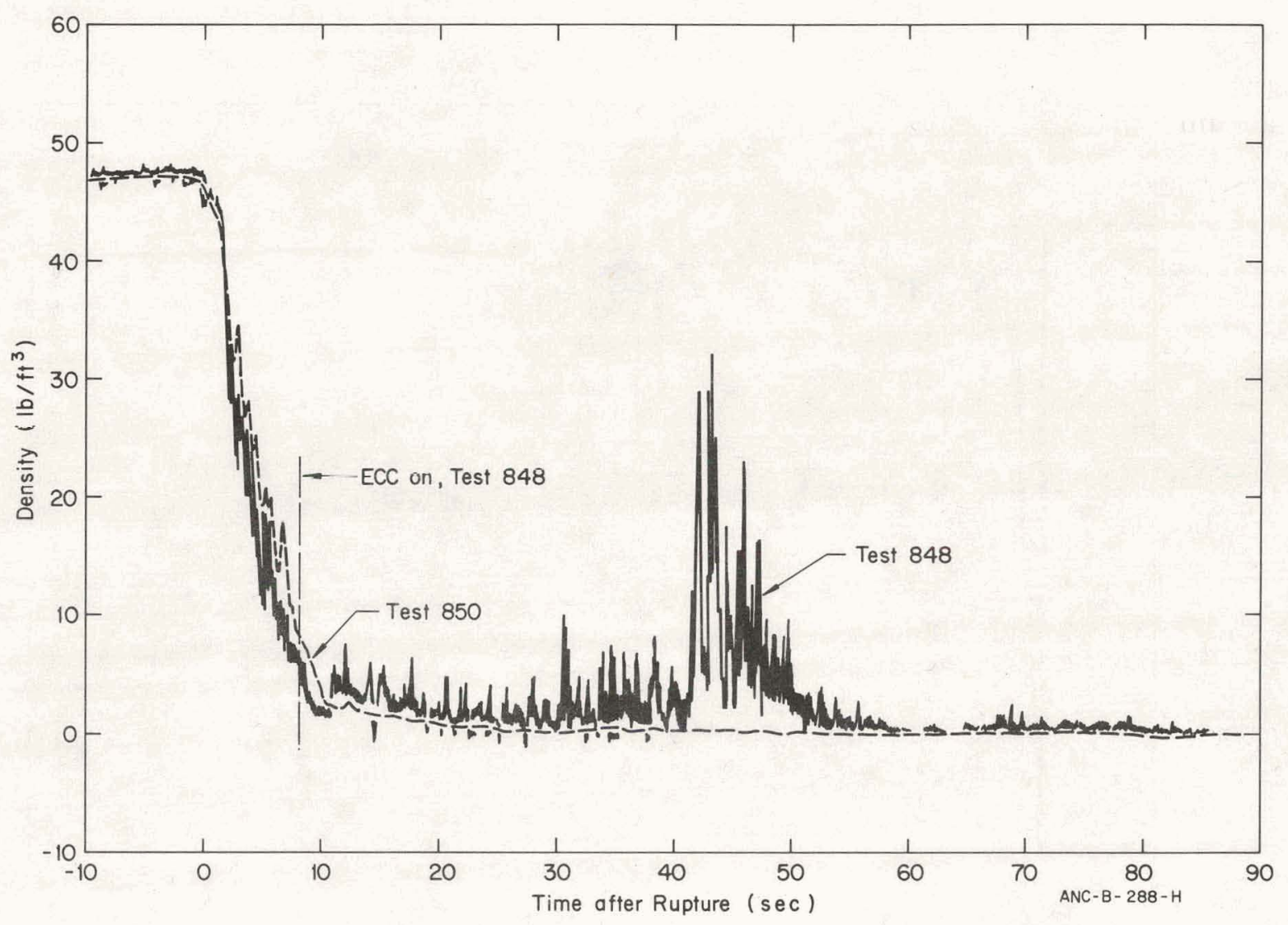

Fig. 48 Density at the blowdown nozzle -- Tests 848 and 850 .

\subsection{ECC Expulsion Mechanism}

The failure of ECC to reach the semiscale core and the absence or the eventual expulsion of all ECC from the inlet plenum was observed for all of the inlet break semiscale ECC injection tests [a].

[a] For Semiscale Test 845[8], the absence of ECC from the plenum was attributed to the fact that ECC was injected into the annulus between the core flow skirt and the vessel wall and was entrained in the blowdown stream. The upward steam velocity in the annulus exceeded that which would have allowed the free fall of liquid in the annulus. As a result, ECC fluid injected into the annulus was swept directly out of the vessel through the inlet nozzle and to the break. No ECC reached the core or inlet plenum. For Test 846 , the ECC injection point was relocated so that injection was directly into the inlet plenum, the break size was reduced, and the ECC injection rate was lowered. During Test 846 , some ECC liquild accumulated in the inlet plenum but was rapidly expelled shortly after completion of ECC liquid injection. The semiscale system was further modified for Test 847 by adjusting the loop pressure drops (by means of orifices) to study the effects of system resistances. The rapid expulsion of accumulated ECC liquid after termination of injection was again observed. 
During previous tests, the ECC accumulator gas (driving force for the ECC injection) was allowed to flow into the vessel following depletion of the accumulator liquid inventory. For Test 848, provisions were made for valving off the ECC system at the start of gas flow from the accumulator. Accumulated ECC fluid was still expelled from the inlet plenum.

Test 849 was conducted to determine whether a water seal at the steam generator low point near Station 5 (Figure 1) resulted in a pressure buildup between Station 5 and the inlet plenum sufficient to expel the accumulated ECC out the break. [ The height that water must be pushed from the inlet plenum to the break (4 ft) is less than from Station 5 to Station 6 (8 ft).] A steam generator bypass line was installed across the steam generator low point (Station 4 to Station 6). A quick-opening valve in the normally closed position was included in the bypass line. Actuation of the bypass valve was accomplished simultaneously with the closure of the ECC system block valve. Additional measurements taken were: a density measurement at the steam generator inlet (Station 5), a differential pressure measurement across the bypass line between Stations 4 and 6 , and a differential pressure measurement between the outlet plenum and the blowdown nozzle. The quick-closing ECC system block valve and the quick-opening bypass valve were actuated simultaneously about $36 \mathrm{sec}$ after rupture in Test 849 , when the inlet plenum pressure had decreased to 80 to 100 psig and after about $95 \%$ of the ECC liquid had been injected into the inlet plenum. ECC accumulated in the inlet plenum but was subsequently pushed from the vessel after injection was terminated (about $38 \mathrm{sec}$ ) in the same manner as had occurred in Test 848.

The differential pressure measurement across the bypass line from Station 4 to Station 6 for Test 849, shown in Figure 49, recorded pressure oscillations of $\pm 0.5 \mathrm{psi}$ just prior to opening of the valve. These oscillations subsequently diminished to $\pm 0.25 \mathrm{psi}$. A two- to three-psi head was required to push the water out of the inlet plenum; therefore, back pressure from a water seal at the loop low point was not the expulsion mechanism.

During Test 850 , the differential pressure between the outlet plenum and the blowdown nozzle was measured. The results of that measurement are compared with the results for Test 849 in Figure 50. The data for Test 850 from about $18 \mathrm{sec}$ on are almost exactly the average of the pressure oscillations recorded for Test 849 . The pressure oscillations begin at about the same time as the chugging is noticeable in the flow data, gradually increase to an amplitude of \pm 2 psi just prior to ECC shutoff, and significantly decrease 4 to $6 \mathrm{sec}$ later to amplitudes less than \pm 1 psi.

The data for Test 850 reflect the natural pressure decay of the system without obstructions in the flow path and the data for Test 849 reflect the effect of the accumulated water level in the inlet plenum periodically obstructing the flow path. Once the level of the accumulated fluid reaches an elevation above the flow skirt, pressure oscillations occur because of steam generation from liquid flashing from hot metal surfaces, residual back flow from the hot leg, or both. Calculations were made to determine the required amount of steam input (either by generation or back flow) to support $2-\mathrm{Hz}$ pressure oscillations of $\pm 2 \mathrm{psi}$ at the thermodynamic conditions existing in the vessel 


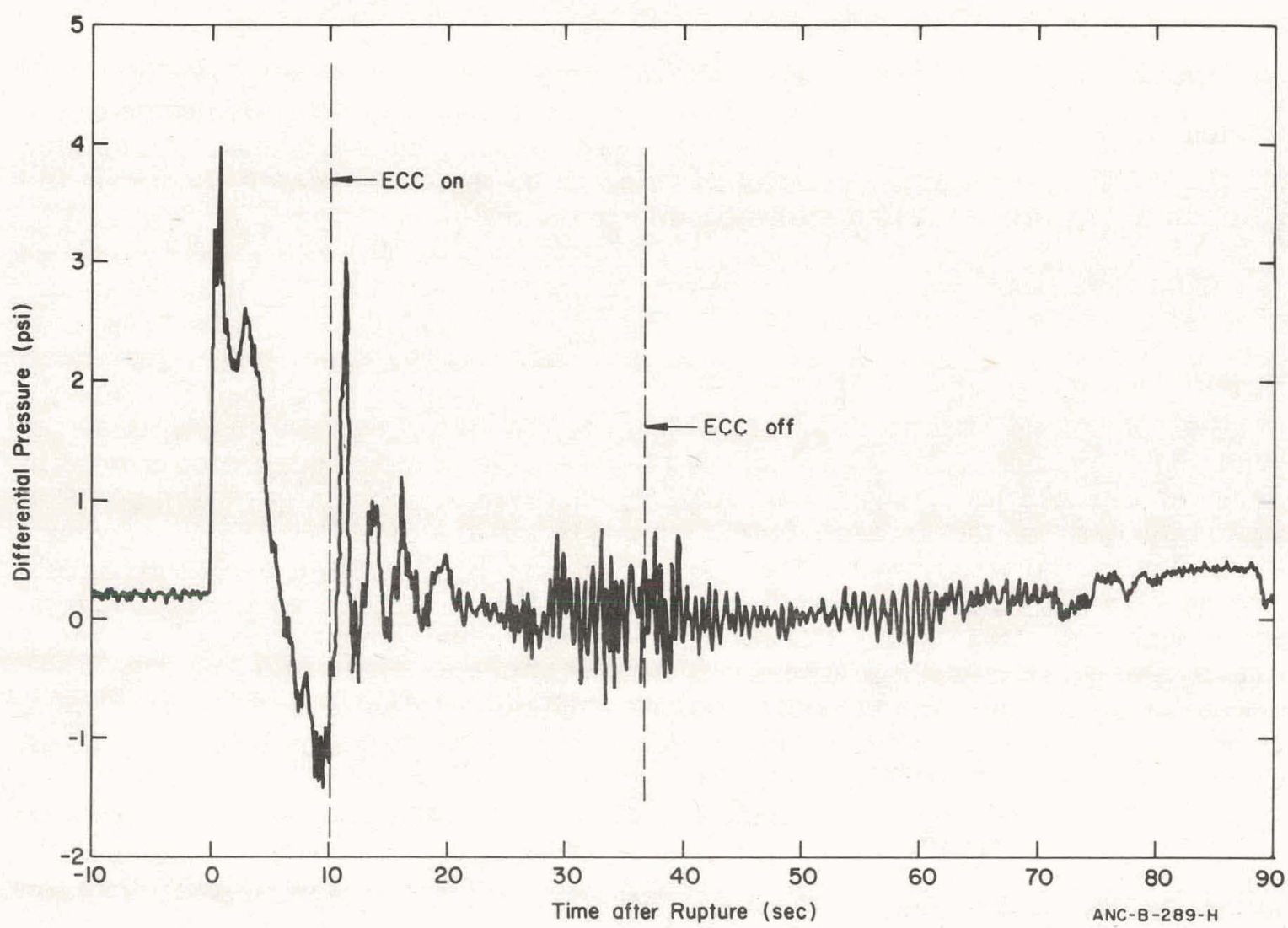

Fig. 49 Differential pressure across the steam generator bypass -- Test 849 .

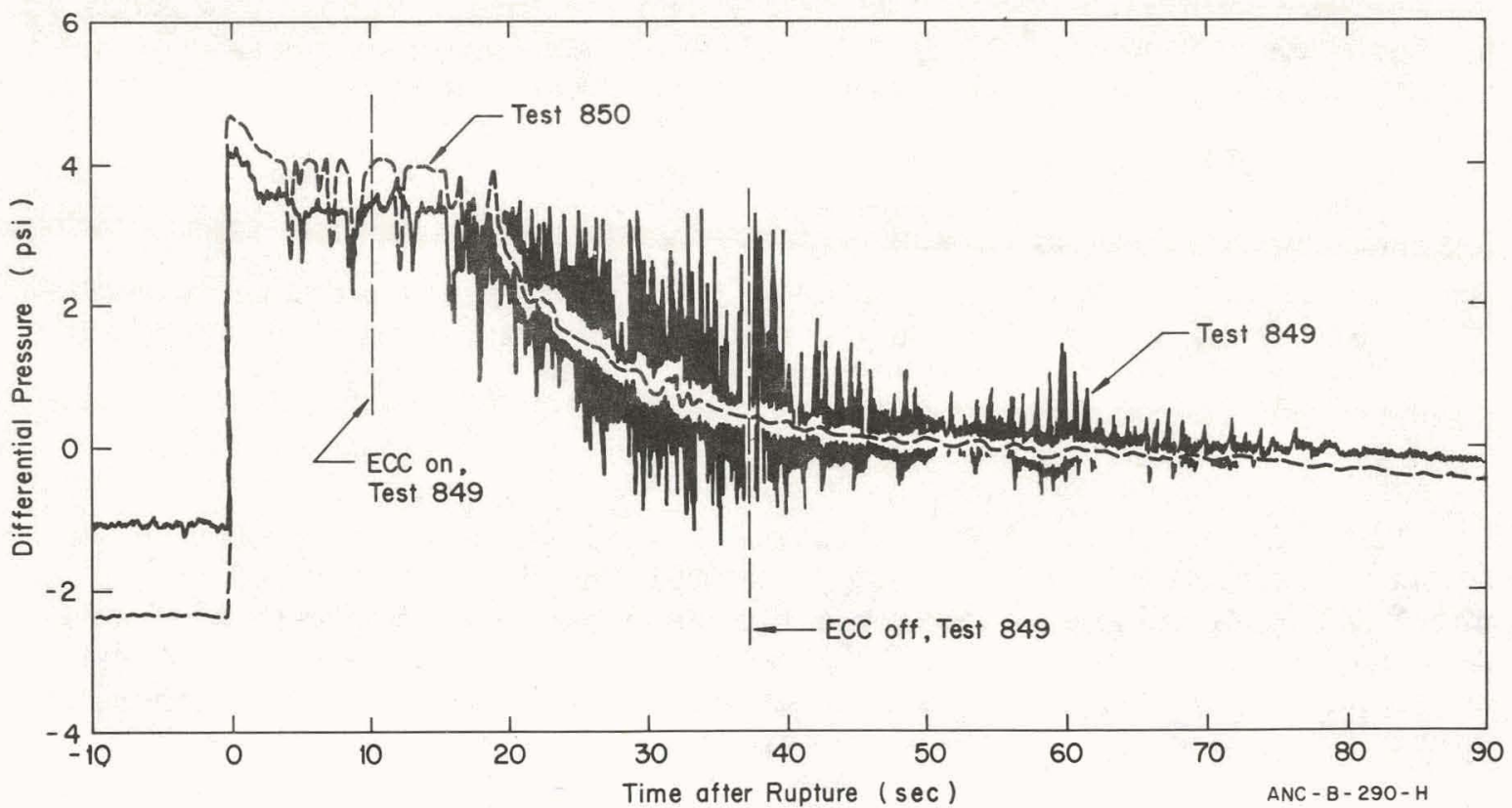

Fig. 50 Differential pressure between outlet plenum and blowdown nozzle -- Tests 849 and 850 . 
preceding ECC expulsion. The value is extremely small; $0.1 \mathrm{lb}$ or less. Maximum possible back flow rates supported by the pressure oscillations were calculated to be 0.7 to $1.2 \mathrm{lb} / \mathrm{sec}$.

Measurement techniques at this time are not sufficiently accurate to conclusively define the driving force for the chugging phenomena nor to positively determine the expulsion mechanism. Apparently, a fine balance is reached during the ECC injection period between energy sources (steam back flow and generation) and energy sinks (ECC). Additionally, the pressure buildup required to lift water from the inlet plenum to the break is less than that required to overcome the resistance of the loop. The expulsion mechanism is apparently the same mechanism causing the "chugging" phenomena, except that the influence of pressure generation suddenly increases when the ECC system is valved off; steam addition from back flow and steam generation continuc whereas condensation slows down and eventually ceases (perhaps 4 to 6 sec later).

Even though a precise experimental determination of the exact mechanism responsible for ECC expulsion is not avallable from the semiscale data, the results of these three tests have indicated the following:

(1) Entrainment of ECC by steam back flow to the break for an inlet break case may be a significant consideration in the LOCA

(2) The thermodynamic interaction of energy sources and sinks during the latter stages of the ECC injection period results in low frequency pressure pulses within the vessel

(3) Because of these pressure pulses, an osctllatory or chugging motion of the accumulated ECC fluid occurs. Apparently, the same mechanism which causes chugging eventually results in the expulsion of essentially all fluld from the vessel.

Whether similar ECC expulsion behavior will occur in systems more nearly typical of operating reactors cannot be determined on the basis of data from the semiscale tests to date. The exact behavior appears to be affected by a complex combination of: thermodynamic conditions in both the vessel and system loop at the start of, and during, ECC injection; system geometry factors, such as volume ratios, elevations, and diameters; and system fluid flow resistances and flow history. Although the semiscale system utilized in these tests is not typical of a reactor system, phenomena have been observed which may warrant consideration and possibly inclusion in existing LOCA analytical methods. 


\section{SUMMARY OF OBSERVATIONS}

The following observations are based on the data presented in Sections IV and V for Semiscale Tests 848,849 , and 850 . The sequence in which the observations are presented is the same as that in which they are discussed in the report and is not intended to reflect the priority or importance of the observations.

(1) The subcooled decompression processes in the piping and the vessel plenums follow the behavior expected for the test system configuration and for the relative break size represented in these tests.

(2) The maximum pressure difference across the core during subcooled decompression was about 50 psi.

(3) The effect of substituting a reducing nozzle in place of an orifice in the blowdown assembly was to damp out more quickly and reduce in magnitude the subcooled pressure oscillations in the system.

(4) Subcooled pressure oscillations occurred at the steam generator. The pressure difference across the steam generator was as high as 400 psi; oscillations subsequently diminished to less than \pm 100 psi by the end of subcooled decompression.

(5) Subcooled expansion of the fluid to the hot-leg saturation temperature was essentially complete within 50 to $55 \mathrm{msec}$ after rupture. Complete transition from subcooled to saturated conditions throughout the loop required about 0.7 to $0.8 \mathrm{sec}$. The fluid at the lowest initial temperature (greatest degree of subcooling) remained subcooled until the system decompressed to the saturation pressure for that temperature.

(6) Following the transition phase from subcooled conditions the system decompressed essentially at saturation conditions for the remainder of the transient.

(7) Comparison of fluid conditions in the vessel for tests with and without ECC indicated little difference in fluid behavior until late in the transient.

(8) Initiation of ECC infection caused no discernible effect on inlet plenum pressures as would be expected for significant or effective mixing of injected and resident fluids.

(9) Following ECC injection, fluid temperature measurements indicate the fluid in the inlet plenum was not homogeneous, but was stratifled; fluid layers of different degrees of subcooling were evident in the lower plenum with the bottom layer subcooled as much as $70^{\circ} \mathrm{F}$.

(10) Except for locations in the direct path from the inlet plenum to the break, ECC injection had little effect on loop fluid behavior. 
(11) During the latter stages of decompression when the fluld quality became high, thermocouples at several locations in the core and loop indicated high temperatures due to radiation from nearby metal surfaces.

(12) Cladding temperature increases resulting from DNB occurred at various pin locations starting at 3 to $6 \mathrm{sec}$ after system rupture. Heatup rates were about 150 to $200^{\circ} \mathrm{F} / \mathrm{sec}$.

(13) No significant overall difference in cladding temperature behavior is evident from comparison of data for tests with and without ECC. Localized differences appear to be related to steam flow paths.

(14) Fluid density in the loop was unaffected by the presence of ECC in the system except at locations in the open path to the break.

(15) Cold leg density was unaffected by the rupture for about 4 or $5 \mathrm{sec}$ after system rupture.

(16) A comparison of outlet plenum densities indic ated no effect due to ECC injection.

(17) The inlet plenum density measurement indicated liquid accumulated in the lower plenum.

(18) The density measured at the vessel inlet nozzle indicated the presence of the ECC fluid after ECC injection.

(19) The fluid flow rate through the discharge nozzle increased to a value about ten times the system steady state flow rate immediately after rupture.

(20) The discharge flow rates for tests with and without ECC injection were quite similar until late in the transient, indicating the rate of fluld discharge for the system was insensitive to ECC injection.

(21) Flow rates in the hot leg were unaffected by initiation and continuance of ECC injection.

(22) Hot leg flow continued in the normal flow direction at about one-half the initial magnitude for about 5 sec after rupture before reversing to flow into the vessel.

(23) Just prior to ECC infection, the vessel was $90 \%$ volded and the loop had lost $75 \%$ of the initial loop fluld mass.

(24) Maximum fluid inventory in the lower plenum prior to depletion of the ECC accumulator was approximately $75 \mathrm{lb}$. 
(25) Mass balance calculations show a measurement accuracy of about $95 \%$ in accounting for the initial fluid mass inventory.

(26) A system fluid mass balance indicated that half of the initial system fluid was ejected from the vessel side of the break and about half was ejected from the cold side of the break.

(27) For the first 10 to $15 \mathrm{sec}$ of the transient, fluid in the hot leg was of relatively low quality with peak values of about $35 \%$. Subsequently the hot leg fluld quality increased rapidly.

(28) Fluid qualities in the vessel rose lu valuca olose to 1 nn\% very rapidly. Fluid qualities at all three vessel locations (inlet and outlet plenums and core) were almost identical for the first 5 sec of the transient.

(29) For the first 8 to 10 sec of ECC injection, some ECC fell to the bottom of the inlet plenum and mixed with a small amount of the initial fluid inventory, whereas the larger percentage of ECC water was entrained in the steam back flow through the core and was carried out the break.

(30) Accumulation of ECC in the inlet plenum occurred as steam velocities decreased and more ECC fell to the bottom of the plenum.

(31) At the time the level of accumulated liquid in the lower plenum reached the flow skirt and interrupted an open flow path to the break, system pressure was still 100 to $150 \mathrm{psi}$.

(32) The force required to lift water from the inlet plenum to the break was less than that required to overcome the resistance of the loop. With the open path cut off, a liquid chugging phenomenon was initiated because of bulldup and release of back pressure.

(33) Apparently, the same mechanism which caused the chugging eventually resulted in the expulsion of essentially all fluid from the vessel. 
1. H. W. Helselmann, J. F. Whitbeck, J. O. Zane, Semiscale Blowdown and Emergency Core Cooling (ECC) Project, IN-1384 (July 1970).

2. Water Reactor Safety Program Office, Water Reactor Safety Program Plan, WASH-1146 (February 1970).

3. G. F. Brockett, H. D. Curet, H. W. Heiselmann, Experimental Invest1gation of Reactor System Blowdown, IN-1348 (September 1970).

4. H. W. Helselmann, D. J. Olson, J. F. Whitbeck, Semiscale Blowdown and Emergency Core Cooling (ECC). Project Test Report -- Tests 803 through 820, IN-1404 (October 1970).

5. D. J. Olson and J. F. Whitbeck, Semiscale Blowdown and Emergency Core Cooling (ECC) Project Test Report -- Test 821, IN-ITR-203 (July 1970) (limited distribution).

6. D. J. Olson and J. F. Whitbeck, Semiscale Blowdown and Emergency Core Cooling (ECC) Project Test Report -- Tests 822 and 823, IN-1393 (October 1970).

7. D. J. Olson, C. M. Moser, H. W. Heiselmann, Semiscale Blowdown and Emergency Core Cooling (ECC) Project Test Report-- Tests 824 and 825, IN-1481 (June 1971).

8. D. J. Olson and H. W. Heiselmann, Semiscale Blowdown and Emergency Core Cooling (ECC) Project Test Report - Test 845 (ECC Injection), ANCR-1014 (January 1972).

9. D. J. Olson and J. G. VanHaverbeke, Description of Facility and Data Acquisition and Processing System for the Heated Core Portion of the 800 Test series of the Semiscale Blowdown and Emergency Core Cooling (ECC) Project, IN-ITR-202 (July 1970) (limited distribution). 


\section{THIS PAGE}

\section{WAS INTENTIONALLY \\ LEFT BLANK}


APPENDIX A

DATA RECORDED -- SEMISCALE TESTS 848, 849, AND 850 
THIS PAGE

\section{WAS INTENTIONALLY LEFT BLANK}




\section{APPENDIX A}

-DATA RECORDED -- SEMISCALE TESTS 848, 849, AND $850^{\circ}$

Table A-I summarizes the data recorded during Tests $848, .849$, and 850 . The techniques applied to the data to account for instrument drift and thermal sensitivity are presented in Appendix B and selected examples of test data are given in Appendix $C$.

The location of the measurement instrumentation can be determined from Figures A-1, -2 , and -3 . Detector identification is accomplished by the following alpha-numeric characterizations:

(1) The first one or two letters define the variable being measured (for example: $P=$ pressure and $T F=$ fluid temperature).

(2) The second character, if it is a numeral, defines either a station number (Figure A-1) or a heater pin number; if it is a letter(s), it designates a location with the vessel (for example, $I=$ inlet) or a specific part of the internal structure (for example, CS = core structure).

(3) Detectors located within the vessel are generally identified by third and fourth characters which are specific in regard to the locations (angular, vertical, horizontal) of the detector on the core structure, as shown in Figures A-2 and -3. 


\section{TABLE A-I}

SUMMARY OF RECORDED DATA FOR SEMISCALE TESTS 848, 849, AND.850

\begin{tabular}{|c|c|c|c|c|c|}
\hline \multirow[b]{2}{*}{ Variable } & \multirow[b]{2}{*}{$\begin{array}{c}\text { Detector } \\
\text { Identification } \\
\end{array}$} & \multicolumn{3}{|c|}{ Quantity } & \multirow[b]{2}{*}{$\begin{array}{c}\text { Figure } \\
\text { Reference }\end{array}$} \\
\hline & & Test 848 & Test 849 & Test 850 & \\
\hline \multicolumn{6}{|l|}{ Pressure. } \\
\hline Tinng & $P$ & 16 & 15 & 15 & 1 \\
\hline \multicolumn{6}{|l|}{ Yessel } \\
\hline $\begin{array}{l}\text { Outlet plenum } \\
\text { Inlet plenum }\end{array}$ & $\begin{array}{l}P-0-1 S, P-0-1 D \\
P-I-1 S, P-I-1 D\end{array}$ & $\begin{array}{l}2 \\
2\end{array}$ & $\begin{array}{l}3 \\
3\end{array}$ & $\begin{array}{l}3 \\
3\end{array}$ & $\begin{array}{l}2 \\
2\end{array}$ \\
\hline \multicolumn{6}{|l|}{ Temperature } \\
\hline Loop & & & & & \\
\hline $\begin{array}{l}\text { Fluid } \\
\text { Material }\end{array}$ & $\begin{array}{l}\mathrm{TF} \\
\mathrm{TM}\end{array}$ & $\begin{array}{r}9 \\
12\end{array}$ & $\begin{array}{r}9 \\
12\end{array}$ & $\begin{array}{l}10 \\
12\end{array}$ & $\begin{array}{l}1 \\
1\end{array}$ \\
\hline \multicolumn{6}{|l|}{ Vessel } \\
\hline $\begin{array}{l}\text { Fluid } \\
\text { Material }\end{array}$ & $\begin{array}{l}\mathrm{TF} \\
\mathrm{TM}\end{array}$ & 19 & 18 & 18 & 2 \\
\hline $\begin{array}{l}\text { Internals } \\
\text { Pins }\end{array}$ & & $\begin{array}{r}5 \\
36\end{array}$ & $\begin{array}{r}5 \\
35\end{array}$ & $\begin{array}{r}5 \\
35\end{array}$ & $\begin{array}{l}2 \\
3\end{array}$ \\
\hline \multicolumn{6}{|l|}{ Differential Temperature } \\
\hline $\begin{array}{l}\text { Core } \\
\text { Steam generator }\end{array}$ & $\begin{array}{l}\text { DT-C-1 } \\
\text { DT-SG-1 }\end{array}$ & $\begin{array}{l}1 \\
1\end{array}$ & $\begin{array}{l}1 \\
1\end{array}$ & & 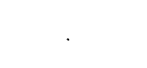 \\
\hline \multicolumn{6}{|l|}{$\underline{\text { Loads }}$} \\
\hline \multicolumn{6}{|l|}{ Vessel } \\
\hline $\begin{array}{l}\text { Horizontal } \\
\text { Vertical }\end{array}$ & $\begin{array}{l}L C-5 A, L C-6 A \\
L C-1 A, L C-2 A\end{array}$ & $\begin{array}{l}2 \\
2\end{array}$ & $\begin{array}{l}1 \\
2\end{array}$ & $\begin{array}{l}1 \\
2\end{array}$ & \\
\hline Displacement & & & & & \\
\hline $\begin{array}{l}\text { Vcascl, internal } \\
\text { Vessel, vertical } \\
\text { Nozzle, horizontal }\end{array}$ & $\begin{array}{l}\text { M-UG-2 } \\
M-37 A \\
M-17 x\end{array}$ & $\begin{array}{l}1 \\
1 \\
1\end{array}$ & $\begin{array}{l}0 \\
1 \\
1\end{array}$ & $\begin{array}{l}0 \\
1 \\
1\end{array}$ & $\begin{array}{l}2 \\
2\end{array}$ \\
\hline \multicolumn{6}{|l|}{ Acceleration } \\
\hline Vessel, vertical & $A C-382$ & 1 & 1 & 1 & 2 \\
\hline Brcak Time, Rupture Disc & $R-18$ & 1 & 1 & 1 & 1 \\
\hline \multicolumn{6}{|l|}{ Density } \\
\hline $\begin{array}{l}\text { Loop } \\
\text { Core } \\
\text { Plenums }\end{array}$ & $\begin{array}{l}D-1, D-2, \ldots \\
D-C-1 \\
D-0-1, D-I-1\end{array}$ & $\begin{array}{l}5 \\
1 \\
2\end{array}$ & $\begin{array}{l}6 \\
1 \\
2\end{array}$ & $\begin{array}{l}6 \\
1 \\
2\end{array}$ & $\begin{array}{l}1 \\
2\end{array}$ \\
\hline \multicolumn{6}{|l|}{ Differential Pressure } \\
\hline $\begin{array}{l}\text { Core } \\
\text { Loop }\end{array}$ & $\begin{array}{l}D P-I-0 \\
D P-14-1, \ldots\end{array}$ & $\frac{1}{6}$ & $\begin{array}{l}1 \\
9\end{array}$ & $\frac{1}{8}$ & $\begin{array}{l}2 \\
2\end{array}$ \\
\hline \multicolumn{6}{|l|}{ Dras Force (Fluid $\rho v^{2}$ ) } \\
\hline $\begin{array}{l}\text { Loop } \\
\text { Vessel }\end{array}$ & $\begin{array}{l}V-1, V-3, \ldots \\
V-I-1, \ldots\end{array}$ & $\begin{array}{l}5 \\
1\end{array}$ & $\begin{array}{l}7 \\
1\end{array}$ & $\begin{array}{l}7 \\
1\end{array}$ & 1 \\
\hline Power & PWR- & 6 & 6 & 6 & \\
\hline Voltage & ET, E- & 5 & 5 & 5 & \\
\hline Current & IT & 1 & 1 & 1 & \\
\hline Miscellaneous & & 17 & 14 & 12 & \\
\hline
\end{tabular}




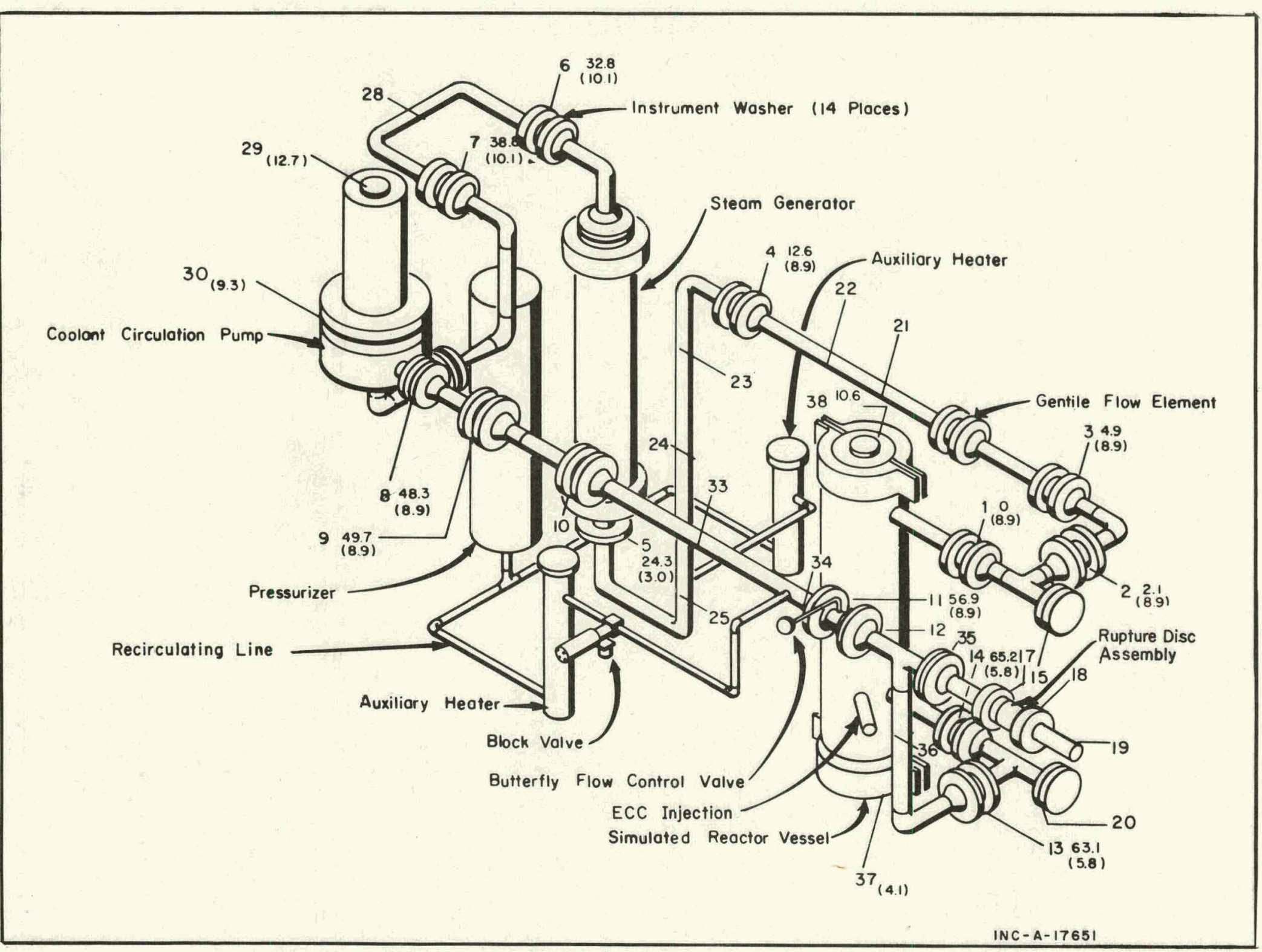

Fig. A-1 Single-loop semiscale isometric. 


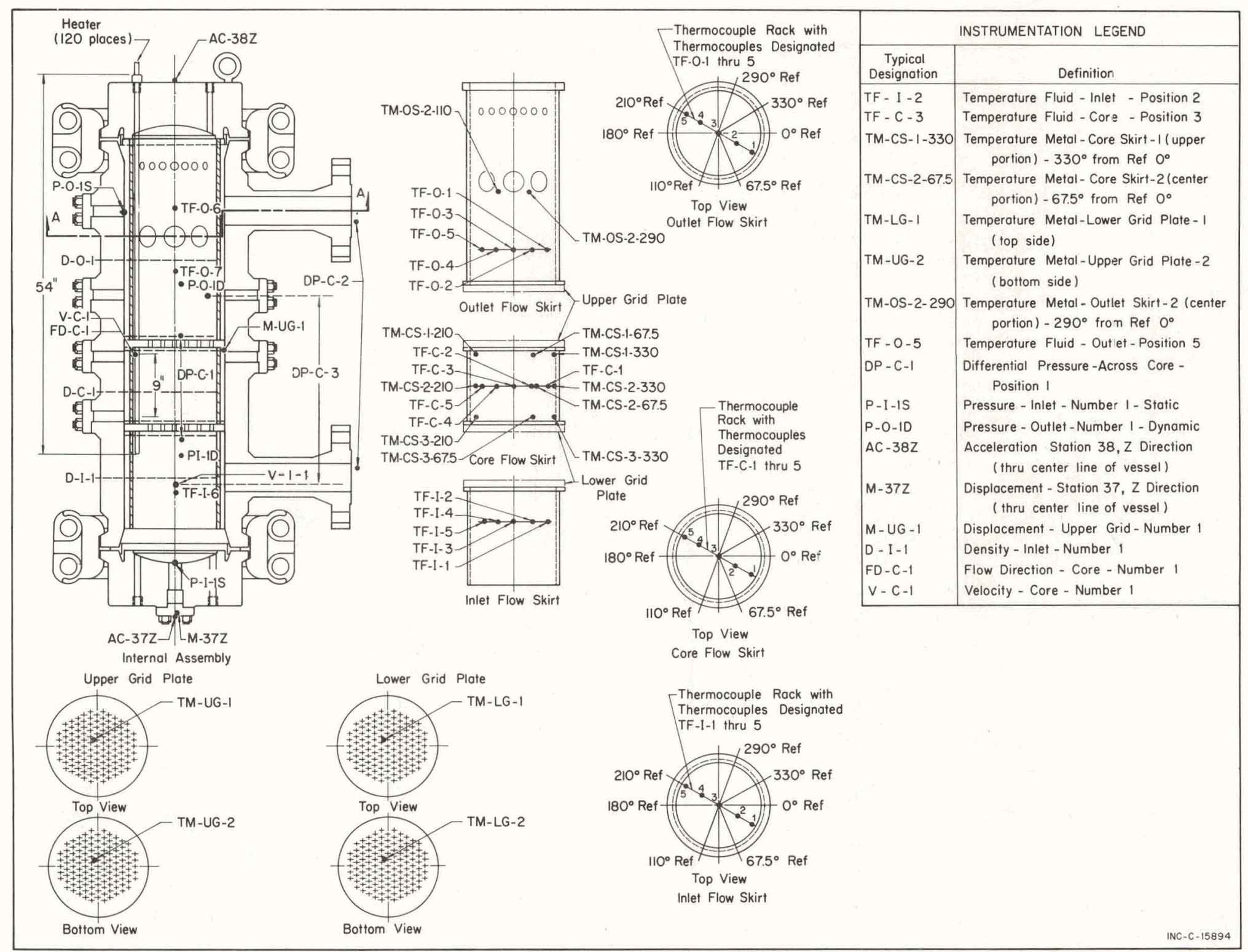

Fig. A-2 In-vessel instrumentation. 


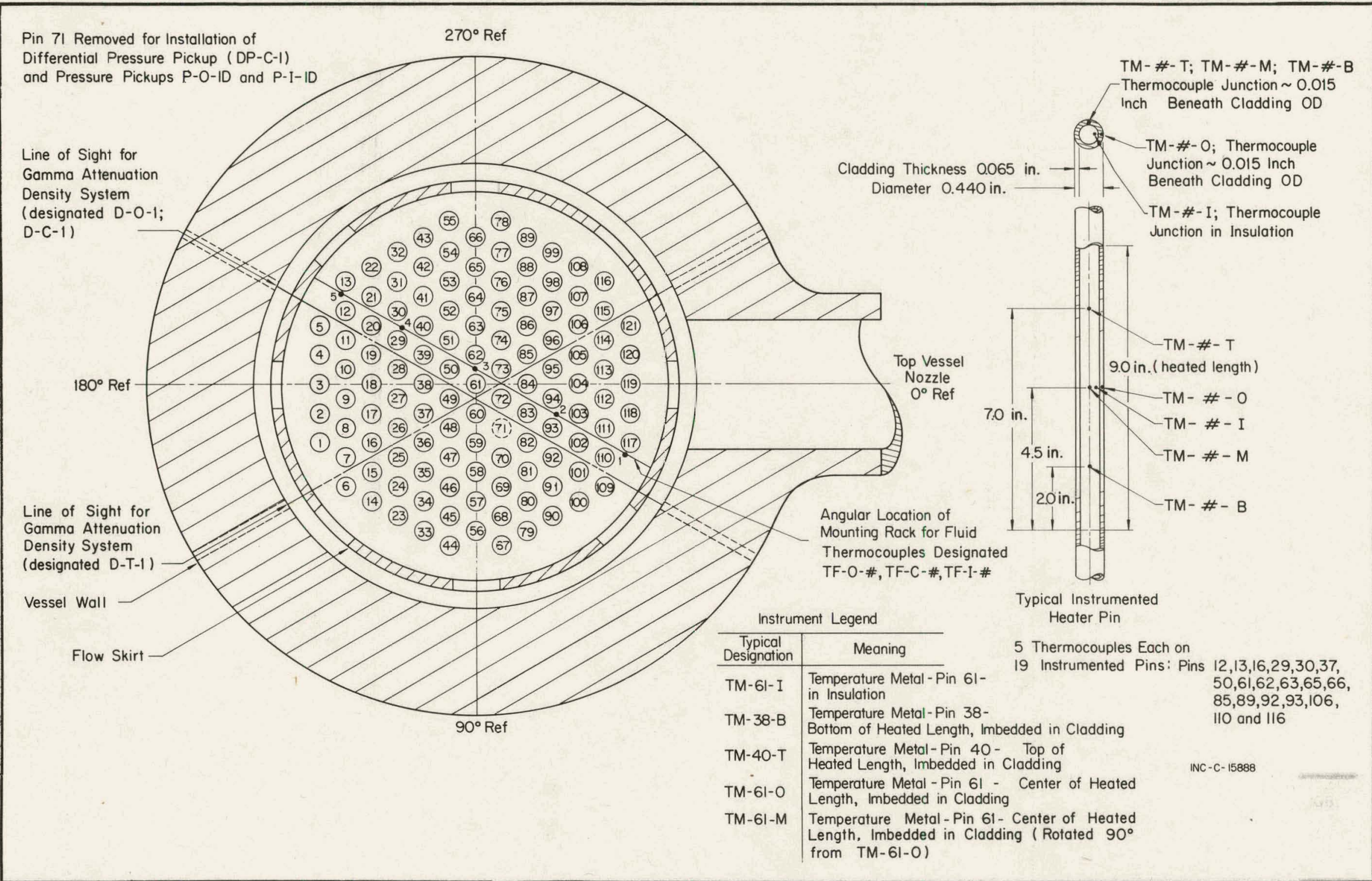

Fig. A-3 Heater pin and thermocouple locations. 
THIS PAGE

\section{WAS INTENTIONALLY LEFT BLANK}


APPENDIX B

METHODS USED TO NORMALIZE TEST DATA TO ACCOUNT FOR INSTRUMENT DRIFT AND THERMAL EFFECTS 
THIS PAGE

\section{WAS INTENTIONALLY LEFT BLANK}




\section{APPENDIX B}

\section{METHODS USED TO NORMALIZE TEST DATA TO ACCOUNT FOR INSTRUMENT DRIFT AND THERMAL EFFECTS}

The data reported for Tests 848,849 , and 850 have, in many cases, been corrected to account for instrument drift and detector thermal sensitivity. The purpose of this appendix is to explain the methods used to normalize the test data.

\section{B-I. PRESSURE}

The majority of the pressure transducers used are of the strain gage type with a 3000-psi range. On the basis of the manufacturer's specifications, at constant temperature the absolute value of the pressure measurements is within $\pm 5 \%$ of full scale. In addition, the manufacturer's specifications indicate that for a $400^{\circ} \mathrm{F}$ temperature change the error for a full scale reading is less than $480 \mathrm{psig}$ and for a zero pressure reading the error is less than 60 psig.

In a typical decompression experiment, starting at $2250 \mathrm{psig}$, the pressure drops about 1000 psi during subcooled blowdown in less than $100 \mathrm{msec}$ and is accompanied by a fluid temperature change of about 5 to $6^{\circ} \mathrm{F}$. For the remainder of the decompression (saturated blowdown), the pressure changes relatively slowly down to atmospheric pressure; fluid temperatures, however, decrease about $400^{\circ} \mathrm{F}$ during the time required to reach atmospheric conditions. The information obtained from the pressure transducers was modified in the following manner:

(1) With the semiscale system at steady state pretest conditions (approximately $2250 \mathrm{psi}$ and $580^{\circ} \mathrm{F}$ ), each pressure transducer output was normallzed to agree with pretest pressures obtained from a prectston pressure gage 10cated on the vessel head, with appropriate corrections made for fluid pressure drop around the loop..

(2) The total pressure change measured for each transducer as the system drops from the saturation pressure to atmospheric was modified by use of a linear correction factor to obtain the required total pressure drop. For example, if a pressure transducer indicates a pressure of $-50 \mathrm{psi}$ at the end of the transient (pressure at atmospheric conditions), the entire pressure history would be modified to decrease the measured drop from saturation to atmospheric pressure by $50 \mathrm{psi}$ in a manner linear with time. 


\section{B-I. DIFFERENTIAL PRESSURE}

Several different types of differential pressure transducers are used in the semiscale blowdown experiments. These devices have ranges from $\pm 100 \mathrm{in}$. of water to $\pm 1000 \mathrm{psi}$. The instruments are frequently recalibrated following a test to determine the zero shift in the instruments. The differential pressure traces are then modified in the following manner.

(1) The zero shift determined from the calibration of the transducer is applied to the data.

(2) The Initial prerupture output is normalized to the initial differential pressure which is known from system flow tests and pump characteristic curves.

(3) If the zero shift correction did not result in a zero output indication at the end of the transient, a linear (with time) correction for thermal drift similar to that used for the pressure transducers is applied.

\section{B-III. TEMPERATURE}

The only modification of the temperature data for Tests 848,849 , and 850 consisted of assigning the initial-condition temperature to all fluid temperature data at the time of rupture (as much as a $20^{\circ} \mathrm{F}$ correction). For materials temperatures this modification of the data was not made.

\section{B-IV. DENSITY}

Fluid density measurements are processed using a computer data conversion program. Initial output from density detectors is in volts which must be converted to $\mathrm{lb} / \mathrm{ft}^{3}$ based on the detector sensitivity.

With the semiscale system at pretest steady state conditions, the initial voltage output of the detectors is assigned the appropriate initial density value. The final voltage recorded is assigned a value of $0.03 \mathrm{lb} / \mathrm{ft}^{3}$ (essentially zero) and a linear (with time) calibration factor is applied between these two points. The estimated accuracy of the density measurements is within $\pm 5 \%$ of full scale, or within approximately $\pm 2.2 \mathrm{lb} / \mathrm{ft}^{3}$.

\section{B-V. MOMENTUM FLUX}

Momentum flux measurements are made using calibrated drag disc devices which give an output in volts. On the basis of the initial density and the callbration curve for a particular detector, the initial voltage from the detector 
Is assigned a value commensurate with initial pretest steady state flow conditions. To compensate for thermal sensitivity of the detector, a computer data-conversion program supplies a linear (with time) correction to the data based on the detector calibration curve and on the initial and final conditions. 
THIS PAGE

\section{WAS INTENTIONALLY LEFT BLANK}


APPENDIX C

SELECTED EXAMPLES OF DIGITIZED DATA -- SEMISCALE TESTS $848 ; 849$, AND 850 
THIS PAGE

\section{WAS INTENTIONALLY LEFT BLANK}




\section{APPENDIX C \\ SELECTED EXAMPLES OF DIGITIZED DATA -- SEMIISCALE}

TESTS 848,849 , AND 850

The figures included in this appendix are intended to illustrate the type of-information recelved from Semiscale Tests 848,849 , and 850 . Unless otherwise indicated, this information is as received directly from the digitized analog data prior to application of any corrective process. The method of data processing requires a 10-second lead time prior to rupture; therefore, the time of rupture on the plots given in this appendix is 10 sec.

\section{C-I. PRESSURE HISTORIES}

Figures C-1 through -12 present the total pressure histories at three loop locations and one ressel location for each of the three tests. The corrective process outlined in Section I of Appendix B has been applied to these data.

\section{C-II. DIFFERENTIAL PRESSURES}

Figures C-13 through -24 present the complete differential pressure measurements around the loop and across the vessel for the three tests discussed in this report. Corrective procedures as outlined in Section II of Appendix B have been applied to these data.

\section{C-III. MATERIAL TEMPERATURE BEHAVIOR}

Figures C-25 through -29 present typical material temperature behavior curing decompression. The identification and location of detectors are given in Appendix A, Figure A-3. These selected traces give typical rod behavior during the transient for different elevations and locations in the core structure. In all cases, the onset of DNB and the pin response during tests with and without ECC are evident.

\section{C-IV. FLUID DENSITY}

Figures $\mathrm{C}-40$ through -51 show the fluid density behavior for three-loop locations and two vessel locations. In all cases the data have been corrected according to the method outlined in Section IV of Appendix B. 
Figures C-52 through -54 present a representive drag disc output from each of the three tests. The data in these figures have been initialized for zero shift and a linear correction for thermal drift applied as outlined in Section $\mathrm{V}$ of Appendix B. 


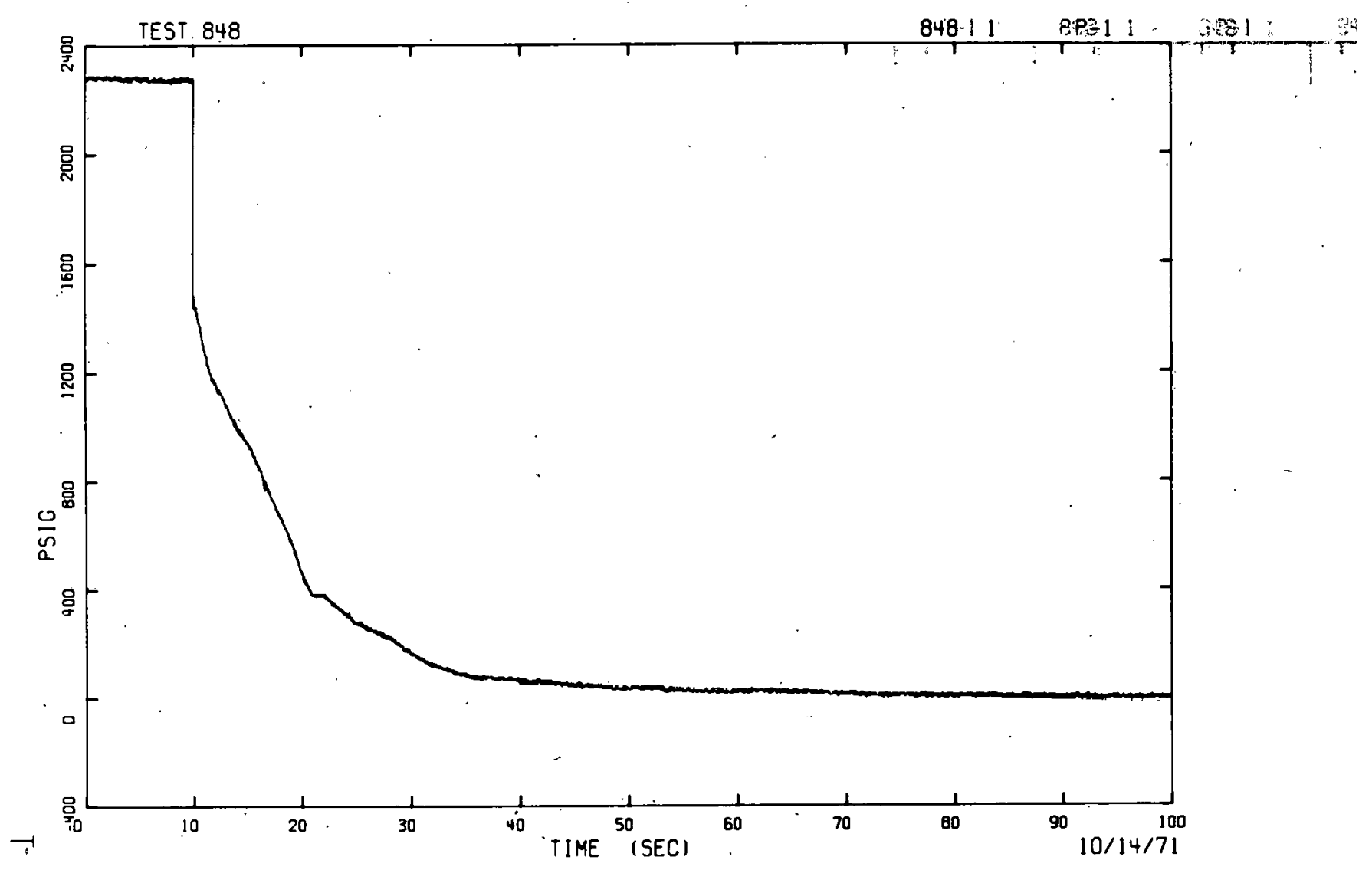

Fig. C-1 Outlet nozzle pressure -- Test 848 .

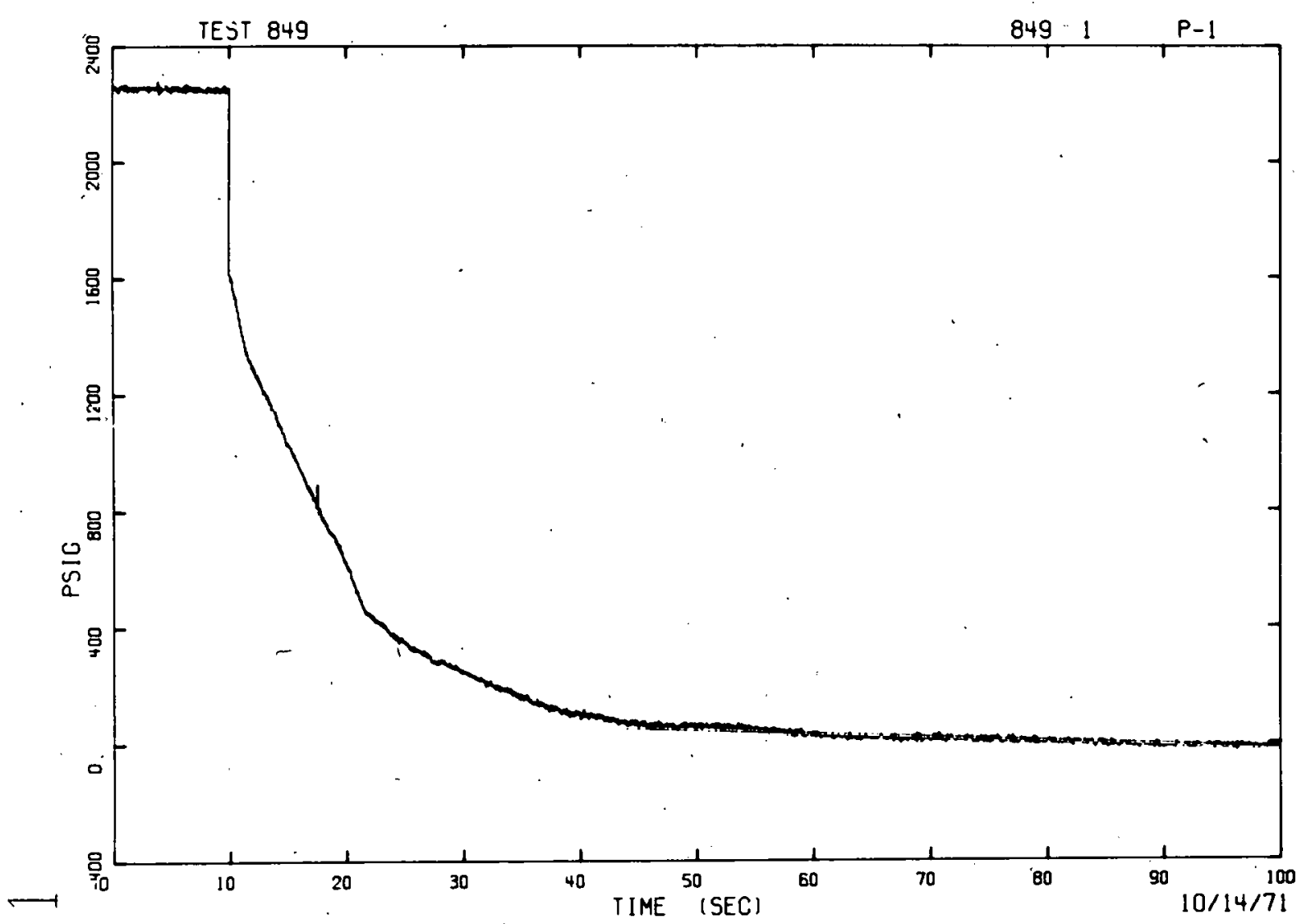

Fig. C-2 Outlet nozzle pressure -- Test 849. 


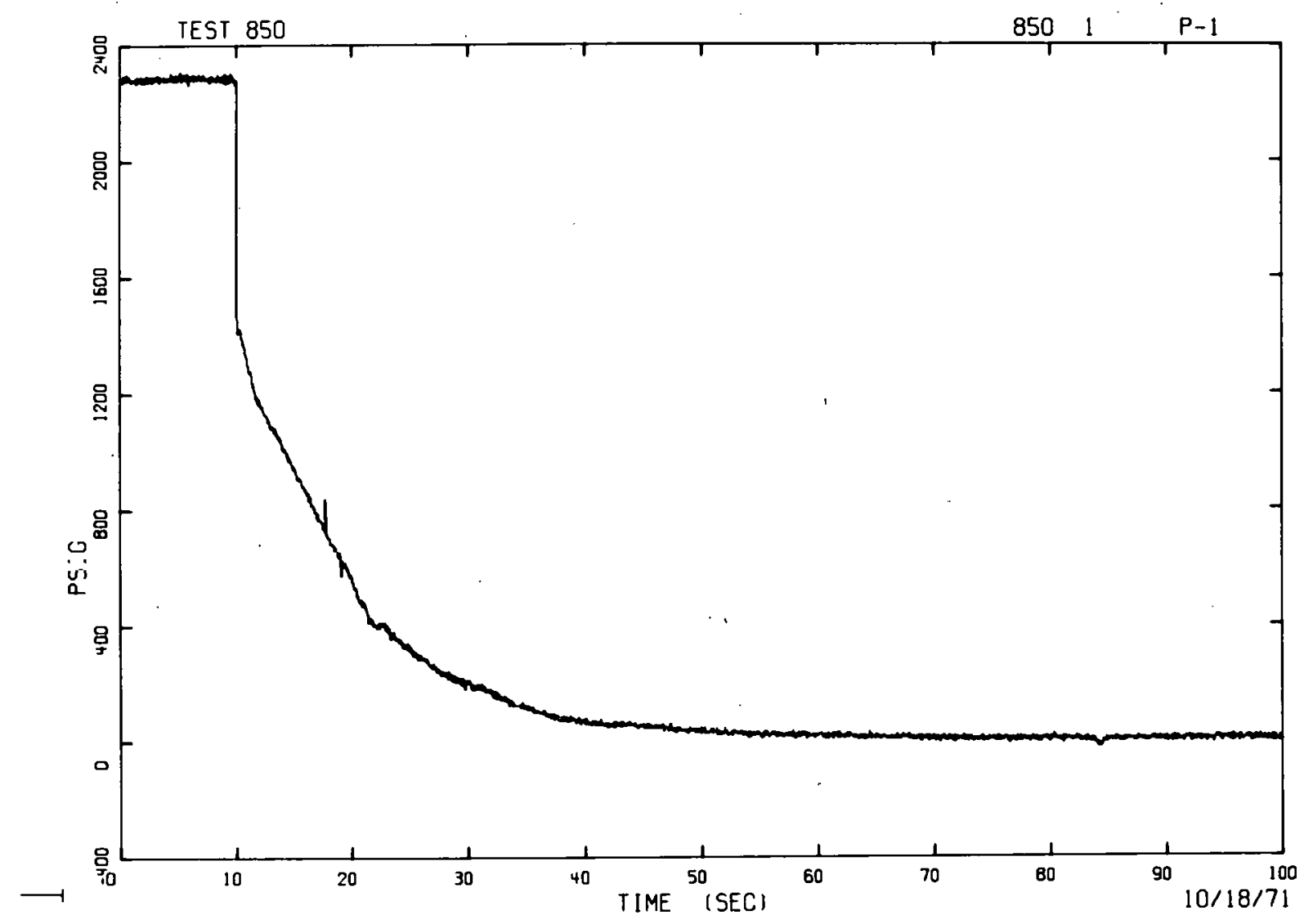

Fig. C-3 Outlet nozzle pressure -- Test 850 .

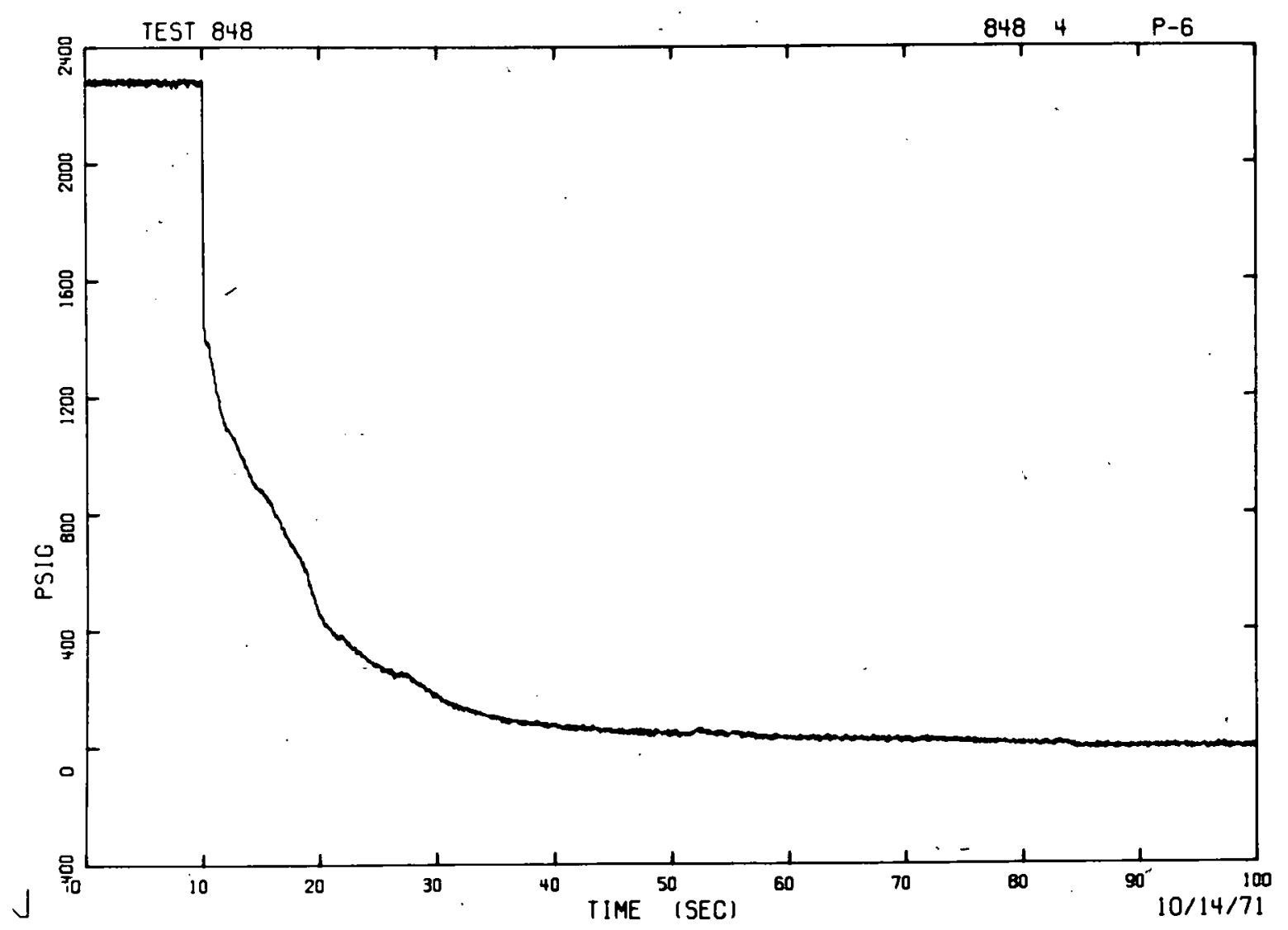

Fig. C-4 Steam generator outlet pressure -- Test 848. 


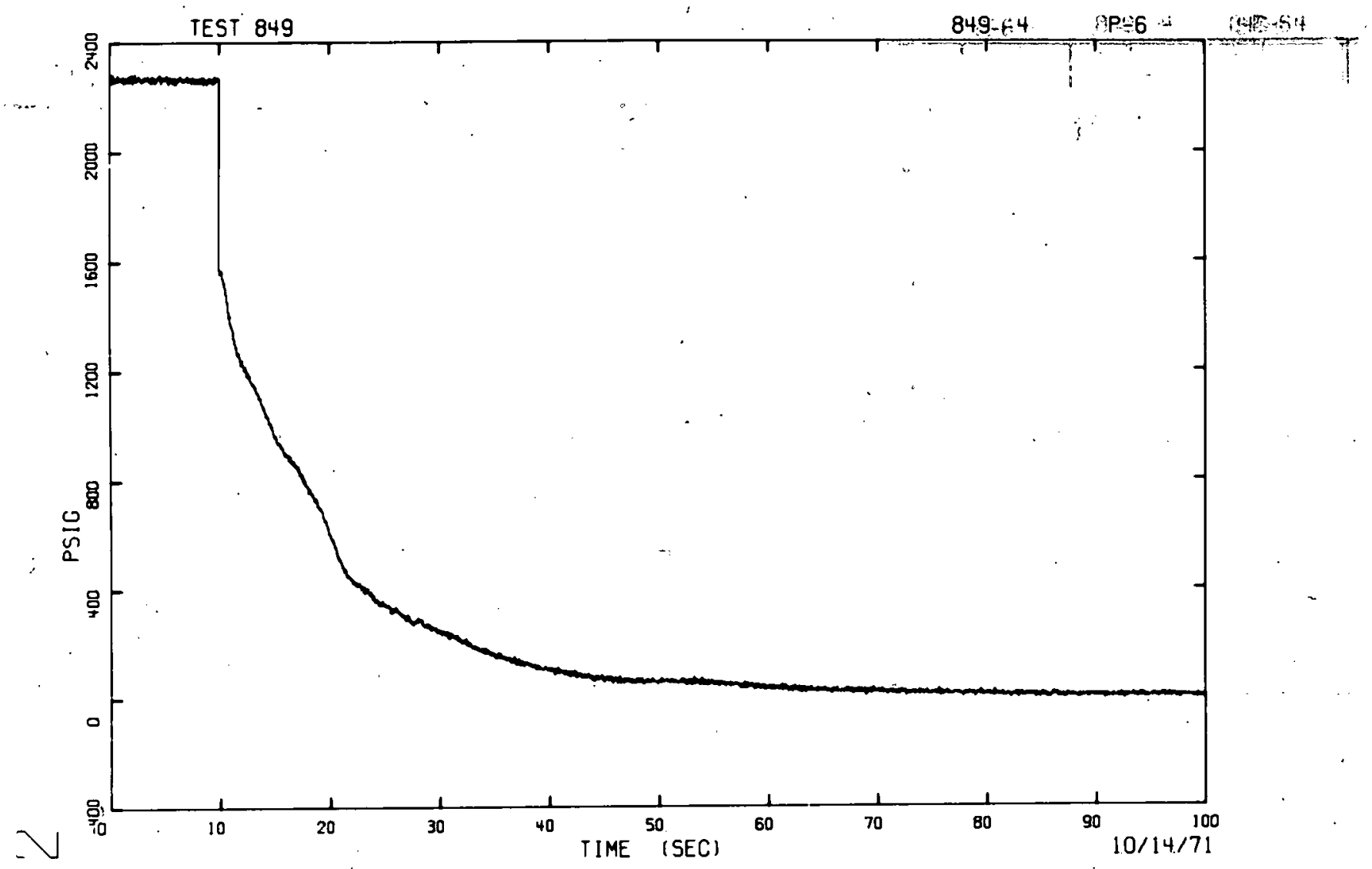

Fig. C-5 Steam generator outlet pressure -- Test 849 .

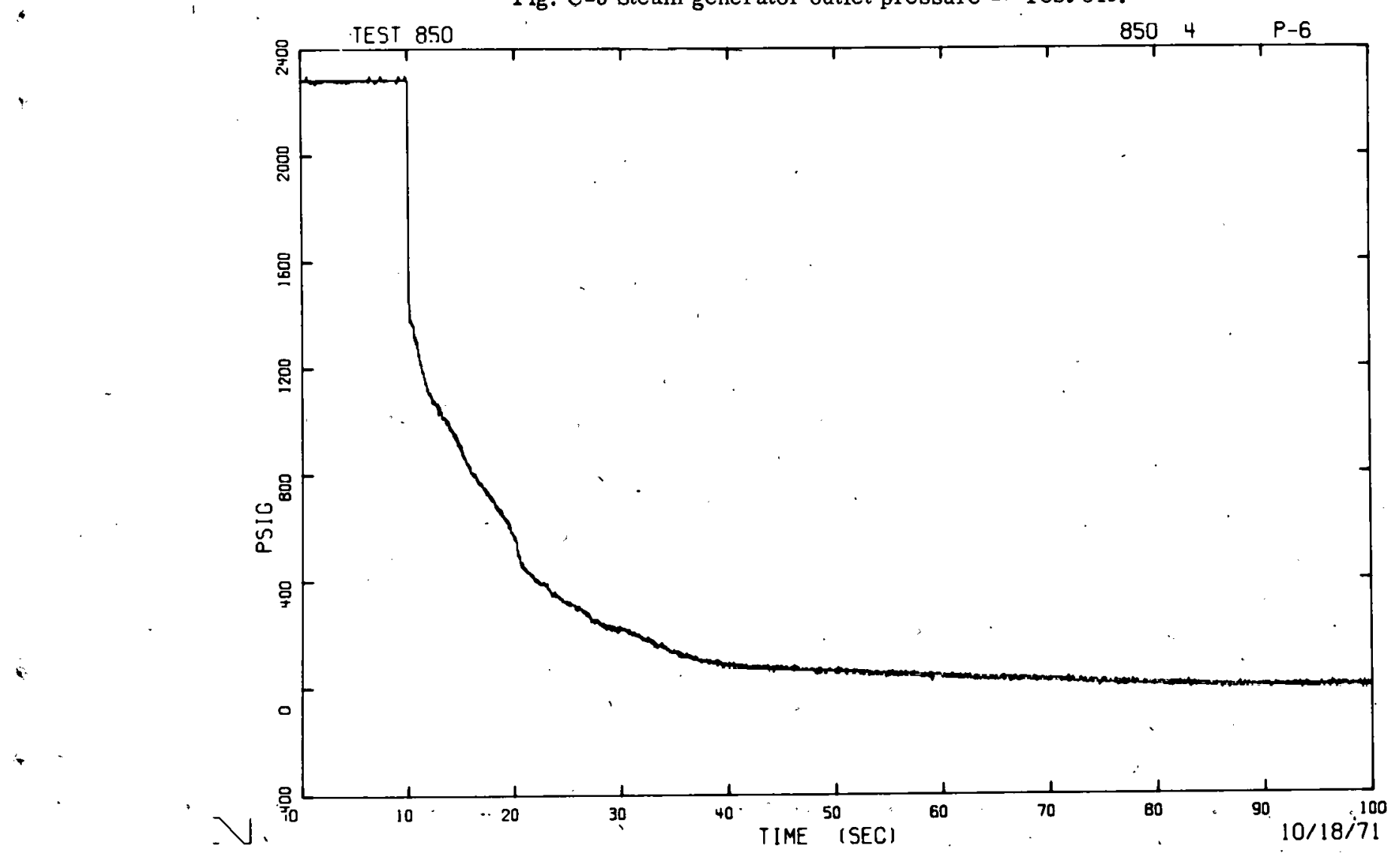

Fig. C-6 Steam generator outlet pressure -- Test 850. 


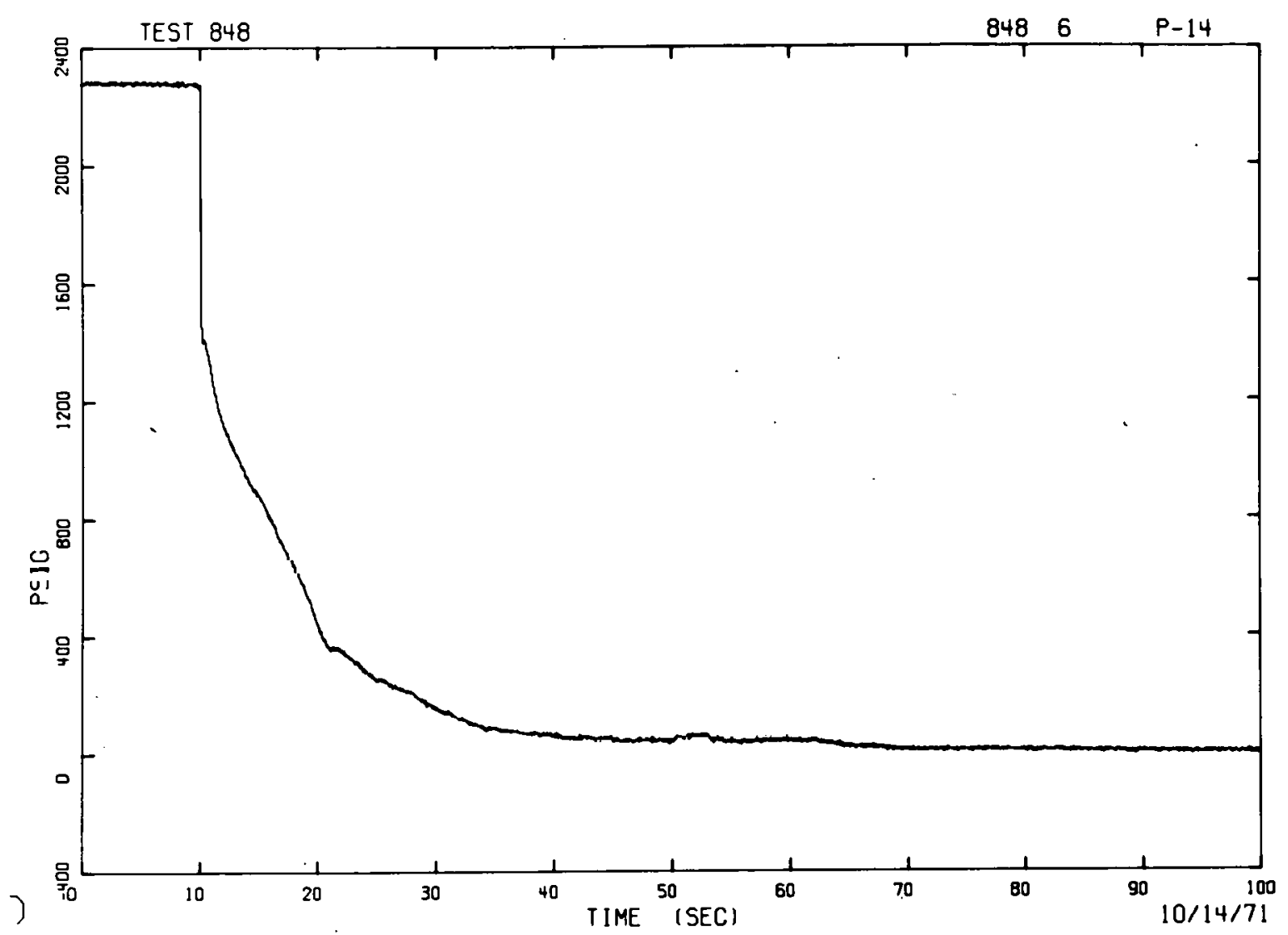

Fig. C-7 Inlet nozzle pressure -- Test 848 .

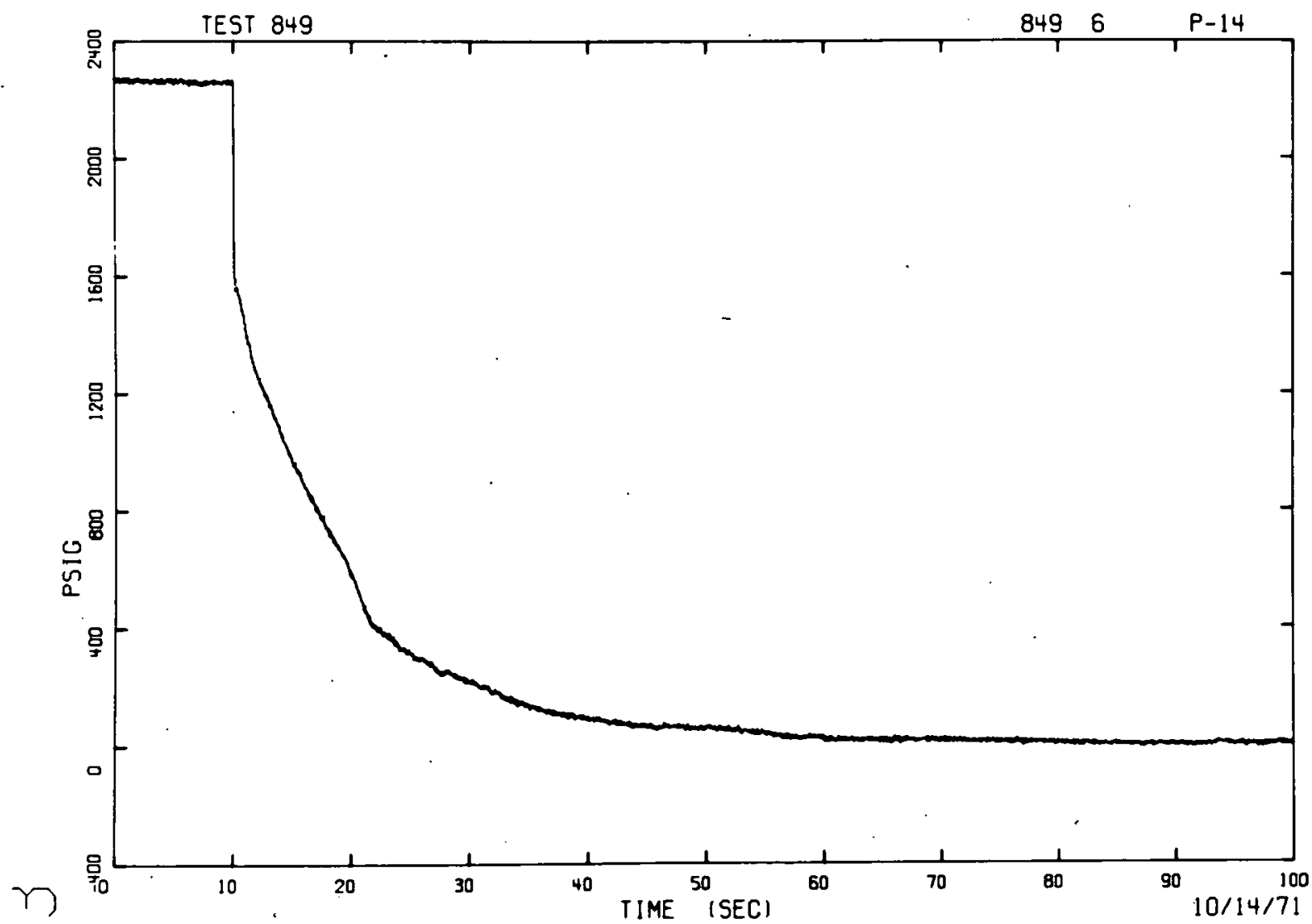

Fig. C-8 Inlet nozzle pressure -- Test 849. 


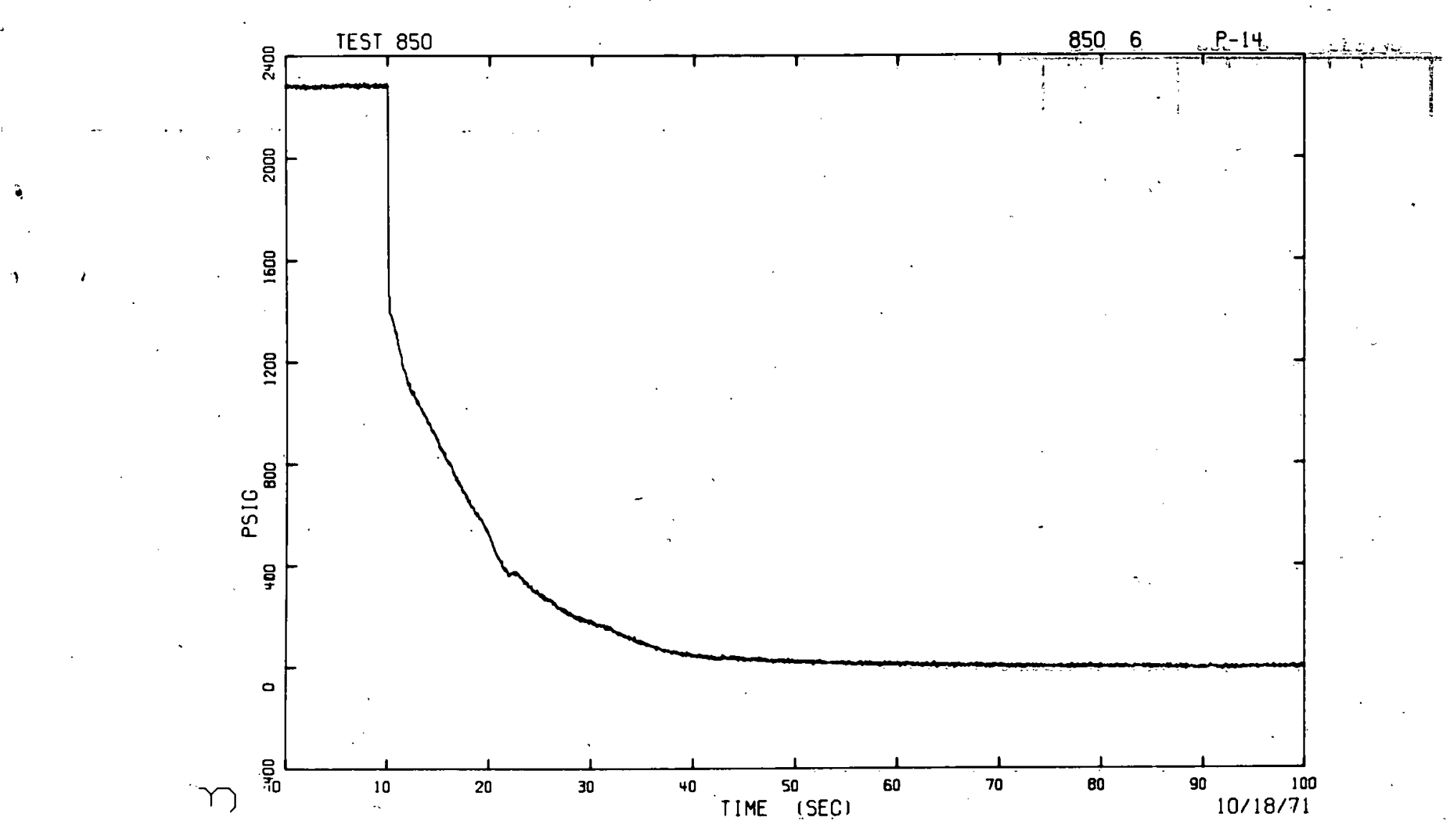

Ftg. C-9 Inlet nozzle pressure -- Test 850 .

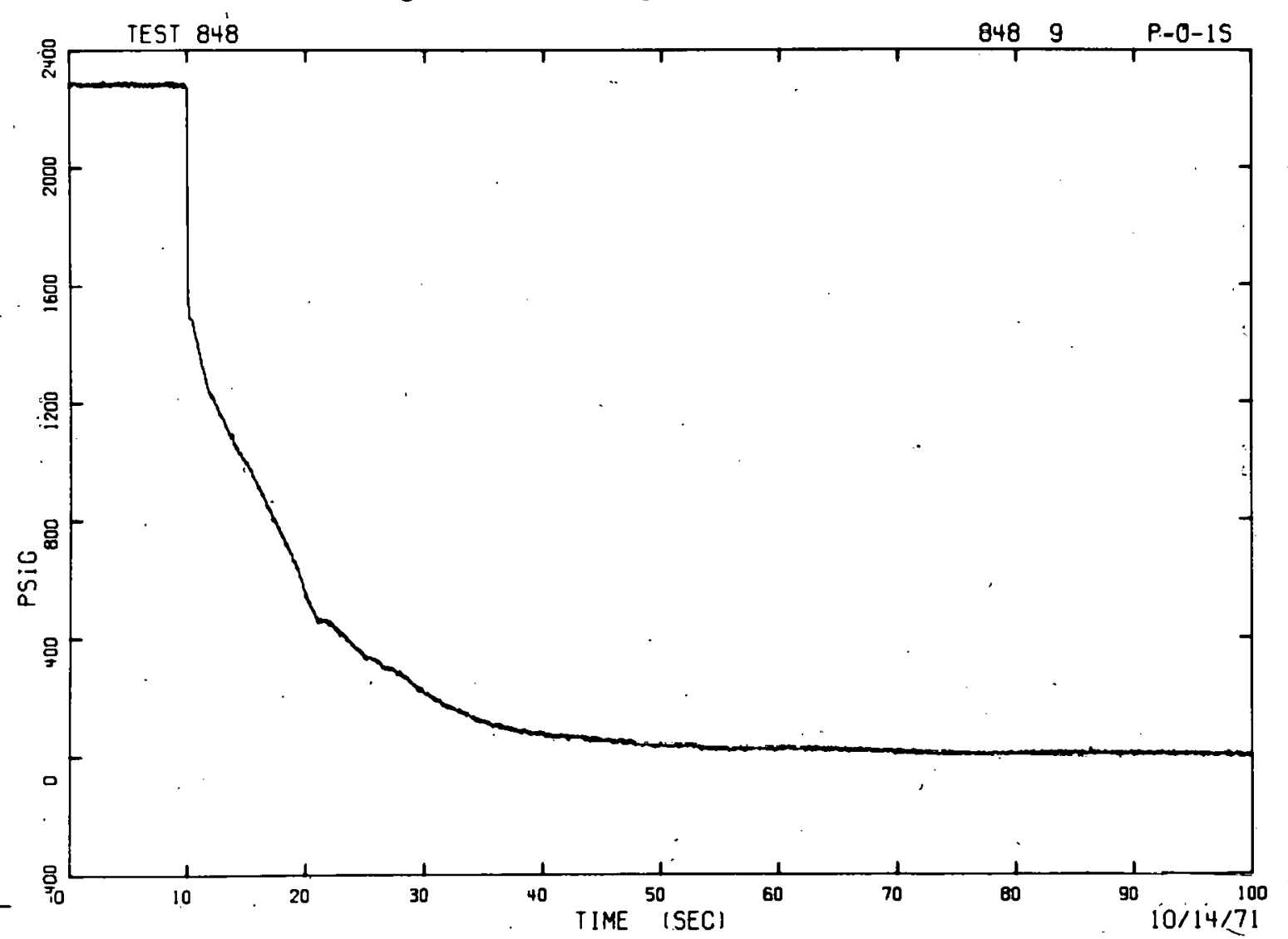

Fig. C-10 Outlet plenum pressure -- Test 848. 


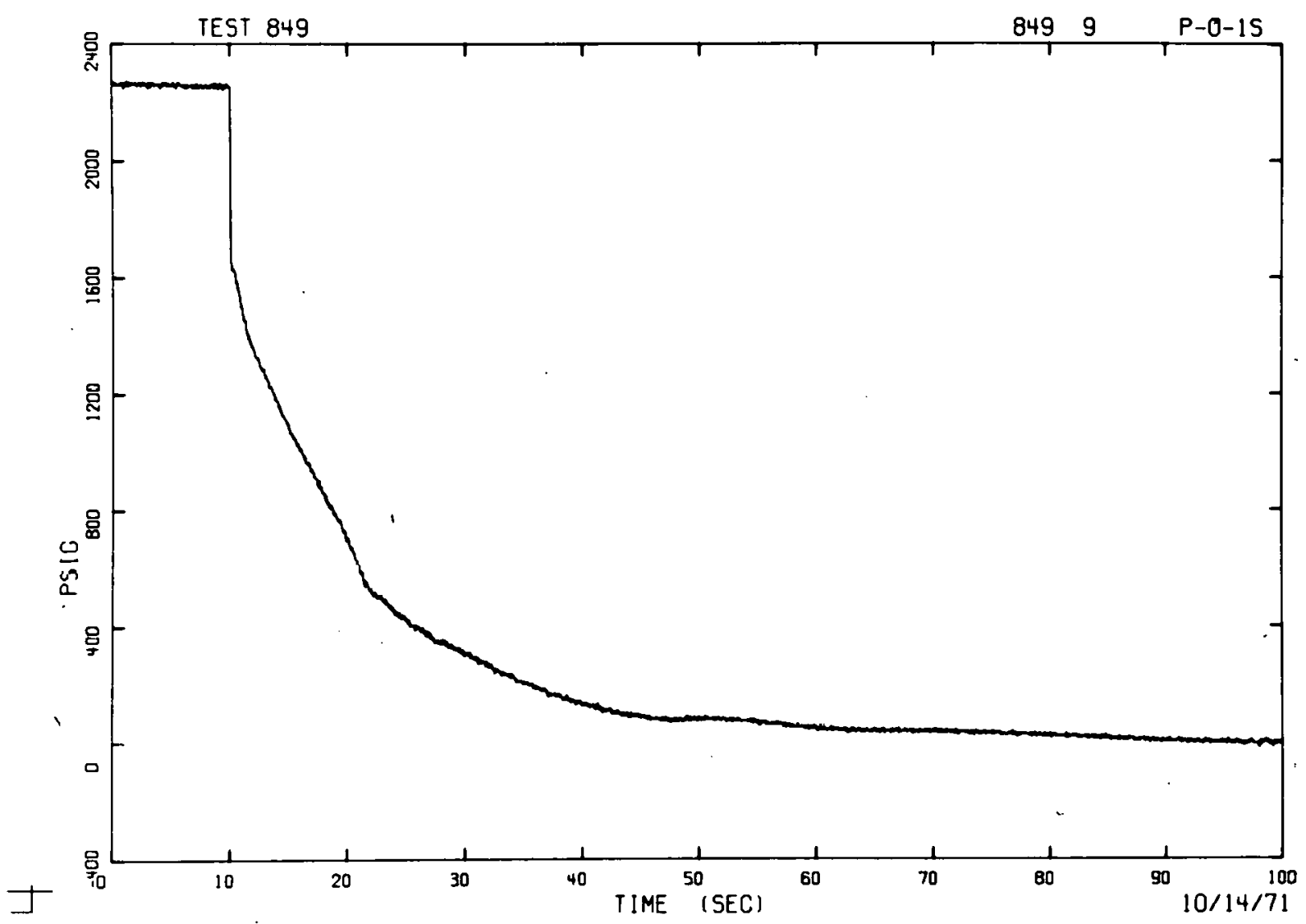

Fig. C-11 Outlet plenum pressure -- Test 849 .

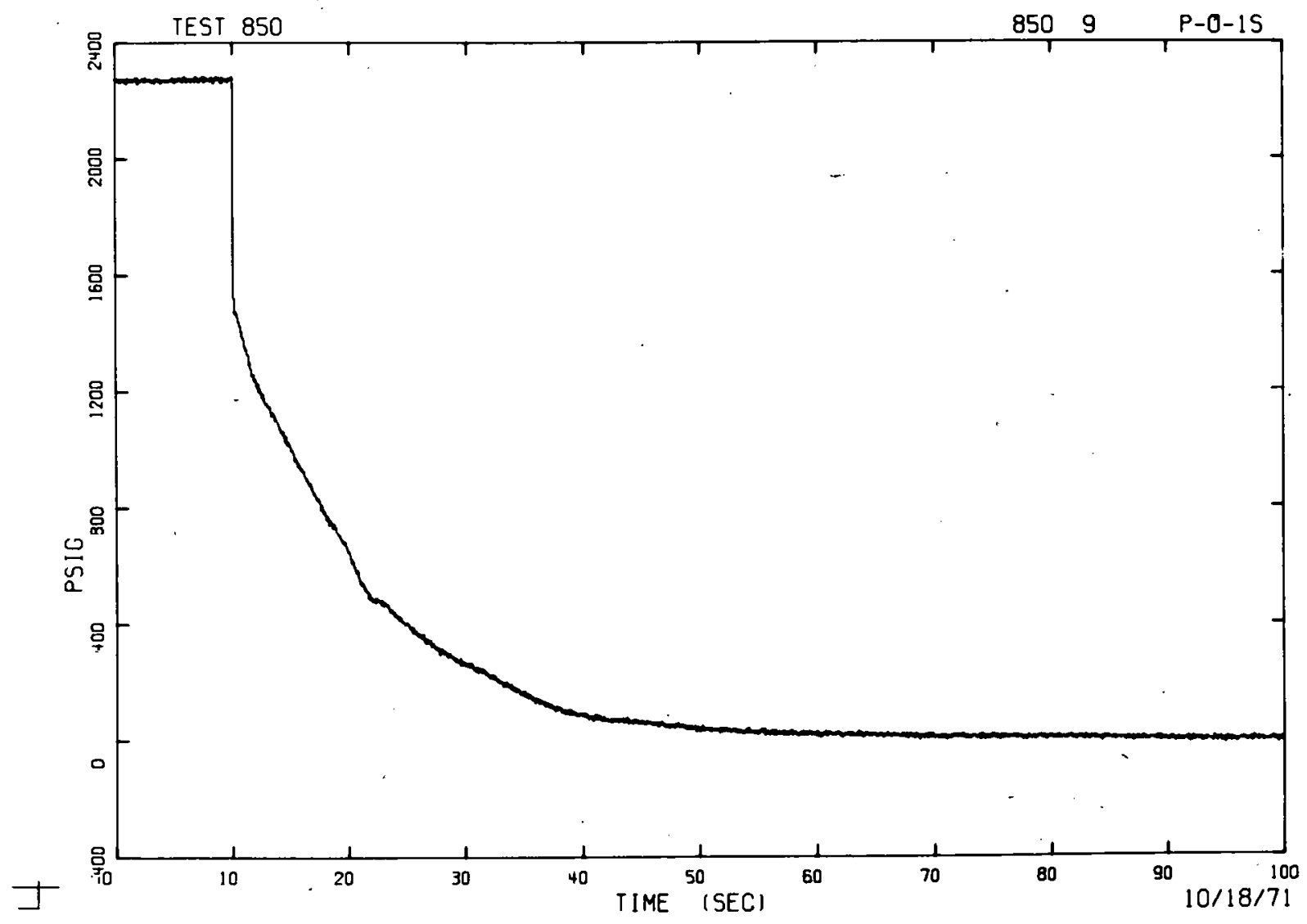

Fig. C-12 Outlet plenum pressure -- Test 850 . 


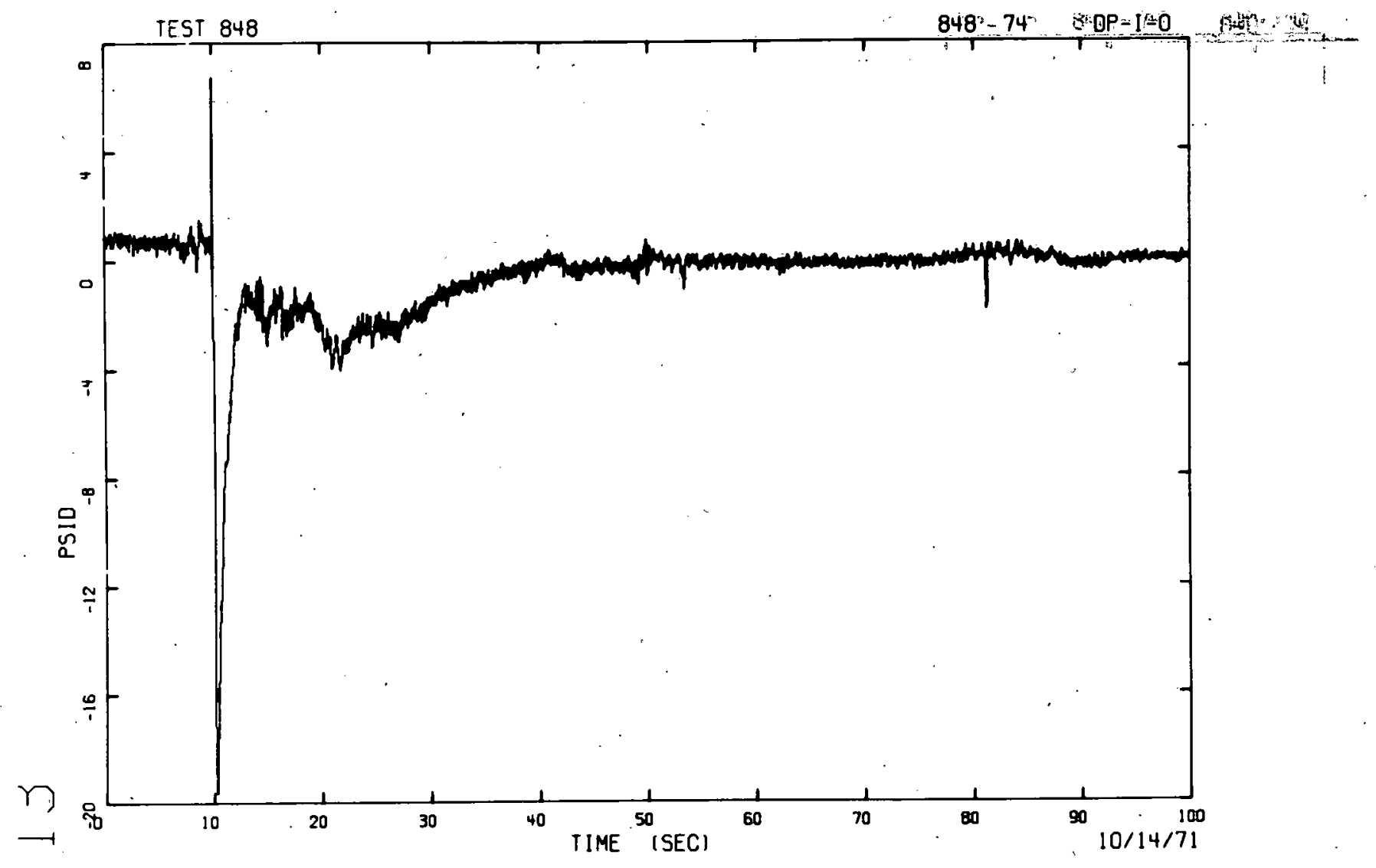

Fig. C-13 Differential pressure -- Inlet to outlet plenum -- Test 848.

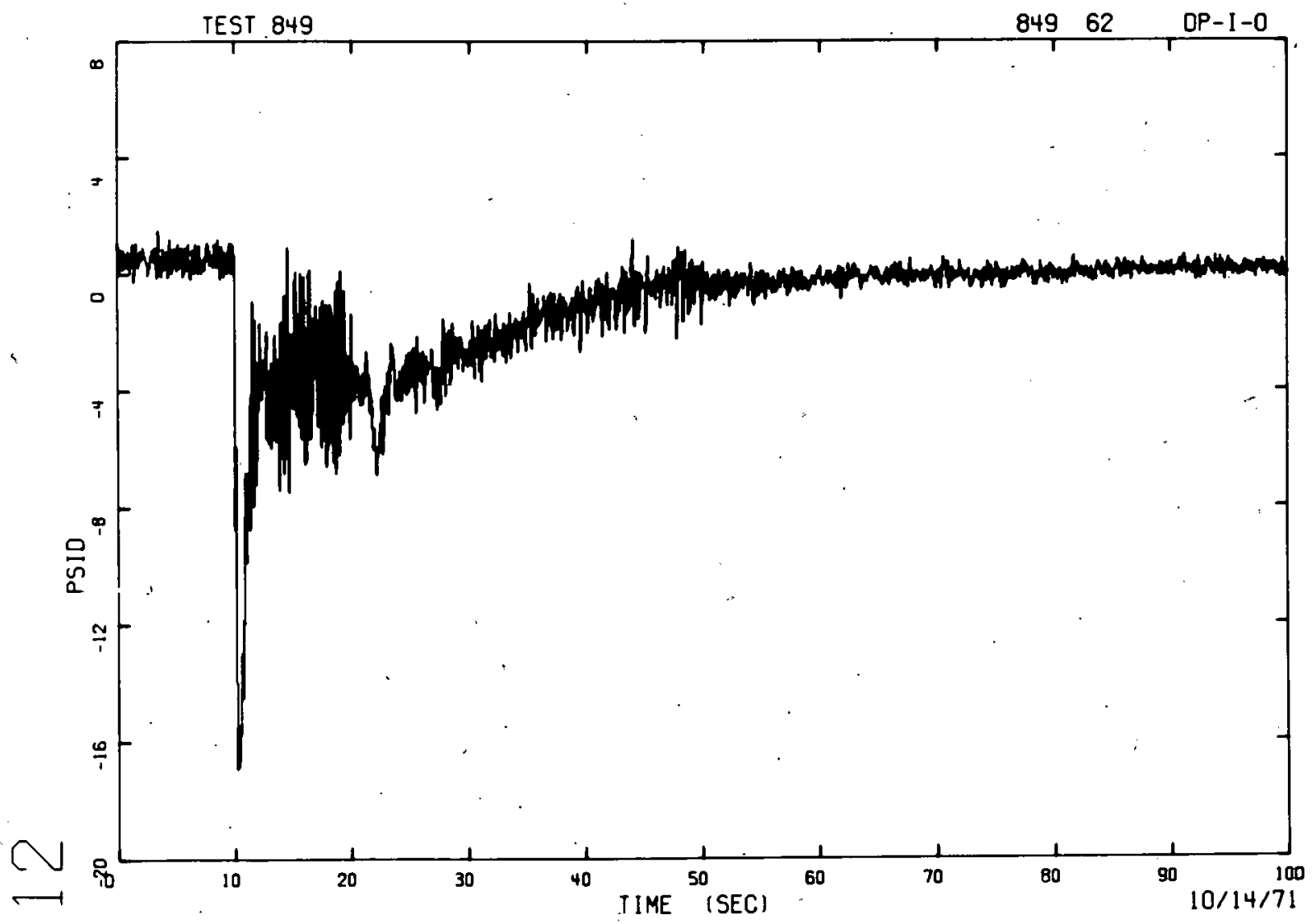

Fig. C-14 Differentlal pressure -- inlet to outlet plenum -- Test 849. 


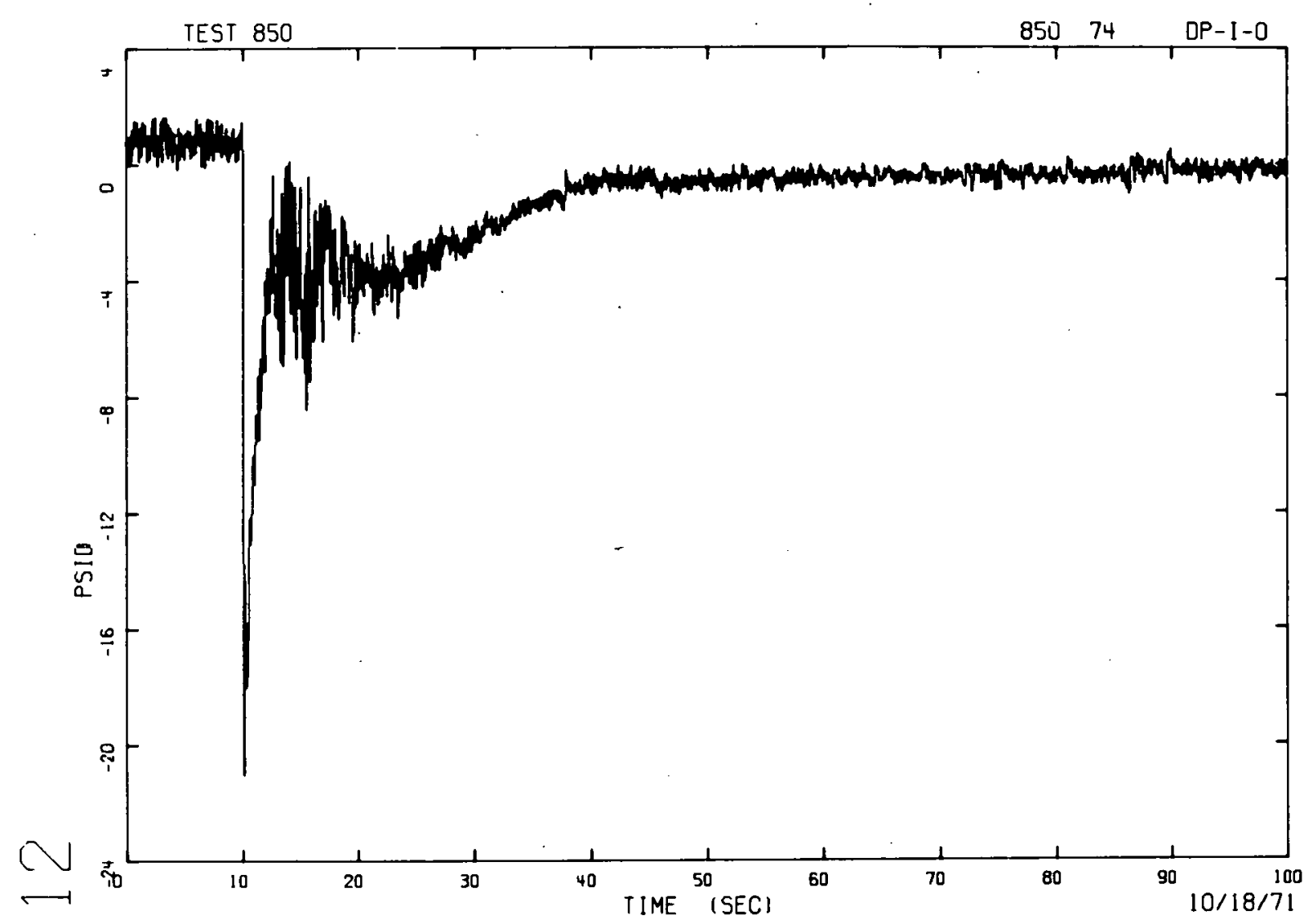

Fig. C-15 Differential pressure -- Inlet to outlet plenum -- Test 850.

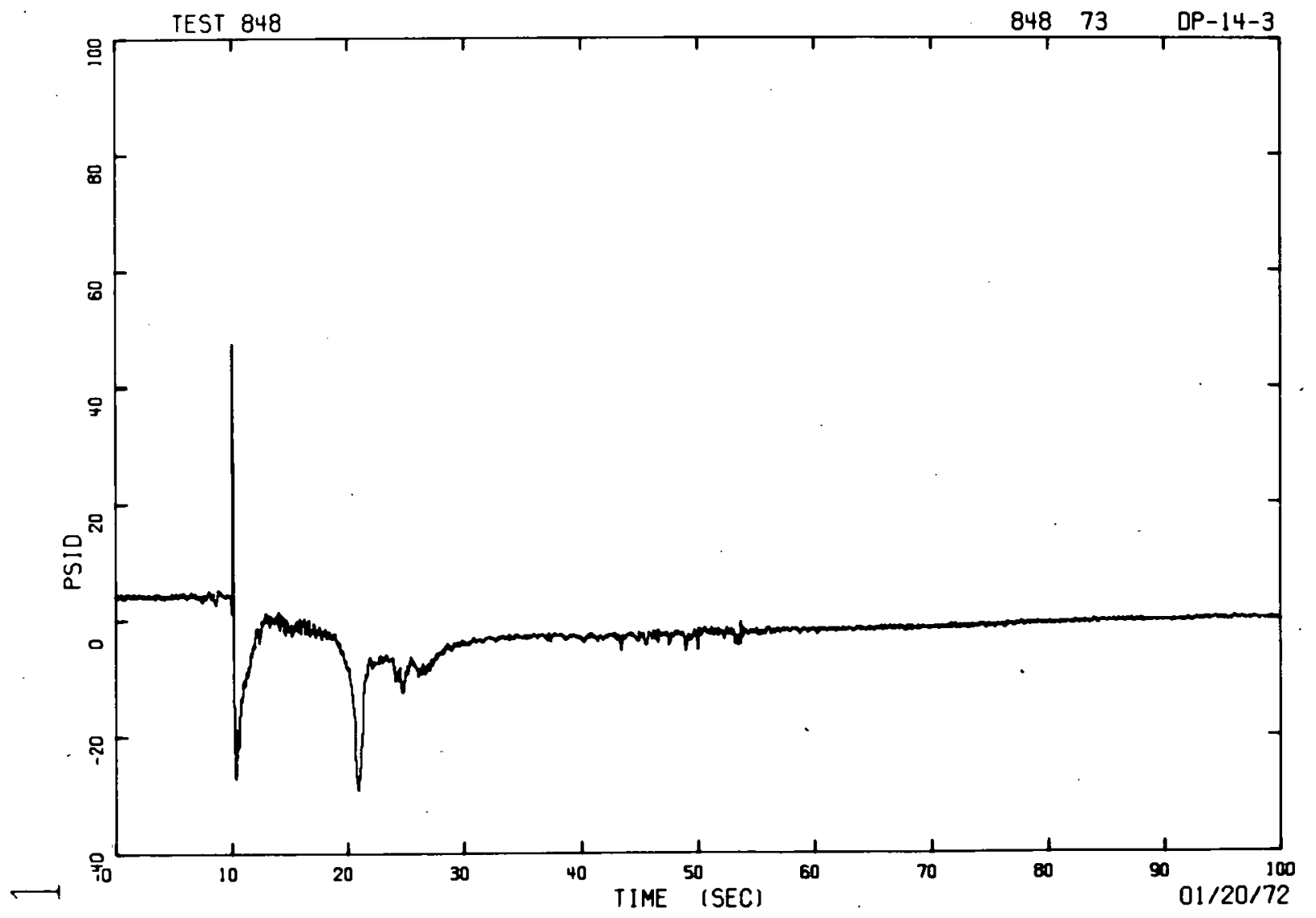

Fig. C-16 Differentlal pressure across the vesse1 -- Test 848 . 

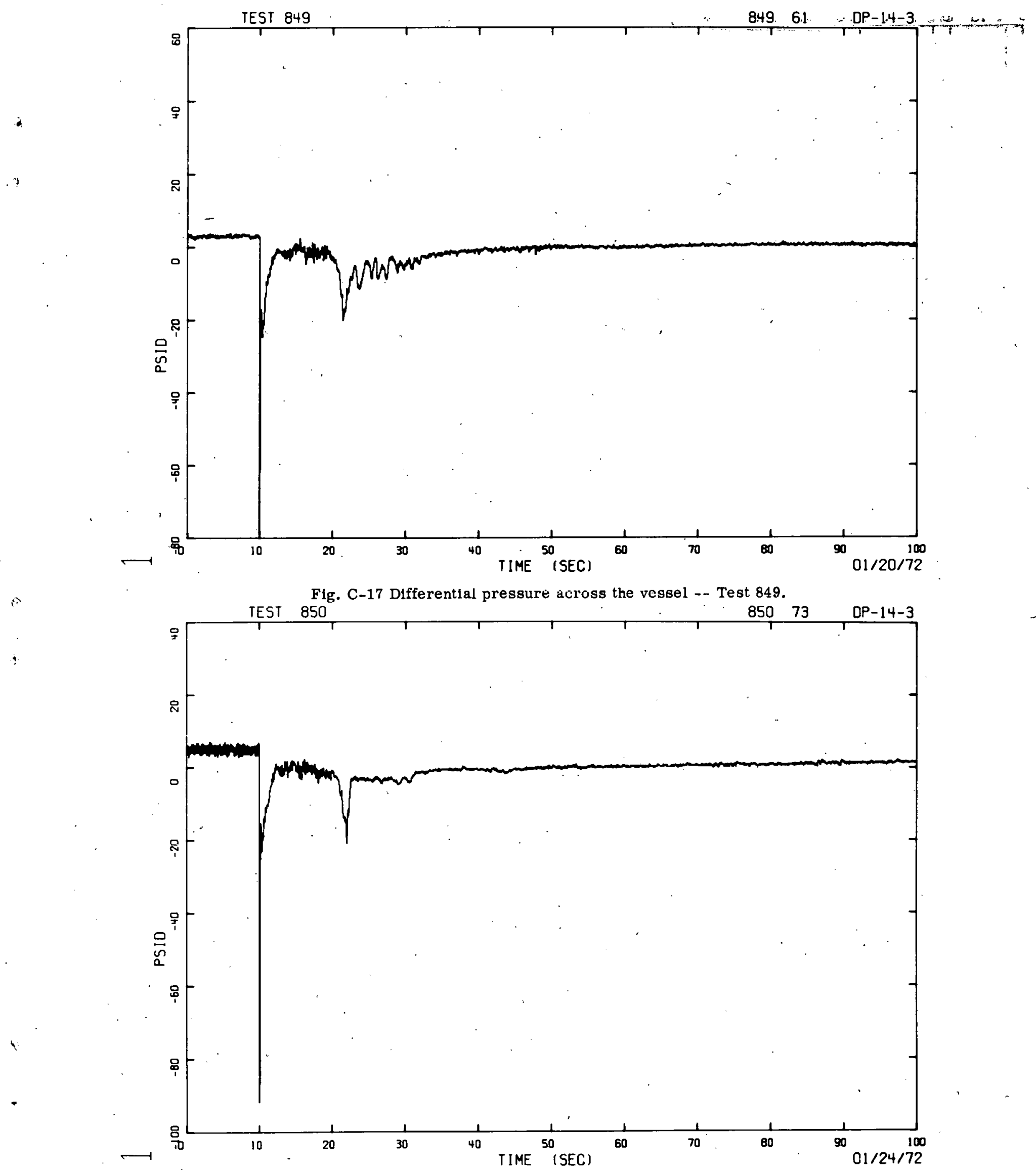

Fig. C-18 Different1al pressure across the vessel -- Test 850 . 


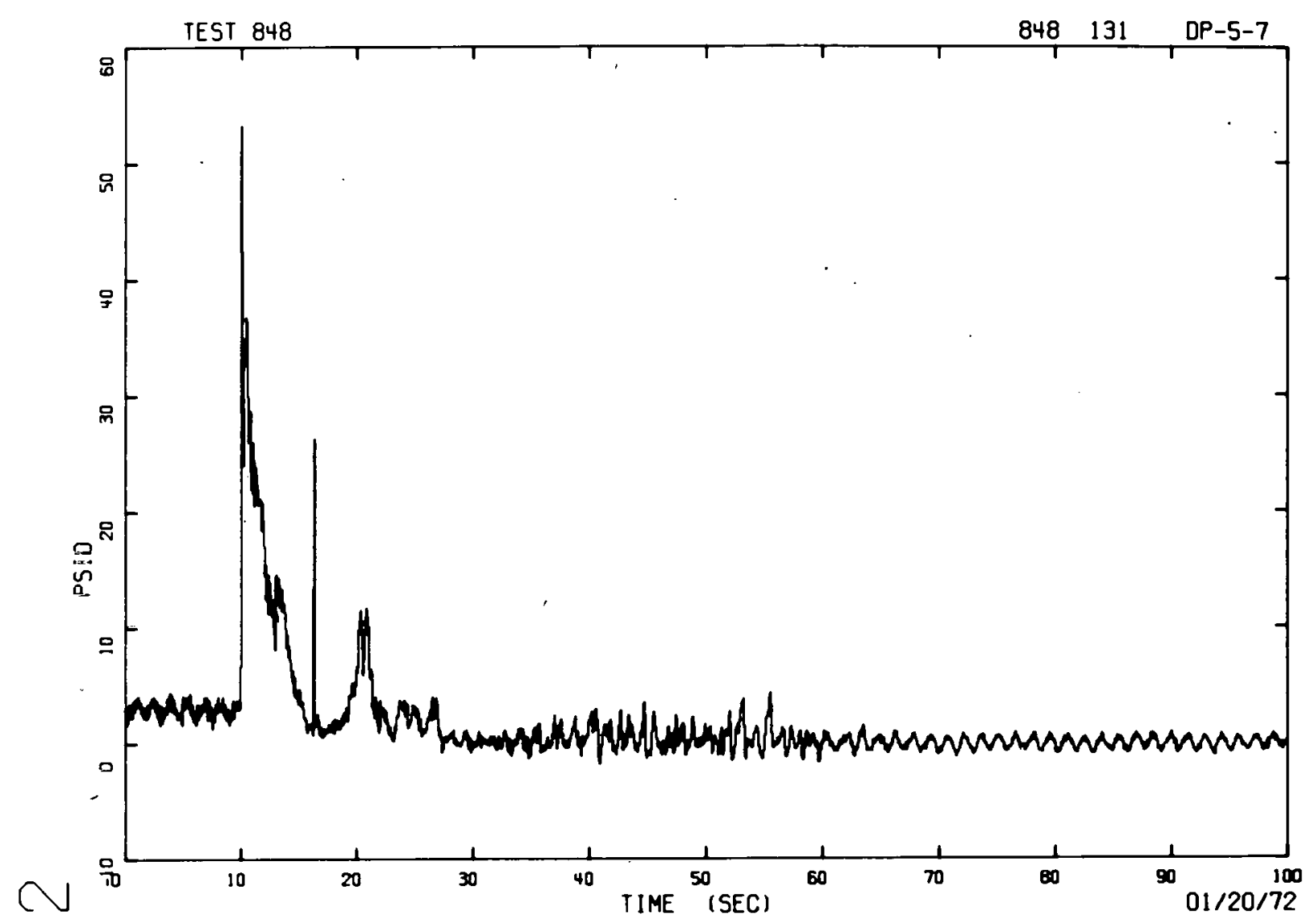

Fig. C-19.Differential pressure across the steam generator -- Test 848 .

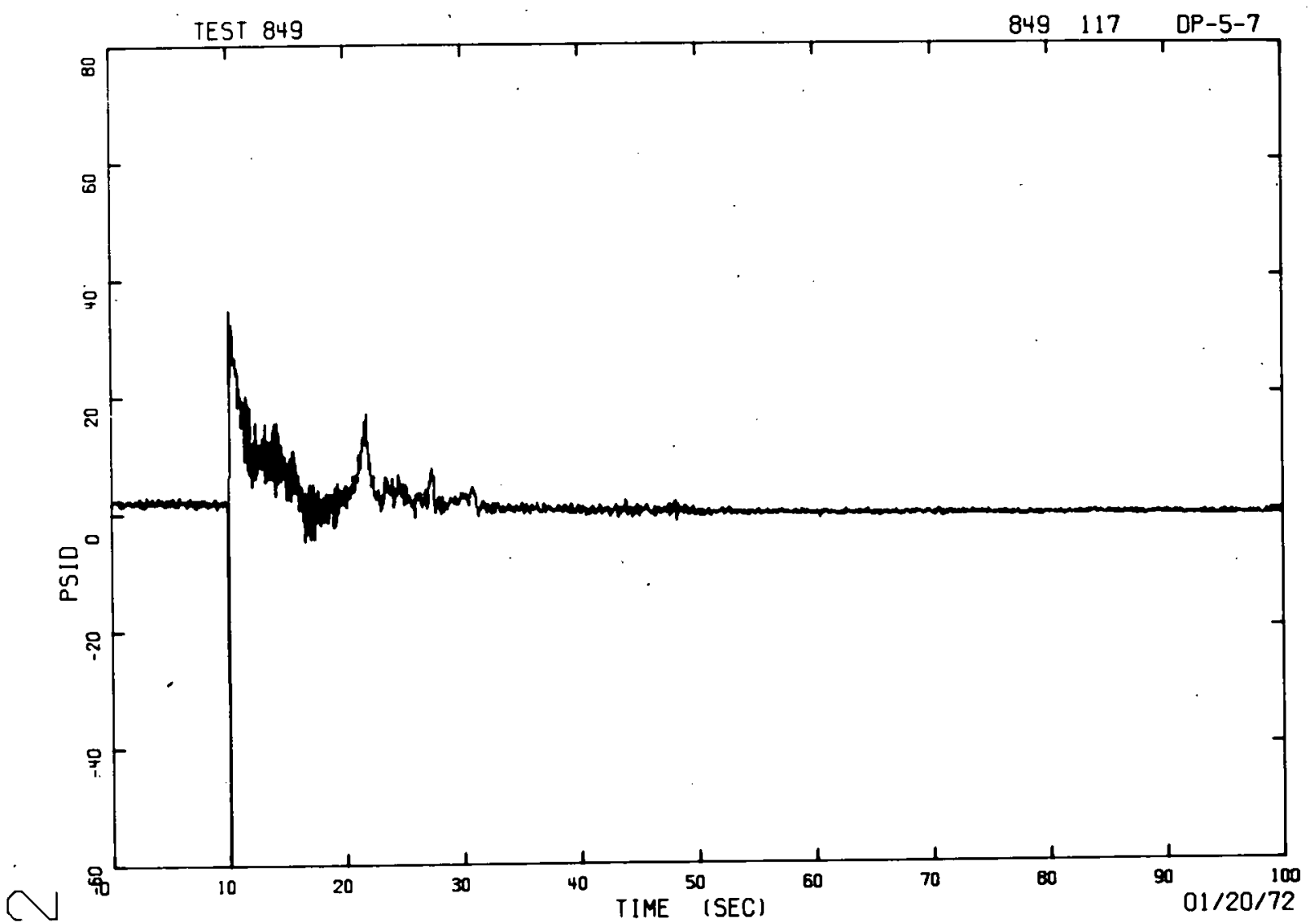

Fig. C-20 Differential pressure across the steam generator -- Test 849. 

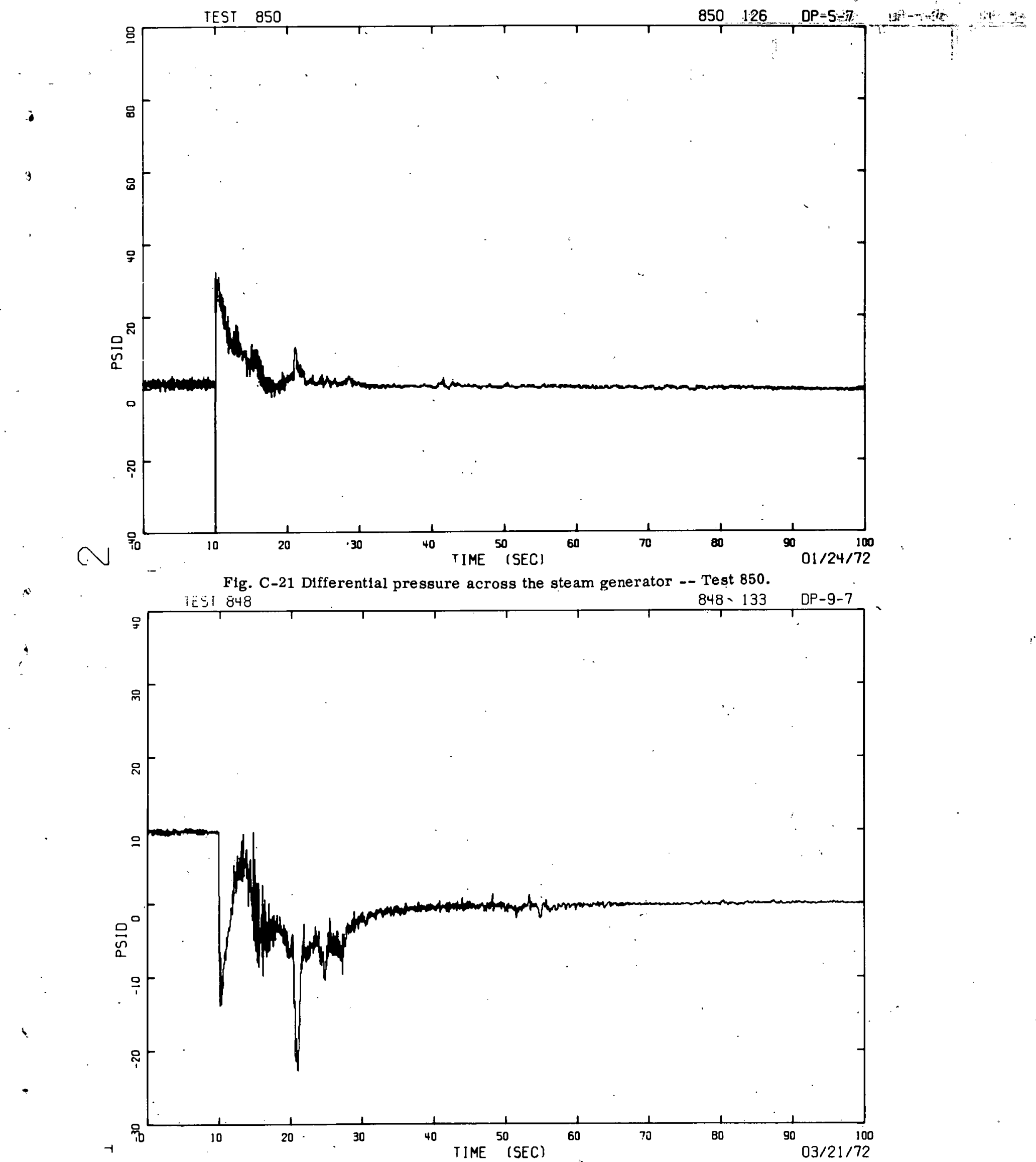

Fig. C-22 Pump differential pressure -- Test 848. 


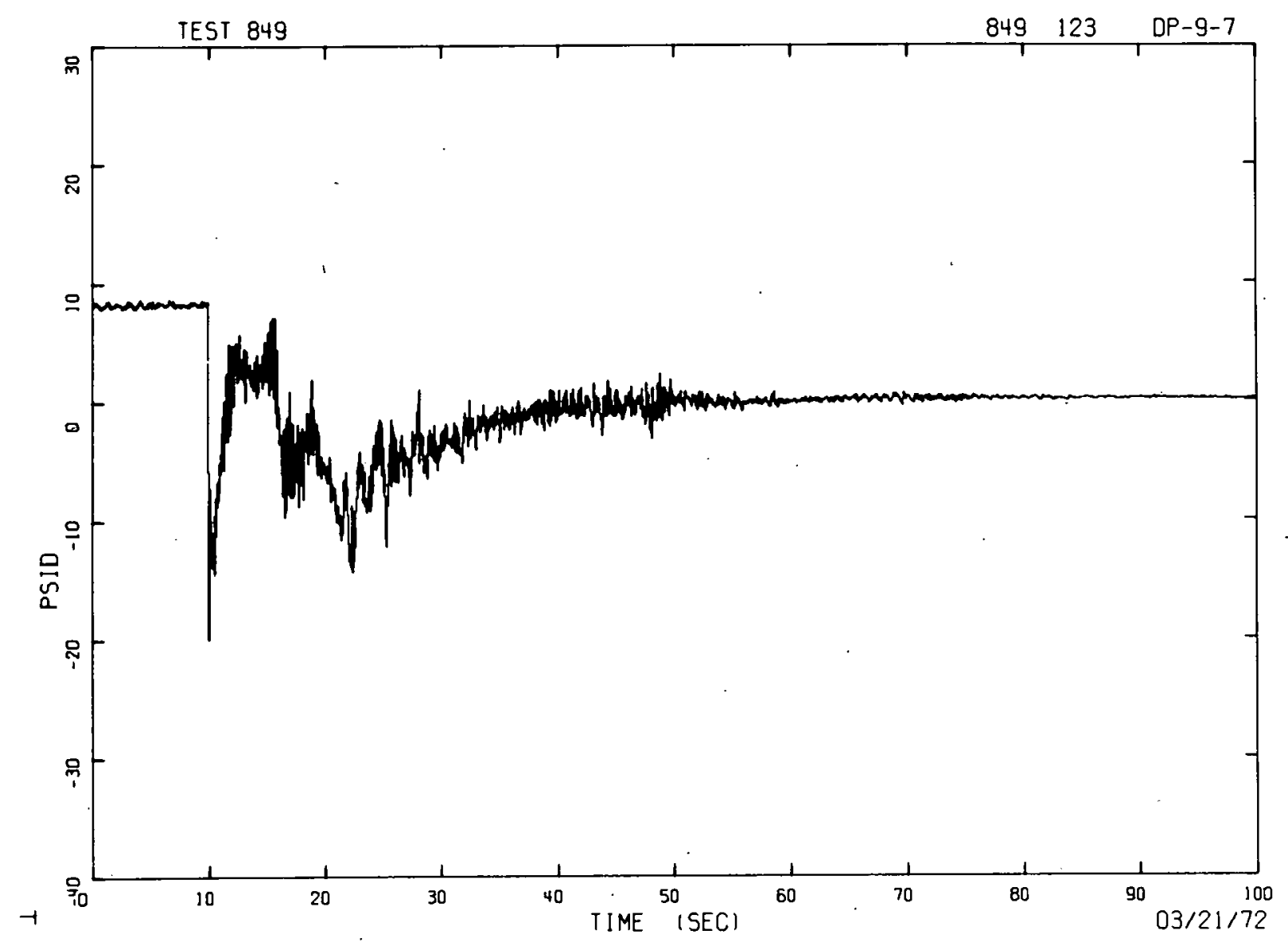

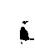

so

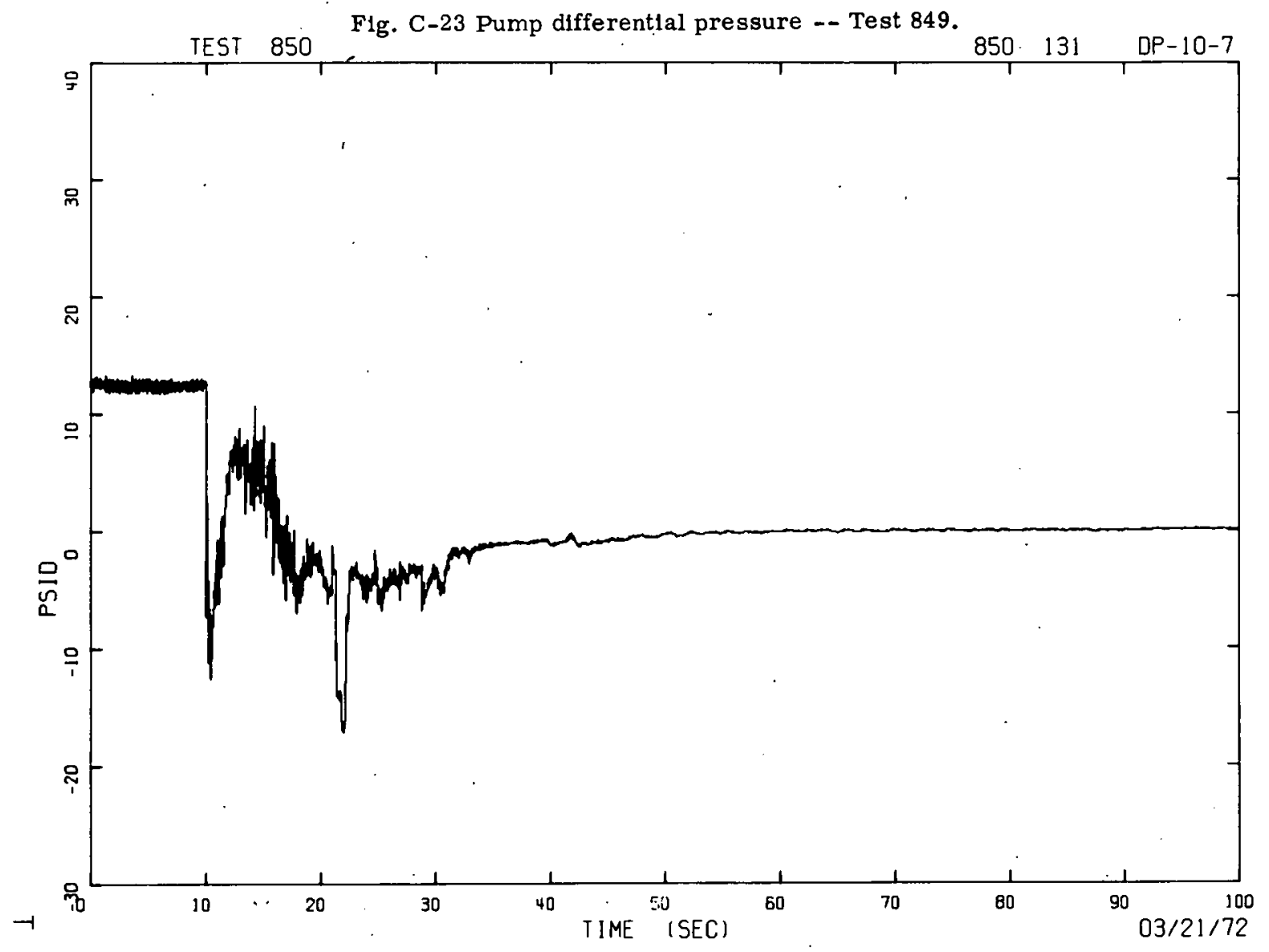

Fig. C-24 Pump differential pressure -- Test 850. 
3

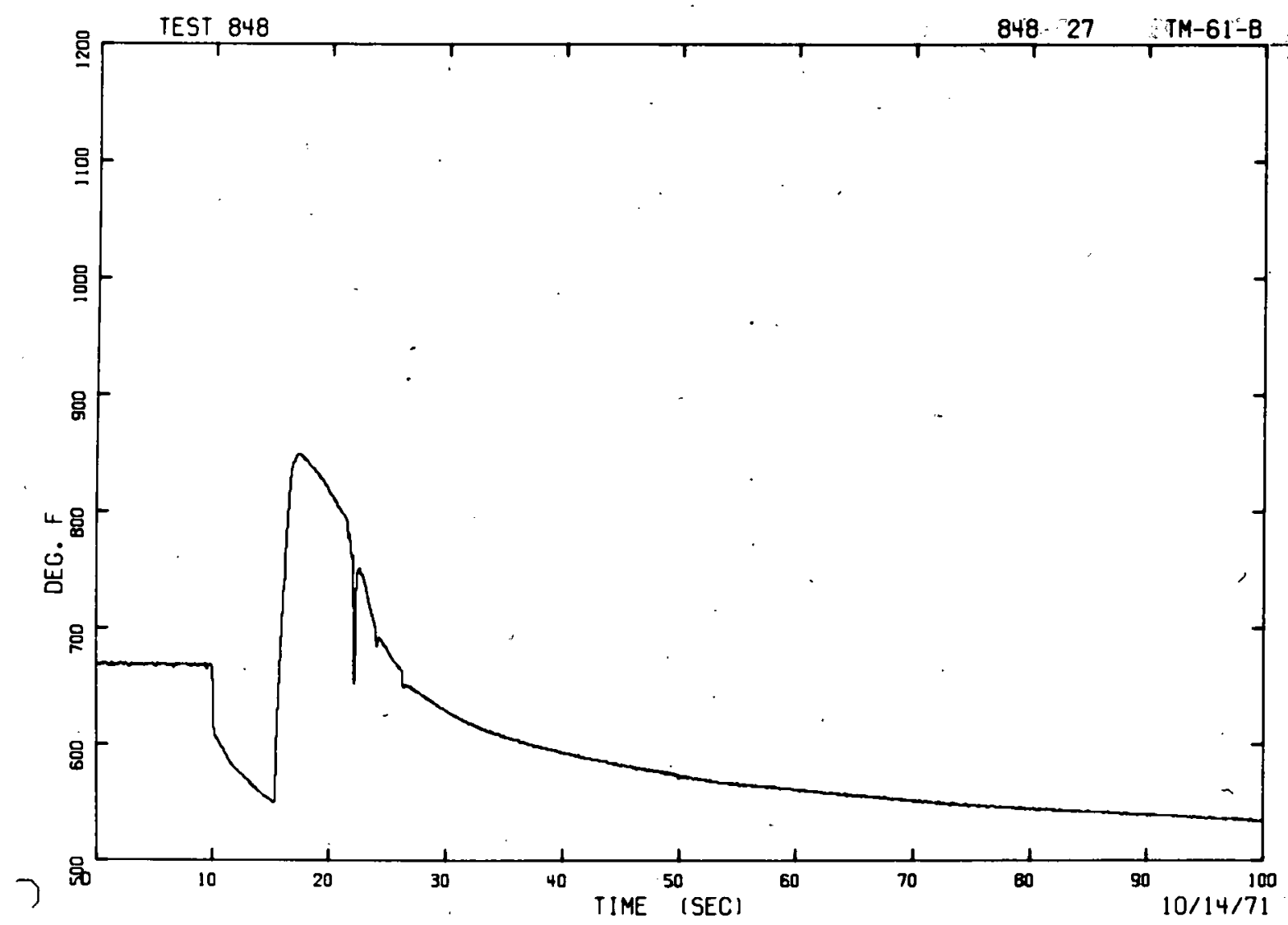

Fig. C-25 Cladding temperature of the center pin - bottom -- Test 848.

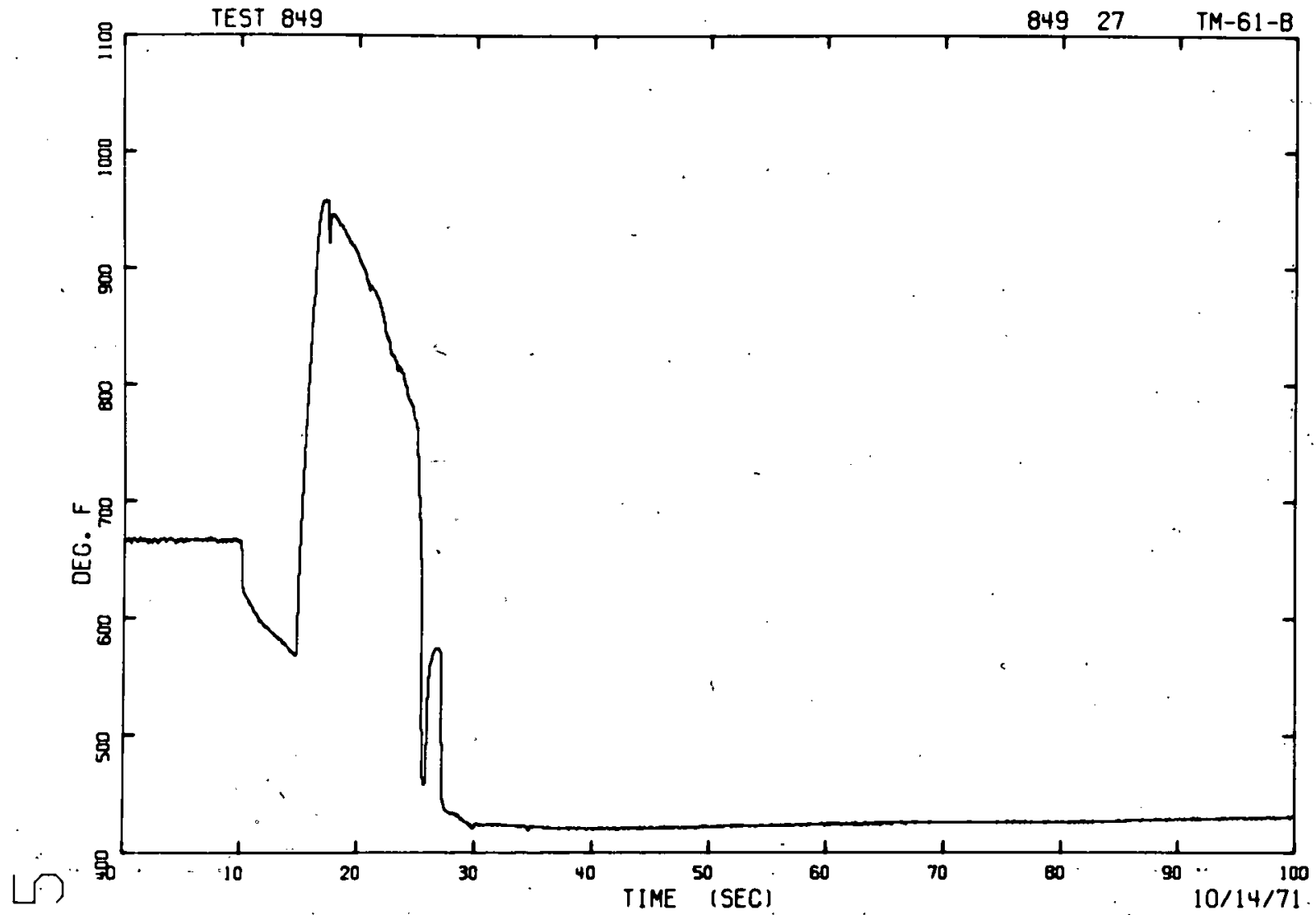

Fig. C-26 Cladding temperature of the center pin - bottom -- Test 849. 


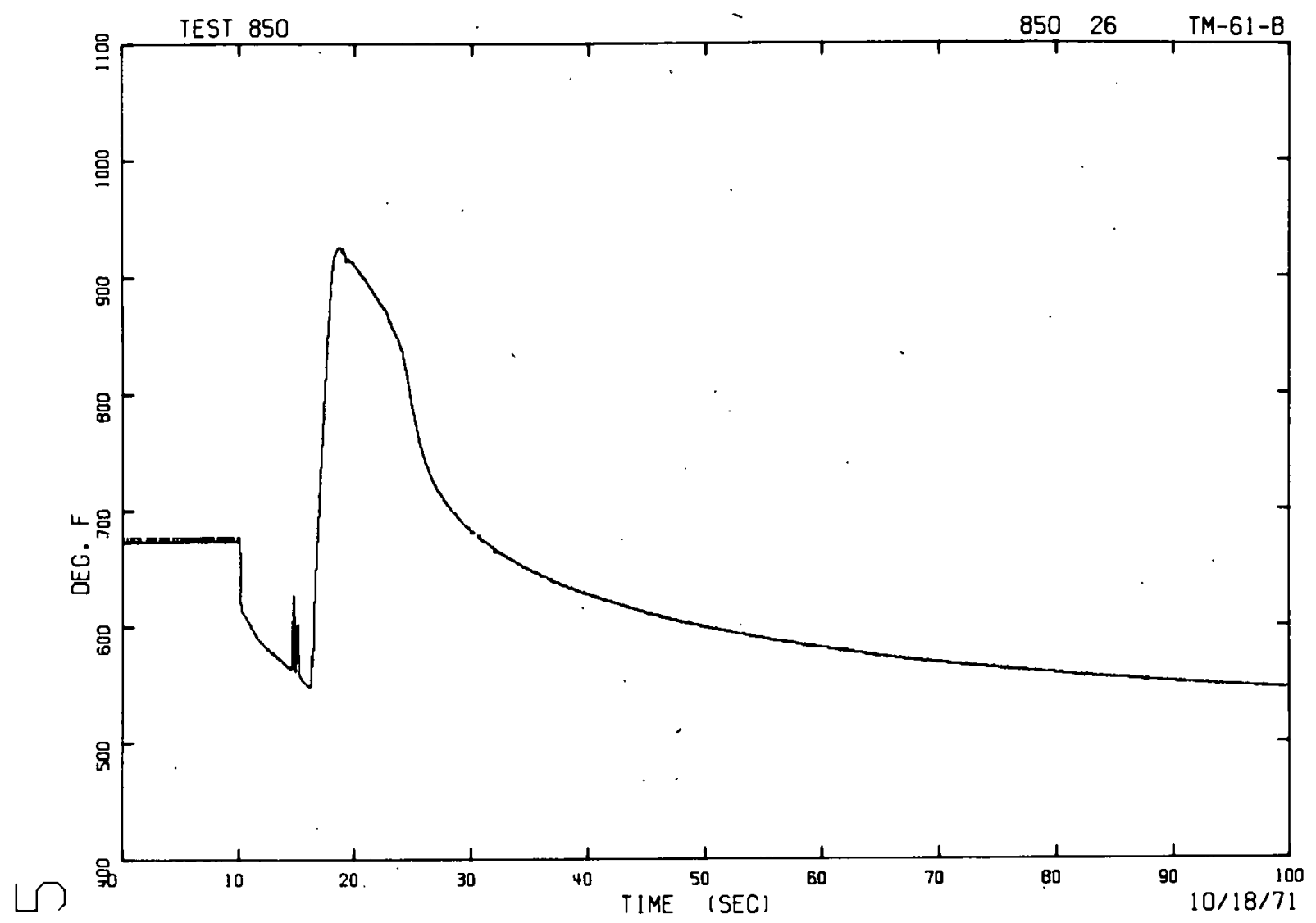

Fig. C-27 Cladding temperature of the center pin - bottom -- Test 850.

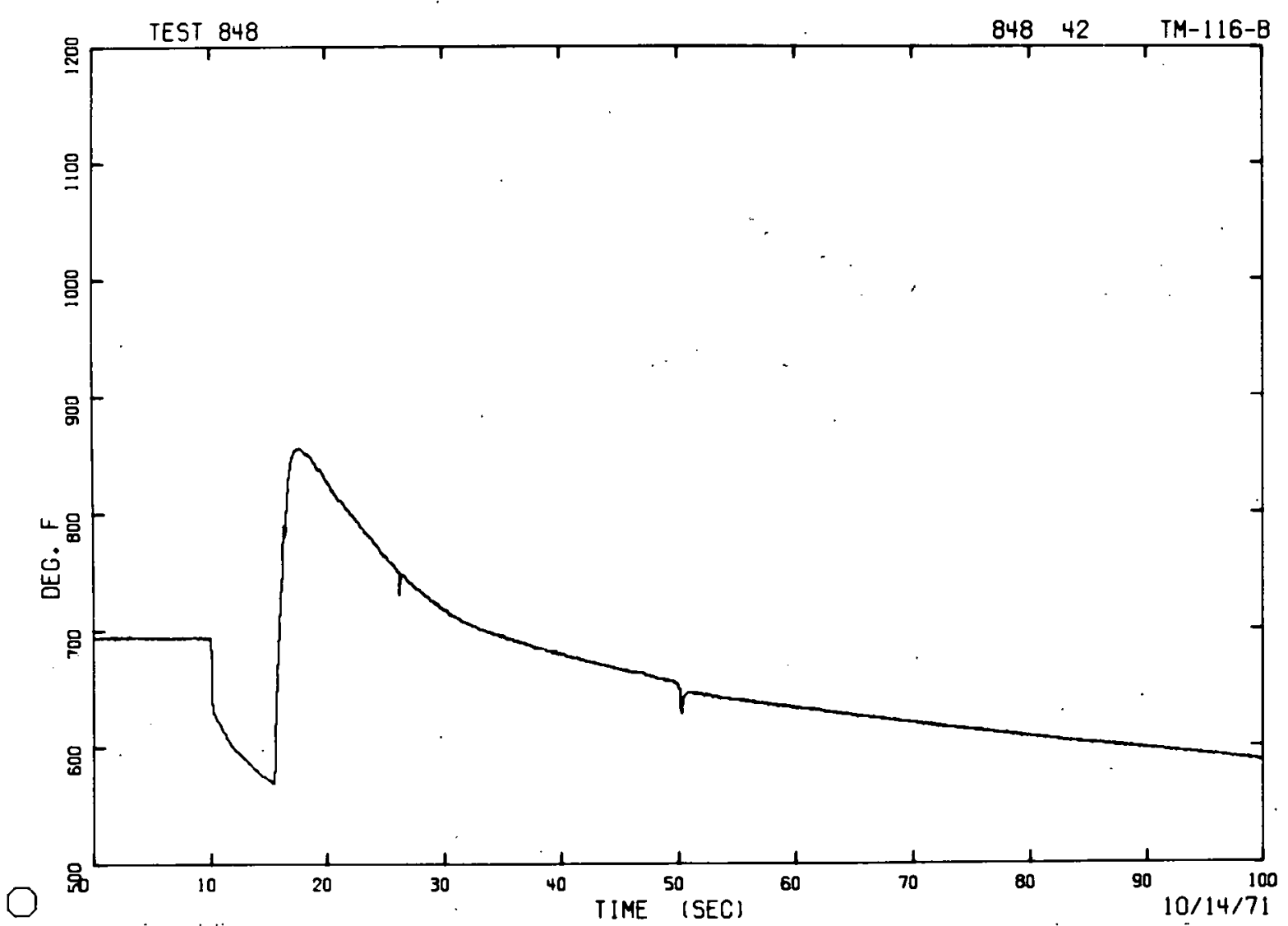

Fig. C-28 Cladding temperature of an outside pin - bottom -- Test 848 . 


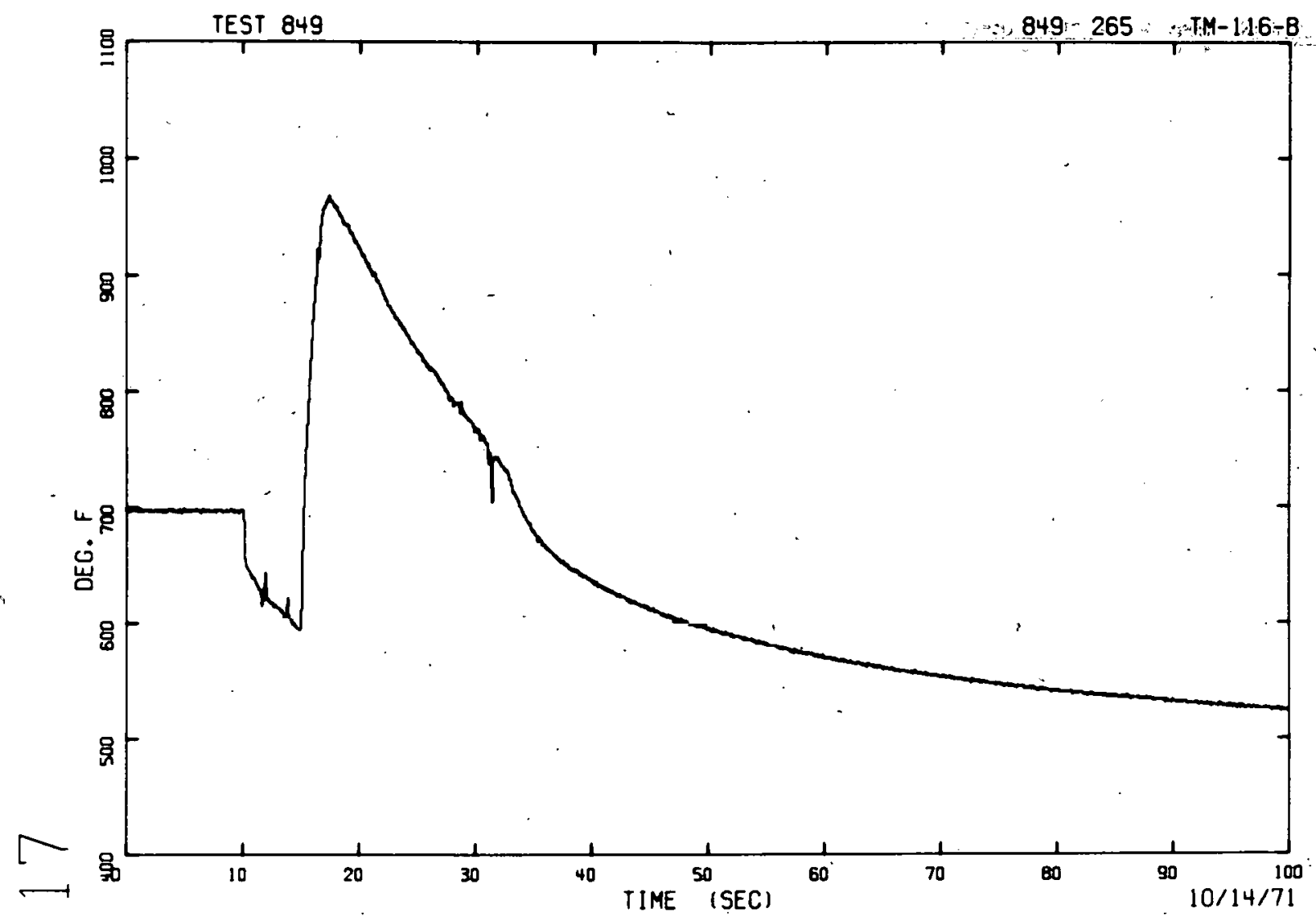

Fig. C-29 Cladding temperature of an outside pin - bottom -- Test 849.

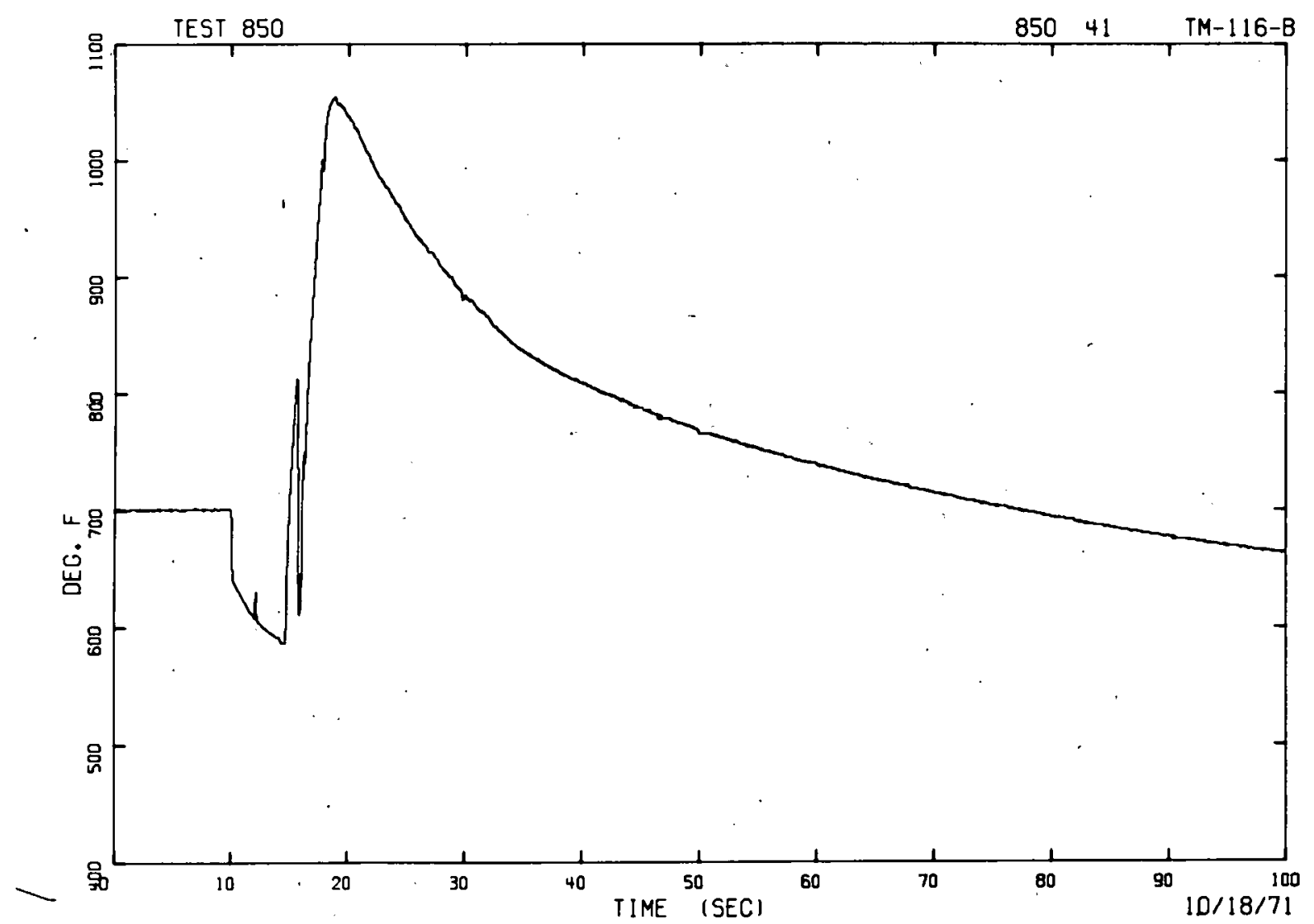

Fig. C-30 Cladding temperature of an outside pin - bottom -- Test 850 . 


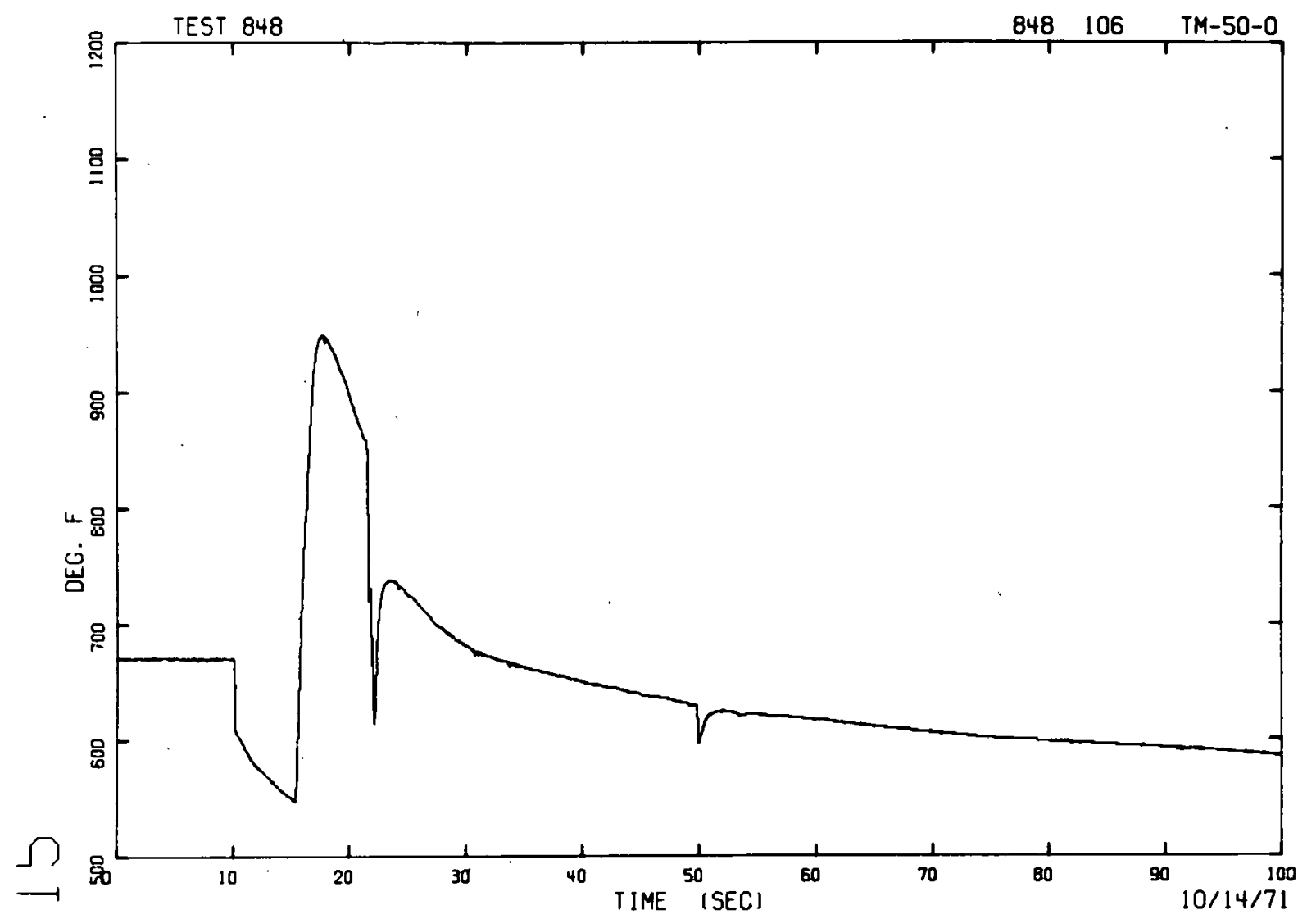

Fig. C-31 Cladding temperature of an inside pin - midplane -- Test 848.

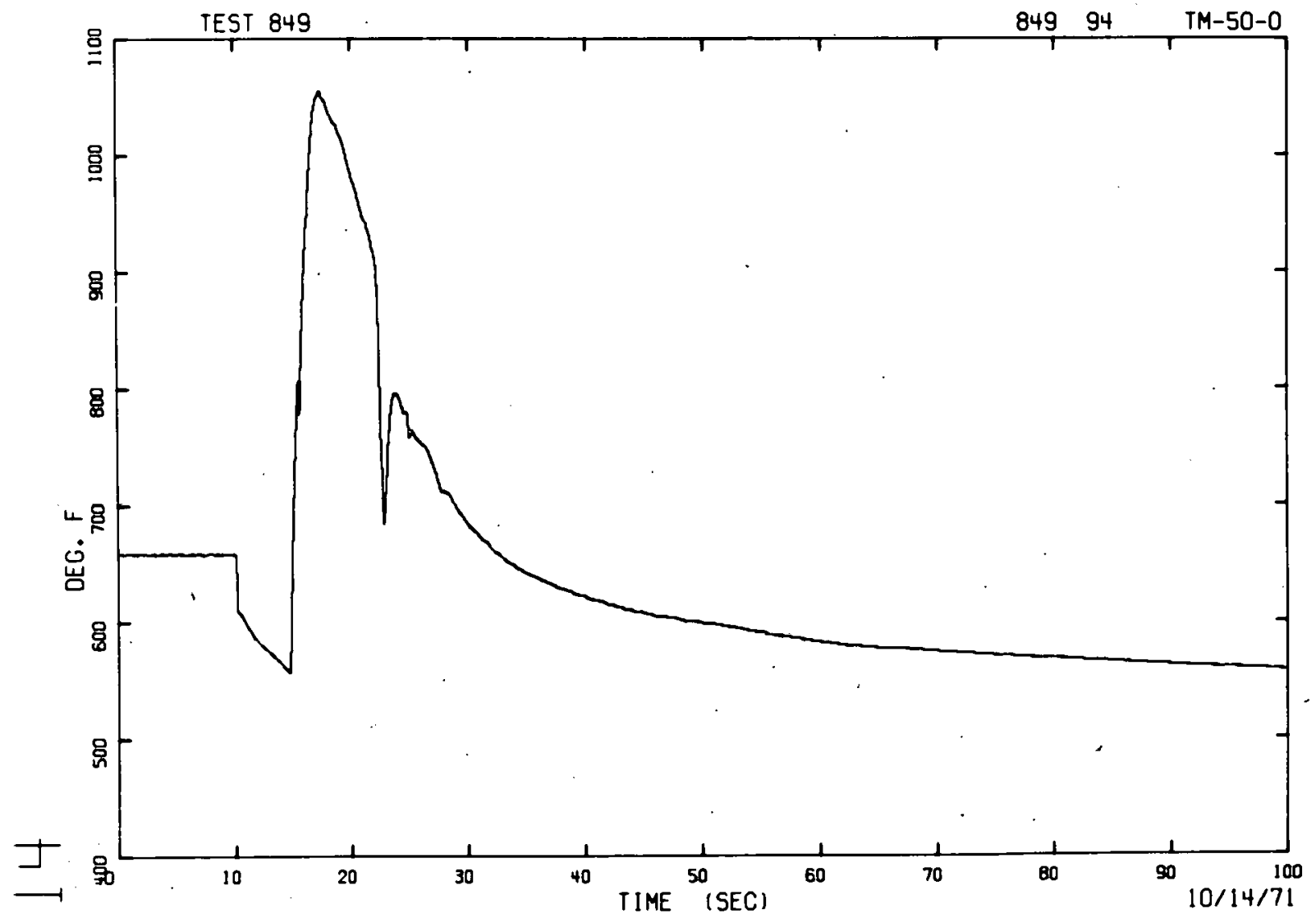

Fig. C-32 Cladding temperature of an inside pin - midplane -- Test 849. 


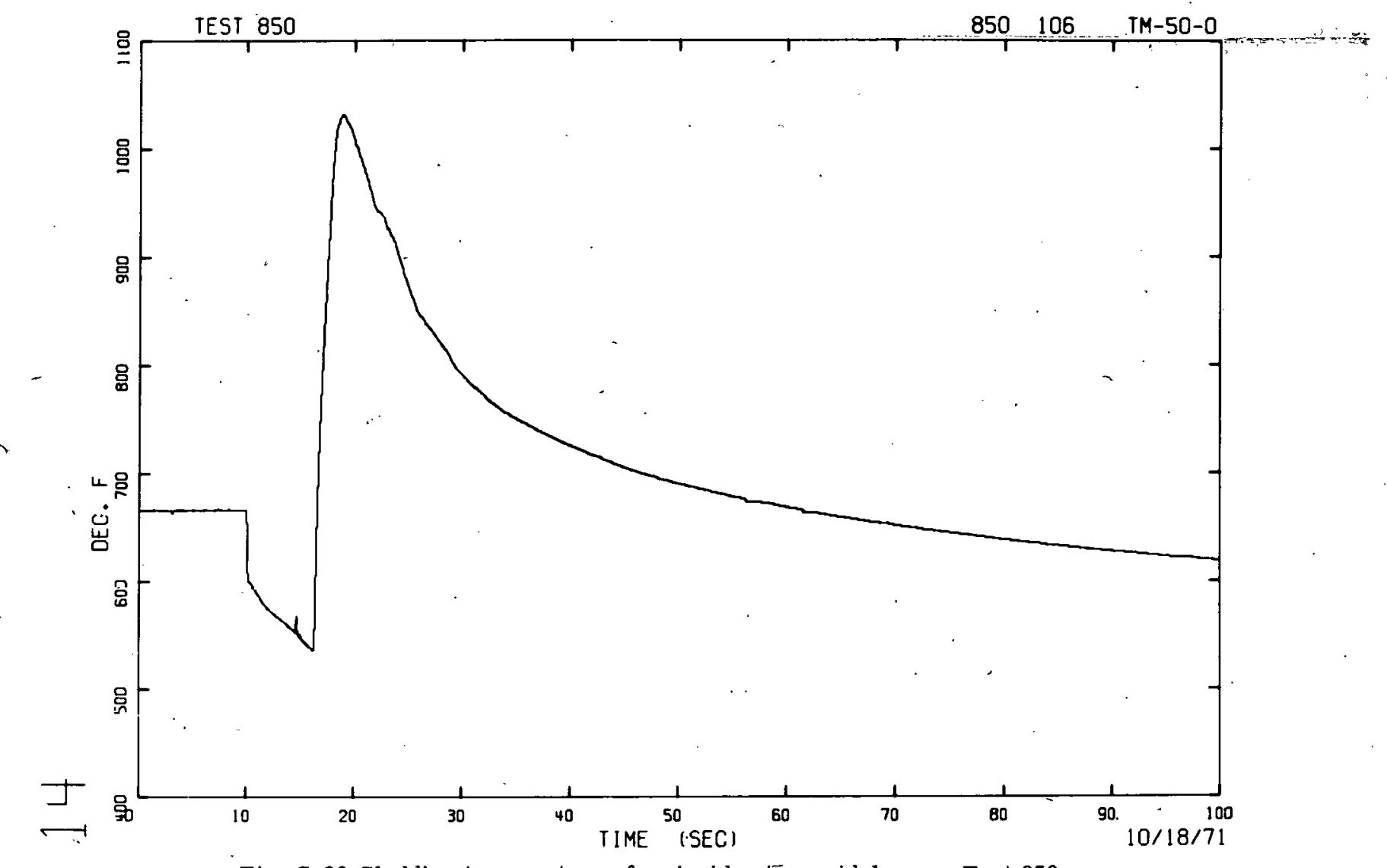

Fig. C-33 Cladding temperature of an inside pi $\bar{n}$ - midplane -- Test 850.
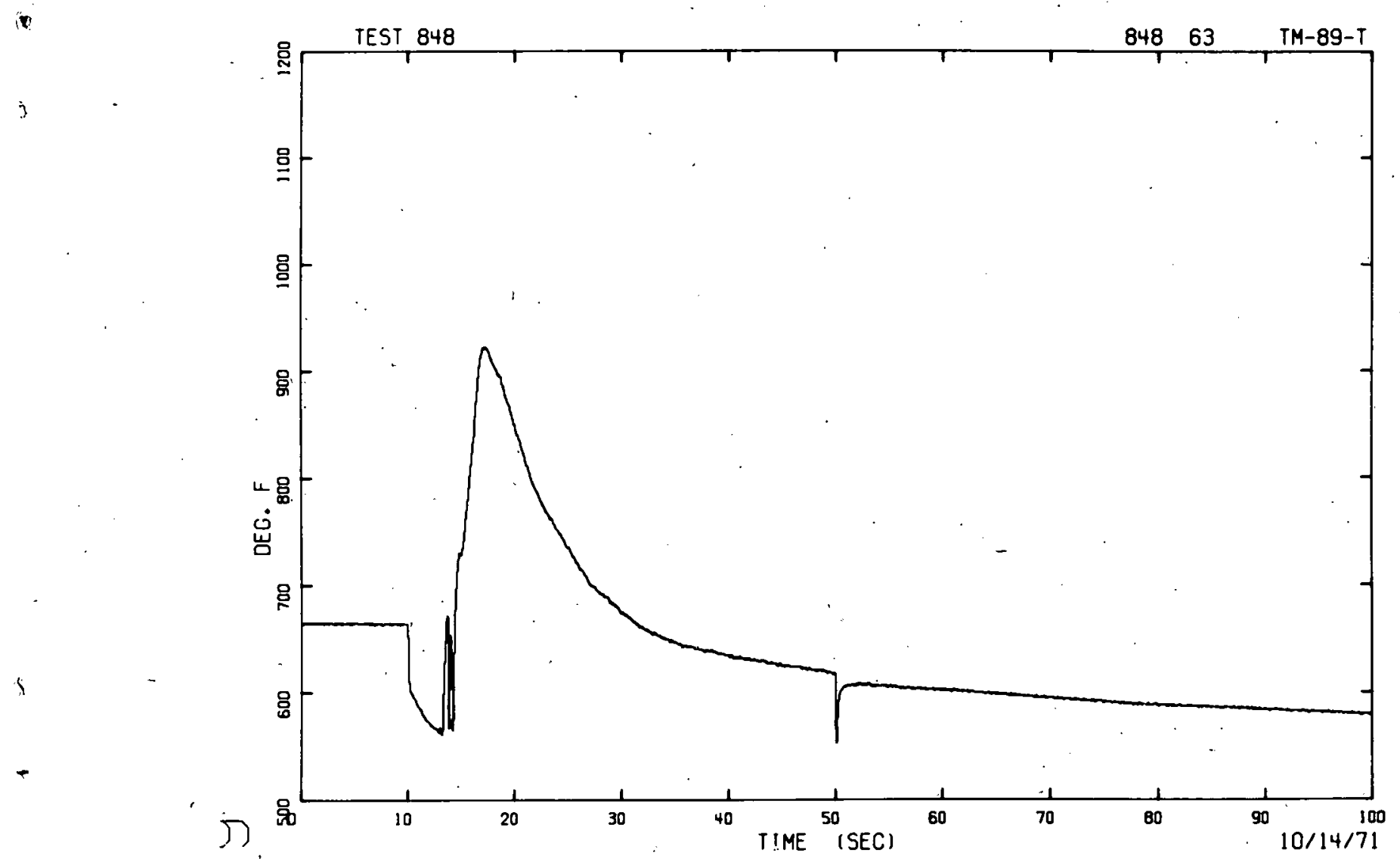

Fig. C-34 Cladding temperature of an outside pin - top -- Test 848. 


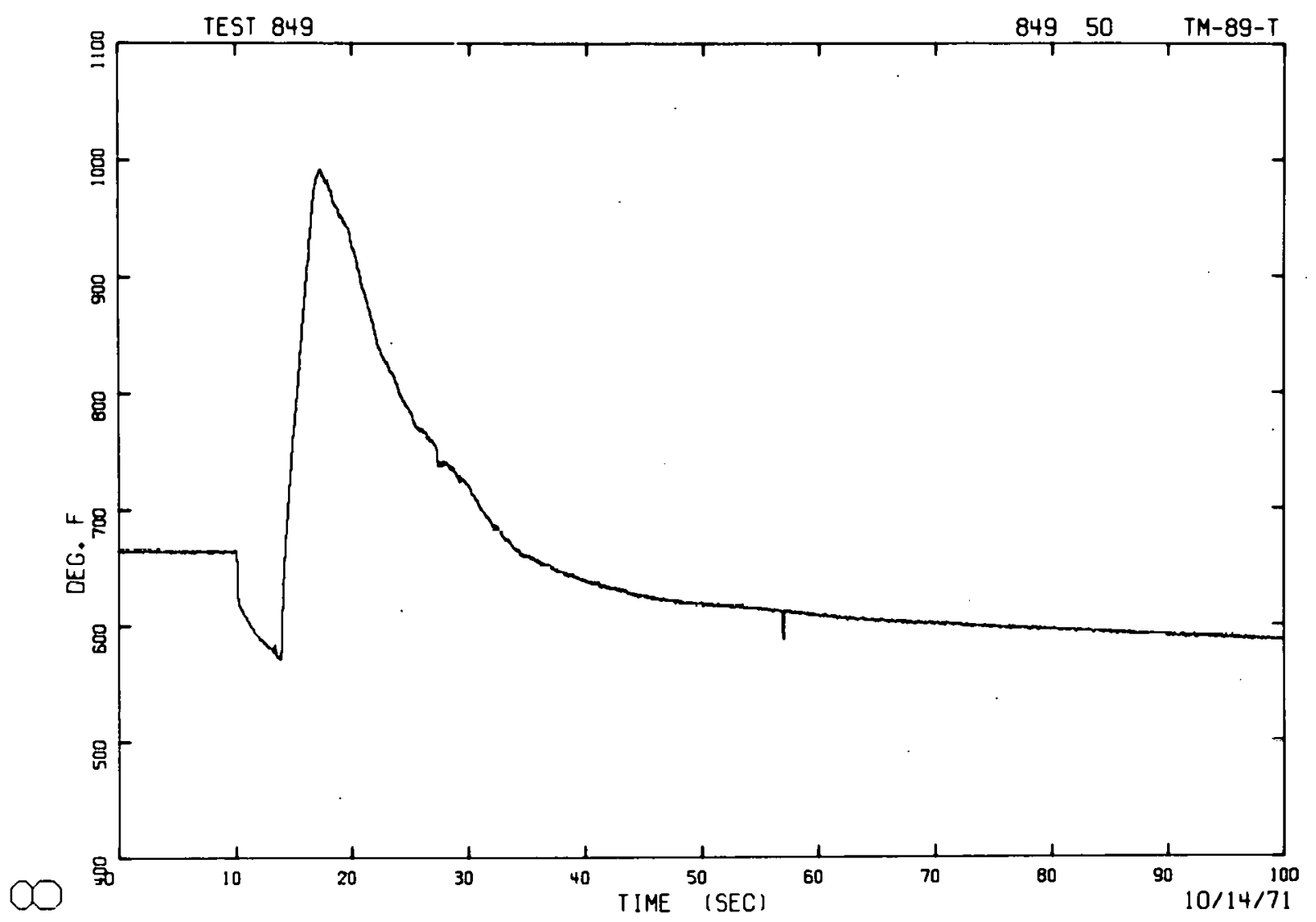

Fig. C-35.Cladding temperature of an outside pin - top -- Test 849.

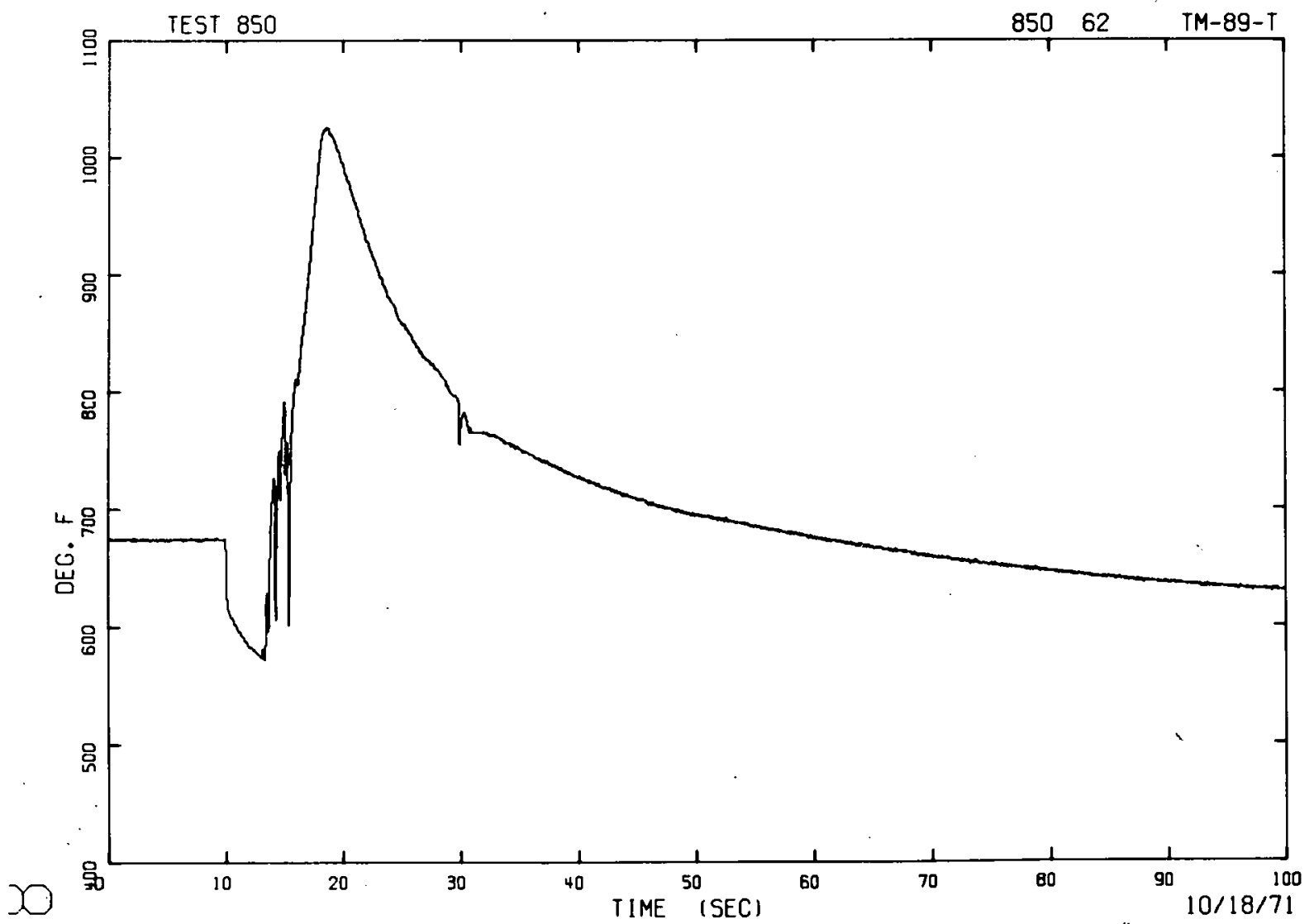

Fig. C-36 Cladding temperature of an outside pin - top -- Test 850 . 


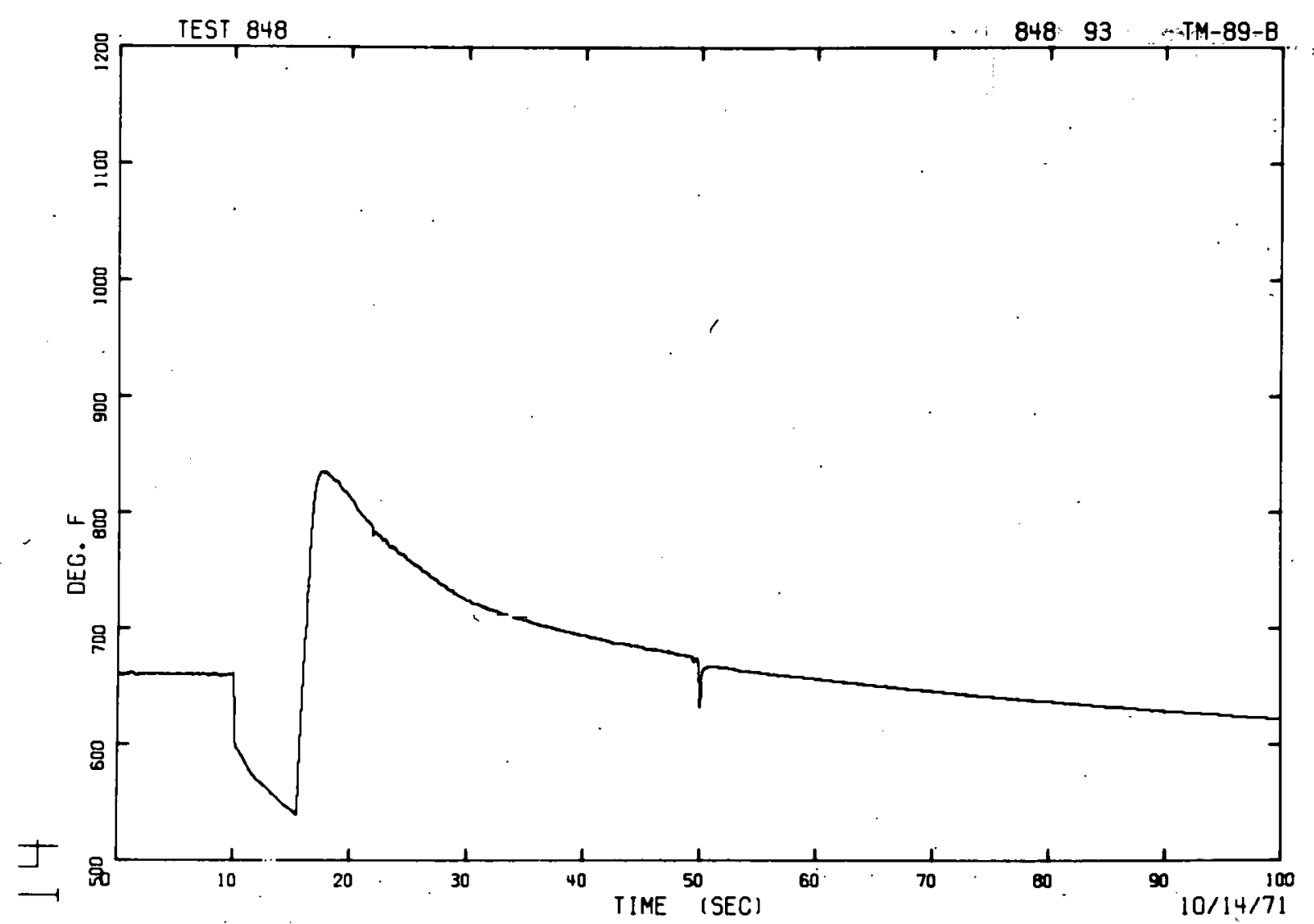

Fig. C-37 Cladding temperature of an outside pin - bottom -- Test 848.

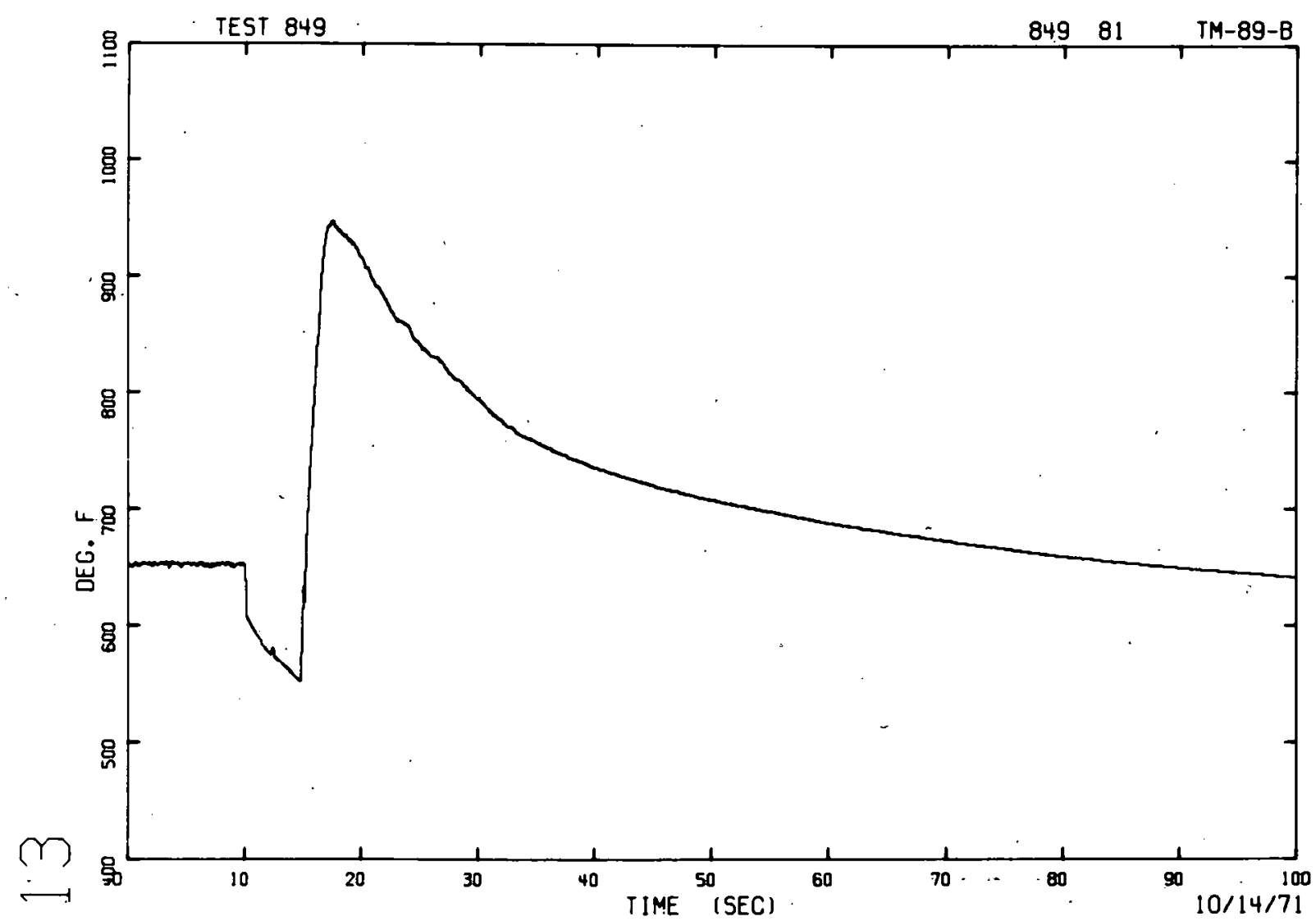

Fig. C-38 Cladding temperature of an outside pin - bottom -- Test 849 . 


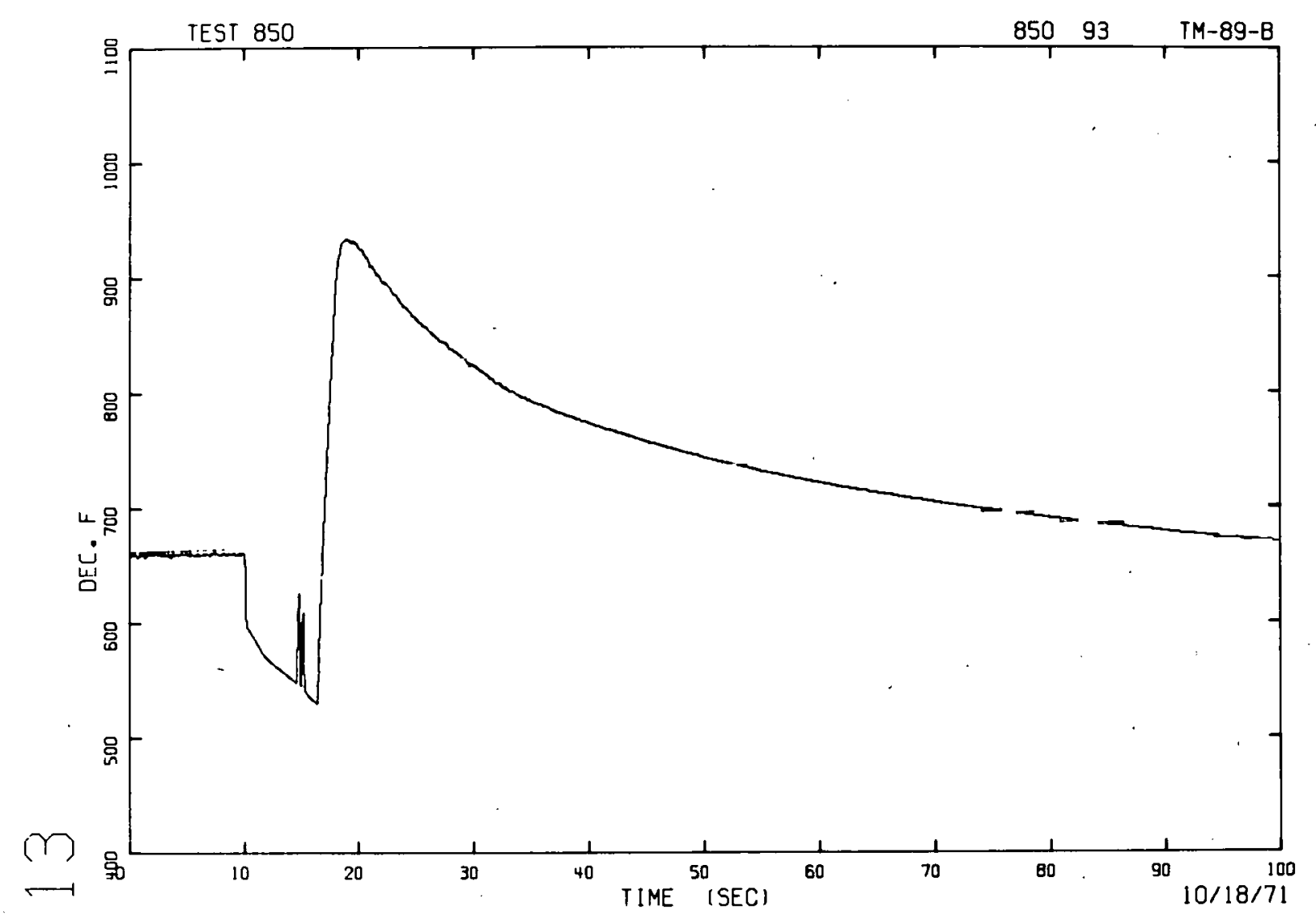

Fig. C-39 Cladding temperature of an outside pin - bottom -- Test 850 .

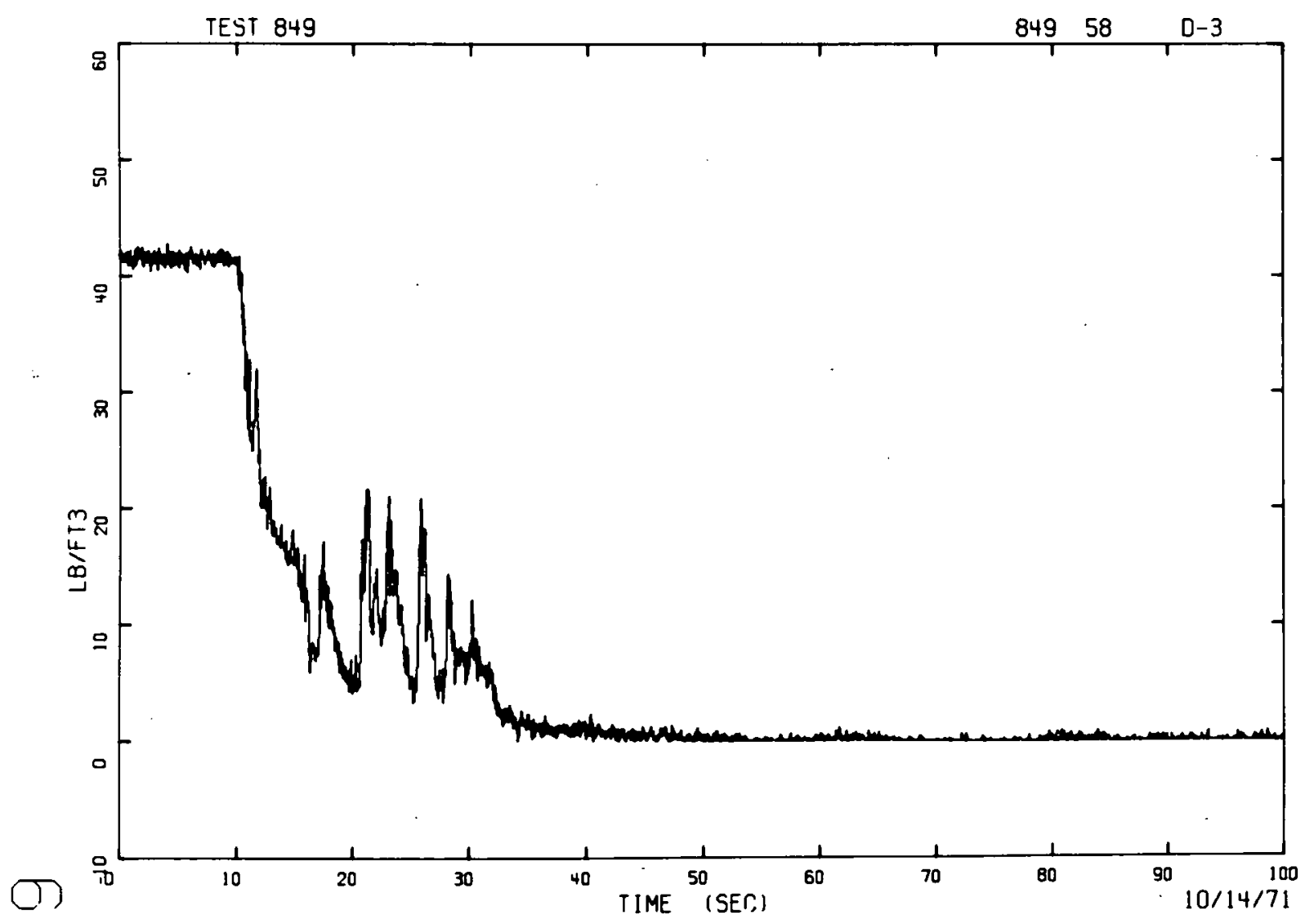

Fig. C-40 Hot leg density -- Test 849. 


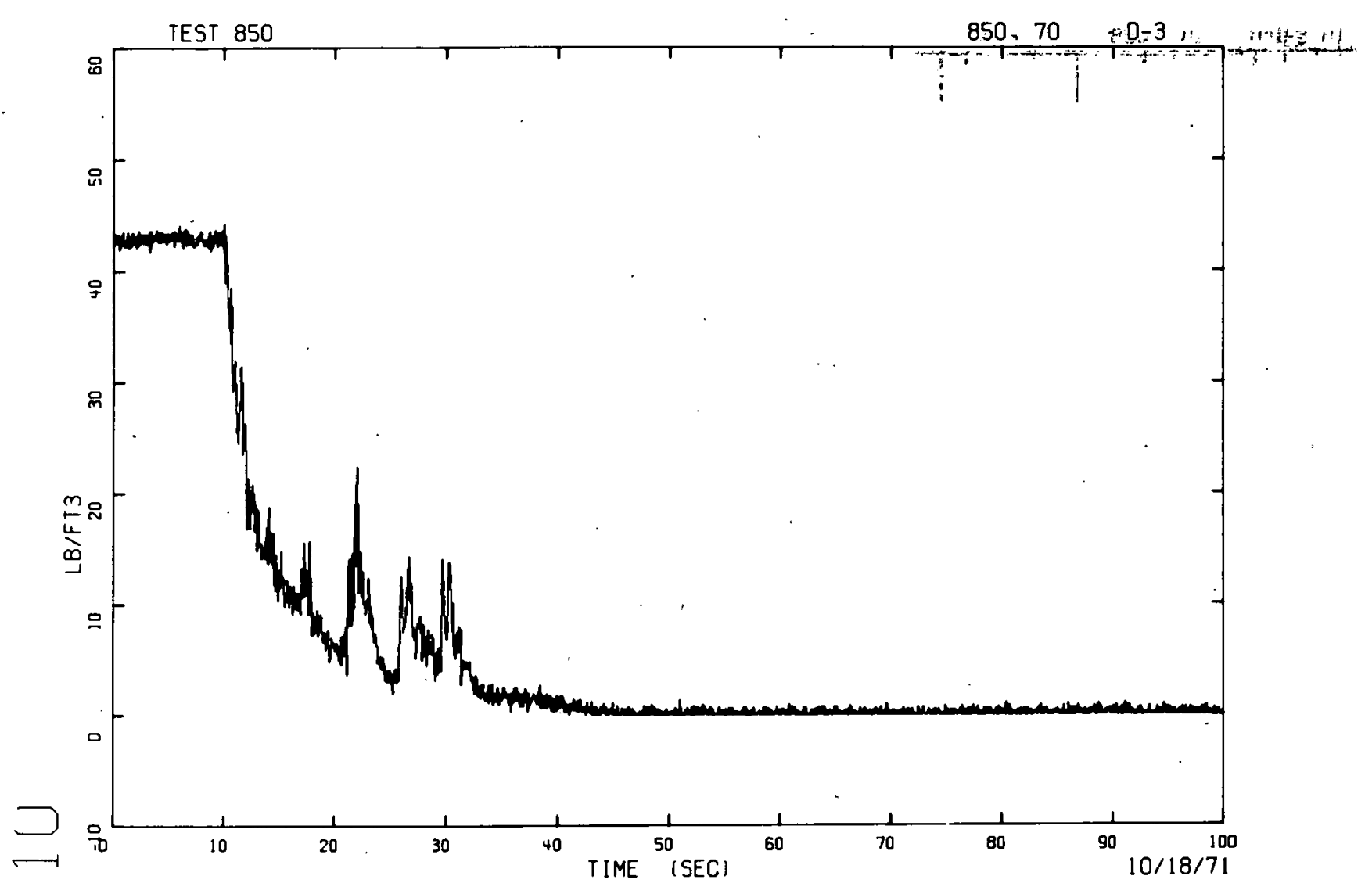

$\pi$

Fig. C-41 Hot leg denisity -- Test 850 .

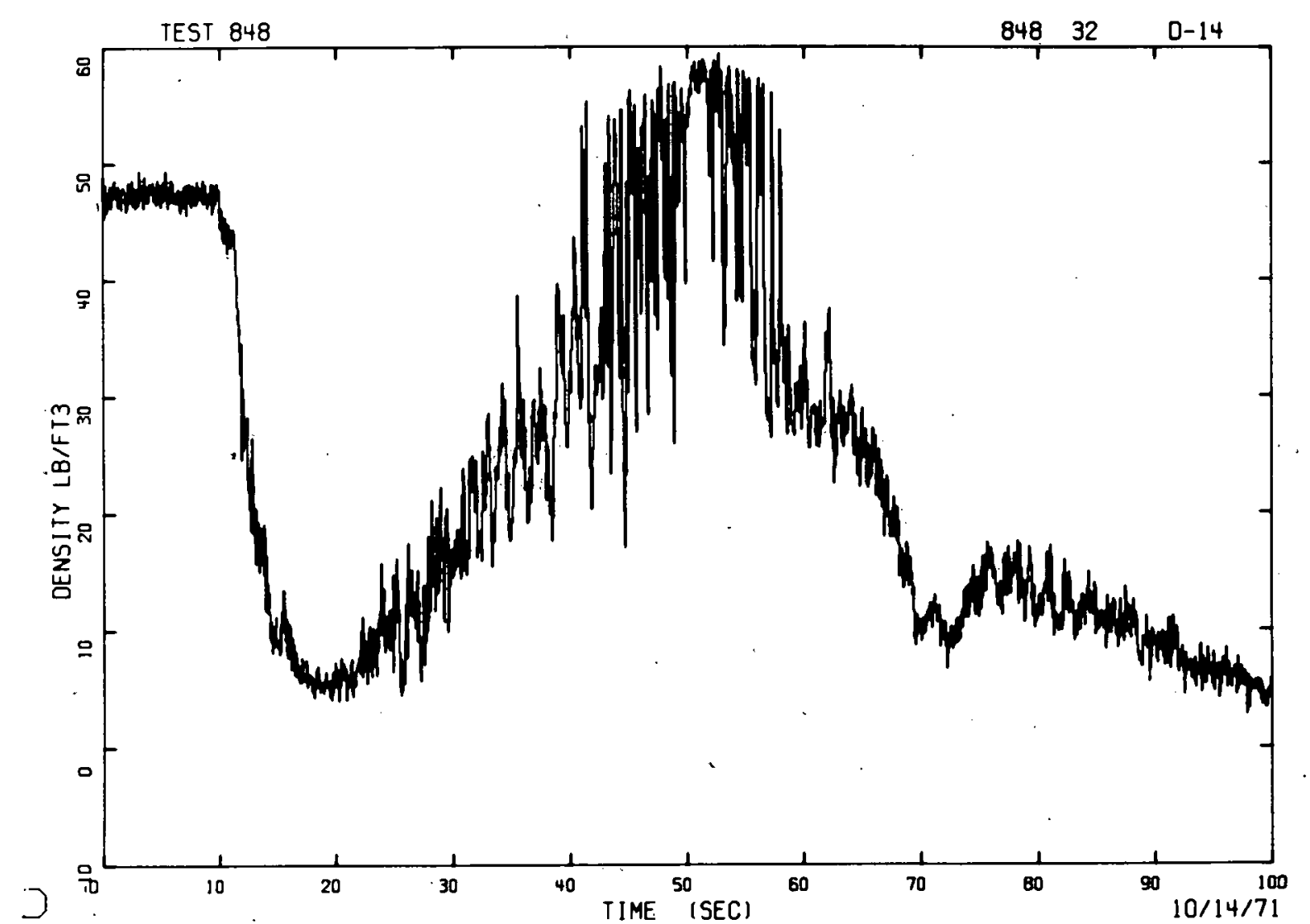

Fig. C-42 Inlet nozzle density -- Test 848 . 


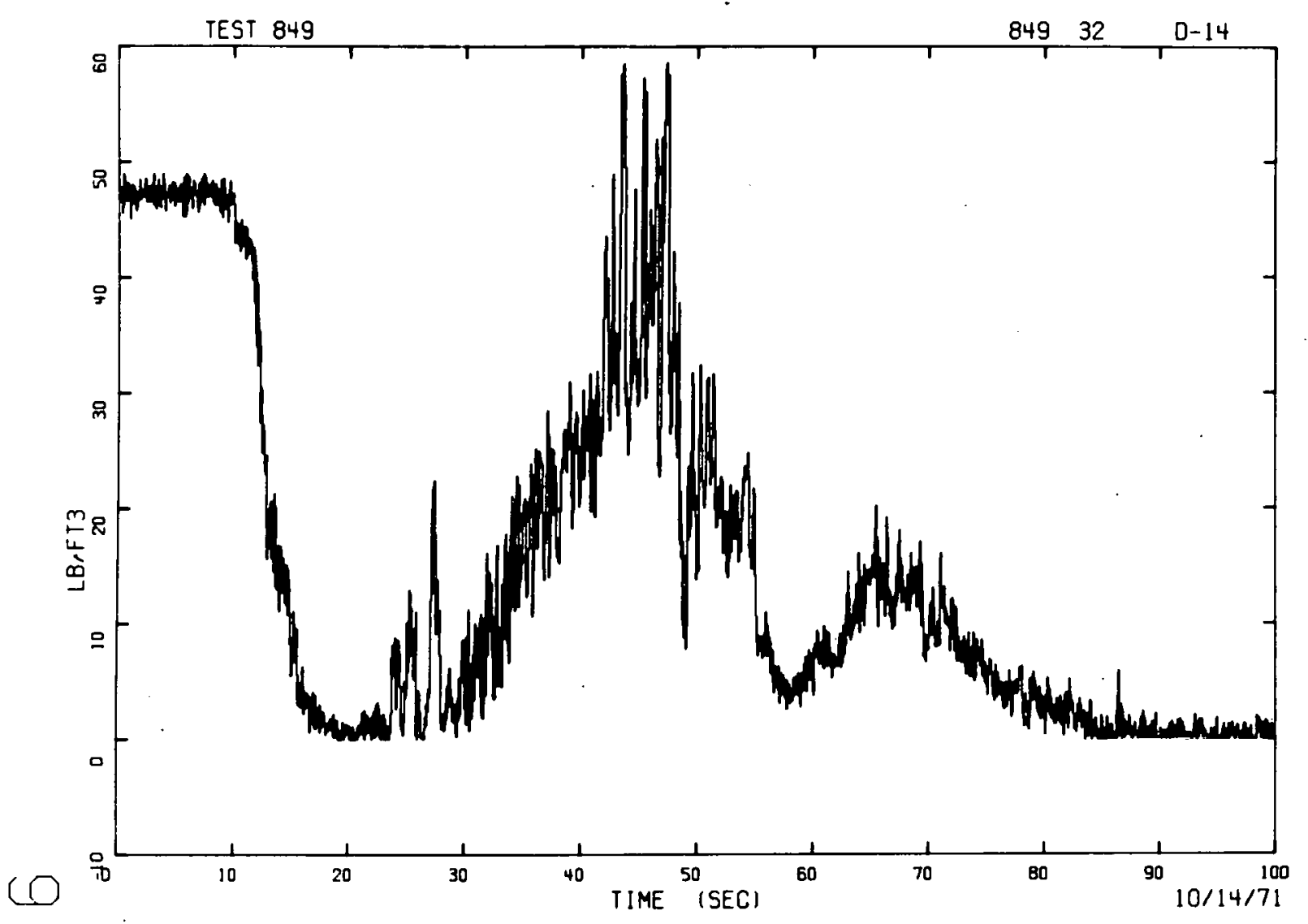

Fig. C-43 Inlet nozzle density -- Test 849.

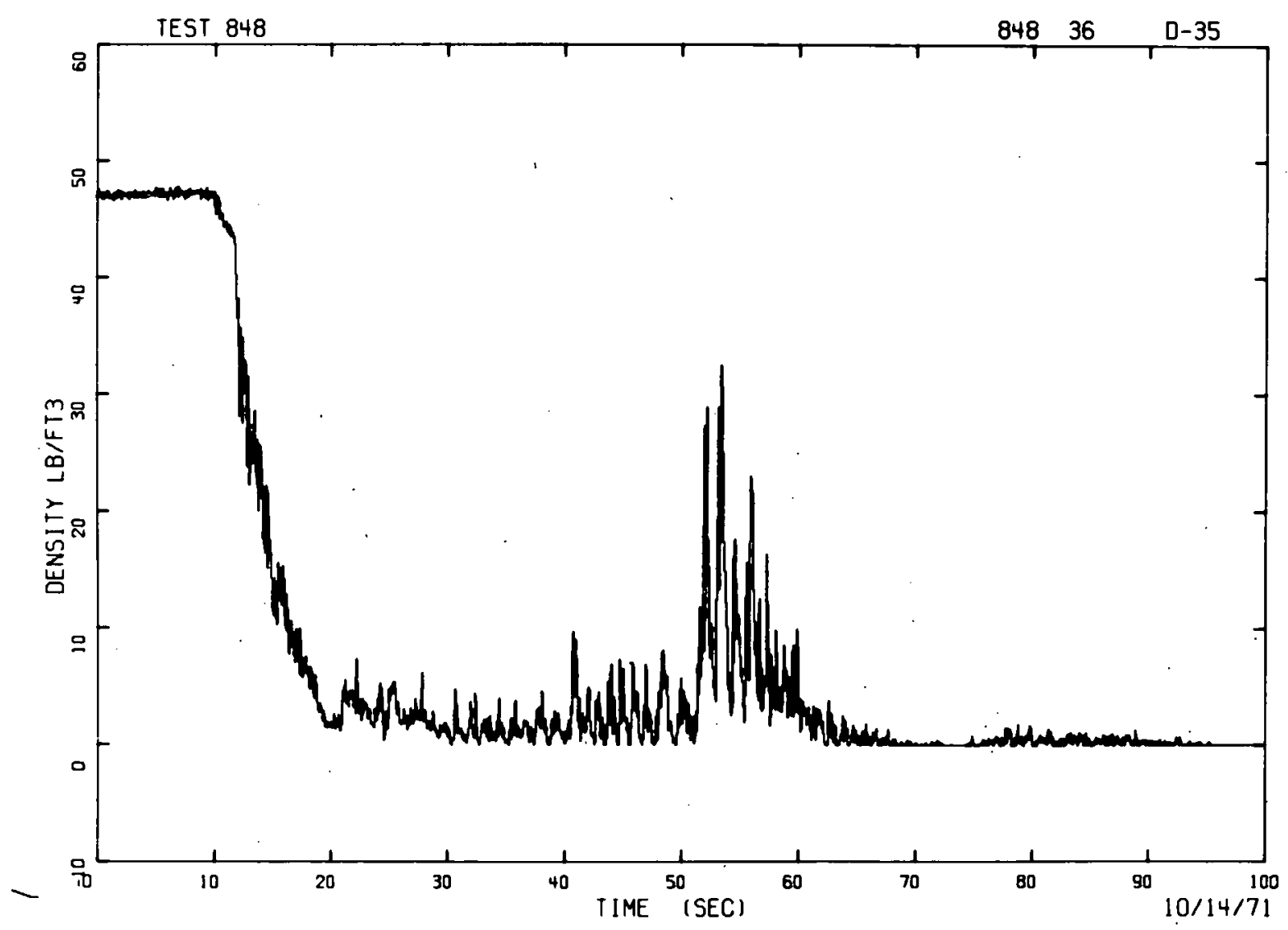

Fig. C-44 Blowdown nozzle density -- Test 848 . 


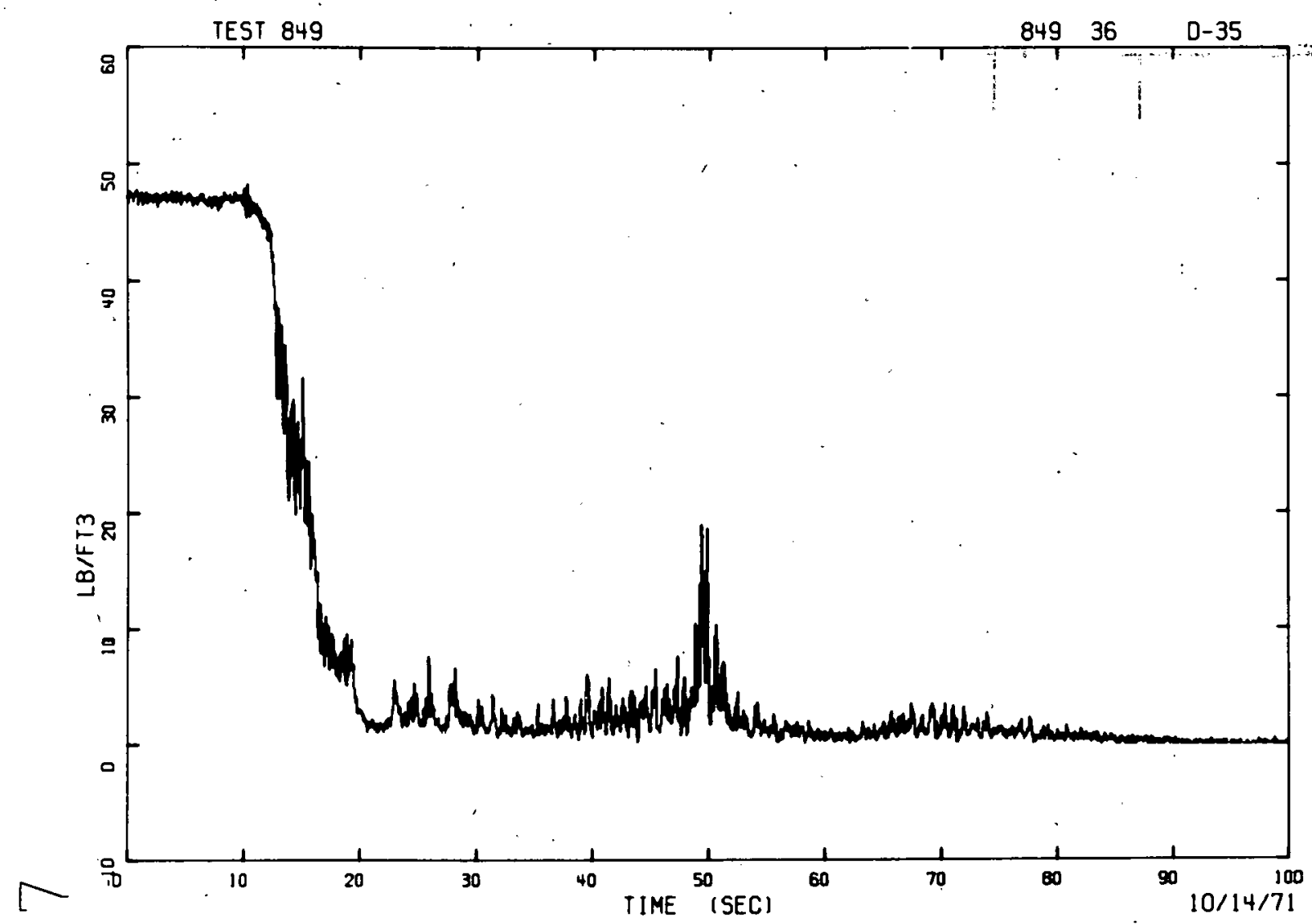

Fig. C-45 Blowdown nozzle density -- Test 849.

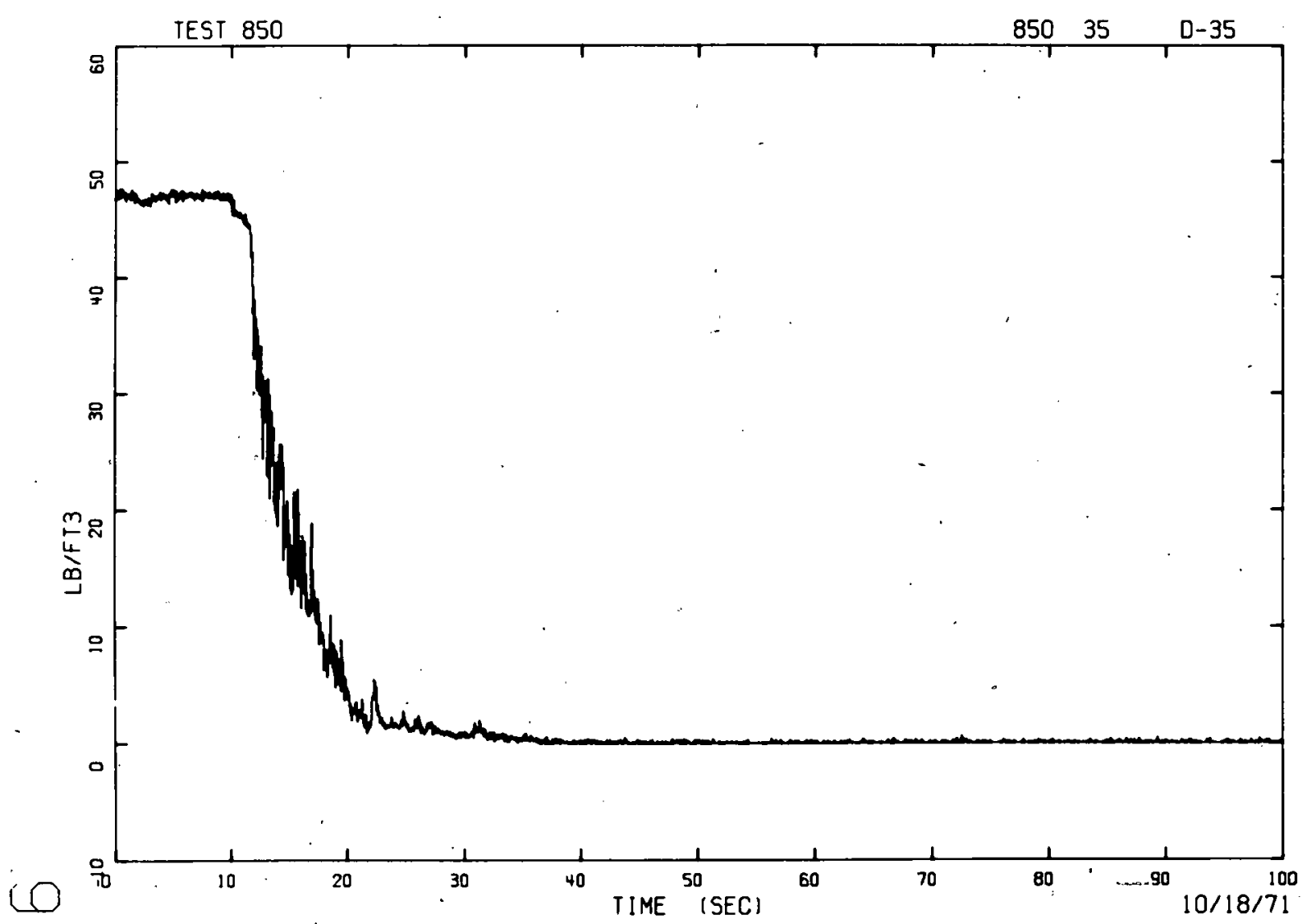

Fig. C-46́ Blowdown nozzle density -- Test 850 . 


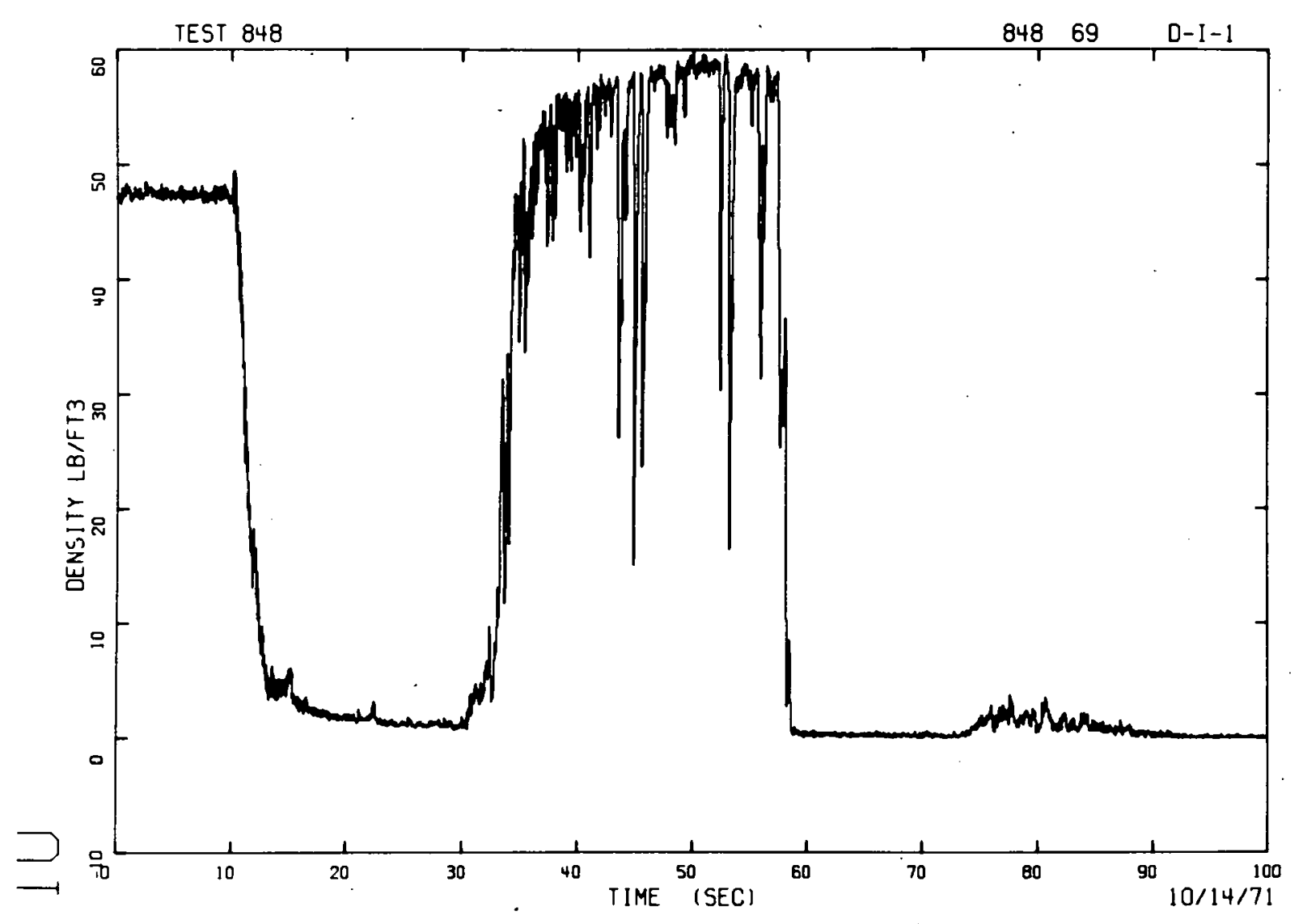

Fig. C-47 Inlet plenum density -- Test 848 .

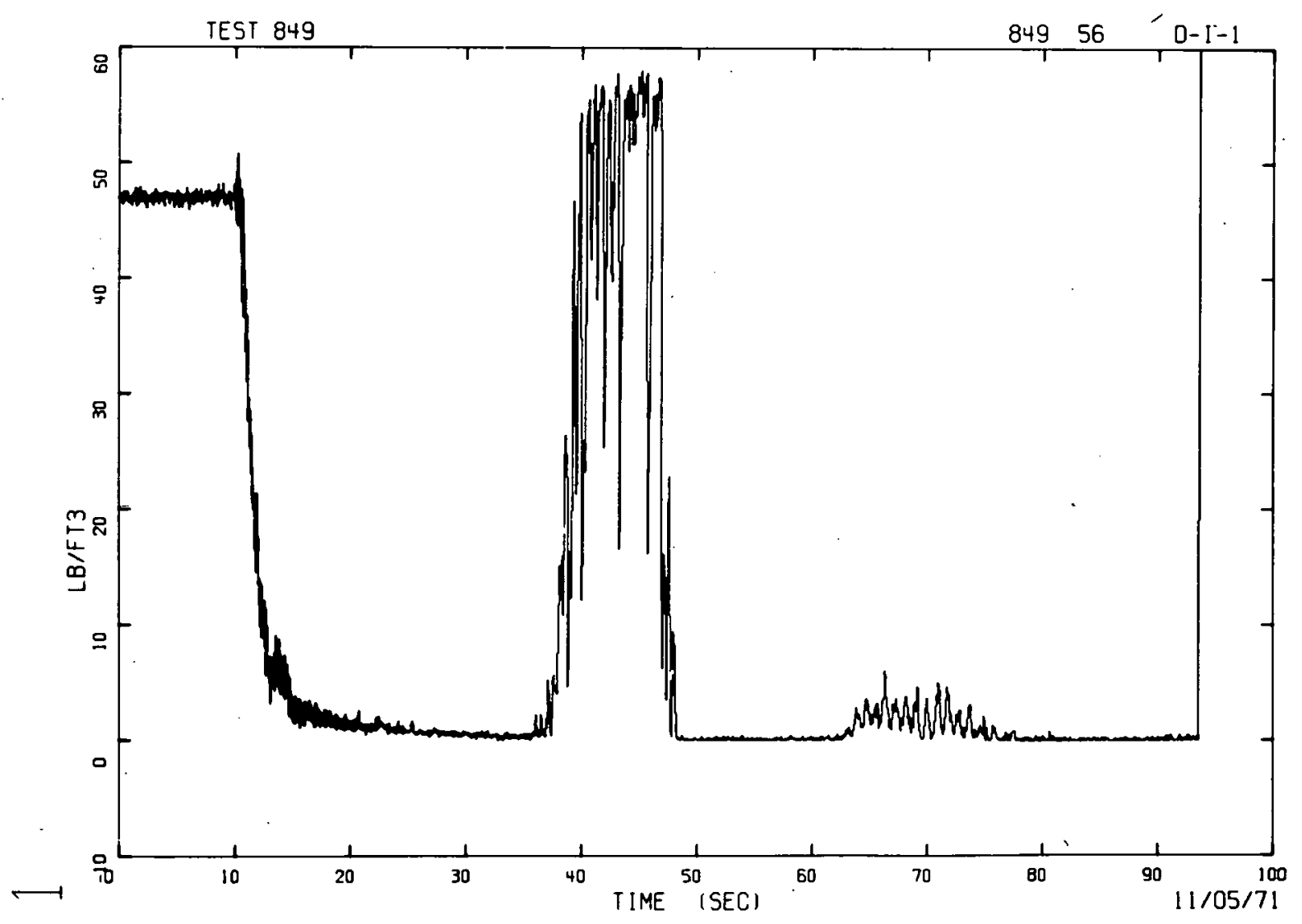

Fig. C-48 Inlet plenum density -- Test 849. 


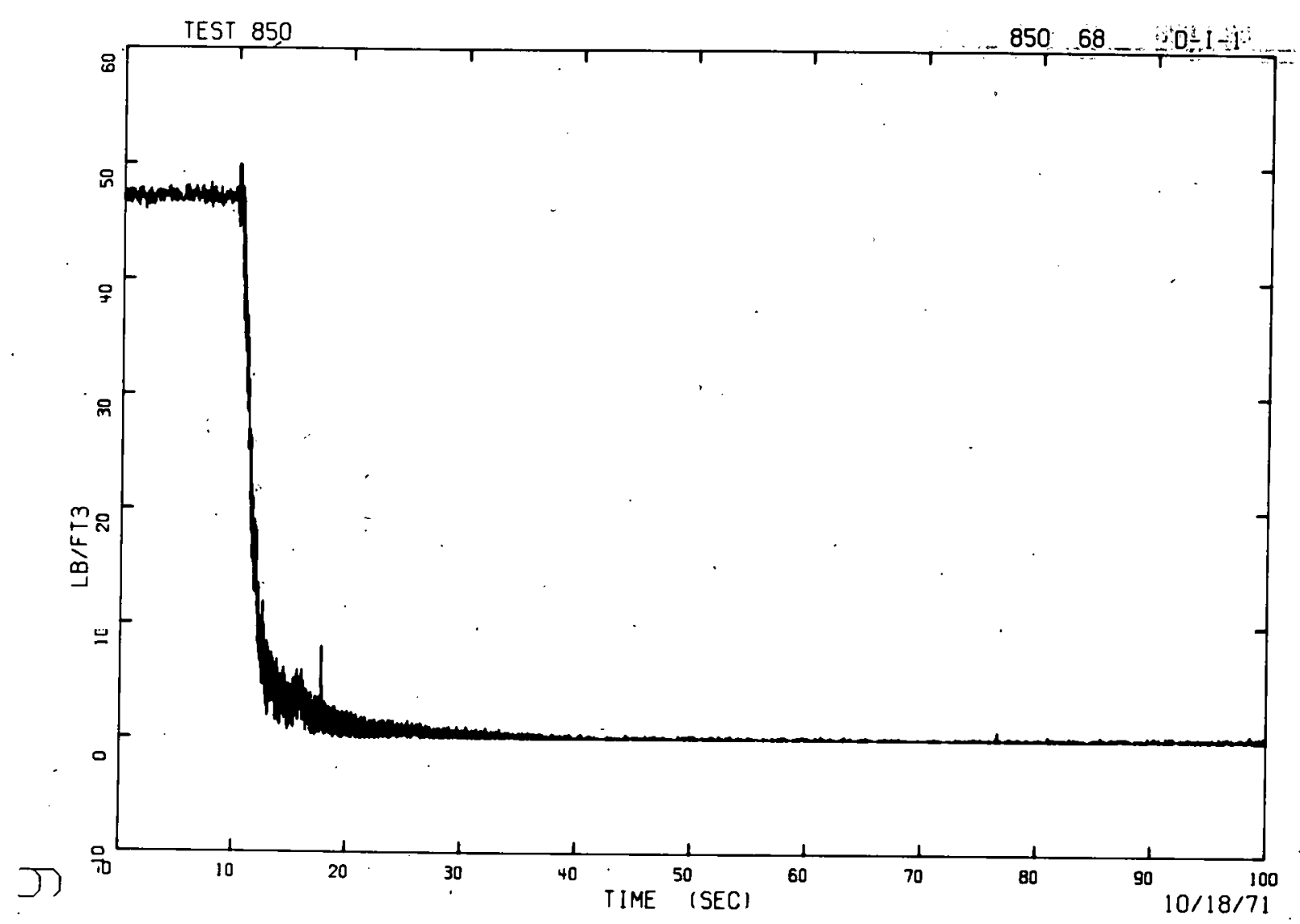

Fig. C -49 Inlet plenum density -- Test 850 .

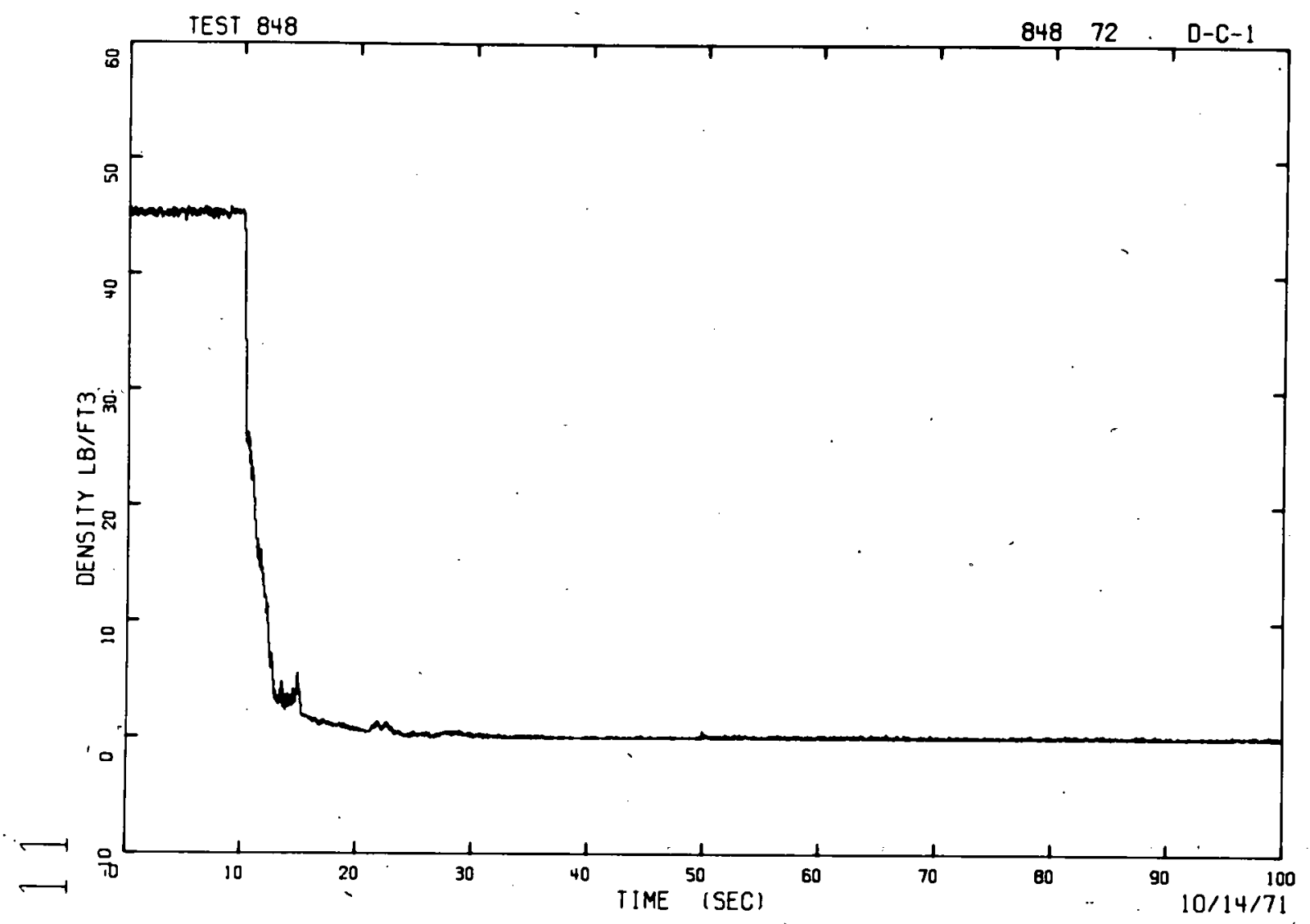

Fig. C-50 Core density -- Test 848 . 


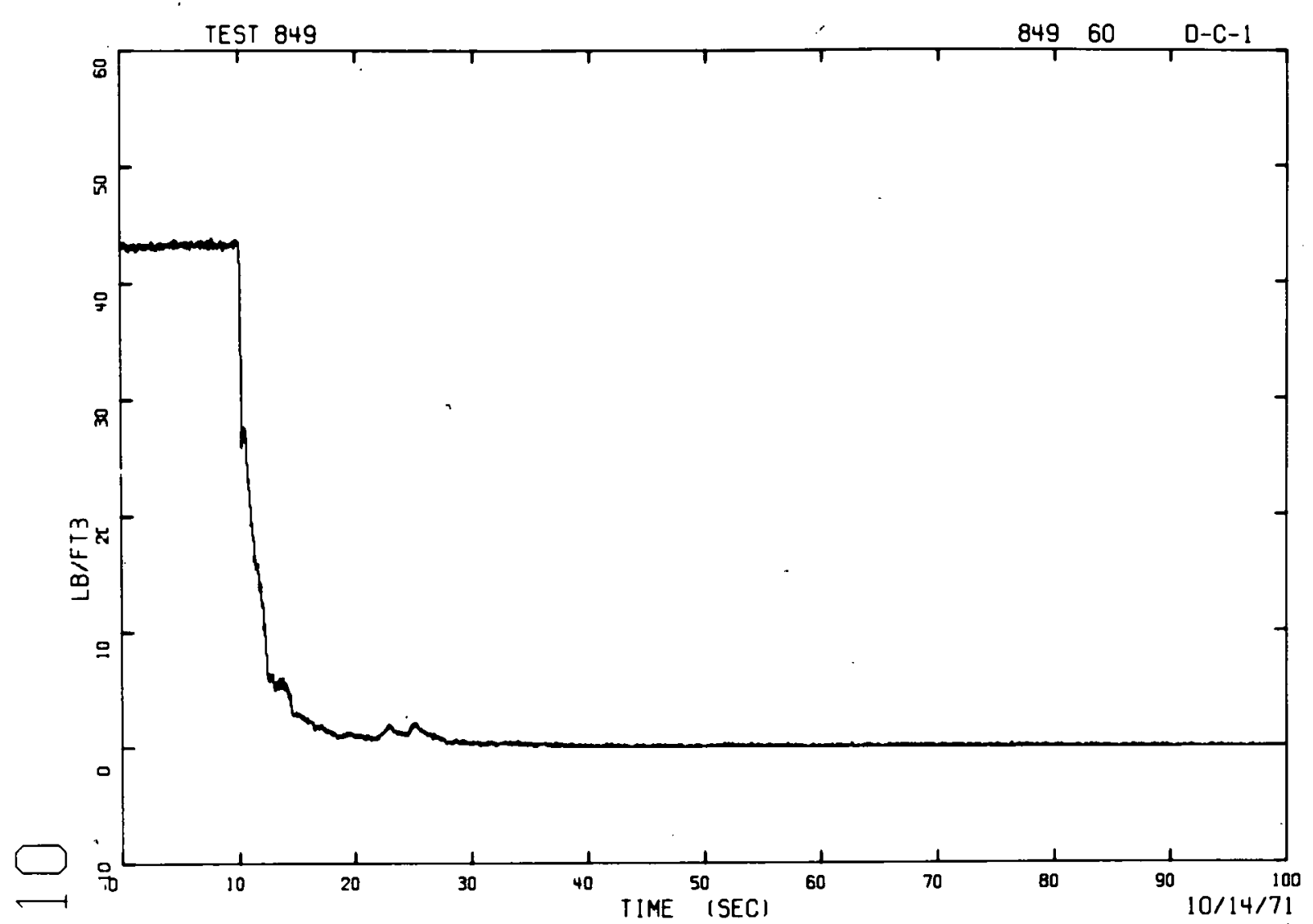

Ftg. C-51 Core density -- Test 849.

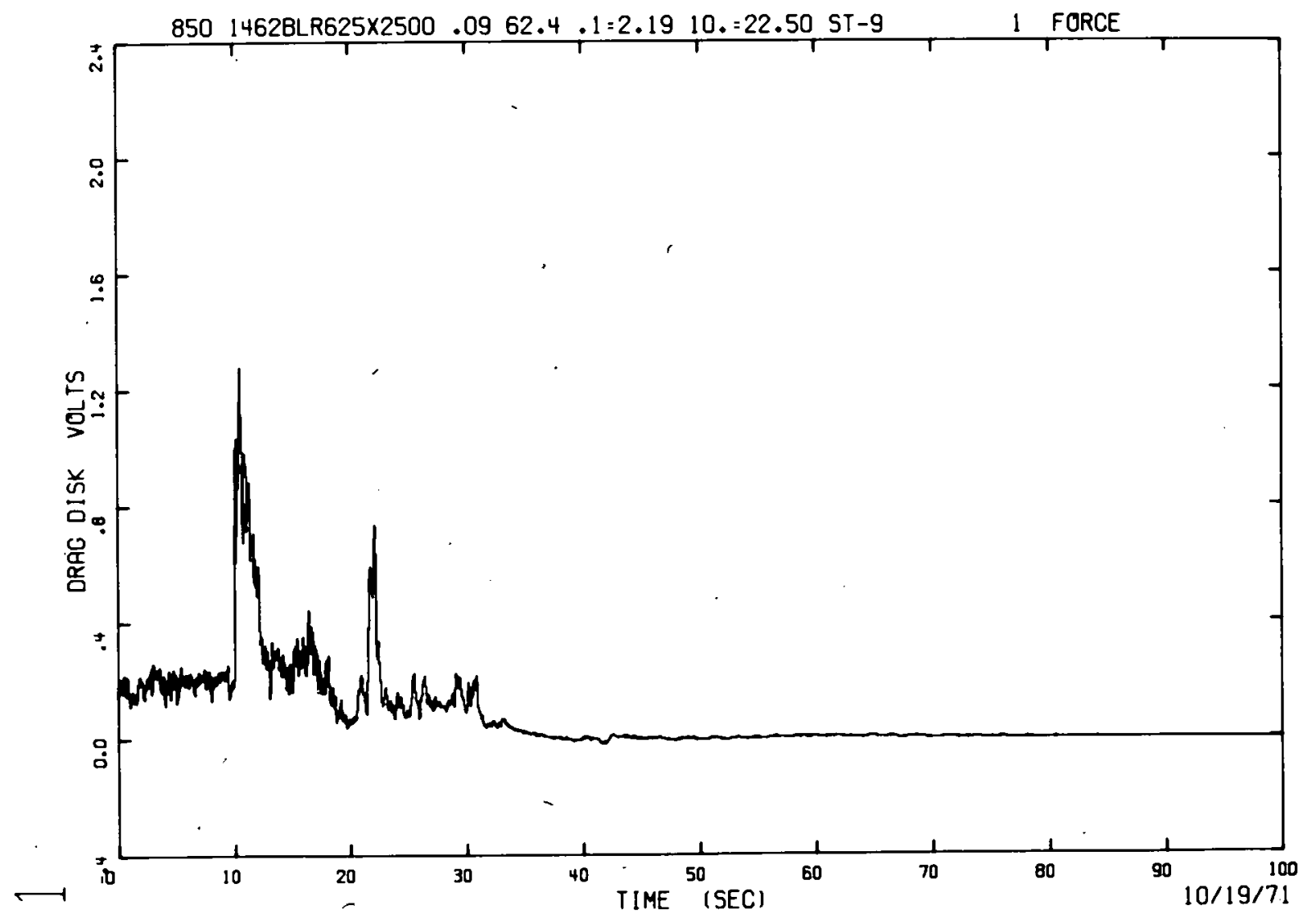

Fig. C-52 Drag disc output - cold leg -- Test 850. 


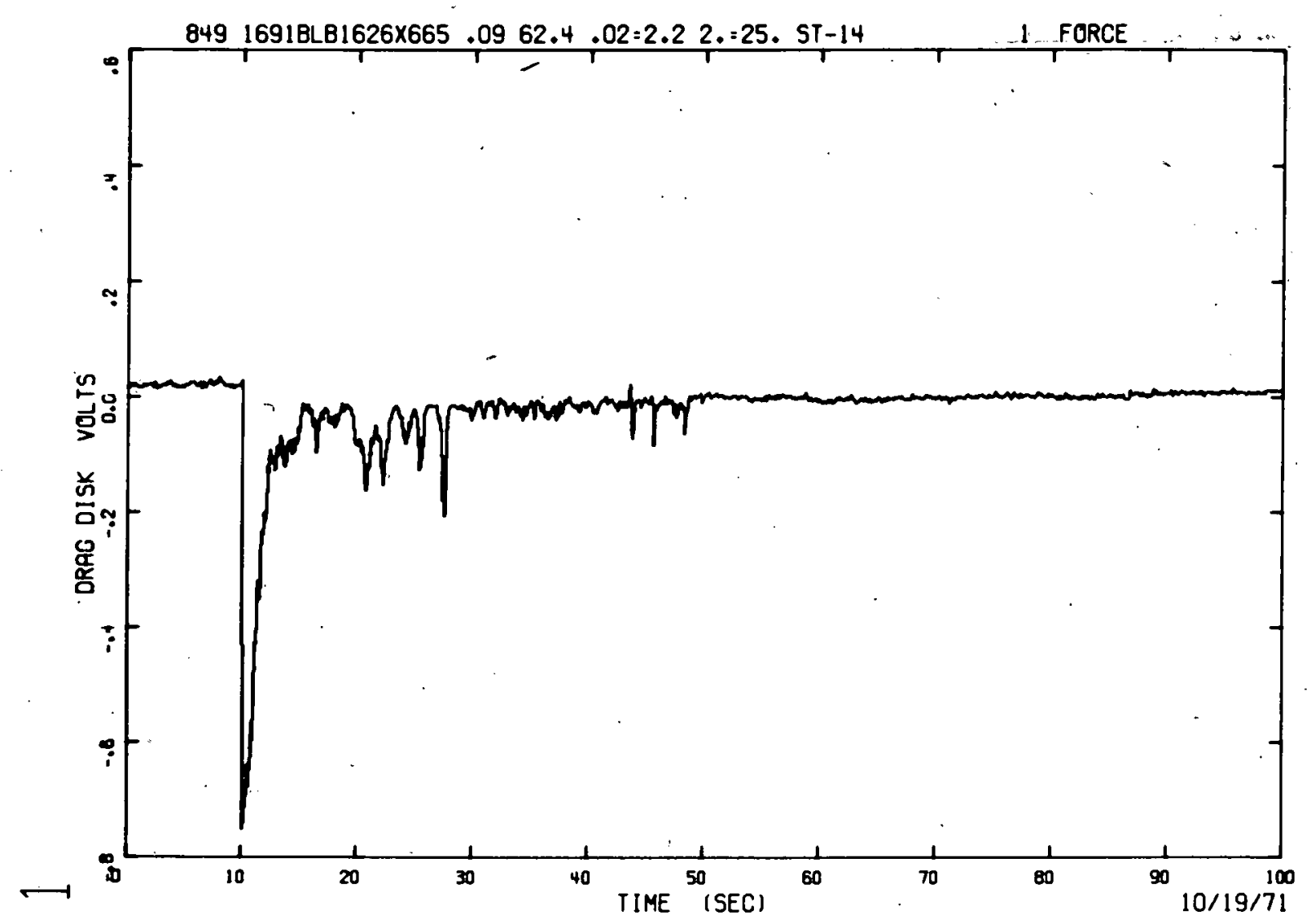

Fig. C-53 Drag disc output - Inlet nozzle -- Test 849.

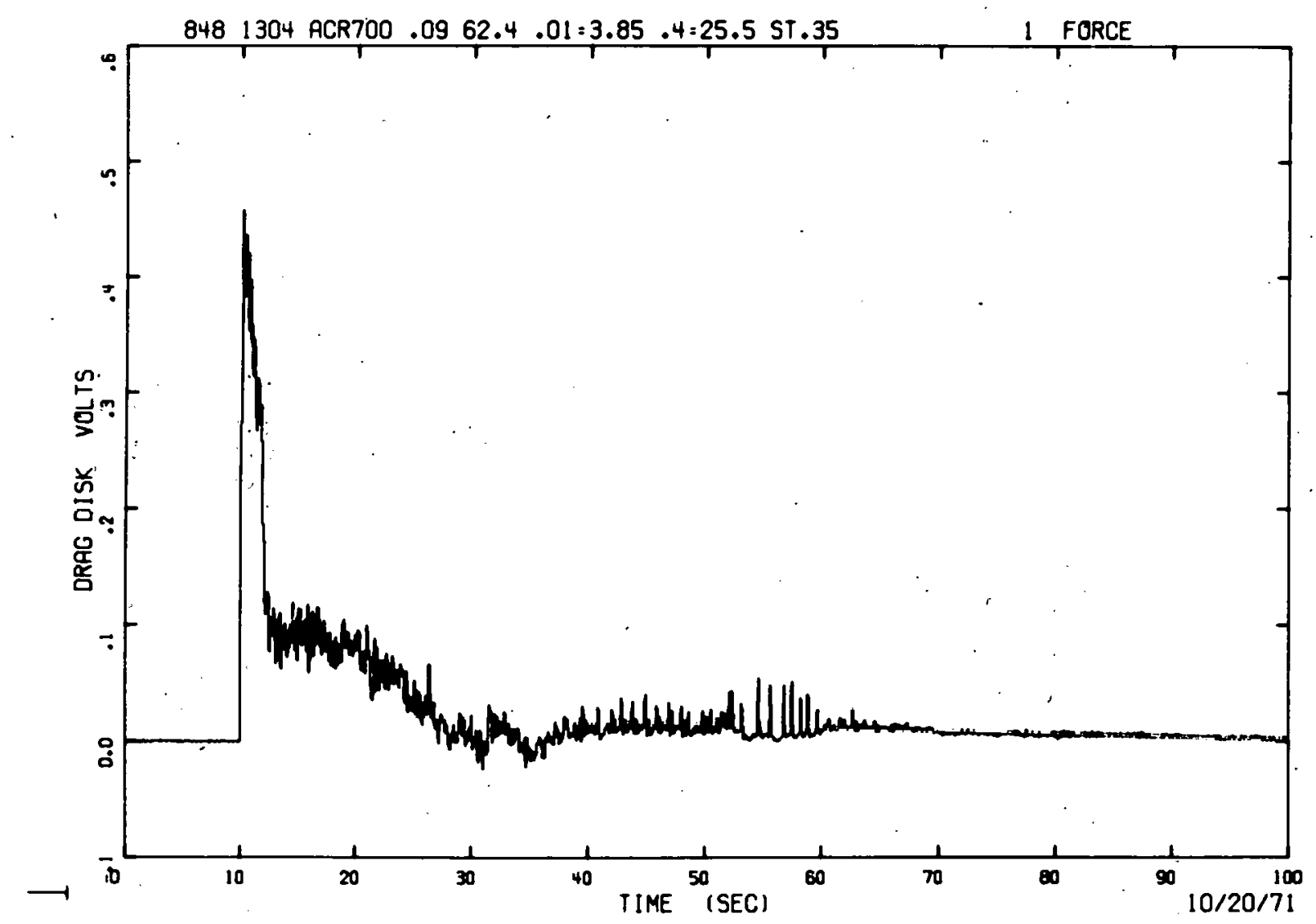

Fig. C-54 Drag disc output - blowdown nozzle -- Test 848. 